Tratamento de condições especiais para busca por similaridade em bancos de dados complexos 


\title{
Tratamento de condições especiais para busca por similaridade em banco de dados complexos
}

\author{
Daniel dos Santos Kaster
}

Orientador: Prof. Dr. Caetano Traina Jr.

Tese apresentada ao Instituto de Ciências Matemáticas e de Computação - ICMC-USP, como parte dos requisitos para obtenção do título de Doutor em Ciências - Ciências de Computação e Matemática Computacional. VERSÃO REVISADA.

USP - São Carlos

Junho de 2012 
Ficha catalográfica elaborada pela Biblioteca Prof. Achille Bassi e Seção Técnica de Informática, ICMC/USP, com os dados fornecidos pelo(a) autor(a)

Kaster, Daniel dos Santos
Tratamento de condições especiais para busca por
similaridade em bancos de dados complexos / Daniel
dos Santos Kaster; orientador Caetano Traina Jr. --
São Carlos, 2012.
177 p.
Tese (Doutorado - Programa de Pós-Graduação em --
Ciências de Computação e Matemática Computacional) --
Instituto de Ciências Matemáticas e de Computação,
Universidade de São Paulo, 2012.
1. Consultas por similaridade. 2. Banco de dados
multimídia. I. Traina Jr, Caetano, orient. II. Título.


Trabalho realizado com apoio do Conselho Nacional de Desenvolvimento Científico e Tecnológico (CNPq) - bolsa de doutorado, processo no 141460/2009-1, de 01/04/2009 a 14/09/2011 - e também da Fundação de Amparo à Pesquisa do Estado de São Paulo (FAPESP) e da Coordenação de Aperfeiçoamento de Pessoal de Nível Superior (CAPES). 
À minha família.

Aos meus alunos, aos meus colegas de trabalho e a todas as pessoas que direta ou indiretamente se beneficiarem deste trabalho. 


\section{Agradecimentos}

Primeiramente a Deus, pelo dom da vida e por todas as oportunidades que tive a graça de ter.

À minha querida esposa, Isabella, e aos meus filhos, Gabriela e Matheus, pelo amor, apoio incondicional, carinho e paciência que fazem de mim uma pessoa realizada.

Aos meus pais, pelo amor, carinho, dedicação e exemplo em todos os momentos da minha vida.

Aos meus sogros, irmãos, cunhadas e cunhados, sobrinhos, tios e primos, pela maravilhosa família da qual tenho a graça de pertencer.

Ao meu orientador, prof. Caetano, por ter me aceitado, apoiado e orientado durante todo esse período de aprendizado rico e frutuoso.

À profa. Agma, pelas sugestões, críticas e conselhos, que muito enriqueceram o meu trabalho.

Aos demais professores do Grupo de Bases e Dados e Imagens (GBdI) do ICMC-USP, Eduardo Hruschka, Cristina, Elaine e Júnior, pelas dicas e conselhos.

Aos grandes amigos que fiz no GBdI, em especial os que tive a oportunidade de trabalhar junto: Renato Bueno, Pedro Bugatti, Humberto, Camila, Adriano Paterlini, Paulinha Appel, Willian, Marcelo Ponciano e Robson; os amigos de futebol e basquete: Pedro Lopes, Bruno Tomazela, André Balan, Ives, Lucio, Joe, Felipe Louza, Alceu, Marcos Bêdo, Sérgio e Letrícia; e os demais amigos do grupo. Muito obrigado pela oportunidade de compartilhar tantos momentos com vocês.

Aos "amigos de São Carlos", que foram sustento e alegria para a nossa família, em especial: Lino, Liana e Alícia; Campos, Marcia e Lara; Jair, Geni e Línia; e Dawson, Laura, Pedro, Mariana e Malu. Vocês sempre farão parte da nossa vida.

Aos funcionários e professores do ICMC-USP.

À Universidade Estadual de Londrina e ao Departamento de Computação, pelo incentivo à minha capacitação e aos colegas que me substituíram em minhas atribuições no período de licença.

Ao CNPq, à FAPESP e à CAPES, pelo apoio financeiro. 
A quantidade de dados complexos (imagens, vídeos, séries temporais e outros) tem crescido rapidamente. Dados complexos são adequados para serem recuperados por similaridade, o que significa definir consultas de acordo com um dado critério de similaridade. Além disso, dados complexos usualmente são associados com outras informações, geralmente de tipos de dados convencionais, que devem ser utilizadas em conjunto com operações por similaridade para responder a consultas complexas. Vários trabalhos propuseram técnicas para busca por similaridade, entretanto, a maioria das abordagens não foi concebida para ser integrada com um SGBD, tratando consultas por similaridade como operações isoladas, disassociadas do processador de consultas. O objetivo principal desta tese é propor alternativas algébricas, estruturas de dados e algoritmos para permitir um uso abrangente de consultas por similaridade associadas às demais operações de busca disponibilizadas pelos SGBDs relacionais e executar essas consultas compostas eficientemente. Para alcançar este objetivo, este trabalho apresenta duas contribuições principais. A primeira contribuição é a proposta de uma nova operação por similaridade, chamada consulta aos $k$-vizinhos mais próximos estendida com condições $\left({ }_{c} k-\mathrm{NNq}\right)$, que estende a consulta aos $k$-vizinhos mais próximos $(k$-NNq) de maneira a fornecer uma condição adicional, modificando a semântica da operação. A operação proposta permite representar consultas demandadas por várias aplicações, que não eram capazes de ser representadas anteriormente, e permite homogeneamente integrar condições de filtragem complementares à $k$-NNq. A segunda contribuição é o desenvolvimento do FMI-SiR (user-defined Features, Metrics and Indexes for Similarity Retrieval), que é um módulo de banco de dados que permite executar consultas por similaridade integradas às demais operações do SGBD. O módulo permite incluir métodos de extração de características e funções de distância definidos pelo usuário no núcleo do gerenciador de banco de dados, fornecendo grande flexibilidade, e também possui um tratamento especial para imagens médicas. Além disso, foi verificado através de experimentos sobre bancos de dados reais que a implementação do FMI-SiR sobre o SGBD Oracle é capaz de consultar eficientemente grandes bancos de dados complexos.

KASTER, D. S. Tratamento de condições especiais para busca por similaridade em bancos de dados complexos. Tese de Doutoramento, Instituto de Ciências Matemáticas e de Computação (ICMC), Universidade de São Paulo (USP), São Carlos, SP, 2012. 177 p. 


\section{Abstract}

The amount of complex data (images, videos, time series and others) has been growing at a very fast pace. Complex data are well-suited to be searched by similarity, which means to define queries according to a given similarity criterion. Moreover, complex data are usually associated with other information, usually of conventional data types, which must be employed in conjunction with similarity operations to answer complex queries. Several works proposed techniques for similarity searching, however, the majority of the approaches was not conceived to be integrated into a DBMS, treating similarity queries as isolated operations detached from the query processor. The main objective of this thesis is to propose algebraic alternatives, data structures and algorithms to allow a wide use of similarity queries associated to the search operations provided by the relational DBMSs and to execute such composite queries efficiently. To reach this goal, this work presents two main contributions. The first contribution is the proposal of a new similarity operation, called condition-extended $k$-Nearest Neighbor query $\left({ }_{c} k\right.$-NNq), that extends the $k$-Nearest Neighbor query $(k-\mathrm{NNq})$ to provide an additional condition, modifying the operation semantics. The proposed operation allows representing queries required by several applications, which were not able to be represented before, and allows to homogeneously integrate complementary filtering conditions to the $k$-NNq. The second contribution is the development of the FMI-SiR (user-defined Features, Metrics and Indexes for Similarity Retrieval), which is a database module that allows executing similarity queries integrated to the DBMS operations. The module allows including user-defined feature extraction methods and distance functions into the database core, providing great flexibility, and also has a special treatment for medical images. Moreover, it was verified through experiments over real datasets that the implementation of FMI-SiR over the Oracle DBMS is able to efficiently search very large complex databases.

KASTER, D. S. Treatment of special conditions for similarity searching in complex databases. PhD Thesis, Institute of Mathematics and Computer Sciences (ICMC), University of São Paulo (USP), São Carlos, SP, 2012. 177 p. 
Lista de Tabelas $\quad$ xxi

Lista de Algoritmos $\quad$ xxiii

1 Introdução 1

1.1 Motivação . . . . . . . . . . . . . . . . . . . . 2

1.2 Objetivos e Contribuições . . . . . . . . . . . . . . . . . . 4

1.3 Organização do trabalho . . . . . . . . . . . . . . . . . . . . 5

2 Recuperação de Dados Complexos por Similaridade $\quad 7$

2.1 O Problema da Representação de Consultas . . . . . . . . . . . . . . . . 8

2.1.1 Abordagem de Operadores Baseados em Conteúdo . . . . . . . . . . 9

2.1.2 Abordagem de Operadores Baseados em Similaridade . . . . . . . . 10

2.2 Avaliação de Similaridade . . . . . . . . . . . . . . . . . . . . . 11

2.2.1 Uma Abstração do Espaço de Similaridade . . . . . . . . . . . . . . 11

2.2.2 O Componente Vetor de Características . . . . . . . . . . . . . 13

2.2.3 O Componente Função de Distância . . . . . . . . . . . . . . . . . . 17

2.3 Consultas por Similaridade . . . . . . . . . . . . . . . . . 20

2.3.1 Consulta por Abrangência . . . . . . . . . . . . . . 21

2.3.2 Consulta aos $k$-Vizinhos Mais Próximos . . . . . . . . . . . . . . . 22

2.3.3 Consultas por Similaridade Agregada . . . . . . . . . . . . . . . . . 23

2.3.4 Junções por Similaridade . . . . . . . . . . . . . . . . . . . 25

2.4 Recuperação de Imagens Médicas por Similaridade . . . . . . . . . . . . . 26

2.4.1 Dados Inerentes à Prática Médica . . . . . . . . . . . . 26

2.4 .2 O Padrão para Imagens Médicas DICOM . . . . . . . . . . . . . 28

2.4.3 Sistemas de Apoio ao Diagnóstico por Imagens . . . . . . . . . . . . 30

2.4.4 Recuperação de Imagens Médicas por Conteúdo . . . . . . . . . . . . . 32

2.4.5 Recuperação de Imagens Médicas Combinando Metadados e Conteúdo 33

2.5 Considerações Finais . . . . . . . . . . . . . . . . . . 35 
3 Inclusão de Consultas por Similaridade em SGBDRs $\quad 37$

3.1 Abordagens Algébricas para Consultas por Similaridade . . . . . . . . . . . 38

3.2 Representação Algébrica de Consultas por Similaridade . . . . . . . . . . . 39

3.2.1 Seleções por Similaridade . . . . . . . . . . . . . . . . . . 40

3.2.2 Seleções por Similaridade Agregada . . . . . . . . . . . . . . . . . . 42

3.2 .3 Junções por Similaridade . . . . . . . . . . . . . . . . . . . . . . . . 42

3.3 Algoritmos para Consultas por Similaridade em Métodos de Acesso Métricos 43

3.3.1 Métodos de Acesso para Consultas por Similaridade . . . . . . . . . 44

3.3.2 Estrutura da Slim-tree . . . . . . . . . . . . . . . . . . . 46

3.3.3 Algoritmo para Consulta por Abrangência . . . . . . . . . . . . . 47

3.3.4 Algoritmo para Consulta aos $k$-Vizinhos Mais Próximos . . . . . . . 51

3.4 Consultas por Similaridade entre Imagens em SGBDs . . . . . . . . . . . 54

3.4 .1 CBIR no SGBD IBM DB2 . . . . . . . . . . . . . 56

3.4 .2 CBIR no SGBD Oracle . . . . . . . . . . . . . . . 57

3.4.3 Sistemas Acadêmicos de CBIR sobre SGBDs . . . . . . . . . . . . . 60

3.5 Considerações Finais . . . . . . . . . . . . . . . . . . . . . 62

4 Consulta aos Vizinhos mais Próximos com Condições $\quad 65$

4.1 Definição da Consulta . . . . . . . . . . . . . . . . . . 66

4.2 Tipos de Condições Aplicáveis a Consultas aos Vizinhos mais Próximos . . 71

4.2.1 Condições Baseadas em Agregação por Contagem . . . . . . . . . . . 72

4.2.2 Condições Baseadas em Agregação por Soma ou por Média . . . . . 78

4.2.3 Condições Baseadas em Agregação por Mínimo ou por Máximo . . 83

4.3 Regras Algébricas . . . . . . . . . . . . . . . . . . . . . . 84

4.3.1 Regras Algébricas Envolvendo Condições em Geral Restringindo o

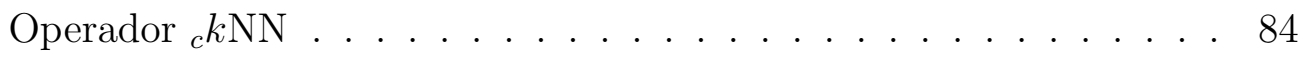

4.3.2 Regras Algébricas Envolvendo Condições Baseadas em Agregação por Contagem . . . . . . . . . . . . . . . . . 87

4.3.3 Regras Algébricas Envolvendo Condições Baseadas em Agregação por Soma ou por Média . . . . . . . . . . . . . . . . 90

4.3.4 Regras Algébricas Envolvendo Condições Baseadas em Agregação por Mínimo ou por Máximo . . . . . . . . . . . . . . . . . 90

4.4 Algoritmos . . . . . . . . . . . . . . . . . . . . . . . 93

4.4.1 Fundamentos e Complexidade dos Algoritmos . . . . . . . . . . . . 93

4.4.2 Algoritmo Sequencial para Consultas ${ }_{c} k$-NN com Condições Baseadas em Tupla . . . . . . . . . . . . . . . . . . 96

4.4.3 Algoritmos Sequenciais para Consultas ${ }_{c} k$-NN com Condições Baseadas em Agregação por Contagem . . . . . . . . . . . . . . . . 97

4.4.4 Algoritmos Utilizando o Método de Acesso Métrico Slim-tree . . . . 102

4.5 Experimentos . . . . . . . . . . . . . . . . . . 103

4.5.1 Conjuntos de Dados e Descrição dos Experimentos ...... . 104

4.5.2 Resultados e Discussão . . . . . . . . . . . . . . . . . . 106

4.6 Considerações Finais . . . . . . . . . . . . . . . . . . . . . . . . 114

5 FMI-SiR: Um Módulo de Banco de Dados para Consultas por Simila$\begin{array}{lr}\text { ridade } & 117\end{array}$

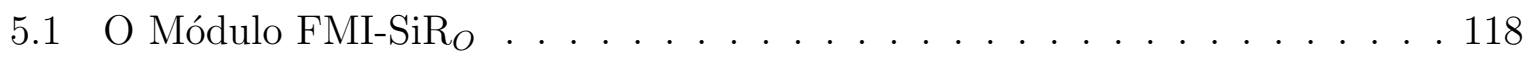

5.1.1 Extração de Características . . . . . . . . . . . . . . . . . . . 119

5.1.2 Seleções por Similaridade com Execução Sequencial . . . . . . . . . 121 
5.1 .3 Índices para Consultas por Similaridade . . . . . . . . . . . . . . . 123

5.1.4 Seleções por Similaridade com Execução Indexada . . . . . . . . . . 125

5.1 .5 Junções por Similaridade . . . . . . . . . . . . . . . . . . . . . . 129

5.1 .6 Seleções por Similaridade Agregada . . . . . . . . . . . . . . . . . 132

5.1.7 Seleções aos $k$-Vizinhos Mais Próximos com Condições . . . . . . . 134

5.2 A Extensão MedFMI-SiR . . . . . . . . . . . . . . . . . . . . . . 138

5.2.1 A Arquitetura do MedFMI-SiR . . . . . . . . . . . . . . . 138

5.2 .2 Extração de Características . . . . . . . . . . . . . . . . . 139

5.2.3 Recuperação Combinando Metadados e Conteúdo de Imagens DICOM140

5.3 Experimentos Sobre o Módulo FMI-SiR $O$. . . . . . . . . . . . . . . . . . 143

5.3.1 Avaliação de Qualidade dos Resultados . . . . . . . . . . . . . . . . . 144

5.3.2 Desempenho de Execução de Seleções por Similaridade . . . . . . . . 145

5.3.3 Desempenho de Junções por Similaridade por Abrangência . . . . . 148

5.4 Experimentos Sobre a Extensão MedFMI-SiR . . . . . . . . . . . . . . . 151

5.4.1 Escalabilidade da Construção dos Índices para Consultas por Similaridade . . . . . . . . . . . . . . . . . . . 151

5.4.2 Desempenho de Consultas Combinando Condições Baseadas em Similaridade e Condições Baseadas em Metadados . . . . . . . . . . . 152

5.5 Considerações Finais . . . . . . . . . . . . . . . . . 155

6 Conclusão $\quad 157$

6.1 Principais Contribuições . . . . . . . . . . . . . . . . . . . 158

6.2 Contribuições Complementares . . . . . . . . . . . . . . . . . . 159

6.3 Publicações . . . . . . . . . . . . . . . . . . . . . . . 160

6.4 Trabalhos Futuros . . . . . . . . . . . . . . . . . 162

$\begin{array}{ll}\text { Referências Bibliográficas } & 165\end{array}$ 


\section{Lista de Figuras}

1.1 As duas imagens de cada uma das mamas que compõem um exame de mamografia. . . . . . . . . . . . . . . . . . 3

2.1 Espaço de similaridade e técnicas envolvidas na definição de sua semântica. 13

2.2 Imagens visualmente distintas e com histogramas idênticos. . . . . . . . . . 15

2.3 Representação da consulta por abrangência. . . . . . . . . . . . . . . . 21

2.4 Representação da consulta aos $k$-vizinhos mais próximos. . . . . . . . . . . 22

2.5 Operações de junção por similaridade. . . . . . . . . . . . . . . . 26

2.6 Aparelhos de radiologia digital. . . . . . . . . . . . . . . . . . 27

2.7 Exemplos de imagens médicas digitais de cabeça. . . . . . . . . . . . . 28

2.8 Diagrama conceitual de integração lógica de sistemas de informações médicas integrando imagens. . . . . . . . . . . . . . . . . . . . 31

2.9 Fluxo de dados em um sistema de CBIR com consulta por exemplo. . . . . 32

3.1 Representação visual de uma Slim-tree e sua estrutura lógica. . . . . . . . 48

3.2 Descarte por desigualdade triangular. . . . . . . . . . . . . . . . . . . 49

3.3 Descarte de subárvores na Slim-tree. . . . . . . . . . . . . . . . . . . . . 49

4.1 Conjunto CidadesAmericanas. . . . . . . . . . . . . . . . . 68

4.2 Conjunto induzido sobre o conjunto de cidades americanas . . . . . . . . 68

4.3 Conjunto restrito pela condição $\left\langle e s t a d o \neq{ }^{\prime} V A\right.$ ' $\rangle$ e induzido sobre o conjunto de cidades americanas . . . . . . . . . . . . . . . . . 69

4.4 Exemplo de um $k$-conjunto minimal por soma restrito induzido por similaridade . . . . . . . . . . . . . . . . . . . . . 69

4.5 Conjunto induzido sobre o conjunto CidadesAmericanas por $L_{2}$ e Bristol city, apresentado em ordem do valor de dissimilaridade. . . . . . . 74

4.6 Conjunto resposta da Consulta $1 \ldots \ldots$. . . . . . . . . . . . 74

4.7 Comparação dos resultados de uma $k$-NNq e de consultas ${ }_{c} k$-NN com variações de condições baseadas em agregação por contagem. . . . . . . . . . . 77

4.8 Conjunto resposta da Consulta 5 com opção de minimização min-min. . . . 81

4.9 Conjunto resposta da Consulta 5 com opção de minimização min-sum. . 81

4.10 Conjunto resposta da Consulta 5 com opção de minimização min-max. . . 81

4.11 Representação visual de uma instância da relação PontosTuristicos. . . . 82 
4.12 Resultados da execução da Consulta 9 sobre o conjunto de dados CidadesAmericanas, comparando o comportamento dos algoritmos Sequencial, Table-Slim e Covering-Slim . . . . . . . . . . . . . . . . . . 108

4.13 Resultados da execução da Consulta 12 sobre o conjunto DICOM_HC200k, comparando o comportamento dos algoritmos desenvolvidos . . . . . . . 109

4.14 Resultados de experimentos avaliando os algoritmos para execução de ${ }_{c} k$-NNq restritas por $c d$-aconds . . . . . . . . . . . . . . . 111

4.15 Resultados de experimentos avaliando os algoritmos para execução de ${ }_{c} k$-NNq com condições baseadas em tupla . . . . . . . . . . . . . . 113

5.1 Passos da execução da função generateSignature. . . . . . . . . . . . . . . 120

5.2 Passos executados pela função ODCIIndexCreate. . . . . . . . . . . . 125

5.3 Execução de uma consulta por similaridade indexada no FMI-SiR ${ }_{O}$. . . . . 127

5.4 Arquitetura do MedFMI-SiR. . . . . . . . . . . . . . . . . . . . 139

5.5 Amostra das imagens do conjunto ALOI. . . . . . . . . . . . . . . . . . 143

5.6 Gráficos de $\mathrm{P} \times \mathrm{R}$ comparando a qualidade dos resultados do FMI-SiR $O$ e do Oracle padrão. . . . . . . . . . . . . . . . . . . . . . . 145

5.7 Comparativo do tempo de execução de consultas $k$-NN no FMI-SiR $O$ e no Oracle padrão. . . . . . . . . . . . . . . . . . . . . . 146

5.8 Comparativo do tempo de execução de consultas por abrangência no FMI-SiR $_{O}$ e no Oracle padrão. . . . . . . . . . . . . . . . . . . . . . . . 147

5.9 Avaliação de falsos negativos gerados pelos algoritmos de busca por abrangência. . . . . . . . . . . . . . . . . . . . . . . . . . 148

5.10 Comparativo de tempo de execução dos algoritmos junção baseada em laços aninhados do Oracle padrão e do FMI-SiR $O$ e o algoritmo de junção baseada em índice do FMI-SiR $O$, variando a cardinalidade de junção. . . . . . . . . . 149

5.11 Avaliação de escalabilidade do algoritmo de junção baseada em índice do FMI-SiR $_{O}$, variando o tamanho da relação interna. . . . . . . . . . . . . 150

5.12 Escalabilidade do algoritmo de junção baseada em índice do FMI-SiR ${ }_{O}$, variando o tamanho da relação externa. . . . . . . . . . . . . . . . . . . . 150

5.13 Análise de escalabilidade do MedFMI-SiR. . . . . . . . . . . . . . . . . . 152

5.14 Planos de execução gerados sobre o MedFMI-SiR. . . . . . . . . . . . . . 153

5.15 Comparativo dos tempos de execução dos diferentes planos gerados usando o MedFMI-SiR. . . . . . . . . . . . . . . . . . . . . 154 


\section{Lista de Tabelas}

2.1 Exemplos de metadados descritos no dicionário de dados do padrão DICOM. 30

4.1 Relações usadas nos exemplos do Capítulo 4. . . . . . . . . . . . . . . . . . 71

5.1 Funcionalidades implementadas no FMI-SiR $O$ para suporte à recuperação por conteúdo. . . . . . . . . . . . . . . . . . . . . 119 


\section{Lista de Algoritmos}

3.1 Consulta por abrangência em um MAM (rangeQuery) . . . . . . . . . . . 50

3.2 Consulta aos $k$-vizinhos mais próximos em um MAM (knnQuery) . . . . . . 53

4.1 Consulta ${ }_{c} k$-NN com condição baseada em tupla . . . . . . . . . . . . . 96

4.2 Consulta ${ }_{c} k$-NN com condição baseada em agregação por contagem, sendo que $\theta={ }^{\prime} \geq$ ' . . . . . . . . . . . . . . . . . . . . . . . . . 98

4.3 Consulta ${ }_{c} k$-NN com agregação por contagem de distintos $\left(\theta=\geq^{\prime}{ }^{\prime}\right) \ldots$. . . 100 


\section{Capítulo \\ 1 \\ Introdução}

Com o advento da computação, as primeiras aplicações a serem desenvolvidas foram voltadas ao processamento numérico e de textos curtos. Na década de 60 surgiram os primeiros Sistemas de Gerenciamento de Banco de Dados (SGBDs), inicialmente visando atender as aplicações de grandes organizações, como corporações, universidades, hospitais e bancos. Gradativamente, outras áreas começaram a fazer uso dos SGBDs para armazenamento de dados, porém ainda tipicamente manipulando números, datas e textos curtos.

O sucesso dos SGBDs nessas aplicações, hoje consideradas tradicionais, encorajou os desenvolvedores de outros tipos de aplicações, que exigem a manipulação de novos tipos de dados. Esses novos tipos de dados são comumente denominados dados não escalares ou dados complexos, termo utilizado neste texto para denotar toda informação que não é representável por apenas um dado escalar, que nesta tese é referenciado como dado tradicional. Alguns exemplos de aplicações que requerem manipular dados complexos são: aplicações científicas, que armazenam uma grande quantidade de dados resultantes de experimentos científicos; aplicações multimídia, que provêm funções para que os usuários possam manipular e interagir com textos de grande extensão, imagens, sons e vídeos digitais; aplicações espaciais e de geoprocessamento, que armazenam as localizações espaciais dos dados; e aplicações referentes a séries temporais, que manipulam os dados considerando sua evolução histórica e sua validade temporal.

Para explorar os novos tipos de dados analisando seu conteúdo é preciso criar funções para manipulá-los adequadamente e estender os SGBDs existentes para suportar as características particulares desses dados nos diversos componentes desses gerenciadores. Esta tese de doutorado se insere neste contexto, tendo como foco principal propor alternativas 
para a recuperação de dados envolvendo operações por similaridade integradas às demais operações tradicionalmente oferecidas pelos SGBD Relacionais (SGBDRs). O benefício almejado é que as aplicações sobre dados complexos possam formular consultas complexas envolvendo critérios baseados em similaridade e critérios baseados em dados tradicionais utilizando uma linguagem de consulta relacional e ter sua execução realizada de forma eficiente sobre grandes volumes de dados.

\subsection{Motivação}

Dados complexos trazem uma demanda inerente por recursos de recuperação de dados que os SGBDs tradicionalmente não provêm. Isto se deve, principalmente, ao fato de que a maioria dos domínios de dados complexos não definem uma relação de ordem total entre elementos. Assim, os operadores de comparação relacionais ('<', ' $\leq$, ' '> e ' $\geq$ ') não podem ser usados. De forma similar, as consultas por igualdade têm pouca utilidade sobre dados complexos, fazendo com que, nesse contexto, os operadores ' $=$ ' e ' $\neq$ ' se tornem praticamente inúteis (Chávez et al., 2001). Por exemplo, de uma forma geral não faz sentido dizer que uma imagem é menor do que outra e fazer uma busca por igualdade em um banco de imagens é útil apenas para saber se exatamente aquela imagem já está armazenada, pois qualquer variação na imagem, mesmo que inperceptível ao olho humano, corresponde a um dado diferente.

Para dados complexos é mais natural realizar consultas por similaridade, definindo relações de similaridade entre pares de elementos, que consideram as características particulares de cada domínio de aplicação. Estas consultas retornam os elementos do conjunto de dados que atendem a certos critérios de similaridade em relação a um ou mais elementos de referência, também chamados elementos de consulta. Desta forma, o objetivo torna-se encontrar elementos semelhantes, não necessariamente iguais, pois, para dados complexos é extremamente difícil encontrar no conjunto de dados elementos distintos estritamente iguais.

A área de consultas por similaridade tem evoluído consideravelmente nos últimos anos. Vários algoritmos e estruturas de indexação têm sido propostos (Hjaltason e Samet, 2003), subsidiando inúmeras áreas de aplicação. Entretanto, a maioria das abordagens de busca por similaridade considera cada consulta como uma operação isolada, ao invés de operações integradas em expressões de consulta mais complexas. Aplicações reais, por outro lado, freqüentemente precisam manipular dados complexos e tradicionais de forma homogênea. Por exemplo, os sistemas de apoio à área biomédica em geral manipulam uma grande variedade de tipos de dados, tais como dados tradicionais (dados de pacientes, prontuários e outros), gráficos e séries de sinais (tais como eletrocardiogramas e eletroencefalogramas) e imagens digitais de exames (raios-x digitais, ultra-sons, tomografias computadorizadas, dentre outros). Neste contexto, considere-se uma aplicação 
de apoio ao diagnóstico de câncer de mama. Um exame muito usado neste tipo de análise é a mamografia, cujo resultado é apresentado por meio de duas imagens de cada mama (Figura 1.1): uma visão lateral (Médio-Lateral Oblíqua - MLO) e uma horizontal (Crânio-Caudal - CC). Estas imagens permitem identificar nódulos benignos e malignos, micro-calcificações e anomalias por assimetria. Um aplicativo de apoio ao diagnóstico (CAD - Computer Aided Diagnosis) usando tecnologia de busca por similaridade poderia buscar em um banco de dados casos prévios semelhantes ao caso atual, que poderiam ser utilizados para balizar o diagnóstico corrente ou para auxiliar o ensino para a prática desse tipo de diagnóstico em cursos de medicina e radiologia. Contudo, para que o processo de busca seja eficaz é necessário manipular de forma integrada o conteúdo de pares de imagens de mamografia, seus metadados associados e dados textuais contidos no prontuário do paciente.
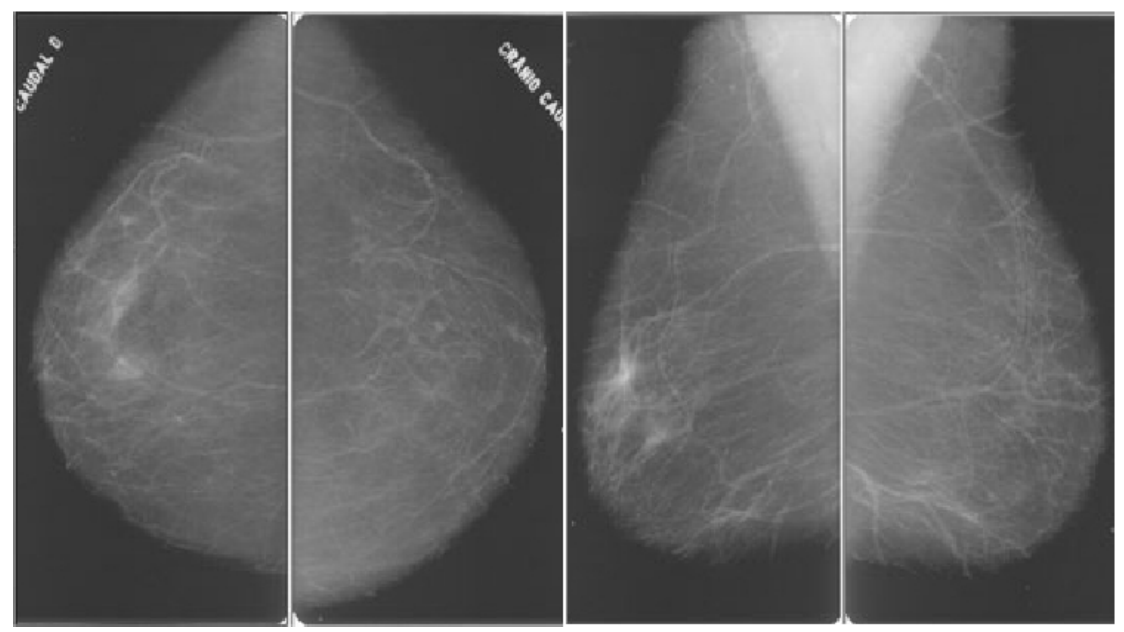

Figura 1.1: As duas imagens de cada uma das mamas que compõem um exame de mamografia. As imagens à esquerda foram obtidas por incidência CrânioCaudal e as imagens à direita por incidência Médio-Lateral Oblíqua.

As abordagens existentes para recuperação de dados complexos em geral são aplicações particularizadas, muitas vezes compostas por códigos ineficientes e de difícil reutilização, mesmo em aplicações semelhantes, com o tratamento das buscas baseadas em similaridade dissociadas das buscas baseadas em dados tradicionais. Por outro lado, a inclusão de operações baseadas em similaridade nas máquinas de busca dos SGBDs possibilita aumentar o poder de expressividade das linguagens de consulta e também explorar as otimizações que podem ser alcançadas pela combinação de expressões mais simples. Desta forma, pode-se concentrar o esforço em desenvolver um subsistema de recuperação por similaridade, que seja eficiente e integrado às demais operações fornecidas pelo SGBD, para suportar o desenvolvimento de uma variedade de aplicações de forma eficaz e otimizada.

Existem vários tipos de consultas por similaridade, incluindo buscas por abrangência e aos $k$-vizinhos mais próximos, junções por similaridade e consultas por similaridade agregada. As buscas por similaridade por abrangência podem ser resolvidas por meio 
de seleções relacionais e, portanto, inseridas sem maiores dificuldades no processador de consultas de um SGBD. As buscas aos $k$-vizinhos mais próximos, por outro lado, são mais complexas em termos de representação e manipulação algébrica, levando-se em conta que elas não são comutativas. Desta forma, faz-se necessário um tratamento especializado para permitir expressar e executar consultas envolvendo condições baseadas em buscas aos $k$-vizinhos mais próximos e condições baseadas em atributos tradicionais.

\subsection{Objetivos e Contribuições}

O objetivo geral deste projeto de doutorado foi propor alternativas algébricas, estruturas e algoritmos para permitir o uso abrangente e a execução eficiente de consultas por similaridade associadas às demais operações de busca atendidas pelos SGBDs relacionais.

Em particular, a consulta aos $k$-vizinhos mais próximos ( $k$-Nearest Neighbors query $k$-NNq) tem dificultada sua integração a outras condições baseadas em atributos tradicionais, pois ela não pode ser comutada com as operações envolvendo as demais condições. No entanto, ela é utilizada frequentemente junto a diversos outros predicados (usualmente não baseados em similaridade) em muitos algoritmos que apoiam a análise de dados, mineração de dados e sistemas de apoio à decisão em geral. Visando atacar esse problema, a tese explorada neste trabalho é sucintamente descrita conforme segue.

"Embora o operador de consulta aos k-vizinhos mais próximos em sua forma canônica não propicie sua integração com outras condições para a formulação de consultas sobre dados complexos, é possível estender este operador permitindo que sejam fornecidas condições adicionais à busca, aumentando assim o seu poder de expressividade. Além disso, esta extensão do operador $k$-NN pode ser integrada com os demais operadores de busca disponíveis e os algoritmos que implementam as variações de buscas habilitadas por esta operação podem ser inseridos homogeneamente no ambiente de processamento de consultas de um SGBDR."

As principais contribuições desta tese podem ser divididas em duas frentes de trabalho. A primeira frente compreendeu a definição de uma proposta de extensão da $k$-NNq, denominada consulta aos $k$-vizinhos mais próximos estendida com condições (condition-extended $k$-NN query $-{ }_{c} k$-NNq). Esta nova operação possibilita modificar o comportamento da busca aos vizinhos mais próximos, de forma que atenda a uma restrição definida sobre propriedades adicionais dos dados complexos consultados, tipicamente envolvendo atributos de tipos escalares. Além da definição formal da consulta ${ }_{c} k$-NN, foram identificadas as principais propriedades algébricas que envolvem esta operação no processo de otimização de consultas e também foram desenvolvidos algoritmos para executar variações das buscas habilitadas com o uso desta operação. 
A segunda frente de trabalho concentrou-se em integrar operadores de busca por similaridade no ambiente de processamento de consultas de um SGBD. Nesta linha, foi desenvolvido o FMI-SiR (user-defined Features, Metrics and Indexes for Similarity $\boldsymbol{R}$ etrieval - características, métricas e índices definidos pelo usuário para recuperação por similaridade), um módulo de SGBD que implementa os principais recursos necessários para a representação e execução eficiente de consultas por similaridade integradas às operações existentes no SGBD. Além disso, também é apresentada uma extensão desse módulo voltada à recuperação de imagens médicas combinando condições baseadas em similaridade e condições baseadas em metadados.

Foram realizados diversos experimentos nas duas frentes citadas, que mostraram a aplicabilidade e eficiência das contribuições geradas durante o trabalho. Os resultados dessa pesquisa podem ser aplicados a várias áreas de atuação, entretanto, houve particular interesse em subsidiar sistemas de apoio à área médica.

\subsection{Organização do trabalho}

O restante desta tese está organizado como segue.

- O Capítulo 2 apresenta os principais aspectos relacionados à recuperação de dados complexos por similaridade, incluindo as técnicas envolvidas no processo de avaliação de similaridade, os tipos de consulta por similaridade mais difundidos e uma visão geral da recuperação de imagens médicas por similaridade.

- O Capítulo 3 mostra as principais propostas para representação algébrica de consultas por similaridade, os algoritmos que respondem aos tipos básicos de consulta por similaridade encontrados na literatura e o suporte à recuperação por similaridade oferecido por alguns protótipos e SGBDs comerciais.

- O Capítulo 4 apresenta a proposta da consulta aos $k$-vizinhos mais próximos estendida com condições, incluindo a definição formal da consulta, regras algébricas envolvendo o operador proposto, algoritmos para as principais variações de buscas do operador e experimentos sobre os algoritmos desenvolvidos.

- O Capítulo 5 apresenta o módulo de recuperação por similaridade FMI-SiR, incluindo os principais aspectos de sua implementação sobre o SGBD Oracle, como os principais tipos de consulta por similaridade podem ser expressos com o uso do módulo, a extensão MedFMI-SiR, desenvolvida particularmente para recuperação de imagens médicas por similaridade, e experimentos sobre bancos de dados reais.

- Finalmente, o Capítulo 6 traz as conclusões do trabalho, incluindo as referências às publicações geradas e propostas de trabalhos futuros. 


\section{Capítulo \\ 2 \\ Recuperação de Dados Complexos por Similaridade}

Com o aumento da disponibilidade e capacidade de equipamentos de aquisição de dados, gerenciar grandes volumes de dados complexos, tais como dados multimídia e dados georeferenciados, tem se tornado cada vez mais importante. Sem um mecanismo adequado de recuperação, os dados gerados acabam arquivados em enormes repositórios de dados que raramente são utilizados (Fayyad e Uthurusamy, 2002).

Usualmente, os mecanismos de recuperação de dados complexos representam os dados como elementos em um espaço definido por suas características. Por exemplo, um dado georeferenciado é representado como um elemento (ponto, linha ou polígono) no espaço geográfico definido pela latitude e longitude do elemento, ou de suas partes (um polígono geralmente é definido por uma sequência de pontos) (Yeung e Hall, 2007). Um dado multimídia geralmente é representado por um conjunto de características extraídas do conteúdo do dado. Isto porque dados multimídia são basicamente arranjos multidimensionais de valores derivados de vários sensores, que é uma representação limitada para definir a semântica do dado. Neste sentido, dados complexos raramente são comparados diretamente. Em vez disso, o conteúdo do dado (ou uma faceta do conteúdo) é analisado por meio de algoritmos especializados de análise, extraindo um conjunto de características que descrevem numericamente o dado. Desta forma, um dado multimídia pode ser representado como um ponto no espaço de características, de acordo com o valor extraído para cada uma das características.

Representando dados complexos em um espaço de características, torna-se possível estabelecer relações de similaridade entre os dados. Na literatura de filosofia e de psicologia, 
a noção de Espaço de Similaridade estabelece que a mente humana define um hiperespaço de representação (Gauker, 2007). Neste espaço, as dimensões representam formas pelas quais objetos podem ser distinguidos, pontos representam objetos que podem existir e distâncias entre pontos são inversamente proporcionais à similaridade percebida entre estes objetos. Assim, é possível recuperar os dados multimídia que sejam similares a um determinado dado indicado como referência da consulta analisando as distâncias no espaço de similaridade. Da mesma forma, consultas por proximidade em um banco de dados georeferenciados podem ser consideradas consultas por similaridade no espaço definido por suas coordenadas. Este tipo de recuperação é o que se define como Recuperação por Similaridade.

Este capítulo trata da recuperação por similaridade de dados complexos, com foco particular em dados multimídia e em dados médicos. A Seção 2.1 discute o problema da representação de consultas baseadas em conteúdo de dados complexos. A Seção 2.2 descreve as técnicas envolvidas no processo de avaliação de similaridade. A Seção 2.3 apresenta as principais consultas por similaridade encontradas na literatura. Por fim, a Seção 2.4 apresenta as estratégias mais comuns utilizadas para a recuperação de imagens médicas por similaridade, que é uma das áreas fundamentais de aplicação das técnicas desenvolvidas nesta tese.

\subsection{O Problema da Representação de Consultas}

Uma das razões que motivaram a adoção massiva de sistemas de gerenciamento de bancos de dados é sua capacidade de armazenar e recuperar grandes volumes de dados, propiciando acesso concorrente e seguro para múltiplas aplicações. A linguagem SQL (Structured Query Language) é a linguagem padrão de fato para definição e manipulação de dados em SGBDs relacionais e objeto-relacionais. Ela define um conjunto abrangente de operadores para representar consultas envolvendo dados simples, tais como números, datas e textos curtos (Groff et al., 2009). Entretanto, as operações de consulta sobre o conteúdo de um dado complexo trazem outras necessidades e possibilidades, diferentes daquelas aplicáveis a dados simples. Se, por um lado, a recuperação de dados de domínios simples pode ser feita utilizando relações de ordem total ou funções matemáticas bem definidas sobre os dados, por outro lado, a recuperação de dados complexos pode envolver abstrações não triviais inferidas a partir do seu conteúdo. Por exemplo, as consultas a seguir são relevantes para aplicações multimídia:

- retorne as imagens que possuem uma massa de tamanho anormal em um exame radiológico por imagem;

- retorne as imagens que mostram um pôr-do-sol sobre o mar; 
- retorne os vídeos que contêm partes de um dado vídeo protegido por direitos autorais;

- retorne os vídeos de crianças brincando com animais de estimação;

- retorne as músicas que possuem um solo de bateria.

Cada uma destas consultas exige um processamento particular sobre o conteúdo do dado para ser respondida. O ponto em questão é: como representar a consulta para ser respondida por um sistema de recuperação de propósito geral? Ou seja, um sistema que provê conjuntos de primitivas que podem ser reutilizadas e especializadas por aplicações distintas, mas que compartilham um conjunto comum de requisitos no que tange a recuperação de dados. A próximas seções apresentam duas abordagens diferentes para este problema, definidas em (Barioni et al., 2011).

\subsubsection{Abordagem de Operadores Baseados em Conteúdo}

A abordagem que visa definir um operador, ou função, específico para cada abstração identificada no conteúdo de um dado complexo é conhecida como abordagem de Operadores Baseados em Conteúdo. Por exemplo, para representar a primeira consulta apresentada na seção anterior, esta abordagem requer que exista uma função que identifique um padrão específico em imagens médicas (uma massa) e outra que calcule a área. De forma semelhante, a segunda consulta demanda funções que identifiquem os elementos desejados na cena (pôr-do-sol e mar) e operadores baseados na relação espacial entre eles (por exemplo, acima, abaixo e ao lado).

Embora esta abordagem seja factível para aplicações específicas, a quantidade de operadores necessários para representar as consultas pode ser excessivamente grande. Os operadores utilizados para identificar os objetos devem ser especializados para cada domínio de aplicação, gerando uma variedade de funções para representar cada (classe de) objeto(s). Além disso, embora existam trabalhos voltados à recuperação de imagens por similaridade espacial entre regiões segmentadas, tais como (Huang et al., 2008; Yeh e Chang, 2008), consultas deste tipo são usualmente representadas utilizando um esquema ou um exemplo contendo as associações espaciais desejadas, pois representar a associação entre vários objetos pode ser bastante difícil.

A representação de categorias de consultas mais complexas é ainda mais complicada utilizando operadores baseados em conteúdo. As três últimas consultas citadas na seção anterior exigem definir, respectivamente: o que determina o fato de um vídeo ser protegido por direitos autorais, qual é o padrão visual que representa o ato de brincar e o que é um solo de bateria. É fácil perceber que esta abordagem tende a gerar uma explosão na quantidade de operadores para satisfazer cada situação e a variedade das associações entre dados complexos e entre suas partes. 


\subsubsection{Abordagem de Operadores Baseados em Similaridade}

A abordagem de consultas definidas por meio de Operadores Baseados em Similaridade é aquela que provê alguns operadores de busca baseados em critérios de similaridade entre dados complexos para uso em uma grande variedade de situações. Estes operadores têm o objetivo de computar a similaridade entre dados complexos, de acordo com um padrão predefinido entre os dados armazenados e o elemento (ou conjunto de elementos) fornecidos como referência na consulta, e verificar quando a similaridade satisfaz o(s) critério(s) desejado(s). O elemento de referência da consulta também pode ser um esboço do padrão visual desejado (Szańto et al., 2011).

O suporte à abordagem de operadores baseados em similaridade tem duas vias: (i) fornecer um exemplo do padrão desejado é, em geral, mais fácil do que tentar descrevê-lo; e (ii) fornecer um conjunto limitado de operadores é suficiente para representar a maioria das consultas sobre dados complexos, pois a peculiaridade de cada domínio fica embutida em sua definição de similaridade.

O primeiro aspecto que subsidia a abordagem de operadores baseados em similaridade é derivado da idéia de "consulta por exemplo", que tem sido utilizada na área de bancos de dados por muito tempo. A maior parte das ferramentas de recuperação de dados multimídia por conteúdo usa este método. O segundo aspecto tem por objetivo simplificar o processo de execução de consultas como um todo, para possibilitar o desenvolvimento de um ambiente de processamento de consultas consistente. Esta simplificação pode ser feita sem correr o risco de perder a generalidade da abordagem, pois a definição de similaridade é dependente do problema. Por exemplo, uma boa medida de similaridade para responder à segunda consulta apresentada poderia se concentrar no padrão de distribuição de cores das imagens. Contudo, esta medida provavelmente produziria resultados ruins se aplicada à primeira consulta, pois o que identifica uma massa em uma imagem radiológica é a diferença entre a massa e o tecido em volta. Este padrão não é adequadamente capturado por uma avaliação comum de cores, sendo geralmente melhor detectado por um processo baseado em análise de texturas. O conhecimento do domínio de cada classe de problema é embutido no processo de análise de similaridade, que deve ser especializado de acordo com os requisitos de cada caso. Isto possibilita definir condições especializadas de consulta para uma grande variedade de domínios utilizando poucos operadores de consulta.

Vale ressaltar que pode surgir o questionamento se esta abordagem não está apenas transferindo o problema da explosão da quantidade de operadores mencionado na abordagem anterior para uma explosão da quantidade de medidas de similaridade. Em parte esta observação é correta. Entretanto, manter um conjunto reduzido de operadores de consulta permite definir um conjunto bem definido de alternativas de otimização e um conjunto de estruturas de dados e primitivas que podem ser aplicadas em várias situações distintas. 
Esta tese adota a abordagem de Operadores Baseados em Similaridade para a representação de consultas. A próxima seção apresenta os conceitos relacionados à avaliação de similaridade de dados complexos.

\subsection{Avaliação de Similaridade}

A avaliação de similaridade compreende uma sequência de tarefas computacionais que resultam em um valor que quantifica o quão similares dois dados complexos são. Como citado anteriormente, há autores que defendem a idéia de que a mente humana define um espaço de similaridade, onde os conceitos são organizados segundo suas relações de similaridade (Gauker, 2007). Entretanto, ao tratar de vários tipos de dados complexos, ainda sabe-se pouco sobre as regras que definem o espaço de similaridade que corresponde à percepção humana para cada contexto de uso. Por exemplo, pessoas diferentes podem ter percepções diferentes de uma mesma imagem ou vídeo, dependendo do seu interesse e do seu conhecimento prévio. Além disso, a noção de similaridade entre dois dados complexos geralmente é definida por medidas diferentes em contextos diferentes. Ou seja, as distâncias percebidas entre dados variam de acordo com a situação.

\subsubsection{Uma Abstração do Espaço de Similaridade}

O processo de avaliação de similaridade tende a ser bastante complexo e especializado, assim várias técnicas e abordagens diferentes são encontradas na literatura. Neste texto, os vários elementos envolvidos nesse processo são organizados segundo uma abstração do conceito de espaço de similaridade (Barioni et al., 2011). Dados complexos em geral podem ser modelados por meio de conjuntos de atributos que sumarizam o seu conteúdo. Esses conjuntos de atributos são denominados na literatura como vetores de características, embora não necessariamente formem um espaço vetorial (por exemplo, dados complexos de um mesmo conjunto podem ter vetores de características de tamanhos diferentes) (Traina et al., 2003). Os algoritmos que fazem algum tipo de processamento sobre dados complexos para produzir vetores de características são conhecidos como extratores de características. A similaridade entre dois vetores de características é calculada por meio de uma função matemática. Em geral, a avaliação de similaridade utiliza funções de distância, que calculam a dissimilaridade entre dois vetores de características. $\mathrm{Ou}$ seja, quanto menor a distância, maior a similaridade entre os elementos. Uma das vantagens do uso de funções de distância é que a similaridade entre dois elementos idênticos tem um valor definido, indicada como distância zero. A combinação de vetores de características e funções de distância constituem descritores, que determinam o valor de similaridade entre elementos (Torres et al., 2009). Interpretando cada descritor, ou seja, cada par $\langle\mathbb{S}, \delta\rangle$, onde $\mathbb{S}$ é um domínio definido por um vetor de características e $\delta$ é uma 
função de distância definida sobre este domínio, como uma instância do espaço de similaridade, a abstração do espaço de similaridade humano utilizada nesta tese é formada pelo conjunto de todas instâncias de espaço de similaridade possíveis. Como citado anteriormente, ocorrem variações na interpretação humana a respeito de um dado complexo, influenciadas por fatores como o conhecimento prévio do usuário, sua intenção de uso para o dado complexo no momento da consulta e o contexto de aplicação. Na abstração do espaço de similaridade, este processo é modelado pela escolha de uma instância do espaço de similaridade que defina da maneira mais próxima possível a interpretação do usuário.

O resultado de uma consulta por similaridade depende da instância do espaço de similaridade utilizada. Em alguns domínios, esta escolha não é um problema. Por exemplo, aplicações de geoprocessamento geralmente tratam similaridade como a distância entre objetos na superfície terrestre. Neste contexto, consultas típicas, tais como "retorne os restaurantes que estão a até $2 \mathrm{Km}$ de onde estou" e "retorne os 2 hospitais mais próximos a uma escola infantil", são respondidas adequadamente utilizando as coordenadas geográficas dos elementos como o vetor de características e utilizando como função a distância Euclideana, ou o caminho mais curto entre vértices, se as rotas de acesso forem modeladas como um grafo. Entretanto, para dados multimídia é frequentemente necessário identificar qual par $\langle\mathbb{S}, \delta\rangle$ define a instância do espaço de similaridade que melhor representa a interpretação do usuário em uma dada situação. Resultados experimentais mostram que encontrar a melhor combinação entre vetor de características e função de distância aprimora a precisão das consultas (Bugatti et al., 2008).

Desta forma, para obter resultados relevantes em consultas por similaridade sobre dados complexos, o maior desafio é identificar a instância do espaço de similaridade que melhor satisfaz a expectativa do usuário. Esta instância "ideal" é referenciada na literatura como espaço (de similaridade) semântico (He et al., 2002). Há inúmeras áreas de pesquisa e técnicas envolvidas no processo de aproximação do espaço de similaridade semântico, como mostra a Figura 2.1. Esta ilustração não tem o intuito de ser exaustiva, mas de incluir os conceitos mais comuns em torno da avaliação de similaridade. A figura destaca que alguns conceitos afetam diretamente os componentes de uma instância do espaço de similaridade. Por exemplo, as tarefas de extração, seleção e transformação de características constroem ou modificam o vetor de características, definindo o domínio do conjunto de dados. De forma semelhante, a função de distância pode ser modificada aplicando-se técnicas de ponderação de características específicas, bem como ponderação de distâncias parciais, no caso de funções que agregam resultados de outras distâncias.

A base de uma instância do espaço de similaridade é formada por um domínio definido por um vetor de características (após todos os procedimentos de pré-processamento, extração e pós-processamento) e uma função de distância (definida pela função de cálculo e por todos os valores para os parâmetros utilizados). Portanto, qualquer modificação 
realizada em um destes componentes gera uma nova instância do espaço de similaridade. Isto significa que a partir de um mesmo extrator de características e de uma mesma função de distância podem ser obtidas várias instâncias do espaço de similaridade, dependendo dos pré- e pós-processamentos realizados, modificando o vetor de características e/ou a função de distância. A Figura 2.1 também mostra que em um nível mais alto estão as informações externas, técnicas e algoritmos que são utilizados para para definir como serão implementados os conceitos que afetam diretamente os componentes de uma instância do espaço de similaridade (extração, seleção e transformação de características e ponderação de distâncias). Neste nível encontram-se algoritmos de processamento de dados complexos, técnicas de descoberta de conhecimento, realimentação de relevância, aprendizado de máquina e outros.

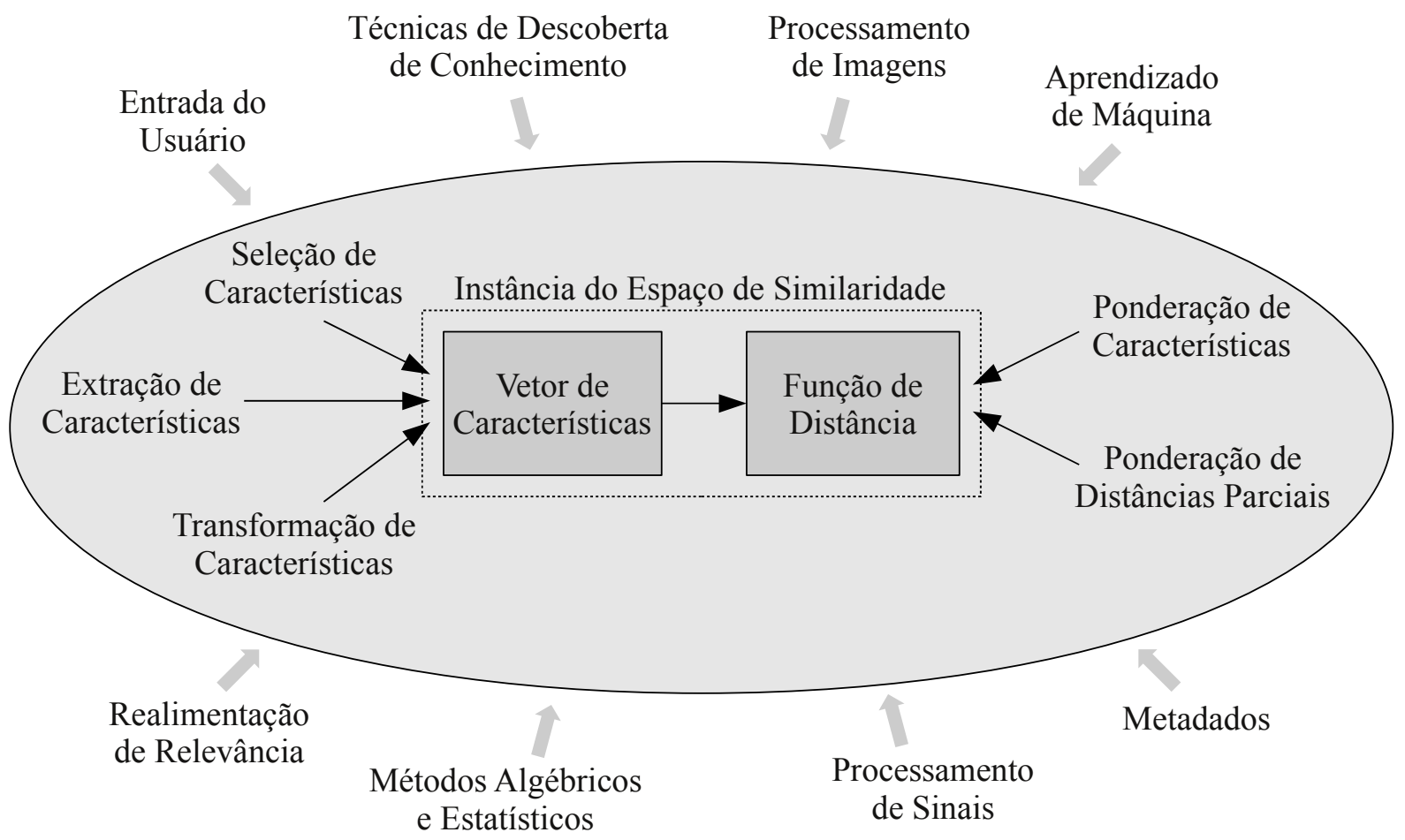

Figura 2.1: Espaço de similaridade e técnicas envolvidas na definição de sua semântica.

As seções a seguir apresentam uma breve revisão da literatura a respeito de propostas envolvendo os componentes de uma instância de espaço de similaridade.

\subsubsection{O Componente Vetor de Características}

Para muitos tipos de dados complexos e multimídia, a sua representação original é limitada para descrever o seu conteúdo. Por exemplo, uma imagem digital monocromática é definida como uma função bidimensional discreta de intensidade da luz $f(x, y)$, onde $x$ e $y$ denotam as coordenadas espaciais discretas e o valor de $f$ é proporcional ao brilho (ou níveis de cinza) da imagem naquele ponto (Gonzalez e Woods, 2007). Esta matriz de pixels não possui informação semântica que corresponda à percepção visual humana. 
Por este motivo, inúmeras propostas de descrições matemáticas de imagens podem ser encontradas na literatura, visando extrair a semântica da cena retratada na imagem. Nessas propostas, a imagem passa a ser um elemento de um conjunto definido pelas suas características, que são medidas numéricas que capturam alguma propriedade visual da imagem.

As características que descrevem dados multimídia podem ser classificadas em três níveis de abstração, conforme os tipos de consultas que podem ser realizadas (Eakins e Graham, 1999).

Nível 1 Compreende a recuperação por características primitivas (ou intrínsecas), obtidas diretamente do objeto multimídia, sem utilizar conhecimento externo. Por exemplo, considerando imagens, este tipo de características seriam padrões genéricos baseados em cor, textura, forma ou localização de elementos na cena. Considerando vídeos, as características incluiriam estas características e também padrões de movimento.

Nível 2 Corresponde à recuperação baseada em atributos derivados, identificados através de algum grau de inferência lógica sobre o conteúdo do dado. São exemplos de características deste nível a identificação de elementos (por exemplo, uma pessoa ou um objeto) e/ou movimentos simples (por exemplo, um avião decolando).

Nível 3 Compreende a recuperação por características abstratas, envolvendo um nível considerável de raciocínio. Características deste nível poderiam representar ações mais elaboradas, tais como imagens de dança ou vídeos de crianças brincando com animais de estimação.

Estes níveis de abstração apresentam uma complexidade gradativa, e também uma tendência de redução do escopo do domínio de aplicação. A baixa coincidência entre características de baixo nível (nível 1), extraídas automaticamente dos dados, e a interpretação humana de alto nível (baseada em características dos níveis 2 e 3) é conhecida na literatura como lacuna semântica (semantic gap) (Smeulders et al., 2000). Muitos esforços de pesquisa têm sido direcionados para extrair características de nível mais alto, com uma semântica mais rica, para reduzir esta lacuna semântica e produzir resultados de melhor qualidade para os usuários.

A extração de características é o passo elementar de processamento de dados complexos e multimídia para definir o componente vetor de características. Há vários extratores de características para dados multimídia propostos na literatura, sumarizados a seguir.

\section{Extração de Características de Dados Multimídia}

Imagens são normalmente representadas por seus padrões de cor, textura e forma. Estas características podem ser extraídas automaticamente da imagem como um todo (escopo 
global) ou de pequenas regiões da imagem (escopo local). As primeiras técnicas de extração de características propostas foram na sua maioria de escopo global, porém, as pesquisas mais recentes têm se concentrado em extrair características de regiões das imagens (Datta et al., 2008). A representação de imagens baseada em regiões aproxima-se mais da percepção humana do que a representação de imagens inteiras (Jing et al., 2003). Desta forma, é possível identificar e destacar elementos visuais diferentes presentes na cena e estabelecer associações entre eles. Para obter assinaturas baseadas em região, o primeiro passo essencial é a segmentação das imagens, que é um processo que consiste na subdivisão de uma imagem em regiões distintas, visando identificar os elementos presentes na cena (uma pessoa ou um objeto, por exemplo). Gonzalez e Woods (2007) classificam os métodos de segmentação em três categorias básicas: limiarização (thresholding), segmentação baseada em bordas e segmentação baseada em regiões.

Após realizada a segmentação da imagem, se for o caso, aplicam-se algoritmos para extrair as características primitivas das regiões obtidas. As características baseadas em cor são as mais utilizadas na recuperação por conteúdo, especialmente nas abordagens menos recentes ou menos específicas. O exemplo clássico de extrator de características baseado em cor é o histograma normalizado (Gonzalez e Woods, 2007). A intensa aplicação de extratores baseados em cor, especialmente os histogramas, se justifica principalmente devido à menor complexidade dos métodos empregados e, consequentemente, ao menor custo computacional e por serem invariantes a rotações e translações das imagens. Entretanto, os histogramas apresentam uma capacidade reduzida de discriminação e não trazem por si só informação sobre a distribuição espacial das cores na imagem. Por exemplo, as imagens descritas na Figura 2.2 embora sejam visivelmente diferentes, possuem histogramas idênticos. Diversas técnicas foram propostas para tratar esse problema, incluindo o vetores de coerência de cor (Pass et al., 1996) e o correlograma de cor (Huang et al., 1997).

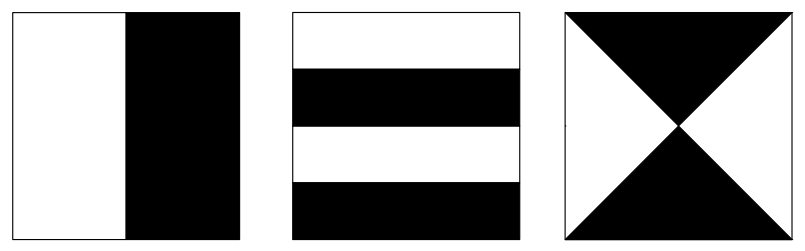

Figura 2.2: Imagens visualmente distintas e com histogramas idênticos.

As características baseadas em textura procuram identificar padrões repetitivos de variações de intensidade de cor nas imagens. A textura é considerada um tipo de característica importante para representar o conteúdo de uma imagem. Em imagens médicas, por exemplo, os extratores baseados em textura têm maior capacidade de discriminar tecidos do que outros extratores e permitem identificar mais facilmente anomalias tais como nódulos e tumores. Algumas das técnicas mais utilizadas para extração de características baseadas em textura são os descritores de Haralick (Haralick, 1979), as características 
obtidas usando transformadas de wavelets (Santini e Gupta, 2001) e os filtros de Gabor (Santini e Jain, 1996).

As características baseadas em forma visam descrever o formato das regiões da imagem. Exemplos de extratores baseados em forma são os descritores de Fourier (Zahn e Roskies, 1972), baseados em contornos, os descritores baseados em curvatura em espaço de escala (Curvature Scale Space - CSS) (Mokhtarian e Mackworth, 1986) e os momentos de Zernike, basedos em regiões (Khotanzad e Hong, 1990).

Para melhorar a relevância do resultado de uma busca por conteúdo, a maioria dos sistemas utilizam combinações de extratores de características para gerar os vetores de características das imagens, ou de suas regiões. Quanto melhor o conjunto de características representar a informação semântica ilustrada na imagem, mais eficaz deverá ser a avaliação de similaridade no processo de busca.

Com relação a vídeos digitais, sua discriminação é muito mais complexa devido à sua informação temporal intrínseca (Ren et al., 2009). Contudo, as técnicas para extração de características de imagens também são utilizadas para a extração de características de vídeos, pois vídeos são essencialmente sequências de quadros (frames), que, por sua vez, são imagens estáticas. Partindo da observação que muitos quadros sequenciais de um vídeo possuem apenas pequenas mudanças, os algoritmos de extração são geralmente baseados em tomadas (shots), que são conjuntos de quadros contíguos que apresentam uma ação. Portanto, a detecção de limites entre tomadas é um processo fundamental aplicado durante a extração de características de vídeos e existem várias abordagens para realizar esta tarefa (Smeaton et al., 2010). Depois de ter detectado as tomadas, normalmente escolhe-se um quadro-chave (key frame) de cada tomada, em geral, aquele que melhor representa a tomada. Os quadros-chave são então submetidos a algoritmos de extração de características de imagens para gerar os vetores de características que serão associados às tomadas. O processo de extração de características de vídeos também pode extrair atributos complementares de outros elementos do vídeo, tais como a trilha sonora e a legenda, sincronizados temporalmente com as tomadas identificadas (Hu et al., 2011).

Extratores de características de áudio também segmentam os arquivos em quadros. Os quadros cuja energia é menor do que um limite predefinido são considerados como silêncio e, então, descartados. Dos quadros que restarem são extraídas características baseadas em tempo, frequência e amplitude. Exemplos de extratores de áudio são os coeficientes mel-cepstrais (Mel-Frequency Cepstral Coefficients - MFCC) e atributos baseados na transformada rápida de Fourier (Short Time Fourier Transform - STFT) (Tzanetakis e Cook, 2002) e abordagens baseadas em assinaturas de áudio (Audio Fingerprintings) (Baluja e Covell, 2008). 


\section{Seleção e Transformação de Características}

Outros conceitos que afetam diretamente a definição dos vetores de características são a seleção de características e a transformação de características. Estes métodos têm o objetivo de reduzir a dimensionalidade do vetor de características, otimizando a representação através da eliminação de informação redundante. Com a redução da dimensionalidade, também são reduzidos o consumo de memória e de outros recursos, melhorando o desempenho das consultas.

O processo de seleção de características consiste em obter um subconjunto do vetor de características original, incluindo as características que são relevantes para discriminar os objetos. Em geral, os métodos de seleção de características são fortemente baseados em estatística e em algoritmos de aprendizado de máquina. Guyon e Elisseeff (2003) apresentam uma visão geral dos métodos de seleção de características.

A transformação de características tem por objetivo criar novas dimensões no espaço de características, combinando e transformando as dimensões definidas pelas características originais. Os métodos de transformação mais utilizados são a análise de componentes principais (Principal Component Analysis - PCA) e a análise discriminante linear (Linear Discriminant Analysis - LDA) (Blanken et al., 2007). Muitos trabalhos usam transformação de características para indexar conjuntos de dados multimídia, cujos vetores de características têm tipicamente alta dimensionalidade, em estruturas de indexação de dados de baixa dimensionalidade, como a R-tree (Guttman, 1984).

\subsubsection{O Componente Função de Distância}

A avaliação de similaridade entre dados complexos é realizada comparando-se os vetores de características que descrevem os elementos. Funções de distância medem a dissimilaridade entre dois objetos, retornando um valor real não negativo indicando o grau de diferença entre eles. Quanto maior o valor retornado, menor a similaridade entre os objetos comparados, sendo que uma distância igual a zero significa identidade ou total similaridade.

\section{Funções de Distância}

Existe uma grande variedade de funções de distância relatadas na literatura (Wilson e Martinez, 1997). As mais utilizadas são as funções da família Minkowski $\left(L_{p}\right)$. As funções da família Minkowski podem ser aplicadas a domínios vetoriais e, como comumente usamse vetores de características para representar elementos de domínios complexos, elas são aplicadas para comparar uma vasta gama destes tipos de dados. Essa família de funções é definida pela Equação 2.1, na qual $n$ é a dimensão do espaço vetorial e $p$ é um valor 
inteiro. Quando $p=1,2$ ou $\infty$, têm-se as funções $L_{1}$ (Manhattan), $L_{2}$ (Euclideana) ou $L_{\infty}$ (Chebychev), respectivamente.

$$
d\left(\left(x_{1}, \ldots, x_{n}\right),\left(y_{1}, \ldots, y_{n}\right)\right)=\sqrt[p]{\sum_{i=1}^{n}\left|x_{i}-y_{i}\right|^{p}}
$$

Com a evolução das técnicas de recuperação de dados complexos por conteúdo, várias outras funções de distância existentes têm sido aplicadas e novas propostas têm sido desenvolvidas. Por exemplo, Vasconcelos e Lippman (2000) apresentam uma análise das funções matemáticas mais utilizadas na avaliação de similaridade entre imagens, tais como a distância de Mahalanobis, a divergência de Kullback-Leibler, a distância Quadrática e outras, formulando o problema de recuperação como um problema de classificação.

Em alguns casos, a utilização de funções de distância requer a normalização dos vetores de características para fazer com que os valores de todas as dimensões variem na mesma faixa, para assegurar que cada dimensão influencie igualmente na determinação da similaridade entre os dois vetores. Além disso, como para muitos domínios de dados existe uma grande probabilidade de correlação entre atributos de vetores de características, o que prejudica a avaliação de similaridade devido ao aumento da dimensionalidade do espaço definido pelos vetores de características, algumas propostas abordam esse problema. Por exemplo, as distâncias da família AID (WAID - Weak Attribute Interaction Distance e SAID Strong Attribute Interaction Distance) têm como principal característica analisar como os atributos afetam a percepção humana de similaridade quando seus valores variam em conjunto, permitindo que o usuário estabeleça parâmetros para ajustar a influência entre atributos (Felipe et al., 2009).

Funções de distância que são capazes de definir espaços métricos, denominadas métricas, são particularmente interessantes, pois espaços métricos permitem manipular dados complexos multidimensionais e também adimensionais. Dados adimensionais são aqueles para os quais o conceito de dimensões não se aplica. Por exemplo, um extrator que gera um vetor de características que combina características extraídas de cada região identificada na imagem pode gerar quantidades distintas de características para imagens diferentes, pois depende da quantidade de regiões detectadas em cada imagem. Neste caso, não é possível definir um espaço multidimensional que inclua estes vetores de características porque não existe um número definido de dimensões. Portanto, este é um exemplo de vetor de características adimensional.

Um espaço métrico é formalmente definido como um par $\mathbb{M}=\langle\mathbb{S}, \delta\rangle$, onde $\mathbb{S}$ é um domínio de dados e $\delta$ é uma métrica, isto é, uma função $\delta: \mathbb{S} \times \mathbb{S} \rightarrow \mathbb{R}^{+}$que expressa a distância entre elementos de $\mathbb{S}$ e que satisfaz as seguintes propriedades, para quaisquer $s_{1}, s_{2}, s_{3} \in \mathbb{S}$ :

- identidade: $\delta\left(s_{1}, s_{1}\right)=0$; 
- simetria: $\delta\left(s_{1}, s_{2}\right)=\delta\left(s_{2}, s_{1}\right)$;

- não negatividade: $0<\delta\left(s_{1}, s_{2}\right)<\infty$ se $s_{1} \neq s_{2}$; e

- desigualdade triangular: $\delta\left(s_{1}, s_{3}\right) \leq \delta\left(s_{1}, s_{2}\right)+\delta\left(s_{2}, s_{3}\right)$.

As distâncias da família Minkowski, com $p \geq 1$ são métricas, portanto espaços vetoriais utilizando qualquer uma destas distâncias formam espaços métricos. Outros exemplos de métricas são a distância Canberra (Kokare et al., 2003), a distância de Mahalanobis (Mahalanobis, 1936) e a WAID (Felipe et al., 2009). Uma métrica aplicada a um domínio adimensional é a distância de Levenshtein, ou distância de Edição $\left(L_{E d i t}\right)$ (Levenshtein, 1966), utilizada para cálculo de similaridade entre cadeias de caracteres, que são dados adimensionais.

\section{Ponderação de Distâncias}

Funções de distância podem ser modificadas por técnicas de ponderação, visando produzir instâncias do espaço de similaridade que sejam mais próximas da expectativa do usuário. Estas técnicas podem ser classificadas em: ponderação de características (individuais) e ponderação de distâncias parciais.

A ponderação de características atribui um peso específico para cada dimensão do vetor de características, para destacar ou reduzir a influência de cada uma delas. A abordagem trivial para a ponderação de características individuais é baseada em experimentação exaustiva. Entretanto, há várias abordagens mais elaboradas, tais como (Bugatti et al., 2011; Lee e Street, 2002; Liu et al., 2007; Wan e Liu, 2006), que são dinamicamente guiadas por informações fornecidas na formulação da consulta e em ciclos de realimentação de relevância, onde o usuário realimenta o sistema informando quais resultados retornados são úteis e quais são irrelevantes, permitindo ajustar iterativamente os parâmetros da busca.

Em muitas situações, um dado complexo é representado por vários vetores de características distintos, possivelmente representando propriedades complementares do dado. Nestes casos, é possível fazer com que a avaliação de similaridade utilize a composição desses vetores de características, aumentando a precisão dos resultados. A alternativa elementar para combinar múltiplos vetores de características consiste em concatená-los em um "super-vetor" e utilizar uma função de distância comum para medir a dissimilaridade entre dois "super-vetores". Uma das limitações desta alternativa é que ela exige que os extratores utilizados produzam vetores de características dimensionais, para garantir a correspondência entre as dimensões de todos os vetores. Além disso, o espaço definido por este "super-vetor", em geral, terá alta dimensionalidade, levando ao problema conhecido como maldição da alta dimensionalidade, que torna as distâncias entre elementos mais próxima à medida que o número de dimensões aumenta, degradando a qualidade e o de- 
sempenho da busca (Katayama e Satoh, 2001). Há várias abordagens envolvendo técnicas supervisionadas e não supervisionadas para fundir vetores de características complementares, considerando correlações entre características para reduzir a dimensionalidade (Yuan et al., 2011). Entretanto, outra limitação é que todos os vetores de características têm que ser comparados utilizando a mesma função de distância. Resultados experimentais mostram que vetores de características distintos descrevendo um mesmo dado complexo podem ter resultados melhores utilizando funções de distância distintas. (Bugatti et al., 2008). Outro método para combinar múltiplos vetores de características consiste em agregar as dissimilaridades entre cada par de vetores de características, gerando um valor que indica a dissimilaridade global entre os respectivos dados complexos. Este método permite combinar vetores de características dimensionais e adimensionais, bem como utilizar as funções de distância que são mais adequadas para cada vetor de características.

A ponderação de distâncias parciais é aplicada quando um dado complexo é representado por vários vetores de características distintos e a avaliação de dissimilaridade agrega as dissimilaridades parciais entre pares de vetores de características em uma dissimilaridade global. Neste caso, é crucial balancear corretamente cada uma das distâncias parciais na dissimilaridade global. Esta é a tarefa de ponderação de distâncias parciais, que tem como meta encontrar pesos para as distâncias parciais de forma que nenhuma delas seja subestimada ou superestimada na avaliação global de similaridade. Exemplos de abordagens de ponderação de distâncias parciais encontradas na literatura são o trabalho de Bustos et al. (2004), que determina os pesos utilizando uma heurística que é dinamicamente computada para cada elemento de consulta, baseando-se em elementos previamente classificados, o trabalho de Barrios e Bustos (2011), que define automaticamente os pesos das distâncias parciais baseando-se nos histogramas de distâncias das funções usadas para efetuar uma normalização das distâncias e encontrar valores que maximizam a dimensionalidade intrínseca do conjunto de características, e o trabalho de Bueno et al. (2009), que agrega múltiplos vetores de características utilizando uma métrica produto (uma métrica definida sobre o produto cartesiano de espaços métricos) e utiliza a dimensão de correlação fractal para balancear as distâncias parciais de forma não supervisionada.

\subsection{Consultas por Similaridade}

Os SGBDs oferecem recursos eficazes para realizar buscas sobre os dados usando relações de igualdade e de ordem total existentes nos dados armazenados (tais como números e textos curtos). Porém, para dados multimídia e outros dados complexos, as buscas por igualdade ou por ordem não se aplicam, ou simplesmente, são de pouca serventia. Para esses tipos de dados é mais relevante fazer uso de consultas por similaridade, que consistem em procurar por elementos em um conjunto que, segundo algum critério de similaridade, sejam mais "parecidos" ou mais "distintos" com/de um determinado 
elemento. Em outras palavras, estas são consultas que consistem em comparar todos os elementos do conjunto com um elemento escolhido, selecionando-se apenas aqueles que satisfazem um determinado critério de similaridade.

Existem dois tipos básicos de consultas por similaridade: as consultas por abrangência e as consultas aos $k$-vizinhos mais próximos (Böhm et al., 2001; Chávez et al., 2001). Além desses tipos básicos, existem outros tipos de consultas por similaridade, principalmente as junções por similaridade e as consultas por similaridade agregada. A seguir, essas categorias de consultas são apresentadas.

\subsubsection{Consulta por Abrangência}

Uma consulta por abrangência (Range query - Rq) tem como objetivo encontrar todos os elementos dissimilares de um elemento de consulta até no máximo um certo limiar. Formalmente, seja $\mathbb{S}$ um domínio de dados, $S \subseteq \mathbb{S}$ um conjunto de elementos, $s_{q} \in \mathbb{S}$ um elemento de consulta, $\delta$ uma função de distância definida sobre elementos de $\mathbb{S}$ e $\xi$ um limiar de dissimilaridade, uma consulta por abrangência é dada por:

$$
\left\{s_{i} \in S \mid \delta\left(s_{q}, s_{i}\right) \leq \xi\right\}
$$

A Figura $2.3^{1}$ mostra uma representação visual desta consulta. Os elementos de $S$ localizados na bola centrada em $s_{q}$ com raio $\xi$ compõem a resposta para a consulta.

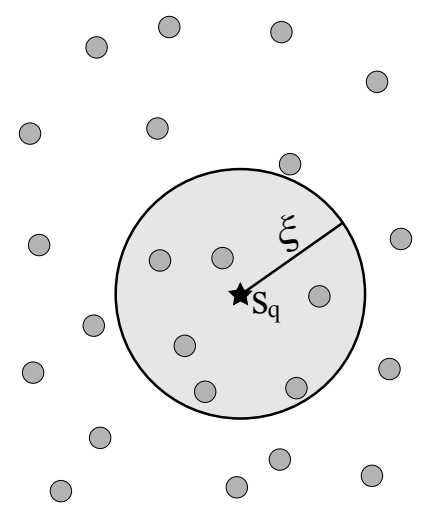

Figura 2.3: Representação da consulta por abrangência.

Existem duas variações básicas para a consulta por abrangência: a consulta pontual e a consulta por abrangência reversa. A consulta pontual (Point query - Pq) é uma consulta por abrangência $\operatorname{com} \xi=0$, cujo objetivo é identificar se o elemento de consulta está armazenado no banco de dados. A consulta por abrangência reversa (Reversed Range query - $\mathrm{Rq}^{-1}$ ), é uma busca por abrangência que procura pelos elementos fora da área de abrangência, isto é, a resposta é formada pelos elementos $s_{i} \in S$ tal que $\delta\left(s_{q}, s_{i}\right)>\xi$.

\footnotetext{
${ }^{1}$ Neste texto, sem perda de generalidade, as figuras que apresentam elementos no espaço são apresentadas no espaço métrico $\mathbb{M}=\left\langle\mathbb{R}^{2}, L_{2}\right\rangle$ para facilitar o entendimento.
} 


\subsubsection{Consulta aos $k$-Vizinhos Mais Próximos}

Uma consulta aos $k$-vizinhos mais próximos ( $k$-Nearest Neighbors query $-k$-NNq) retorna os $k$ elementos mais similares ao elemento de consulta. Observe que é possível que uma $k$-NNq retorne menos que $k$ elementos, se a cardinalidade do conjunto de dados for menor do que $k$. Além disso, pode haver dois ou mais elementos, situados à mesma distância do elemento de referência, que podem ser escolhidos como o $k$-ésimo vizinho mais próximo. Neste caso, pode-se escolher um desses elementos arbitrariamente, que é a opção mais frequentemente adotada nos trabalhos encontrados na literatura, ou podese selecionar todos os elementos "empatados" com o $k$-ésimo, retornando mais do que $k$ elementos. Formalmente, dado um domínio $\mathbb{S}$, um conjunto de elementos $S \subseteq \mathbb{S}$, um elemento de consulta $s_{q} \in \mathbb{S}$, uma função de distância $\delta$ definida sobre $\mathbb{S}$ e um inteiro $k \geq 1$, o resultado de uma $k$-NNq é dado por:

$$
K=\left\{s_{i} \in S\left|\forall s_{j} \in S \backslash K,\right| K \mid=k, \delta\left(s_{q}, s_{i}\right) \leq \delta\left(s_{q}, s_{j}\right)\right\}
$$

onde $K \subseteq S$ é o conjunto resposta da consulta e $|K|$ é a cardinalidade deste conjunto. Mais rigorosamente, esse resultado é obtido por indução (Ferreira et al., 2011), onde $K=\bigcup_{1 \leq i \leq k}\left\{s_{i}\right\}$, tal que cada $\left\{s_{i}\right\}$ é dado por:

$$
\begin{aligned}
& \left\{s_{1}\right\}=\left\{s \in S \mid \forall s_{j} \in S \backslash\{s\}, \delta\left(s_{q}, s\right) \leq \delta\left(s_{q}, s_{j}\right)\right\} \\
& \left\{s_{2}\right\}=\left\{s \in S-\left\{s_{1}\right\} \mid \forall s_{j} \in S \backslash\left\{s_{1}, s\right\}, \delta\left(s_{q}, s\right) \leq \delta\left(s_{q}, s_{j}\right)\right\} \\
& \quad \vdots \\
& \left\{s_{k}\right\}=\left\{s \in S-\left\{s_{1}, \ldots, s_{k-1}\right\} \mid \forall s_{j} \in S \backslash\left\{s_{1}, \ldots, s_{k-1}, s\right\}, \delta\left(s_{q}, s\right) \leq \delta\left(s_{q}, s_{j}\right)\right\} .
\end{aligned}
$$

A Figura 2.4 ilusta uma $4-\mathrm{NNq}$, tendo $s_{q} \in \mathbb{S}$ como elemento de consulta e, neste exemplo, $s_{q} \notin S$.

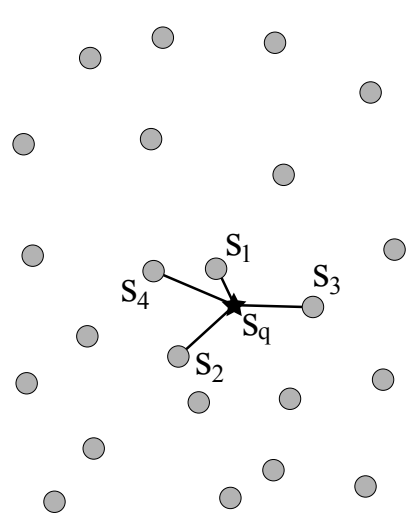

Figura 2.4: Representação da consulta aos $k$-vizinhos mais próximos.

Na literatura, há referências à consulta ao vizinho mais próximo (Nearest Neighbor query - NNq), que nada mais é que uma $k$-NNq com $k=1$. Outra variação de 
busca por vizinhança é a consulta aos $k$-vizinhos mais distantes ( $k$-Farthest Neighbors query $-k$-FNq), que procura pelos $k$ elementos mais dissimilares ao elemento de consulta. Da mesma forma que a consulta por abrangência reversa é complementar à consulta por abrangência, isto é, $\operatorname{Rq}\left(S, s_{q}, \delta, \xi\right) \cup \mathrm{Rq}^{-1}\left(S, s_{q}, \delta, \xi\right)=S$, a consulta aos $k$ vizinhos mais distantes é complementar à consulta aos $k$-vizinhos mais próximos, sendo $k \mathrm{NN}\left(S, s_{q}, \delta, k\right) \cup k-\mathrm{FNq}\left(S, s_{q}, \delta,|S|-k\right)=S$, onde $|S|$ é a quantidade de elementos de $S$.

\subsubsection{Consultas por Similaridade Agregada}

Uma extensão às consultas por abrangência e aos $k$-vizinhos mais próximos são as consultas em que há mais de um elemento de consulta. Neste caso, há algumas interpretações possíveis para a busca:

- retorne os elementos mais próximos ou que estejam no raio de abrangência a/de algum dos elementos de consulta;

- retorne os elementos mais próximos ou que estejam no raio de abrangência a/de todos os elementos de consulta; ou

- retorne os elementos mais próximos ou que estejam no raio de abrangência segundo uma função que agrega todos os elementos de consulta.

A primeira alternativa corresponde a uma união de várias buscas por similaridade sobre o conjunto de entrada, uma para cada elemento de consulta, e a segunda alternativa corresponde a uma interseção dessas buscas. A terceira opção, por outro lado, refere-se às consultas por similaridade agregada, cujo objetivo é avaliar a similaridade de cada elemento armazenado com todos os elementos de consulta, segundo uma função aplicada sobre estas similaridades (Papadias et al., 2005). Nesta tese, esta função é denominada função agregadora de distâncias $(\Delta)$. Por exemplo, Razente et al. (2008) definem uma família de funções agregadoras de distâncias para responder a consultas por similaridade agregada. Dado um domínio $\mathbb{S}$, um conjunto de elementos $S \subseteq \mathbb{S}$, um elemento $s \in S$, um conjunto de elementos de consulta $Q \subseteq \mathbb{S}$, essa família de funções agregadoras de distâncias é dada por:

$$
d_{g}(s, Q)=\sqrt[g]{\sum_{s_{q} \in Q}\left(\delta\left(s, s_{q}\right)^{g} * w_{q}\right)}
$$

onde $\delta$ é uma função de distância definida sobre $\mathbb{S}$, cada $w_{q}$ é um peso correspondente a cada elemento de consulta $s_{q}$ e $g \in \mathbb{R}^{*}$ é o fator de agregação (grip factor), sendo que diferentes valores para $g$ levam a interpretações distintas sobre como a agregação é realizada. 
Com base em uma função agregadora de distâncias, são definidas a consulta por abrangência agregada (Aggregated Range query - ARq) e a consulta aos $k$-vizinhos mais próximos agregados (Aggregated $k$-NN query - $k$-ANNq), que são, essencialmente, generalizações das consultas por abrangência e aos $k$-vizinhos mais próximos quando existem um ou mais elementos de referência e que usam a função $\Delta$ para avaliar os predicados de similaridade.

- Consulta por abrangência agregada: dado um conjunto $S \subseteq \mathbb{S}$, um conjunto de elementos de consulta $Q \subseteq \mathbb{S},|Q| \geq 1$, uma função de distância $\delta$ definida sobre $\mathbb{S}$, uma função $\Delta$ agregadora de distâncias $\delta$ e um limiar de dissimilaridade $\xi$, a consulta ARq retorna os elementos cujo valor da função $\Delta$ seja menor ou igual a $\xi$. O resultado desta consulta é dado por:

$$
\left\{s_{i} \in S \mid \Delta\left(s_{i}, Q\right) \leq \xi\right\}
$$

- Consulta aos $k$-vizinhos mais próximos agregados: dado um conjunto $S \subseteq \mathbb{S}$, um conjunto de elementos de consulta $Q \subseteq \mathbb{S},|Q| \geq 1$, uma função de distância $\delta$ definida sobre $\mathbb{S}$, uma função $\Delta$ agregadora de distâncias $\delta$ e um inteiro $k \geq 1$, a consulta $k$-ANNq retorna os $k$ elementos mais similares aos elementos em $Q$, de acordo com a função $\Delta$. O resultado desta consulta é dado por:

$$
K=\left\{s_{i} \in S\left|\forall s_{j} \in S \backslash K,\right| K \mid=k, \Delta\left(s_{i}, Q\right) \leq \Delta\left(s_{j}, Q\right)\right\}
$$

onde $K \subseteq S$ é o conjunto resposta da consulta. Nesta consulta, o tratamento de empates na escolha do $k$-ésimo elemento segue a mesma estratégia usada nas consultas $k$-NN com um único elemento de referência.

As consultas por similaridade agregada podem ser utilizadas para tratar resultados intermediários de consultas que envolvem vários critérios. Isto porque um resultado intermediário, que pode conter várias tuplas, pode ser utilizado como referência/centro de consulta de uma busca por similaridade posterior no plano de consulta. Outra aplicação típica de consultas por similaridade agregada é em mecanismos de realimentação de relevância baseados na movimentação de múltiplos centros de consulta. As técnicas de realimentação de relevância envolvem o aprendizado a partir da informação fornecida pela interação do usuário com o sistema. O usuário "realimenta" o sistema informando a relevância das respostas retornadas anteriormente e o sistema ajusta automaticamente os parâmetros da consulta com base nas respostas rotuladas pelo usuário e a executa novamente até que o objetivo do usuário seja alcançado (Doulamis e Doulamis, 2006). A técnica de movimentação de múltiplos centros de consulta consiste em utilizar os exemplos positivos (ou seja, aqueles elementos que foram corretamente retornados) são usados em 
consultas posteriores como os novos centros de consulta e a combinação (ponderada) das suas distâncias individuais torna-se a medida de similaridade empregada.

\subsubsection{Junções por Similaridade}

As junções por similaridade atuam sobre dois conjuntos de dados complexos. Existem três tipos de junção por similaridade: junção por abrangência (Range join $-\rtimes_{\mathrm{Rq}}$ ), junção pelos $k$-vizinhos mais próximos $\left(k\right.$-Nearest Neighbors join $\left.-\star_{k \mathrm{NN}}\right)$ e junção dos $k$-pares de vizinhos mais próximos ( $k$-Closest Neighbors join $\left.-\bowtie_{k \mathrm{CN}}\right)$ (Böhm e Krebs, 2002). Essas operações são apresentadas a seguir.

- Junção por abrangência: dados dois conjuntos $R \subseteq \mathbb{S}$ e $S \subseteq \mathbb{S}$, uma função de distância $\delta$ definida sobre $\mathbb{S}$ e um limiar de abrangência $\xi$, a consulta $\rtimes_{\mathrm{Rq}}$ recupera os pares de elementos $r_{i} \in R$ e $s_{j} \in S$ distantes no máximo $\xi$ entre si. A resposta a essa consulta é dada por:

$$
\left\{\left\langle r_{i}, s_{j}\right\rangle \in(R \times S) \mid \delta\left(r_{i}, s_{j}\right) \leq \xi\right\}
$$

- Junção pelos $k$-vizinhos mais próximos: dados dois conjuntos $R \subseteq \mathbb{S}$ e $S \subseteq \mathbb{S}$, uma função de distância $\delta$ definida sobre $\mathbb{S}$ e um número inteiro $k \geq 1$, a consulta $\bowtie_{k \mathrm{NN}}$ retorna os pares de elementos $r_{i} \in R$ e $s_{j} \in S$ de maneira que cada elemento de $R$ aparece no resultado concatenado com cada um dos seus $k$-vizinhos mais próximos em $S$. O resultado dessa consulta é dado por:

$$
\begin{gathered}
K=\left\{\left\langle r_{i}, s_{j}\right\rangle \in(R \times S)\left|\forall\left\langle r_{i}, s_{m}\right\rangle \in((R \times S) \backslash K),\right| K|=| S \mid * k,\right. \\
\left.\delta\left(r_{i}, s_{j}\right) \leq \delta\left(r_{i}, s_{m}\right)\right\}
\end{gathered}
$$

onde $K \subseteq(R \times S)$ é o conjunto resposta da junção $\bowtie_{k N N}$.

- Junção dos $k$-pares de vizinhos mais próximos: dados dois conjuntos $R \subseteq \mathbb{S}$ e $S \subseteq \mathbb{S}$, uma função de distância $\delta$ sobre $\mathbb{S}$ e um número inteiro $k \geq 1$, a consulta $\bowtie_{k \mathrm{CN}}$ retorna os $k$ pares de elementos $r_{i} \in R$ e $s_{i} \in S$ mais próximos entre si. O conjunto resultante desta consulta é dado por:

$$
K=\left\{\left\langle r_{i}, s_{j}\right\rangle \in(R \times S)\left|\forall\left\langle r_{m}, s_{n}\right\rangle \in((R \times S) \backslash K),\right| K \mid=k, \delta\left(r_{i}, s_{j}\right) \leq \delta\left(r_{m}, s_{n}\right)\right\}
$$

onde $K \subseteq(R \times S)$ é o conjunto resposta da junção $\bowtie_{k \mathrm{CN}}$.

A Figura 2.5 ilustra esses três tipos de junção por similaridade. Nessa figura, os círculos pretos representam elementos do conjunto $R$ e os de cor cinza representam elementos do conjunto $S$. Uma outra nomenclatura para as junções por similaridade denomina a $\bowtie_{\mathrm{Rq}}$ 
como junção por similaridade, a $\bowtie_{k \mathrm{CN}}$ como junção por distância e a $\bowtie_{k N N}$ como semijunção por distância (Hjaltason e Samet, 1998; Jacox e Samet, 2008).

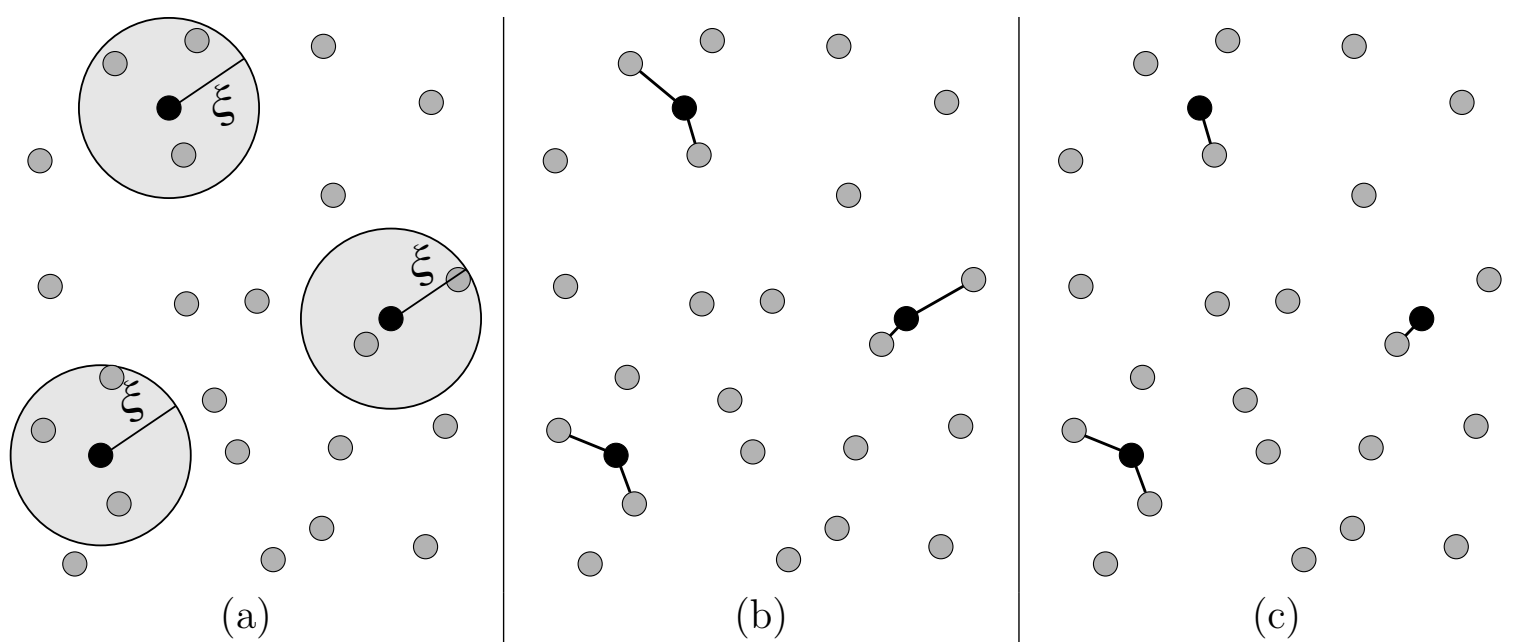

Figura 2.5: Operações de junção por similaridade. (a) Junção por abrangência. (b) Junção pelos $k$-vizinhos mais próximos, com $k=2$. (c) Junção dos $k$-pares de vizinhos mais próximos, com $k=4$.

\subsection{Recuperação de Imagens Médicas por Similaridade}

Os sistemas de apoio à área médica em geral manipulam uma diversidade de tipos de dados, tais como dados tradicionais (dados de pacientes, prontuários e outros), gráficos e séries de sinais (tais como eletrocardiogramas e eletroencefalogramas) e imagens digitais de exames (por exemplo, raios-x digitais, ultra-sons e tomografias computadorizadas). Com essa crescente quantidade de dados, de formatos e conteúdos variáveis (textos, imagens, vídeos e gráficos), a integração de todas as informações do paciente em um sistema só tem sido de grande interesse para médicos, hospitais e clínicas (Furuie et al., 2007).

O objetivo de sistemas de informação para a área médica tem sido definido como disponibilizar a informação necessária no tempo correto, no lugar correto e para as pessoas corretas, para aprimorar a qualidade e eficiência dos processos médicos (Müller et al., 2004). Além do diagnóstico e procedimentos terapêuticos, esses sistemas são úteis para tarefas de ensino e pesquisa, que contribuem para a evolução do conhecimento médico.

\subsubsection{Dados Inerentes à Prática Médica}

Os registros médicos a respeito de um determinado indivíduo compõem o chamado prontuário do paciente. Os dados armazenados no prontuário do paciente podem ser divididos em (Marin et al., 2003):

- demográficos: nome, data de nascimento, filiação, sexo, etnia, local de nascimento, endereço; 
- socioeconômicos: escolaridade, ocupação, situação familiar e conjugal, situação de moradia e saneamento; e

- clínicos: que podem ser subjetivos (queixas, histórico e hábitos do paciente), objetivos (achados clínicos constatados pelo profissional de saúde), avaliações e decisões (resultados de exames e diagnósticos estabelecidos), e planos terapêuticos (tratamentos instituídos, incluindo medicamentos e procedimentos).

Esses dados são coletados ao longo do tempo e registrados pelos médicos, enfermeiros, fisioterapeutas e demais profissionais envolvidos no caso. O armazenamento eletrônico desses registros é essencialmente textual. A padronização dos registros médicos é difícil, tanto pela dificuldade de expressar de uma forma homogênea as variadas situações encontradas quanto pela resistência por parte de muitos profissionais de saúde. Entretanto, vários padrões de dados e vocabulários controlados têm sido elaborados para abordar esse problema.

Todo o processo é subsidiado por exames clínicos (laboratoriais, radiológicos e outros) cada vez mais sofisticados, que agregam dados fundamentais para o médico. De maneira particular, as imagens médicas têm sido amplamente utilizadas em instituições hospitalares, oferecendo uma forma de visualização não-invasiva de estruturas do corpo dos pacientes, em tarefas de diagnóstico e acompanhamento de tratamentos. Com o advento de equipamentos de diagnóstico de radiologia sem filme, tais como aparelhos de ressonância magnética e de tomografia computadorizada (Figura 2.6), a disponibilização dessas imagens em formato digital potencializou a distribuição e acesso rápido a esses dados, integrando os vários setores envolvidos na análise dos exames (Dhawan, 2011).

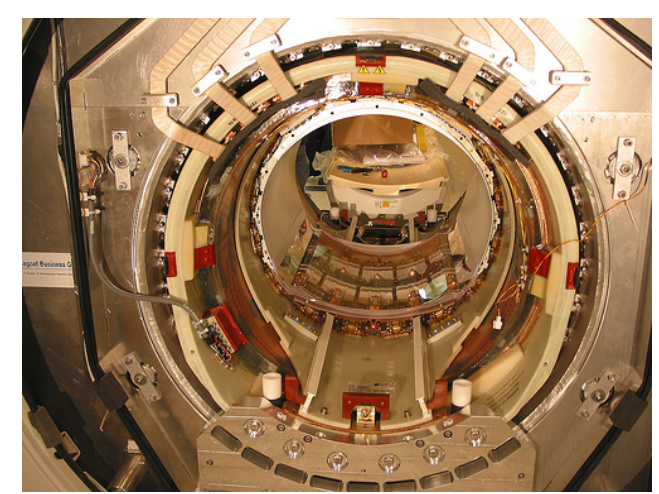

(a)

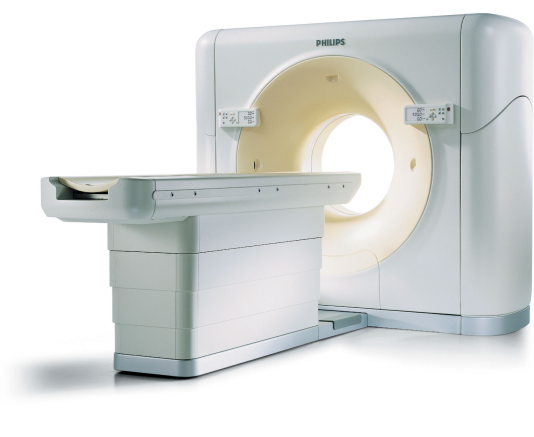

(b)

Figura 2.6: Aparelhos de radiologia digital. (a) Vista interna de um aparelho de ressonância magnética. (b) Equipamento de tomografia computadorizada.

Nas últimas décadas houve uma explosão nas modalidades de imagens médicas digitais: digitalizadores de filmes de raio-X, ultra-som, ressonância magnética (MRI - Magnetic Resonance Imaging), tomografia computadorizada (CT - Computed Tomography), 
tomografia por emissão de pósitrons (PET - Positron Emission Tomography), tomografia computadorizada por emissão de pósitrons simples (SPECT - Simple Positron Emission Computed Tomography), imagem por fonte magnética (MSI - Magnetic Source Imaging), entre outras. A Figura 2.7 mostra exemplos de imagens médicas digitais. Essas modalidades têm revolucionado as formas de aquisição de imagens de pacientes, oferecendo meios de visualizar seções anatômicas e estados fisiológicos, além de reduzir a exposição do paciente à radiação e os traumas de exames invasivos (Dhawan, 2011).

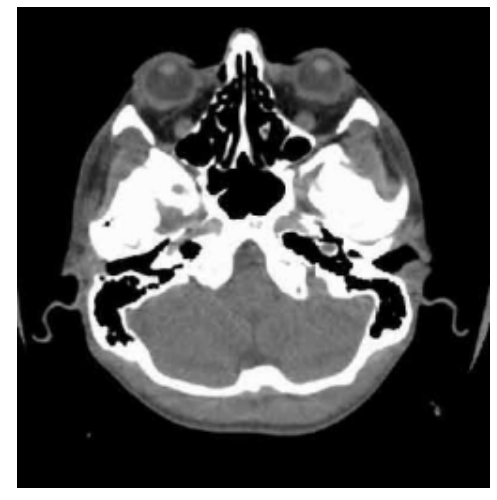

(a)

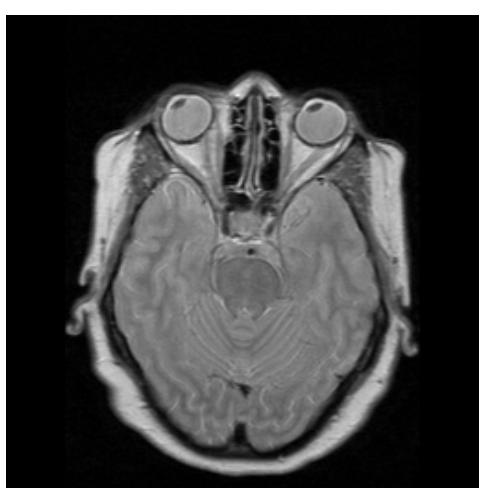

(b)

Figura 2.7: Exemplos de imagens médicas digitais de cabeça. (a) Imagem de tomografia computadorizada. (b) Imagem de ressonância magnética.

As imagens em fomato digital oferecem facilidades de armazenamento e comunicação, permitindo o acesso simultâneo em locais distintos, novas possibilidades de aprimoramento na visualização das imagens, de acordo com a necessidade de cada profissional envolvido, e funcionalidades adicionais advindas do processamento e análise das imagens. Como consequência, novas demandas e oportunidades têm surgido para subsidiar todo o processo, englobando técnicas de sensoreamento e captura das imagens, tecnologias de comunicação, gerenciamento dos bancos de dados de imagens, estratégias de visualização e de interação, e outras.

\subsubsection{O Padrão para Imagens Médicas DICOM}

O DICOM (Digital Imaging and Communications in Medicine) é um padrão internacional, estabelecido em 1993, amplamente aceito e utilizado para imagens médicas, que tem como objetivo facilitar a interoperabilidade dos dispositivos e sistemas (National Electrical Manufacturers Association, 2008). Este padrão foi inicialmente proposto pelo ACR (American College of Radiology) e pela NEMA (National Electrical Manufacturers Association) e é referenciado como DICOM versão 3.0, por ser o sucessor dos padrões ACR-NEMA 1.0 e ACR-NEMA 2.0.

O padrão DICOM especifica:

- um conjunto de protocolos de comunicação de rede, compatível com TCP/IP; 
- a sintaxe e a semântica de comandos e informações associadas que podem ser tranferidas usando esses protocolos;

- um conjunto de serviços de armazenamento de dados, bem como um formato de arquivo e uma estrutura de diretórios para facilitar o acesso às imagens e às informações relacionadas armazenadas; e

- informações que devem ser fornecidas em uma implementação para que seja compatível com o padrão.

O padrão DICOM é formado por várias partes. Uma delas define um conjunto de classes de objetos de informação (IOC - Information Object Classes) que provêm uma definição abstrata para entidades do mundo real aplicáveis à comunicação de imagens médicas digitais e informações relacionadas (por exemplo, relatórios estruturados, formas de onda, dose de terapia de radiação, etc.). Cada classe de objetos de informação possui uma descrição do seu propósito e os atributos que a definem. Para representar uma ocorrência de uma entidade real, por exemplo, uma imagem de CT, é criada uma instância de objeto de informação (Information Object Instance), que inclui os valores para os atributos da classe de objetos de informação, por exemplo, a data e horário do estudo e o nome e sexo do paciente.

Cada instância de objeto de informação é formada por elementos de dados (Data Elements), incluindo um identificador único (por uma Data Element Tag), o tamanho do valor (Value Length) e o valor para o elemento (Value). Os elementos de dados usados para codificar graficamente os dados da imagem são o Pixel Data Element, identificado pela tag (7FE0,0010), e o Overlay Data Element (60xx,3000), cujos valores são cadeias de bytes ou words e suportam o uso da compressão de imagens JPEG. O Waveform Data Element $(5400,1010)$ pode armazenar sinais codificados, tais como sinais biológicos unidimensionais, eletrocardiograma, eletroencefalograma e outros. Os demais elementos de dados armazenam informações associadas à imagem e são de tipos básicos (cadeias de caracteres, números e datas). Alguns exemplos desses metadados são apresentados na Tabela 2.1.

O padrão DICOM especifica também um conjunto de classes de serviço (Service Classes). Uma classe de serviço associa um ou mais objetos de informação com um ou mais comandos que podem ser executados sobre esses objetos. Exemplos de classes de serviço são a de armazenamento (Storage Service Class), a de recuperação (Query/Retrieve Service Class) e a de impressão (Print Management Service Class). O padrão define, ainda, os serviços de comunicação e os protocolos de camadas de mais alto nível necessários para suportar a comunicação entre aplicações DICOM, perfis de gerenciamento de sistema e segurança e até mesmo uma função padrão de apresentação de imagens em níveis de cinza, que fornece métodos para calibrar sistemas de apresentação de forma consistente em diferentes equipamentos (monitores e impressoras). 


\begin{tabular}{ll}
\hline TAG & Nome \\
\hline$(0008,0008)$ & Image Type \\
$(0008,0012)$ & Instance Creation Date \\
$(0008,0013)$ & Instance Creation Time \\
$(0008,0018)$ & SOP Instance UID \\
$(0008,0020)$ & Study Date \\
$(0008,0021)$ & Series Date \\
$(0008,1030)$ & Study Description \\
$(0008,1032)$ & Procedure Code Sequence \\
$(0008,1080)$ & Admitting Diagnoses Description \\
$(0008,1084)$ & Admitting Diagnoses Code Sequence \\
$(0008,2208)$ & Anatomic Structure \\
$(0010,0020)$ & Patient ID \\
$(0010,0030)$ & Patient's Birth Date \\
$(0010,0040)$ & Patient's Sex \\
$(0010,1020)$ & Patient's Size \\
$(0010,1030)$ & Patient's Weight \\
$(0018,0015)$ & Body Part Examined \\
$(0018,0023)$ & MR Acquisition Type \\
$(0018,5100)$ & Patient Position \\
\hline
\end{tabular}

Tabela 2.1: Exemplos de metadados descritos no dicionário de dados do padrão DICOM.

A questão da segurança e confidencialidade de dados é um aspecto importante do padrão DICOM. Afinal, apenas uma única informação sobre uma só pessoa, fornecida de maneira incorreta ou inadequada pode ocasionar grandes transtornos para o paciente, que vão do individual ao coletivo, da invasão de sua privacidade até o desrespeito ao direito de cidadania, passando pela divulgação de seus problemas e podendo ir até a demissão do seu emprego e ao aumento de seus sofrimentos pela angústia do devassamento de sua intimidade (Levy, 2003). O padrão DICOM especifica mecanismos para implementar políticas de segurança na troca de objetos entre aplicações DICOM, tais como autenticação, integridade das mensagens trocadas e confidencialidade.

\subsubsection{Sistemas de Apoio ao Diagnóstico por Imagens}

Os principais sistemas envolvidos no diagnóstico por imagens são o sistema de informação hospitalar (Hospital Information System - HIS), o Prontuário Eletrônico do Paciente (PEP), o sistema de informação de radiologia (Radiology Information System - RIS) e o sistema de arquivamento e comunicação de imagens (Picture Archiving and Communication System - PACS).

O HIS é o componente central de gestão da instituição de saúde, responsável por armazenar os dados cadastrais de pacientes e funcionários, todo o fluxo de informações de procedimentos e demais dados administrativos (Tachinardi e Furuie, 2003). 
O PEP é um sistema projetado para armazenar eletronicamente informações sobre o estado de saúde e os cuidados que um indivíduo recebeu ao longo da vida (Marin et al., 2003). Embora idealmente devesse existir um único e completo PEP de propriedade do paciente, com todo o seu histórico de saúde, na prática cada instituição de saúde mantém seus próprios registros, apenas dos eventos ocorridos nas suas instalações.

O RIS é utilizado para a geração e agendamento de exames radiológicos e a geração de laudos e relatórios (Marques et al., 2000) e o PACS é o sistema responsável por receber as imagens dos dispositivos de aquisição (raio-x digital, ressonância magnética e outros), armazená-las de forma organizada e disponibilizá-las de forma descentralizada (Huang, 2010).

Tachinardi e Furuie (2003) descrevem de uma forma simplificada as tarefas e sistemas envolvidos no processo de diagnóstico por imagem, ilustrados na Figura 2.8. Para a realização de um exame por imagens genérico o primeiro processo é a identificação do paciente, através do acesso ao seu cadastro e o agendamento do exame. Na sequência, ocorre a admissão, ou seja, a recepção do paciente, e o exame, incluindo os procedimentos necessários à sua execução técnica. Com base nas imagens geradas, o radiologista emite o laudo do exame, disponibilizando o resultado por meio do RIS e do PACS aos demais profissionais envolvidos.

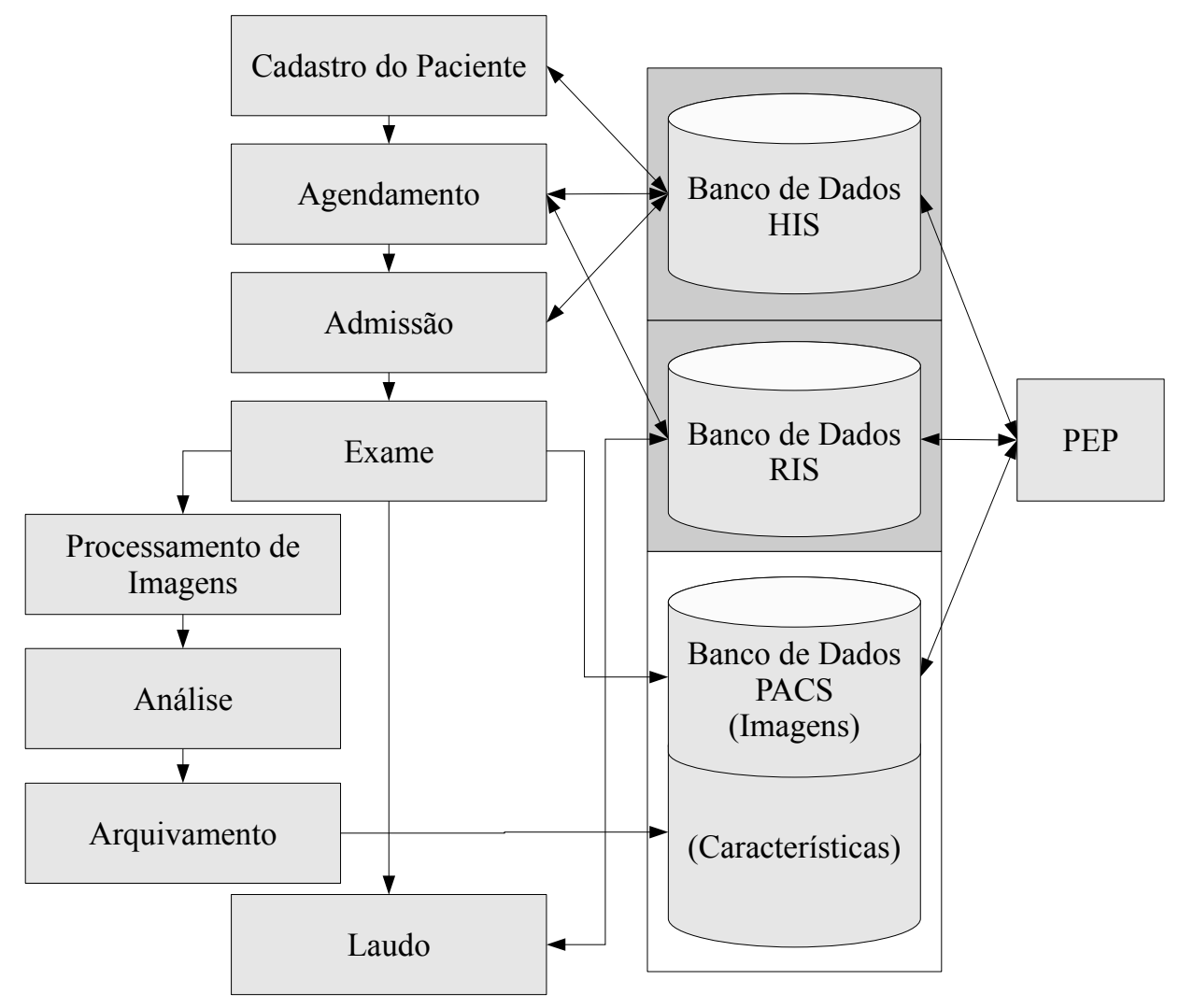

Figura 2.8: Diagrama conceitual de integração lógica de sistemas de informações médicas integrando imagens. (Tachinardi e Furuie, 2003) 
As imagens do exame são armazenadas no PACS, com metadados associados para busca textual. Além disso, em um ambiente PACS com suporte à recuperação por conteúdo, as imagens são submetidas a uma etapa adicional de extração e representação das suas características intrínsecas, gerando assinaturas que representam o conteúdo de cada imagem que também são armazenadas no PACS. O processo de recuperação de imagens médicas por conteúdo é descrito na próxima seção.

\subsubsection{Recuperação de Imagens Médicas por Conteúdo}

A noção de recuperação de imagens por conteúdo (CBIR - Content-Based Image Retrieval) está relacionada a qualquer tecnologia que auxilie a organização de arquivos de imagens digitais de acordo com seu conteúdo visual (Datta et al., 2008).

O fluxo de dados em uma arquitetura genérica de um sistema de CBIR é apresentado na Figura 2.9. No momento da inserção, as novas imagens passam por uma etapa de extração de características, que gera uma representação matemática da imagem por meio de um conjunto de características que refletem diversas propriedades da imagem. Essa representação é denominada assinatura ou vetor de características da imagem. Em seguida, a imagem é associada à sua assinatura e armazenada no banco de imagens, indexada pela assinatura.

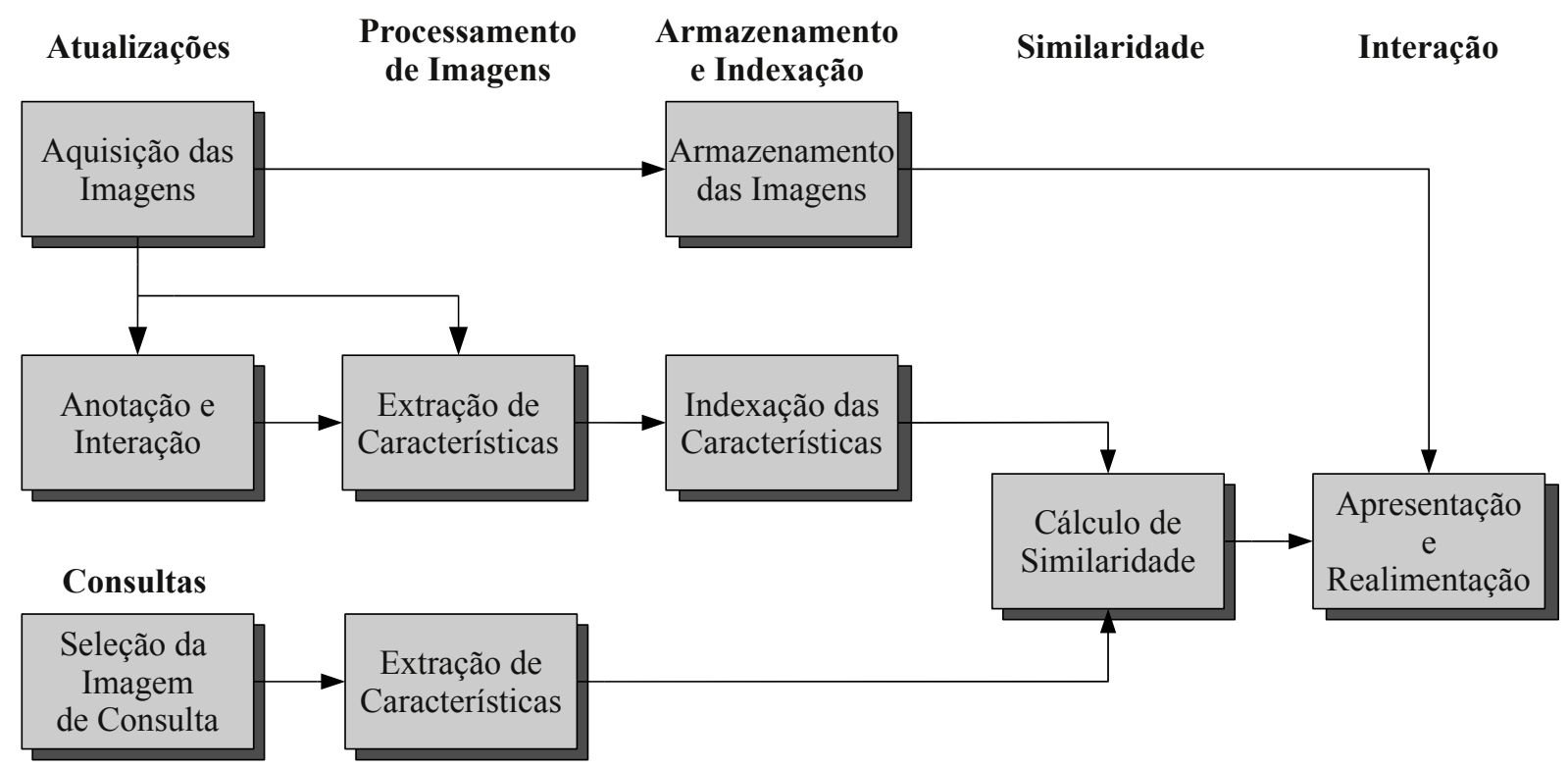

Figura 2.9: Fluxo de dados em um sistema de CBIR com consulta por exemplo. Adaptada de (Smeulders et al., 2000)

O processo de recuperação é iniciado com a definição da consulta. Muitas metodologias foram propostas para especificar uma consulta em sistemas de CBIR, dentre as quais a mais utilizada é a consulta por similaridade baseada em exemplo (Smeulders et al., 2000). Esta modalidade de busca é utilizada aqui para ilustrar o processo de CBIR. Na busca baseada em exemplo, o usuário fornece uma imagem de consulta. Essa imagem passa por 
um processo de extração de características e, em seguida, a assinatura gerada é utilizada para selecionar as imagens armazenadas cujas assinaturas satisfazem a um dado critério de similaridade e retorná-las ao usuário. O usuário pode finalizar a consulta ou realimentar o sistema fazendo refinamentos sucessivos da consulta até obter o resultado desejado.

Inúmeras áreas de aplicação têm se valido de técnicas de CBIR para a manipulação de bancos de imagens. Smeulders et al. (2000) apresentam uma extensa revisão bibliográfica sobre a área de CBIR até o final da década de 90 e Datta et al. (2008) apresentam uma revisão dos trabalhos mais recentes. Uma das áreas mais representativas quanto ao uso de técnicas de CBIR é a área de informática médica. Há vários extratores de características desenvolvidos especialmente para imagens médicas (Deselaers et al., 2008). A maior parte destes extratores são voltados para uma modalidade específica de imagens. Por exemplo, extratores para imagens de fraturas ósseas (Rubin et al., 2003), para imagens de pulmão (Depeursinge et al., 2011), para imagens de mamografia (Wei et al., 2011), para imagens de cérebro (Balan et al., 2007), entre outras. Existem também propostas de integração de CBIR aos PACS, tais como (Bueno et al., 2002), (Tan et al., 2006) e (Welter et al., 2011). Müller et al. (2004), Long et al. (2009) e Akgül et al. (2011) apresentam uma revisões de trabalhos, mostrando o quanto as técnicas de recuperação de imagens por conteúdo têm sido aplicadas na área médica.

\subsubsection{Recuperação de Imagens Médicas Combinando Metadados e Conteúdo}

Uma particularidade das imagens médicas é que elas normalmente têm uma riqueza de atributos descritivos associados. Estes metadados provêm de várias fontes, tais como registros de consultas e dados de exames e laudos. Em especial, o padrão DICOM define um amplo conjunto de atributos (tags) descrevendo o conteúdo da imagem, que são utilizados para responder à grande maioria das buscas em PACS. Entretanto, várias tags DICOM importantes são preenchidas manualmente pelo operador do equipamento radiológico, como, por exemplo, a hipótese diagnóstica e as descrições do estudo e da série. Portanto, os valores para estas tags são sujeitos a erros de digitação e falta de padronização, comprometendo o processo de busca. O mesmo ocorre para metadados de outras fontes (laudos, registros de consulta, etc.). Além disso, quando o usuário não sabe definir exatamente o que procura, o que frequentemente ocorre em aplicações para a área médica, formular corretamente uma consulta torna-se mais difícil e suscetível a erros.

Combinar condições baseadas em metadados e condições baseadas em similaridade pode melhorar a eficácia da busca, pois um tipo de condição complementa o outro. A recuperação baseada em metadados utiliza técnicas consagradas de busca, pois os metadados de uma forma geral são de tipos de dados simples, tais como números, datas e textos curtos. Contudo, esta abordagem depende da existência de metadados associados 
aos dados. Embora a associação manual de anotações textuais a imagens possibilite uma boa descrição do conteúdo do dado, é um processo inviável para tratar grandes massas de dados. Além de trabalhosa, essa tarefa é sensível à subjetividade dos responsáveis pelas anotações. Neste ponto, entram as técnicas de recuperação baseadas em conteúdo, para realizar uma inferência automática do conteúdo da imagem e permitir realizar buscas utilizando padrões visuais.

Há vários trabalhos na literatura que propõem combinar recuperação baseada em metadados e recuperação baseada em conteúdo. Por exemplo, o trabalho descrito em (Kalpathy-Cramer e Hersh, 2010) aplica técnicas para criar anotações automáticas para as imagens, que são utilizadas como atributos textuais para filtrar e ordenar resultados durante a recuperação. Outros trabalhos, tais como (Névéol et al., 2009), permitem aos usuários fornecer tanto palavras-chave quanto imagens de exemplo na definição das consultas. As consultas são submetidas a dois mecanismos de busca complementares, um que executa uma consulta utilizando as palavras-chave e outro que executa a consulta baseada em conteúdo tomando o exemplo fornecido como referência de consulta. Os resultados parciais dos dois mecanismos de busca são combinados em um passo posterior, retornando o resultado final ao usuário. Esta dicotomia entre busca por metadados e busca por conteúdo também ocorre em outros sistemas bastante conhecidos na área, tais como o projeto IRMA (Image Retrieval in Medical Applications - Recuperação de Imagens em Aplicações Médicas) (Lehmann et al., 2004) e o SPIRS (Spine Pathology 6 Image Retrieval System - Sistema de Recuperação de Patologias de Espinha e Imagens) (Hsu et al., 2009). O uso de mecanismos separados impede a aplicação de otimizações na estratégia de consulta, baseadas nas seletividades de cada tipo de condição.

Analisando as abordagens de recuperação de imagens médicas utilizando metadados e conteúdo verifica-se que, em geral, são voltadas para conjuntos de dados controlados e relativamente pequenos. A maior parte dos trabalhos encontrados na literatura foram testados utilizando conjuntos contendo uns poucos milhares de imagens. Alguns trabalhos manipulam bancos de dados maiores, porém ainda armazenando pouco mais de 100.000 imagens (por exemplo, (Hsu et al., 2009) e (Rahman et al., 2010)). Em parte, isto pode ser explicado pelo fato de que para avaliar a eficácia de uma técnica, em termos de qualidade do resultado, é necessário considerar um conjunto de dados controlado, que geralmente é de tamanho reduzido. Entretanto, aplicações reais de gerenciamento de imagens médicas manipulam grandes volumes de dados, pois é comum que centenas ou milhares de imagens sejam geradas diariamente em uma instituição de saúde. Desta forma, se um sistema de CBIR não implementa estratégias de busca escaláveis, ele torna-se inviável à medida que o banco de imagens cresce. Este problema é conhecido como uma lacuna de desempenho (performance gap) em sistemas de recuperação de imagens médicas por conteúdo (Deserno et al., 2009; Traina et al., 2009). 


\subsection{Considerações Finais}

Este capítulo descreveu vários aspectos relacionados à recuperação de dados complexos por similaridade. Foram introduzidos o problema da representação de consultas envolvendo dados complexos e o processo de avaliação de similaridade. Também foram apresentados os principais tipos de consultas por similaridade e uma revisão das abordagens para a recuperação de imagens médicas por conteúdo.

O próximo capítulo apresenta os principais aspectos referentes à inclusão de consultas por similaridade em SGBDs. São apresentadas as principais abordagens para representação algébrica das operações de consulta por similaridade encontradas na literatura, bem como os algoritmos mais difundidos para sua execução. Também é discutido o suporte oferecido por protótipos e SGBDs comerciais existentes para a recuperação de imagens por conteúdo. 


\section{Capítulo \\ 3 \\ Inclusão de Consultas por Similaridade em SGBDRs}

Dados complexos não podem ser acomodados adequadamente em tipos de dados simples. Para dados multimídia, por exemplo, a primeira alternativa é tratá-los apenas como sequências de bytes em um objeto binário grande (BLOB - Binary Large OBject). Nesta representação, as operações de inserção, recuperação e remoção são suportadas de forma trivial pelo SGBD, assemelhando-se à manipulação simples de arquivos em sistemas de arquivos. Para manipular adequadamente o conteúdo desses objetos binários é necessário desenvolver funções de manipulação específicas, em geral, providas por aplicativos e bibliotecas externos ao banco de dados.

Para capacitar um SGBD a realizar recuperação de imagens por conteúdo, é preciso ao menos implementar extratores de características de imagens e funções de distância sobre as assinaturas geradas para as imagens e o registro dessas funções junto ao SGBD, para que possam ser chamadas tanto em tarefas de consulta quanto em tarefas de atualização. A grande motivação de se acoplar consultas por similaridade na máquina de busca dos gerenciadores é fazer proveito dos recursos que os SGBDs provêm e permitir uma manipulação integrada de dados complexos e dados convencionais de maneira eficiente.

Este capítulo discute os principais aspectos relacionados à inclusão de consultas por similaridade em SGBDs relacionais. A Seção 3.1 apresenta uma revisão das principais abordagens algébricas para representação de consultas por similaridade encontradas na literatura. A Seção 3.2 mostra como as buscas por similaridade são representadas utilizando uma notação de álgebra relacional estendida com operações baseadas em similaridade. A Seção 3.3 apresenta os principais algoritmos para execução de buscas por 
similaridade em estruturas de indexação de dados complexos. Por fim, a Seção 3.4 trata do suporte a CBIR oferecido por SGBDs comerciais e sistemas acadêmicos de busca por similaridade integrados a sistemas de bancos de dados.

\subsection{Abordagens Algébricas para Consultas por Similari- dade}

Visto que dados complexos demandam um tratamento adequado em termos de representação e otimização de consultas, algumas abordagens algébricas para consultas por similaridade têm sido propostas na literatura. Uma das primeiras abordagens propostas foi a álgebra por multi-similaridade (multi-similarity algebra) (Adali et al., 1998), cujo intuito é manipular múltiplas medidas de similaridade, codificadas por diferentes algoritmos, e combiná-las conforme a necessidade do usuário. Em (Bufi e Adali, 1999) esse trabalho foi estendido com a definição de uma linguagem baseada na OQL (Object Query Language), implementando as noções da álgebra por multi-similaridade no modelo orientado a objetos.

Os trabalhos voltados a incluir a noção de similaridade no modelo relacional concentram-se em três linhas principais. A primeira linha entende a noção de similaridade como imprecisão, ou grau de pertinência a um conjunto, e define a estrutura da álgebra utilizando conceitos da lógica nebulosa (fuzzy). Por exemplo, a $\mathrm{SAME}^{W}$ (Similarity Algebra for Multimedia Extended with Weights) é uma proposta de álgebra por similaridade para dados multimídia, desenvolvida por Ciaccia et al. (2000) e estendida em (Montesi et al., 2003; Penzo, 2005), que considera imprecisão, tanto no nível de tuplas quanto de atributos, permitindo a atribuição de pesos na maioria dos operadores para refletir as preferências do usuário.

A segunda linha procura estender o modelo relacional através da introdução do conceito de relações ordenadas (ranked relations), cujas tuplas são classificadas segundo um critério de ranking definido pelo usuário. Essa linha está relacionada às consultas top-k, que visam retornar as $k$ tuplas melhor classificadas segundo o critério de ranking. A idéia principal desta categoria de trabalhos é ordenar a(s) relação(ões) de entrada e fazer com que os operadores do plano de consulta preservem a ordem das tuplas. Os trabalhos de Adali et al. (2004, 2007) e de Li et al. (2005) são exemplos de propostas nesta linha de atuação. Já os trabalhos (Belohlávek et al., 2007) e (Belohlávek e Vychodil, 2010) combinam a noção de relações ordenadas e lógica nebulosa, propondo um modelo que contempla essas duas linhas.

A terceira linha de trabalhos visando incluir similaridade no modelo relacional considera apenas acrescentar operadores por similaridade à álgebra relacional, sem modificar a estrutura das relações. Uma proposta nesta linha foi definida em (Atnafu et al., 2001, 
2004), apresentando operadores para busca e junção por abrangência e regras de equivalência, com foco em sistemas de banco de dados multimídia. Essa proposta, entretanto, não aborda consultas aos vizinhos mais próximos. Traina Jr. et al. (2006) exploraram propriedades das consultas por similaridade básicas ( $\mathrm{Rq}$ e $k$-NNq), considerando predicados simples ou compostos envolvendo estes operadores, com um ou vários centros de consulta. Este trabalho também identificou regras de equivalência válidas para predicados compostos e alternativas de reescrita de consultas no processo de otimização. Ferreira et al. (2009) aprofundaram a análise sobre as propriedades dos operadores por similaridade Rq e $k$-NN, mostrando que as consultas por abrangência têm propriedades equivalentes às da seleção tradicional e que as consultas $k-\mathrm{NN}$, na sua forma canônica, possuem poucas regras de equivalência e, consequentemente, têm movimentação muito limitada no plano de consulta. Posteriormente, esses autores exploraram propriedades para as consultas $k$-NN baseadas na continência de conjuntos, que são úteis para adiar o processamento de uma $k$-NNq no plano de consulta (Ferreira et al., 2011). Silva et al. (2009, 2010b) exploraram as operações de junção e agrupamento por similaridade, identificando regras algébricas úteis para reescrita de consultas, propondo algoritmos eficientes para executálas e apresentando um protótipo para execução destas operações dentro do processador de consultas de um SGBD (Silva et al., 2010a). Finalmente, os trabalhos de Barioni et al. (2011, 2009) formalizaram a representação das principais consultas por similaridade seguindo uma notação consistente com os demais operadores da álgebra relacional, além de apresentar uma proposta de extensão da linguagem SQL incluindo operações por similaridade e protótipos funcionais para sua execução. Esta tese adota a terceira linha de abordagem, representando as consultas por similaridade por meio de operadores adicionais, integrados de forma homogênea aos demais operadores da álgebra relacional.

\subsection{Representação Algébrica de Consultas por Similari- dade}

As consultas por abrangência, aos vizinhos mais próximos e por similaridade agregada têm o comportamento semelhante ao da seleção relacional. Isto é, essas consultas retornam os elementos do conjunto de entrada, que podem ser tuplas de uma relação, que satisfazem um determinado critério de similaridade, que pode ser denotado por um predicado de seleção. Estas operações são classificadas como seleções por similaridade. De maneira semelhante, as junções por similaridade são variações da operação de junção relacional, onde o predicado de junção é um predicado baseado em similaridade.

Esta seção apresenta as definições das consultas por similaridade seguindo as definições do modelo relacional, enriquecido com operadores por similaridade. A notação utilizada nesta tese é derivada dos trabalhos de Barioni et al. (2011) e Ferreira et al. (2009). 


\subsubsection{Seleções por Similaridade}

As expressões a seguir consideram uma relação contendo $m$ tuplas $R=\left\{t_{1}, \ldots, t_{m}\right\}$, descrita por um esquema relacional com $n$ atributos $\mathfrak{R}=\left(S_{1}, \ldots, S_{n}\right)$. Cada atributo $S_{j}, 1 \leq k \leq n$, pertence a um domínio de dados $\mathbb{S}_{i}$, que pode ser um domínio simples (números, datas, textos curtos) ou complexo. Observe que dois atributos distintos $S_{1}$ e $S_{2}$ podem compartilhar o mesmo domínio, isto é, pode ocorrer que $\mathbb{S}_{1}=\mathbb{S}_{2}$.

A operação de seleção relacional, aplicada sobre uma relação $R$, produz uma nova relação $R^{\prime}$, que é um subconjunto das tuplas de $R$. Esta operação é denotada como $\sigma_{C}(R)$, onde $C$ é uma expressão condicional cujos os operandos são constantes ou atributos da relação $R$ (Garcia-Molina et al., 2009).

As seleções por similaridade são denotadas por dois operadores, $\hat{\sigma}$ e $\ddot{\sigma}$, utilizados, respectivamente, para representar consultas por similaridade por abrangência (consulta por abrangência, consulta pontual e consulta por abrangência reversa) e por vizinhança (consulta aos $k$-vizinhos mais próximos e consulta aos $k$-vizinhos mais distantes). A expressão condicional aceita por estes operadores tem a forma $\left\langle S_{j} \theta Q\right\rangle$, onde $S_{j}$ é um atributo da relação de entrada, cujo domínio é $\mathbb{S}, \theta$ é um operador por similaridade e $Q \subseteq \mathbb{S}$ é o conjunto de elementos de consulta. Se $Q$ é um conjunto unitário, contendo apenas um elemento $s_{q}$, pode ser denotado na expressão condicional como $\left\{s_{q}\right\}$ ou, simplesmente, $s_{q}$. Os operadores por similaridade utilizados na expressão condicional dos operadores $\hat{\sigma}$ e $\ddot{\sigma}$ recebem como parâmetros a função de distância utilizada $\delta$ e o limiar de consulta ( $\xi$ para consultas por abrangência e $k$ para as consultas aos vizinhos mais próximos/distantes).

Um consulta por abrangência é representada utilizando o operador por similaridade Rq, conforme segue:

$$
\hat{\sigma}_{S_{j} \operatorname{Rq}[\delta, \xi] s_{q}}(R)
$$

e produz uma relação $R^{\prime}$ que contém as tuplas $t_{i} \in R, 1 \leq i \leq m$, tais que $\delta\left(t_{i} . S_{j}, s_{q}\right) \leq \xi$, onde $t_{i} . S_{j}$ é o valor do atributo $S_{j}$ na tupla $t_{i}, s_{q}$ é o elemento de consulta e $\xi$ o limiar de dissimilaridade.

Uma consulta pontual é essencialmente uma consulta por abrangência com $\xi=0$, e, portanto, também utiliza o operador por similaridade $\mathrm{Rq}$, sendo representada como:

$$
\hat{\sigma}_{S_{j} \mathrm{Rq}[\delta, 0] s_{q}}(R)
$$

retornando as tuplas $t_{i} \in R$ tais que $\delta\left(t_{i} . S_{j}, s_{q}\right)=0$. Observe que a relação resultante de uma consulta pontual pode conter mais de uma tupla, caso o atributo $S_{j}$ não seja uma chave candidata da relação de entrada. 
As consultas por abrangência reversa também são representadas usando o operador $\hat{\sigma}$, mas usando o operador de similaridade $\mathrm{Rq}^{-1}$ :

$$
\hat{\sigma}_{S_{j} \mathrm{Rq}^{-1}[\delta, \xi] s_{q}}(R)
$$

gerando uma relação $R^{\prime}$ que contém as tuplas $t_{i} \in R, 1 \leq i \leq m$, tais que $\delta\left(t_{i} . S_{j}, s_{q}\right)>\xi$.

Observe que o operador $\hat{\sigma}$ é um operador conveniente para expressar consultas por similaridade baseadas em abrangência, porém não aumenta o poder de expressividade da álgebra, uma vez que estas consultas podem ser expressas alternativamente usando o operador de seleção relacional. As expressões a seguir respondem, utilizando o operador de seleção relacional: (i) a uma consulta por abrangência, (ii) a uma consulta pontual e (iii) a uma consulta por abrangência reversa:
i) $\sigma_{\delta\left(S_{j}, s_{q}\right) \leq \xi}(R)$
ii) $\sigma_{\delta\left(S_{j}, s_{q}\right)=0}(R)$
iii) $\sigma_{\delta\left(S_{j}, s_{q}\right)>\xi}(R)$

onde a expressão condicional é baseada no resultado da função de distância, computada tupla a tupla.

Consultas aos vizinhos mais próximos ou mais distantes são representados utilizando o operador de seleção por similaridade $\ddot{\sigma}$. Uma consulta aos $k$-vizinhos mais próximos utiliza o operador por similaridade $k \mathrm{NN}$, conforme segue:

$$
\ddot{\sigma}_{S_{j} k \mathrm{NN}[\delta, k] s_{q}}(R)
$$

onde $k$ é o número de vizinhos a serem retornados.

As consultas ao vizinho mais próximo são representadas da mesma forma, mas sempre com $k=1$.

Uma consulta aos $k$-vizinhos mais distantes também é representada utilizando a seleção por similaridade $\ddot{\sigma}$, mas utilizando o operador por similaridade $k \mathrm{FN}$ :

$$
\ddot{\sigma}_{S_{j} k \mathrm{FN}[\delta, k] s_{q}}(R)
$$

retornando até $k$ vizinhos mais distantes do elemento de consulta $s_{q}$, considerando a função de distância $\delta$.

Ferreira et al. (2009) demonstraram que as seleções por abrangência têm propriedades equivalentes às da seleção tradicional, podendo ser movimentadas no plano de consultas seguindo as mesmas estratégias. Por outro lado, as seleções aos $k$-vizinhos mais próximos não são comutativas nem entre si e nem com qualquer outra operação relacional. Em (Ferreira et al., 2011) os autores identificaram um conjunto de propriedades algébricas válidas para as $k$-NNq, baseadas na inclusão de conjuntos. Essas propriedades permitem postergar a aplicação do operador $k \mathrm{NN}$ no plano de execução da consulta, visando reduzir 
o tempo total de execução. Entretanto, muitas aplicações demandam executar consultas que aplicam filtros anteriores à $k$-NNq. Nestas situações, as regras baseadas na inclusão de conjuntos têm aplicabilidade reduzida.

\subsubsection{Seleções por Similaridade Agregada}

As consultas por similaridade agregada também são representadas utilizando os operadores de seleção por similaridade $\hat{\sigma}$ e $\ddot{\sigma}$.

Uma consulta por abrangência agregada utiliza uma generalização do operador por similaridade Rq na expressão condicional do operador $\hat{\sigma}$, que acrescenta um parâmetro que indica a função agregadora de distâncias a ser considerada, conforme segue:

$$
\hat{\sigma}_{S_{j} \operatorname{Rq}[\delta, \Delta, \xi] Q}(R)
$$

onde $\delta$ é uma função de distância, $\Delta$ é uma função agregadora de distâncias $\delta, Q,|Q| \geq 1$, é o conjunto de elementos de consulta e $\xi$ é o limiar de dissimilaridade.

As consultas aos $k$-vizinhos mais próximos agregados são representadas utilizando o operador de seleção $\ddot{\sigma}$ e a generalização do operador por similaridade $k \mathrm{NN}$ incluindo a função agregadora de distâncias:

$$
\ddot{\sigma}_{S_{j} k \mathrm{NN}[\delta, \Delta, k] Q}(R)
$$

onde $k \geq 1$ é o número de vizinhos desejado.

\subsubsection{Junções por Similaridade}

Dadas duas relações de entrada $R_{1}$ e $R_{2}$, a junção theta $(\theta$-join $)$ destas tabelas é o pareamento de tuplas que satisfazem uma condição $C$ envolvendo atributos das relações de entrada (Garcia-Molina et al., 2009). Esta operação é representada como:

$$
R_{1} \bowtie_{C} R_{2}
$$

produzindo uma relação resultante $R^{\prime} \subseteq(R \times S)$ de forma que a condição $C$ é satisfeita para toda tupla $t^{\prime} \in R^{\prime}$.

Uma junção por similaridade é uma junção cuja condição $C$ é baseada em um operador por similaridade. Seja $R_{1}$ uma relação descrita por um esquema relacional $\mathfrak{R}_{1}=\left(S_{a}, \ldots, S_{b}\right), R_{2}$ uma relação descrita por um esquema relacional $\mathfrak{R}_{2}=\left(S_{c}, \ldots, S_{d}\right)$, $a \leq b<c \leq d, S_{i}$ um atributo de $R_{1}$ e $S_{j}$ um atributo de $R_{2}, a \leq i \leq b$ e $c \leq j \leq d$, e $\delta$ uma função de distância definida sobre os domínios complexos de $S_{1}$ e de $S_{2}$. 
A junção por abrangência $\left(\star_{\mathrm{Rq}}\right)$ utiliza o operador por similaridade Rq na condição de junção, com a forma:

$$
R_{1} \bowtie_{S_{i} \operatorname{Rq}[\delta, \xi]} S_{j} R_{2}
$$

onde $\xi$ é o limiar de dissimilaridade fornecido. Esta operação produz uma relação cujas tuplas são a concatenação das tuplas $t_{m} \in R_{1}$ e $t_{n} \in R_{2}$ tais que $\delta\left(t_{m} . S_{i}, t_{n} . S_{j}\right) \leq \xi$.

Uma junção pelos $k$-vizinhos mais próximos $\left(\bowtie_{k N N}\right)$ utiliza o operador por similaridade $k \mathrm{NN}$ na condição de junção, sendo representada como:

$$
R_{1} \rtimes_{S_{i} k \mathrm{NN}[\delta, k] S_{j}} R_{2}
$$

onde $k$ é o número de vizinhos. Esta operação concatena cada tupla $t_{m} \in R_{1}$ com as tuplas $t_{n} \in R_{2}$ que contêm os $k$-vizinhos mais próximos de $t_{m} . S_{i}$. Observe que a junção pelos $k$-vizinhos mais próximos não é comutativa. Ou seja, $R_{1} \bowtie_{S_{i} k \mathrm{NN}[\delta, k] S_{j}} R_{2} \neq R_{2} \bowtie_{S_{j} k \mathrm{NN}[\delta, k] S_{i}} R_{1}$.

A junção dos $k$-pares de vizinhos mais próximos $\left(\bowtie_{k \mathrm{CN}}\right)$ é representada fazendo uso do operador por similaridade $k \mathrm{CN}$, como segue:

$$
R_{1} \bowtie_{S_{i} k \mathrm{CN}[\delta, k] S_{j}} R_{2}
$$

retornando uma relação $R^{\prime}$ contendo $k$ tuplas, formadas pela concatenação das tuplas $t_{m} \in R_{1}$ e $t_{n} \in R_{2}$ que geram os menores de distância $\delta\left(t_{m} . S_{i}, t_{n} . S_{j}\right)$. Observe que uma mesma tupla de $R_{1}$ pode ser concatenada com mais de uma tupla de $R_{2}$, e vice-versa.

\subsection{Algoritmos para Consultas por Similaridade em Métodos de Acesso Métricos}

Se nenhuma estrutura de indexação for utilizada, uma consulta por similaridade deve ser executada utilizando-se uma busca sequencial sobre todos os elementos da relação de entrada. Nesse caso, uma consulta por abrangência $\hat{\sigma}_{S_{j} \mathrm{Rq}[d, \xi] s_{q}}(R)$ pode ser resolvida calculando $\delta\left(t_{i} . S_{j}, s_{q}\right)$, para todas as tuplas $t_{i}$ da relação $R$, e selecionando apenas aqueles cuja dissimilaridade seja menor ou igual a $\xi$. A complexidade dessa busca é $O(n)$, onde $n=|S|$, em termos de cálculos de distância e de número de comparações (do resultado da função de distância com o valor $\xi$ ). Como a comparação da tupla com o elemento de consulta já indica se a tupla faz parte da resposta, não é necessário o uso de memória adicional para executar a busca.

Da mesma forma, uma consulta aos $k$-vizinhos mais próximos $\ddot{\sigma}_{S_{j} k \mathrm{NN}[\delta, k] s_{q}}(R)$ pode ser resolvida percorrendo todas as tuplas $t_{i} \in R$, ordenando-as de acordo com o valor $\delta\left(t_{i} . S_{j}, s_{q}\right)$ e retornando os $k$ primeiros elementos. Esse algoritmo também possui comple- 
xidade $O(n)$, em termos de cálculos de distância, porém, a complexidade em termos de número de comparações (entre os valores de distância) é $O(n \cdot \log n)$, devido ao custo da ordenação. Além disso, esse algoritmo requer armazenar a distância $\delta\left(t_{i} . S_{j}, s_{q}\right)$ para cada tupla da relação, portanto a sua complexidade, em termos de memória adicional, é $O(n)$. Entretanto, não é preciso ordenar todos os elementos do conjunto de entrada para identificar os $k$-vizinhos mais próximos ao elemento de consulta. Com base nesta observação, um algoritmo mais eficiente para a $k$-NNq percorre os elementos do conjunto de entrada e identifica os $k$ elementos com menor valor de $\delta$ utilizando uma estrutura de dados com custo logarítmico de manipulação. A complexidade deste algoritmo em termos do número de comparações é $O(n \cdot \log k)$ e em termos de memória é $O(k)$, embora a complexidade em termos de cálculos de distância ainda seja $O(n)$.

Um aspecto fundamental dos algoritmos para consultas por similaridade está relacionado à utilização de um Método de Acesso (MA) apropriado. A maioria dos SGBDs fornecem estruturas de indexação para dados tradicionais, como variantes da B-Tree e estruturas de hashing. Contudo, essas estruturas não são adequadas para os sistemas de recuperação que lidam com dados que não apresentam relação de ordem total entre os elementos e, normalmente, apresentam alta dimensionalidade. Frente à limitação dos métodos tradicionais, foram propostos novos MA para dar suporte aos novos tipos de dados. As subseções a seguir apresentam os principais tipos de MA usados para consultas por similaridade e os algoritmos para resolver as consultas $\mathrm{Rq}$ e $k$-NNq sobre árvores métricas, que são os MAs que têm se mostrado mais eficientes para a indexação de dados multimídia por conteúdo. A Slim-tree (Traina Jr. et al., 2002) será usada como exemplo para a descrição dos algoritmos.

\subsubsection{Métodos de Acesso para Consultas por Similaridade}

Os Métodos de Acesso Espaciais (MAEs), também conhecidos como Métodos de Acesso Multidimensionais, foram propostos para indexar dados espaciais. Exemplos representativos de MAEs são a k-d-B-tree (Robinson, 1981) e a R-tree (Guttman, 1984) e suas variantes, tais como a $\mathrm{R}^{*}$-tree (Beckmann et al., 1990). Alguns SGBDs comerciais já implementam variantes da R-tree, tais como o Oracle Database, o IBM Informix Dynamic Server e o PostgreSQL, utilizado-a majoritariamente em aplicações de geoprocessamento. MAEs também podem ser utilizados para indexar outros tipos de dados complexos, tais como dados multimídia (Böhm et al., 2001). Neste caso, um vetor de características com $e$ atributos é visto como um ponto no espaço $e$-dimensional definido pelas características e as consultas são agilizadas através da aplicação de propriedades geométricas na construção do MAE e na delimitação da área de consulta. Contudo, quando as assinaturas dos elementos multimídia têm muitas características, os MAEs passam a não ser eficientes. 
Eles degradam rapidamente com o aumento da dimensionalidade dos dados, tornando-se inviáveis para dimensionalidades maiores que uma dezena.

Para dados de alta dimensionalidade ou adimensionais (sem dimensão fixa) foram propostos os Métodos de Acesso Métricos (MAMs). A abordagem dos MAMs assume que os objetos estão em um espaço métrico e relaciona-os apenas por suas relações de similaridade. Os MAMs podem ser utilizados para indexar praticamente qualquer tipo de dado, sendo necessária e suficiente a definição de uma métrica adequada. A idéia geral da maioria dos MAMs consiste em selecionar um ou mais elementos e colocá-los como representantes de subconjuntos de dados. Quando um elemento $s_{i} \in \mathbb{S}$ é inserido, as distâncias entre ele e cada um dos representantes são calculadas e armazenadas juntamente com seus dados. Como as distâncias entre todos os elementos armazenados e os seus respectivos representantes são conhecidas, a propriedade de desigualdade triangular pode ser usada tanto durante a construção do índice quanto em uma consulta por similaridade para descartar elementos que, com certeza, não farão parte do conjunto resposta sem a necessidade de calcular as suas distâncias para o elemento de consulta.

Vários trabalhos têm apresentado propostas de MAMs na literatura. Os MAMs são diferenciados basicamente: (i) pela forma como os representantes são escolhidos, (ii) como os objetos estão dispostos em relação aos representantes, e (iii) se podem sofrer inserções e remoções de objetos sem degenerar a estrutura já criada (dinâmicos ou estáticos). O primeiro trabalho encontrado na literatura descreve as chamadas BK-trees (Burkhard e Keller, 1973). Nele são propostas três técnicas para particionar o espaço métrico de dados de forma recursiva, materializando o processo recursivo através das árvores. A partir de então, vários métodos surgiram, como por exemplo, os métodos hierárquicos VP-tree (Vantage Point tree) (Yianilos, 1993), MVP-tree (Multi-Vantage Point tree) (Bozkaya e Özsoyoglu, 1997) e FQ-tree (Fixed-Queries tree) (Baeza-Yates et al., 1994). Todos esses métodos são estáticos, no sentido que uma vez criados, não podem sofrer novas atualizações/remoções sob pena de se quebrar as propriedades da estrutura criada. O primeiro MAM dinâmico desenvolvido foi a M-tree (Ciaccia et al., 1997), que pode ser visto como uma adaptação do MAE R-tree para indexar dados em domínios métricos. A M-tree é uma árvore balanceada com crescimento bottom-up e com dois tipos de nós (internos e folha), que permite a inserção de elementos a qualquer momento, mantendo-se sempre balanceada, sem a necessidade de reorganizações periódicas. A Slim-tree (Traina Jr. et al., 2002) é uma evolução da M-tree, que traz como melhorias a avaliação e minimização do grau de sobreposição entre seus nós (Bueno et al., 2008; Traina Jr. et al., 2002) e um novo algoritmo de split, baseado na árvore de cobertura minimal (Minimal Spanning Tree - MST). Outros exemplos de MAMs dinâmicos são a DBM-tree (Density-Based Metric tree) (Vieira et al., 2004) e os índices da família Omni (Traina Jr. et al., 2007).

No que tange à recuperação de dados complexos combinando condições baseadas em similaridade e baseadas em metadados associados, os seguintes trabalhos 
merecem destaque. Park e Lee (2011) apresentam uma nova estrutura, denominada SPYTEC+, que estende a técnica de indexação para dados de alta dimensionalidade SPYTEC (Park e Kim, 2003) com a inclusão de um atributo categórico para permitir associar condições semânticas à busca por similaridade. Essencialmente, o SPYTEC+ integra uma estrutura SPYTEC para indexar os atributos visuais e uma S-tree (Deppisch, 1986) para indexar o atributo categórico, que armazena uma palavra-chave indicando a semântica do dado armazenado. Os nós das duas estruturas são alinhados conforme os dados indexados e os atributos semânticos são representados por assinaturas binárias (bitmaps) hierárquicas, cujos bits indicam a presença ou ausência de um dado valor nas subárvores da S-tree. De Felipe et al. (2008) propuseram um método para responder a consultas top$k$ espaciais, cuja localização contenha palavras-chave indicadas na consulta. A estrutura proposta naquele trabalho, denominada $\mathrm{IR}^{2}$-tree (Information Retrieval $R$-tree), estende a R-tree utilizando assinaturas binárias hierárquicas na organização da estrutura. As assinaturas binárias hierárquicas são semelhantes às assinaturas usadas no SPY-TEC+, representando as palavras-chave presentes em uma subárvore da estrutura. Os autores também propõem uma variação da $\mathrm{IR}^{2}$-tree, denominada $\mathrm{MIR}^{2}$-tree (Multilevel $\mathrm{IR}^{2}$-tree), na qual os tamanhos das assinaturas variam de acordo com os níveis da estrutura, o que reduz o número de falsos positivos nos níveis mais altos, melhorando a eficiência da busca, mas aumenta a complexidade das operações de atualização, pois exige acessar os objetos armazenados para recomputar as assinaturas (a $I^{2}$-tree acessa apenas as assinaturas superimpostas dos nós sucessores). O trabalho de Cary et al. (2010) introduz a estrutura SKI (Spatial-Keyword Index), que combina uma R-tree para indexar os dados espaciais e um arquivo invertido para buscas por texto para indexar palavras-chave modificado para permitir associar a informação espacial. Na SKI, as palavras-chave são indexadas em uma árvore $\mathrm{B}+\mathrm{e}$ apontam para assinaturas binárias semelhantes às usadas nos trabalhos citados anteriormente. Os trabalhos de Cong et al. (2009) e Rocha-Junior et al. (2011) também integraram uma R-tree e um índice invertido para buscas textuais, propondo, respectivamente, as estruturas DIR-tree (Document similarity enhanced Inverted file $R$-tree) e S2I (Spatial Inverted Index), que são eficientes e escaláveis para responder a consultas envolvendo similaridade e recuperação baseada em textos. Observe-se que todos esses trabalhos consideram recuperação baseada em textos, ou seja, as condições associadas à condição por similaridade consistem, em essência, no casamento de palavras-chave.

\subsubsection{Estrutura da Slim-tree}

Para facilitar o entendimento dos algoritmos, a estrutura da Slim-tree será descrita resumidamente. Em uma Slim-tree, os elementos são agrupados em disco em páginas de tamanho fixo, cada página correspondendo a um nó da árvore. Os elementos são armazenados nas folhas, organizados em uma estrutura hierárquica que utiliza um elemento representante 
como centro de uma região de cobertura dos elementos de uma subárvore, delimitada por um raio máximo de cobertura. Para reduzir os cálculos de distância durante as buscas, as distâncias entre cada elemento de um nó e o seu respectivo representante são calculadas no momento da inserção e armazenadas na árvore.

Existem dois tipos de nós na Slim-tree, os nós internos (index-nodes) e os nós folha (leaf-nodes). A estrutura de um leaf-node, onde são armazenados todos os elementos, é a seguinte:

$$
\text { leaf-node [vetor de } \left.\left\langle O I d_{i}, d\left(s_{i}, s_{r e p}\right), s_{i}\right\rangle\right]
$$

onde $O I d_{i}$ é o identificador do elemento $s_{i}$ e $d\left(s_{i}, s_{r e p}\right)$ é a distância entre o elemento $s_{i}$ e $s_{\text {rep }}$, que é o representante desse nó.

A estrutura de um index-node, é a seguinte:

$$
\text { index-node [vetor de }\left\langle s_{i}, r_{i}, d\left(s_{i}, s_{r e p}\right), \operatorname{Ptr}\left(T_{s_{i}}\right), \# \operatorname{Ent}\left(\operatorname{Ptr}\left(T_{s_{i}}\right)\right)\right\rangle \text { ] }
$$

onde $s_{i}$ armazena o elemento representante da subárvore apontada por $\operatorname{Ptr}\left(T_{s_{i}}\right), r_{i}$ é o raio de cobertura do nó (distância entre o representante e o elemento mais distante ao representante nesse nó), $d\left(s_{i}, s_{r e p}\right)$ é a distância entre $s_{i}$ e o representante desse nó, e \# Ent $\left(\operatorname{Ptr}\left(T_{s_{i}}\right)\right)$ armazena o número de entradas da subárvore apontada por $\operatorname{Ptr}\left(T_{s_{i}}\right)$.

A Figura 3.1 ilustra a disposição de uma Slim-tree com capacidade máxima de 3 elementos por nó. Os círculos brancos representam nós folha, e os de cor cinza nós índice. Os elementos representantes de cada nó são mostrados em preto, e os demais elementos indexados em cor cinza.

\subsubsection{Algoritmo para Consulta por Abrangência}

Os algoritmos de consulta por abrangência e aos $k$-vizinhos mais próximos são aplicáveis a todas as árvores métricas e espaciais. Entre as abordagens existentes, a mais comum é a branch-and-bound, onde a busca começa pela raiz da estrutura de indexação, e em cada passo utilizam-se propriedades do domínio de dados em questão para determinar quais nós devem ser examinados e quais podem ser descartados. Para dados imersos em um espaço métrico, a desigualdade triangular é a principal propriedade utilizada. O descarte pela desigualdade triangular é realizado como descrito a seguir. Dados um espaço métrico $\mathbb{M}=\langle\mathbb{S}, \delta\rangle$, um conjunto de elementos $S \subseteq \mathbb{S}$, um elemento de consulta $s_{q} \in \mathbb{S}$, um elemento representantivo $s_{\text {rep }}$ de um nó do MAM e um limiar de dissimilaridade $\xi$, um 


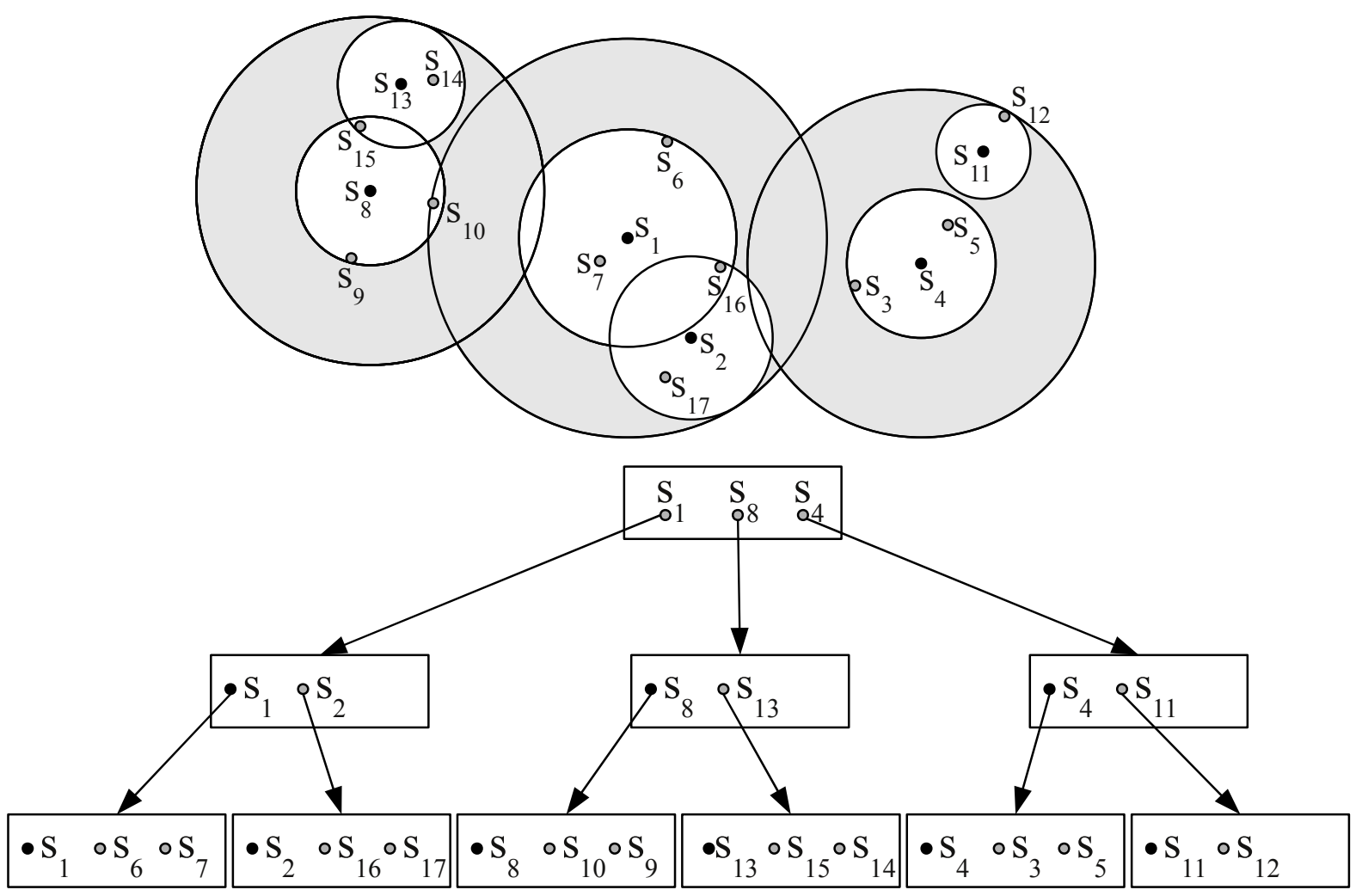

Figura 3.1: Representação visual de uma Slim-tree e sua estrutura lógica. A capacidade máxima dos nós é igual a 3.

elemento $s_{i} \in \mathbb{S}$ pode ser descartado se, e somente se, uma das duas condições a seguir for satisfeita (Burkhard e Keller, 1973):

$$
\begin{aligned}
& \delta\left(s_{\text {rep }}, s_{i}\right)<\delta\left(s_{\text {rep }}, s_{q}\right)-\xi \\
& \delta\left(s_{\text {rep }}, s_{i}\right)>\delta\left(s_{\text {rep }}, s_{q}\right)+\xi
\end{aligned}
$$

A Figura 3.2 ilustra essa noção. A região 1 satisfaz a Condição 3.1 e a região 3 satisfaz a Condição 3.2, portanto, seus elementos ou subárvores podem ser descartados sem a necessidade de calcular sua distância ao elemento de consulta $s_{q}\left(s_{1}\right.$, no caso). Por outro lado, nenhum elemento localizado na região 2 pode ser descartado pela propriedade de desigualdade triangular, embora apenas uma pequena parte dessa região corresponda à resposta da consulta. É necessário calcular a distância entre cada um desses elementos $\left(s_{2}\right.$ e $s_{3}$, no exemplo) e o elemento de consulta para produzir a resposta correta à consulta (apenas $s_{3}$ ).

O descarte por desigualdade triangular também pode ser usado para subárvores inteiras se não houver sobreposição entre a bola centrada no elemento de consulta $s_{q}$ com raio $\xi$ (limiar de dissimilaridade definido na consulta) e a região de cobertura da subárvore. Essa propriedade é utilizada nos algoritmos da Slim-tree para reduzir a quantidade de 


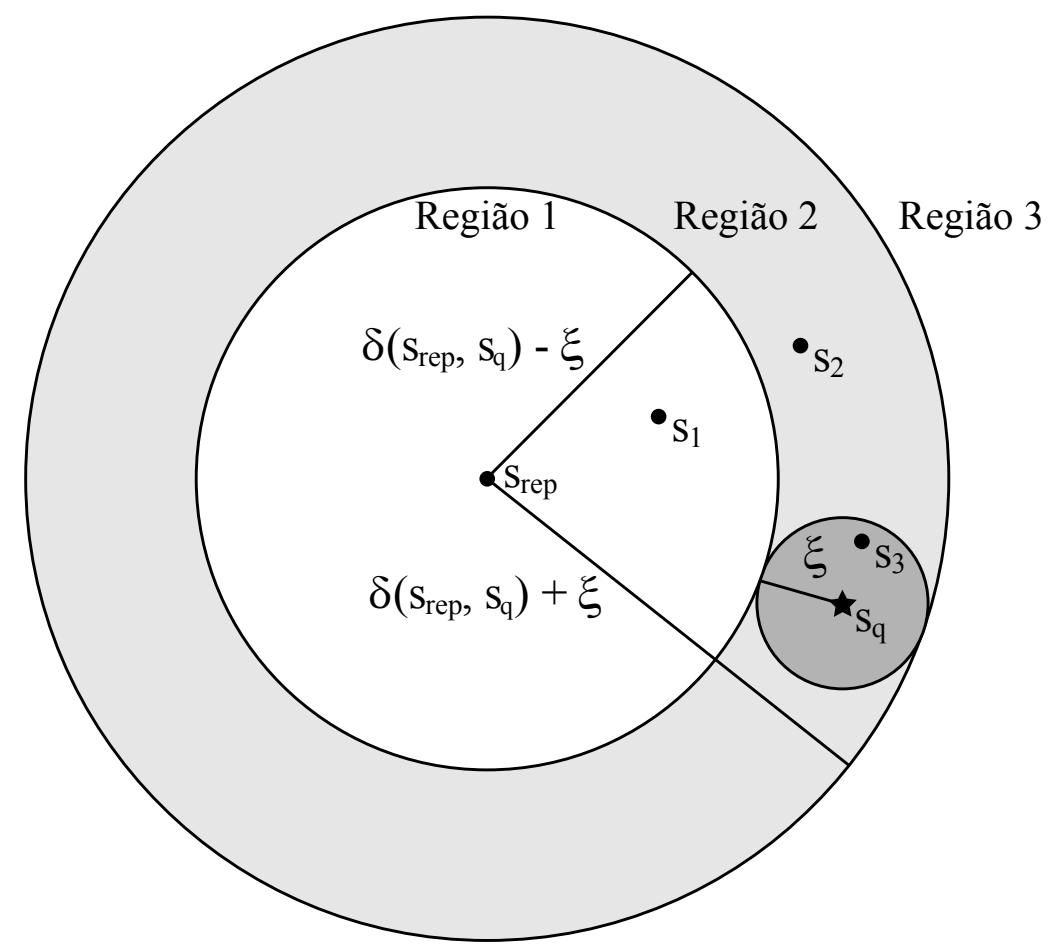

Figura 3.2: Descarte por desigualdade triangular. Os elementos ou subárvores localizados nas regiões 1 ou 3 podem ser descartados sem a necessidade de calcular sua distância ao elemento de consulta $s_{q}$.

cálculos de distância. A Figura 3.3 mostra essa situação, sendo que ambas subárvores enraizadas em $s_{1}$ e $s_{2}$ podem ser podadas na busca.

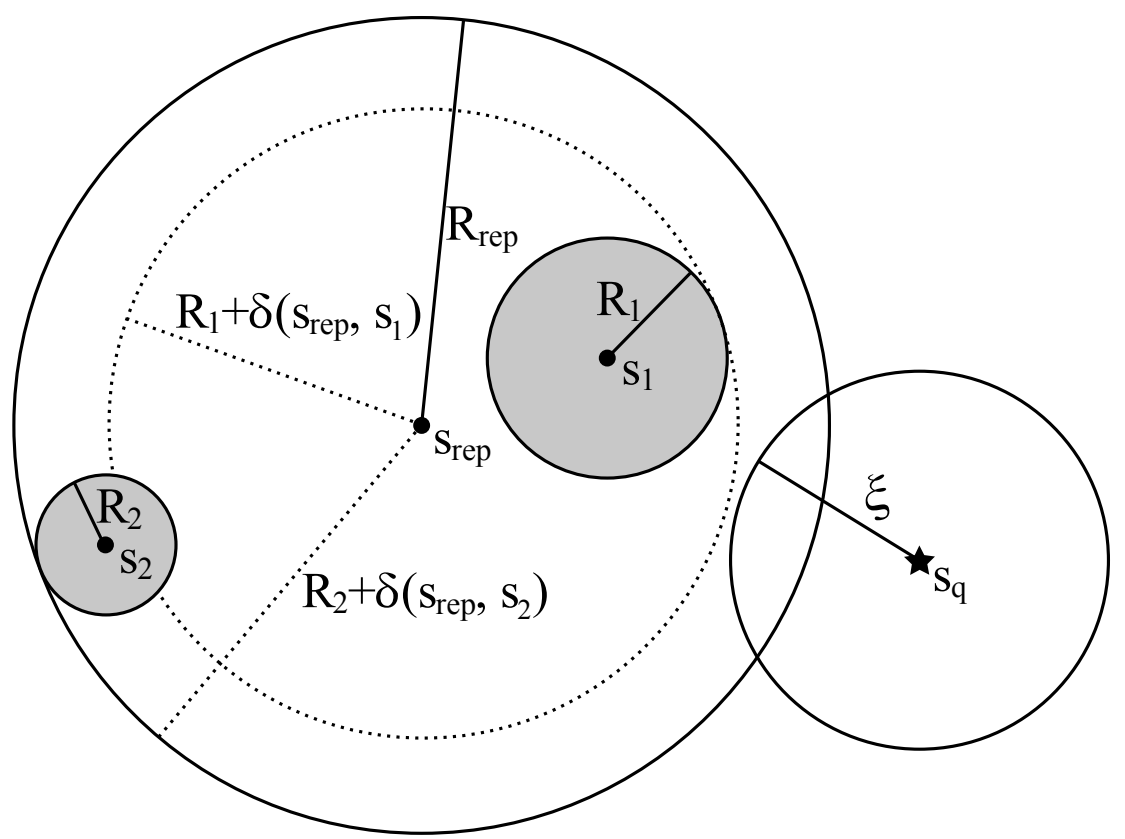

Figura 3.3: Descarte de subárvores na Slim-tree. Ambas subárvores enraizadas em $s_{1}$ e $s_{2}$ podem ser podadas na busca, porém apenas $s_{1}$ é descartado sem a necessidade de se calcular sua distância ao elemento de consulta $s_{q}$. 


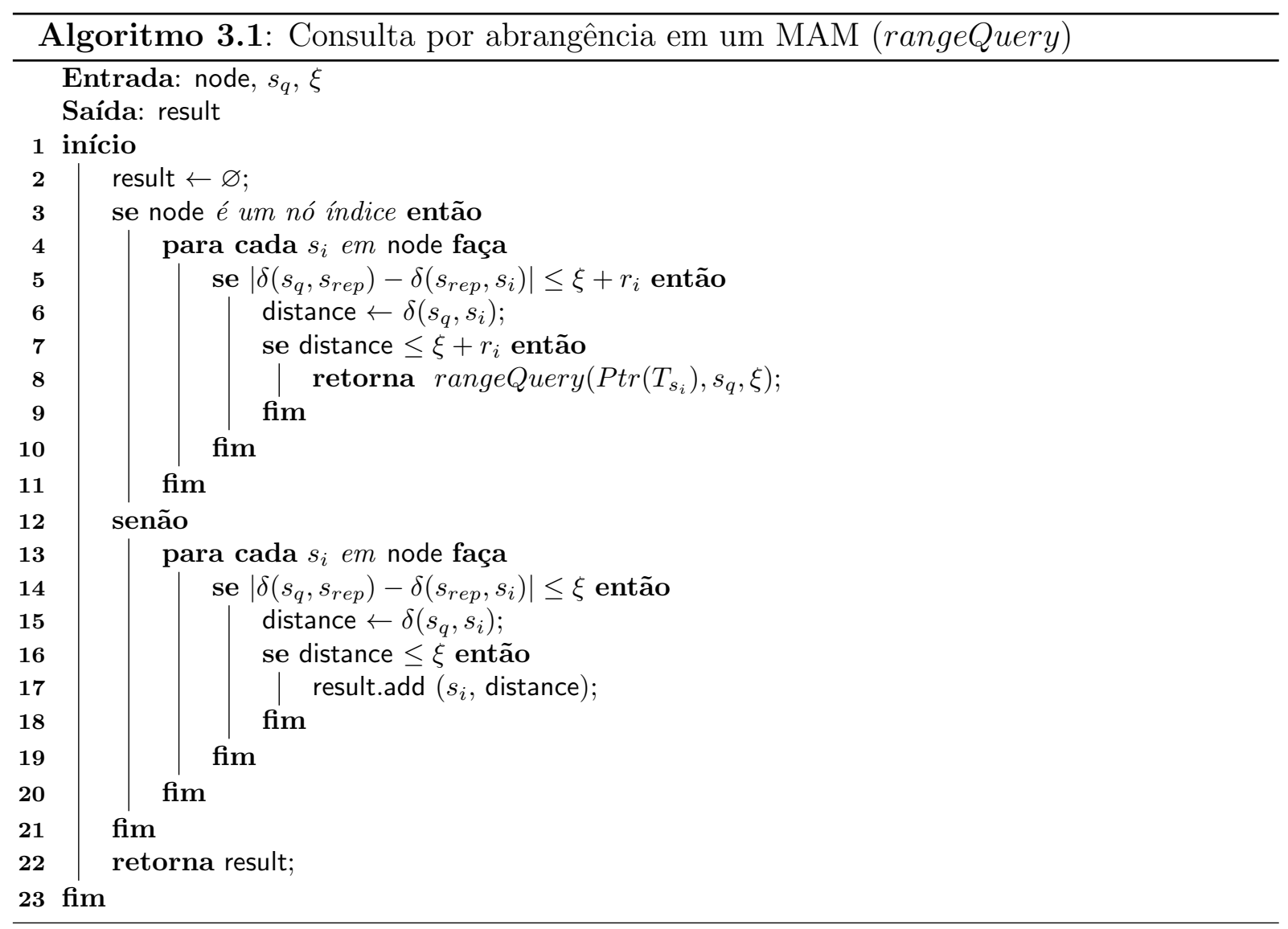

O Algoritmo 3.1 apresenta a função de busca por abrangência na Slim-tree. Inicialmente, o resultado é definido como vazio (linha 2). Se o nó corrente é um nó índice, todos os seus elementos $s_{i}$, representantes dos nós do nível abaixo, são avaliados (linhas 3-4). Na linha 5 o algoritmo tenta primeiramente podar a subárvore utilizando as distâncias entre o elemento de consulta e o representante do nó corrente e entre o representante e o elemento que está sendo avaliado, pois esses valores já foram computados anteriormente $\left(\delta\left(s_{q}, s_{r e p}\right)\right.$ no nível acima da recursão e $\delta\left(s_{r e p}, s_{i}\right)$ na inserção de $\left.s_{i}\right)$. No exemplo da Figura 3.3, apenas a subárvore enraizada em $s_{1}$ seria podada neste passo do algoritmo. Caso ainda não seja possível podar a subárvore, é calculada a distância entre $s_{q}$ e $s_{i}$ e o algoritmo tenta novamente podar a subárvore, agora com base nesse valor (linhas 6-7). Neste passo seria podada a subárvore enraizada em $s_{1}$ no exemplo da Figura 3.3. Caso o descarte não seja possível, na linha 8 o algoritmo percorre recursivamente a subárvore $\operatorname{Ptr}\left(T_{s_{i}}\right)$ apontada pelo elemento $s_{i}$. Por outro lado, se o nó corrente é um nó folha, todos os seus elementos $s_{i}$ são avaliados, e na linha 14 o algoritmo procura descartá-los também usando a propriedade de desigualdade triangular, seguindo a idéia ilustrada na Figura 3.2. Se o descarte não é possível, na linha 15 a distância entre $s_{q}$ e $s_{i}$ é calculada e, se o elemento $s_{i}$ estiver dentro do limiar de dissimilaridade $\xi$ definido na consulta, ele é incluído na resposta (linhas 16-17). Ao final da recursão, o algoritmo retorna o resultado gerado (linha 22). 


\subsubsection{Algoritmo para Consulta aos $k$-Vizinhos Mais Próximos}

Os algoritmos para busca aos $k$-vizinhos mais próximos também procuram reduzir o espaço de busca fazendo uso de propriedades do domínio de dados. Contudo, ao contrário do que ocorre na $\mathrm{Rq}$, na $k$-NNq não existe um raio de consulta definido a princípio.

$\mathrm{O}$ primeiro algoritmo proposto para resolver $k$-NNq em índices, usualmente chamado Depth-First $k$-NN, percorre recursivamente a estrutura utilizando um raio dinâmico, que inicialmente engloba todos os objetos indexados pela estrutura, e é ajustado a medida que o conjunto resposta vai sendo preenchido com os $k$ elementos requisitados. Esta estratégia permite o descarte de elementos e subárvores durante a busca com base na distância entre o elemento de consulta e o $k$-ésimo elemento encontrado até o momento.

A ordem em que a estrutura de indexação é percorrida não influencia o desempenho das consultas por abrangência, mas pode influenciar muito o desempenho dos algoritmos de consultas aos vizinhos mais próximos. Quanto mais cedo forem encontrados os elementos mais próximos ao elemento de consulta, mais rapidamente o raio limitante dinâmico será reduzido, aumentando as possibilidades de poda. Com base nessa premissa, Roussopoulos et al. (1995) propuseram o algoritmo conhecido como Best-First $k$-NN, que explora a ordem de visitação dos nós em uma $k$-NNq utilizando uma fila de prioridade global, organizada em ordem crescente de distância mínima (mindist) entre o elemento de consulta e a região coberta por uma subárvore. Inicialmente, a raiz da árvore é inserida na fila de prioridade global. A cada passo do algoritmo, o elemento com a menor distância é removido da fila de prioridade, pois a subárvore enraizada neste elemento tem a maior probabilidade de conter elementos mais próximos ao elemento de consulta dentre as subárvores não visitadas. Outra estratégia complementar usada é utilizar a menor distância máxima (minmaxdist) entre o elemento de consulta e a região de abrangência de uma subárvore. Esse valor pode ser usado para reduzir o raio dinâmico, pois garante a existência de um elemento situado a no máximo essa distância do elemento de consulta.

Uma terceira abordagem se baseia no uso de algoritmos incrementais para busca aos vizinhos mais próximos (Incremental $k$-NN), que procuram calcular de maneira eficiente o $k+1$ vizinho mais próximo, dado que os $k$ vizinhos já foram calculados (Hjaltason e Samet, 1999; Park e Kim, 2003). Para isso, eles utilizam uma fila de prioridade global, que contém os nós a serem processados e também a resposta para a consulta (elementos). Além disso, os algoritmos definem heurísticas que garantem que os $k$ elementos mais próximos estão sempre no início da lista, e para obter o $k+1$-ésimo elemento não é necessário reiniciar a busca, bastando continuar percorrendo a fila de prioridade a partir do passo anterior. $\mathrm{O}$ problema dessa técnica é o custo de gerenciamento da fila de prioridade, que tende a ser muito elevado, degenerando o desempenho.

Uma outra estratégia de aprimoramento consiste em estimar um raio inicial para a $k$-NNq, de tal forma que a capacidade de poda do algoritmo seja potencializada. Vieira 
et al. (2007) propuseram utilizar a dimensão de correlação fractal $\left(D_{2}\right)$ do conjunto de dados para realizar essa estimativa, obtendo desempenho consideravelmente superior com relação à inicialização do raio dinâmico com $\infty$. Esta estratégia pode ser utilizada para acelerar qualquer um dos algoritmos de $k$-NNq apresentados, embora os autores tenham implementado essa idéia sobre o Best-First $k$-NN. A principal limitação dessa proposta é que é preciso que exista uma quantidade de elementos já armazenada para que a dimensão de correlação fractal do conjunto possa ser calculada. Quando não é possível calcular o valor de $D_{2}$, essa estratégia recai na abordagem básica, onde o raio dinâmico é iniciado $\operatorname{com} \infty$.

Finalmente, existem várias abordagens que utilizam heurísticas para responder a consultas aproximadas aos vizinhos mais próximos, tais como o trabalho de Pan e Manocha (2011), baseado na técnica LSH (Locality Sensitive Hashing) com implementação em unidades de processamento gráfico, e o trabalho de Tao et al. (2010), que propõe uma variação da técnica LSH sobre árvores $\mathrm{B}$, denominada LSB-tree (Locality-Sensitive B-tree).

O restante desta subseção detalha o algoritmo Best-First $k$-NN implementado sobre a Slim-tree. Na Slim-tree, a distância mínima entre um elemento de consulta $s_{q}$ e uma subárvore $T_{s_{i}}$, cuja abrangência é uma bola centrada em $s_{i}$ com raio $r_{i}$, é dada por:

$$
\operatorname{mindist}\left(s_{q}, T_{s_{i}}\right)=\max \left\{\delta\left(s_{q}, s_{i}\right)-r_{i}, 0\right\}
$$

uma vez que nenhum elemento em $T_{s_{i}}$ pode estar a uma distância de $s_{q}$ menor que $\delta\left(s_{q}, s_{i}\right)-r_{i}$. Esse valor é usado para organizar a fila de prioridade global (priorQueue) do algoritmo.

O algoritmo usa também a estrutura de dados result, para armazenar os vizinhos mais próximos encontrados e a sua distância do elemento de consulta. A distância entre $s_{q}$ e o $k$-ésimo elemento corrente é obtida por meio da função getMaxDistance() da estrutura result, que faz o papel do raio de busca dinâmico, uma vez que qualquer subárvore tal que mindist $\left(s_{q}, T_{s_{i}}\right)>$ result.getMaxDistance() pode ser seguramente podada.

Para possibilitar a realização de podas na busca enquanto o processo ainda está visitando nós índice, é preciso definir a menor distância máxima entre o elemento de consulta $s_{q}$ e uma subárvore $T_{s_{i}}$. Na Slim-tree esse valor é dado por:

$$
\operatorname{minmaxdist}\left(s_{q}, T_{s_{i}}\right)=\delta\left(s_{q}, s_{i}\right)+r_{i}
$$

Esse limite superior pode ser utilizado na estrutura result para descartar elementos e subárvores e ajustar o raio dinâmico de consulta, pois garantidamente existe um elemento $s_{j}$ na subárvore $T_{s_{i}}$ tal que $\delta\left(s_{j}, s_{q}\right) \leq \operatorname{minmaxdist}\left(s_{q}, T_{s_{i}}\right)$.

O Algoritmo 3.2 apresenta a consulta aos $k$-vizinhos mais próximos na Slim-tree. O resultado e a fila de prioridade são inicializados, adicionando o nó raiz à fila de prioridade 


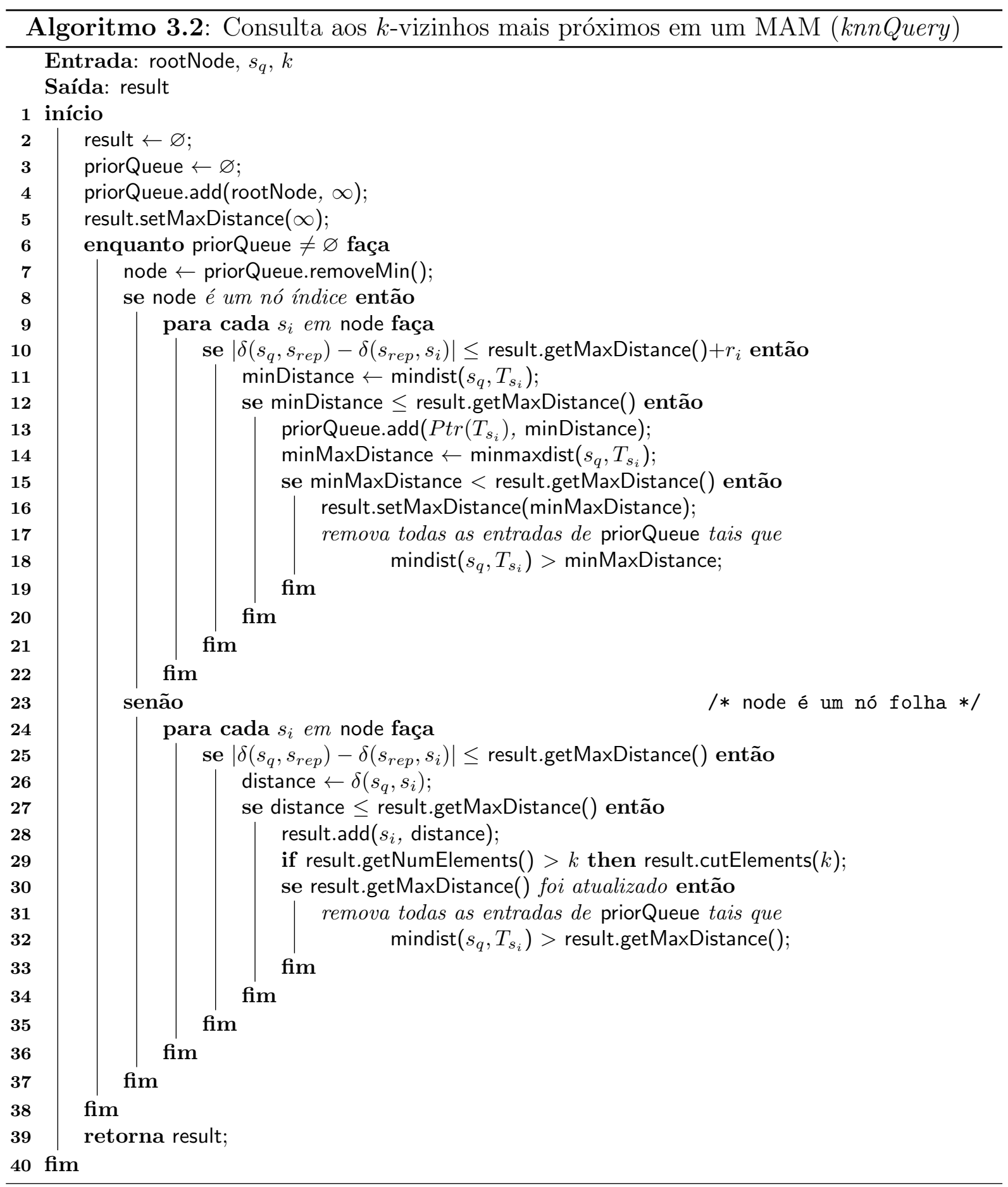

(linhas 2-4). O raio dinâmico do resultado é definido como $\infty$ (linha 5). Enquanto houver elementos na fila de prioridade, o elemento com distância mínima estimada é retirado (linhas 6-7). Se o nó corrente é um nó índice, cada elemento do nó é avaliado e o algoritmo tenta podar a subárvore respectiva usando a desigualdade triangular (linhas 8-10). Se a subárvore não puder ser podada, o algoritmo calcula a distância mínima entre o elemento de consulta e a subárvore $T_{s_{i}}$, o que implica em calcular $\delta\left(s_{q}, s_{i}\right)$, e verifica novamente se a subárvore pode ser descartada, com base neste valor (linhas 11-12). Caso a poda não seja possível, a subárvore é inserida na fila de prioridade, com base no valor mindist $\left(s_{q}, T_{s_{i}}\right)$, 
para ser processada posteriormente (linha 13). Em seguida, o algoritmo calcula a menor distância máxima entre $s_{q}$ e $T_{s_{i}}$ (linha 14). Se esse valor for menor que a distância máxima do resultado atual, o algoritmo atualiza a distância máxima do resultado e remove as entradas da fila de prioridade cujas distâncias são maiores que o novo raio de consulta, pois estas subárvores podem ser seguramente podadas neste momento (linhas 15-18). Se o nó corrente é um nó folha, cada elemento $s_{i}$ do nó é processado e verifica-se se pode ser descartado pela desigualdade triangular sem a necessidade de calcular sua distância ao elemento de consulta (linhas 24-25). Caso não seja possível, essa distância é calculada e verifica-se se o elemento deve ser incluído na resposta (linha 26-27). Caso afirmativo, o elemento é inserido no resultado e, se com a inclusão do novo elemento o resultado passar a ter mais do que $k$ elementos, o elemento mais distante é eliminado, deixando o resultado com $k$ elementos (linhas 28-29). Se após esta última operação a distância máxima for alterada, reduzindo o raio de consulta, as entradas da fila de prioridade com distância mínima estimada maior que o novo raio de consulta são removidas (linhas 30-32). Ao esgotarem os elementos da fila de prioridade, o algoritmo retorna o resultado da consulta (linha 39).

\subsection{Consultas por Similaridade entre Imagens em SGBDs}

Existem vários sistemas de CBIR relatados na literatura (Datta et al., 2008). Entretanto, a maioria das funcionalidades de CBIR não foram concebidas para serem reutilizadas e compartilhadas entre várias aplicações. Se estas funcionalidades são incluídas em um SGBD é possível fornecer um subsistema eficiente para suportar aplicações que demandam recuperação de imagens por similaridade. Neste sentido, o QBIC (Query By Image Content) (Flickner et al., 1995), que foi o primeiro sistema comercial de CBIR, desenvolvido pela IBM, foi posteriormente acoplado ao SGBD IBM DB2. De forma semelhante, o Virage (Bach et al., 1996) posteriormente integrado ao SGBD Oracle. Entretanto, para que os SGBDs suportem efetivamente a recuperação de imagens e outros dados complexos por conteúdo, ainda são necessários muitos esforços de pesquisa e desenvolvimento. Esta seção apresenta as principais abordagens encontradas na literatura para a inclusão de consultas por similaridade entre imagens em SGBDs.

Atualmente é necessário armazenar em bancos de dados muitos tipos de dados que não são aceitos nos SGBDs de maneira nativa. Para facilitar a inclusão de novos tipos, foram criadas duas interfaces padronizadas: os tipos definidos pelo usuário (User Defined Types - UDT) e as funções definidas pelo usuário (User Defined Functions - UDF). O padrão que trata dados multimídia, o ISO/IEC 13249-5:2001 SQL/MM (Melton e Eisenberg, 2001), sugere a inclusão desses dados por meio de UDTs e UDFs. A Parte 5 deste padrão trata de imagens estáticas (still images), onde é definido um tipo de dados para imagens, denominado SI_StillImage, que encapsula: 
- a imagem bidimensional em formato binário;

- metadados sobre a imagem, tais como formato, dimensões (largura e altura) e espaço de cores;

- funções de manipulação da imagem, como, por exemplo, redimensionamento, rotação, recorte, suavização e borramento; e

- um conjunto de atributos de outros tipos complementares definidos pelo SQL/MM para descrever as características primitivas das imagens (SI_AverageColor, SI_ColorHistogram, SI_PositionalColor, SI_Texture e SI_FeatureList).

O tipo SI_AverageColor descreve a cor "média" global da imagem, para suportar consultas do tipo "retorne as imagens cuja cor predominante é verde". O SI_ColorHistogram representa as frequências relativas de cores na imagem, para consultas baseadas em cor em uma granularidade mais fina que o SI_AverageColor. O SI_PositionalColor indica a localização de cores específicas na imagem, para consultas como "retorne imagens que têm alaranjado acima de azul escuro" para obter imagens de pôr-do-sol. O SI_Texture suporta consultas baseadas em textura, armazenando dados como rugosidade, contraste e direção. Todos esses tipos possuem métodos construtores e um método particular Score, que é a base para as consultas por conteúdo, pois calcula a similaridade entre imagens com relação ao critério representado pelo tipo de dado. O SI_FeatureList é uma agregação dos demais tipos e é usado, basicamente, para calcular a similaridade ponderada entre imagens usando mais de um critério.

Alguns SGBDs implementam o padrão SQL/MM StillImage. No entanto, como esse padrão não aborda a questão de como fazer consultas por conteúdo, a escrita e a forma de execução destas consultas utilizam extensões proprietárias. Exemplos representativos de SGBDs comerciais que implementam funcionalidades de CBIR são o IBM DB2, o Oracle Database, e o Informix Dynamic Server. Além dos gerenciadores comerciais existem protótipos acadêmicos que estendem SGBDs com funções de CBIR.

A seguir são mostradas as funcionalidades de CBIR providas pelos SGBDs comerciais IBM DB2, precursor dos sistemas de busca por conteúdo de imagens com o sistema QBIC, e o Oracle Database, atual líder de mercado. São descritos também os protótipos acadêmicos SIREN e PostgreSQL-IE, para CBIR sobre SGBDs. Os exemplos apresentados nesta seção consideram a existência de uma tabela de imagens:

image_table(id, image)

onde id é um identificador e image é um atributo contendo uma imagem. 


\subsubsection{CBIR no SGBD IBM DB2}

O IBM DB2 Image Extender (IBM Corporation, 2003) é uma extensão oferecida para o DB2 Universal Database (UDB) que implementa as especificações do padrão StillImage em um tipo de dados proprietário denominado DB2Image. O DB2Image permite a realização de consultas por conteúdo indexadas, utilizando o QBIC (Flickner et al., 1995).

O QBIC capacita o DB2 a executar as consultas por similaridade $\mathrm{Rq}$ e $k$-NNq sobre o conteúdo de imagens. As características intrínsecas de imagens que podem ser consideradas nas buscas por conteúdo sobre um atributo do tipo imagem são: QbColorFeatureClass, QbColorHistogramFeatureClass, SI_ColorHistogram e QbDrawFeatureClass, todos baseados em cor; e QbTextureFeatureClass, baseado em textura.

As consultas por abrangência são representadas no DB2 utilizando uma UDF, denominada QbScoreFromStr, conforme exemplificado a seguir ${ }^{1}$ :

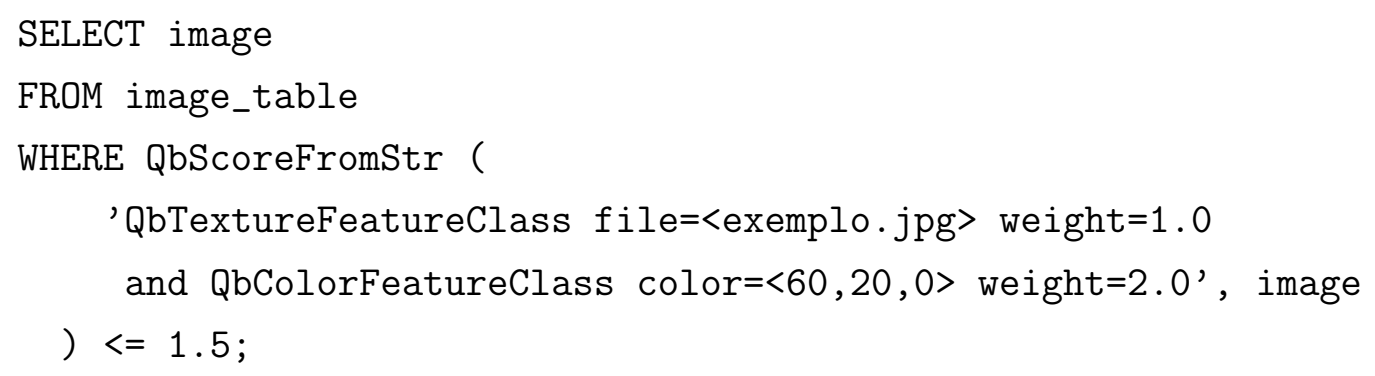

onde a string fornecida como primeiro parâmetro para a função QbScoreFromStr indica as características da avaliação de similaridade e o segundo parâmetro o nome do atributo do tipo imagem, e o limiar de abrangência estipulado é 1.5. Neste exemplo, a avaliação de similaridade compara a textura extraída de uma imagem de exemplo com as texturas das imagens armazenadas e a cor "média" das imagens armazenadas com uma cor especificada $(\mathrm{R}, \mathrm{G}, \mathrm{B})$, e retorna a similaridade final ponderando estas características com os pesos 1 e 2 , respectivamente. Observe que esse módulo não implementa a possibilidade de combinar características com or na avaliação de similaridade.

As $k$-NNq são representadas no DB2 utilizando outra UDF, denominada QbScoreTBFromStr, que gera uma tabela tabela temporária contendo as $k$ imagens mais similares considerando os critérios de fornecidos. A tabela resultante é formada por dois atributos: o identificador da imagem (IMAGE_ID) e a similaridade calculada (SCORE). Por exemplo:

\footnotetext{
${ }^{1}$ Os exemplos apresentados nesta seção usam uma sintaxe simplificada. As sintaxes completas podem ser encontradas nas referências respectivas.
} 


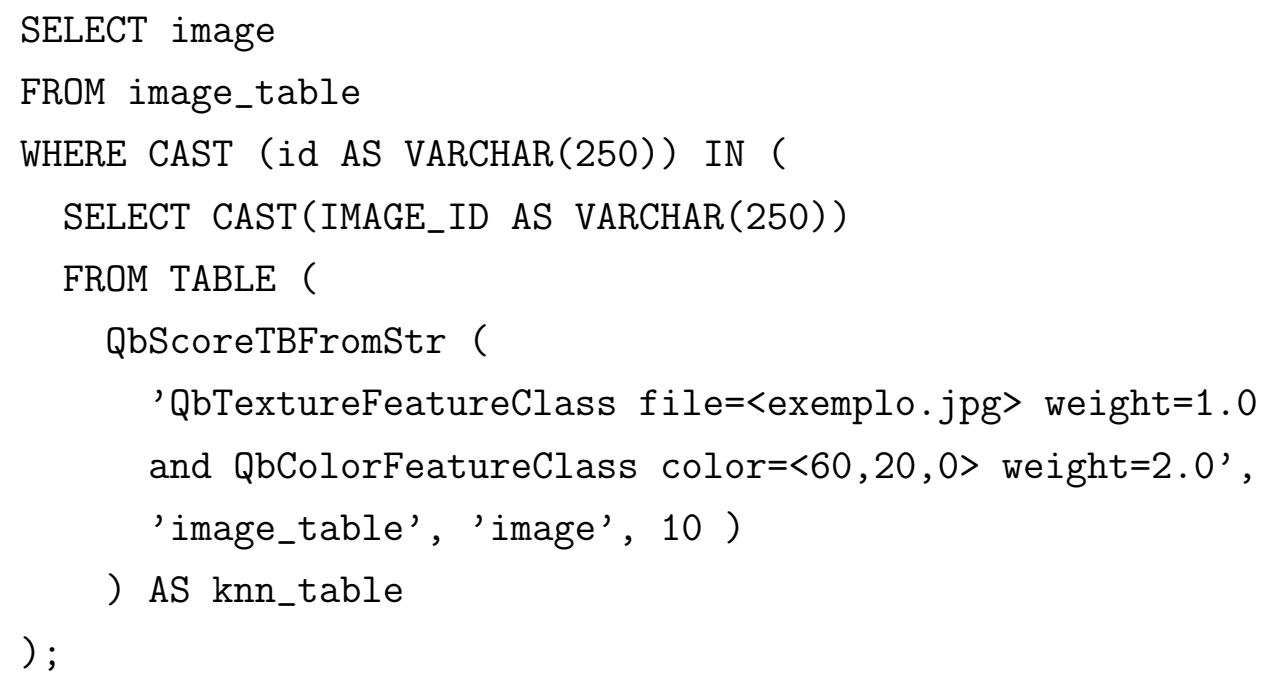

onde o primeiro parâmetro da função QbScoreTBFromStr é o critério de similaridade, o segundo é o nome da tabela, o terceiro o nome do atributo do tipo imagem, e o último parâmetro é o valor de $k$ (essa consulta é uma 10-NNq).

O QBIC utiliza $\mathrm{R}^{*}$-trees (Beckmann et al., 1990) para acelerar consultas por conteúdo, aplicando a transformada K-L (Karhunen-Loève tranformation) para obter os componentes principais do conjunto e gerar uma assinatura aproximada das imagens em um espaço de baixa dimensionalidade. Entretanto, as $k$-NNq são executadas isoladamente de outras operações no plano de consultas, portanto, a interação dessa operação com outras não é explorada no processo de otimização da consulta.

\subsubsection{CBIR no SGBD Oracle}

O Oracle Multimedia (Oracle Corporation, 2007b) é o módulo desenvolvido pela Oracle para suportar dados multimídia no seu gerenciador de banco de dados. O padrão StillImage é parcialmente implementado neste módulo, porém é pouco explorado. Por outro lado, o Oracle Multimedia provê o tipo de dados ORDImage, que suporta várias operações de manipulação de imagens utilizando como base a biblioteca JAI (Java Advanced Imaging $A P I)^{2}$.

As imagens médicas também receberam destaque nas versões mais recentes do Oracle Multimedia. Foi desenvolvido o módulo Oracle Multimedia DICOM, que inclui, dentre outras funcionalidades, um novo tipo de dados, denominado ORDDICOM, que encapsula um objeto ORDImage e atributos e funções para a manipulação de metadados DICOM (Oracle Corporation, 2007a). O padrão DICOM é bastante complexo e permite que os fabricantes definam tags proprietárias, tornando o gerenciamento de metadados DICOM em bancos de dados uma tarefa bastante trabalhosa. O Oracle Multimedia DICOM armazena os metadados do cabeçalho das imagens DICOM em XML, o que possibilita acomodar as

\footnotetext{
${ }^{2}$ http://java.sun.com/javase/technologies/desktop/media/jai/
} 
variações entre os metadados incluídos em imagens de diferentes modalidades e/ou geradas por diferentes equipamentos.

A busca por conteúdo em imagens é implementada por meio de funções proprietárias de extração de características do conteúdo de imagens para a geração de assinaturas. Ao contrário do DB2, no Oracle as assinaturas são armazenadas explicitamente em tabelas, encapsuladas no tipo ORDImageSignature. As funções mais importantes desse tipo são a ORDImageSignature.generateSignature, que gera uma assinatura para uma imagem de entrada, e a ORDImageSignature.evaluateScore, que recebe duas assinaturas de imagens e uma string definindo os parâmetros da avaliação de similaridade, e retorna a distância entre as assinaturas. As características consideradas na avaliação de similaridade podem ser ponderadas e incluem: cor, textura, forma e localização.

Com o Oracle Multimedia é possível executar Rq e $k$-NNq sobre imagens. Os exemplos a seguir consideram que o atributo image da tabela image_table é do tipo ORDImage e que a tabela também contém um atributo image_sign, do tipo ORDImageSignature, que armazena as assinaturas (vetores de características) das imagens.

A consulta a seguir ilustra como uma Rq pode ser escrita usando o Oracle Multimedia:

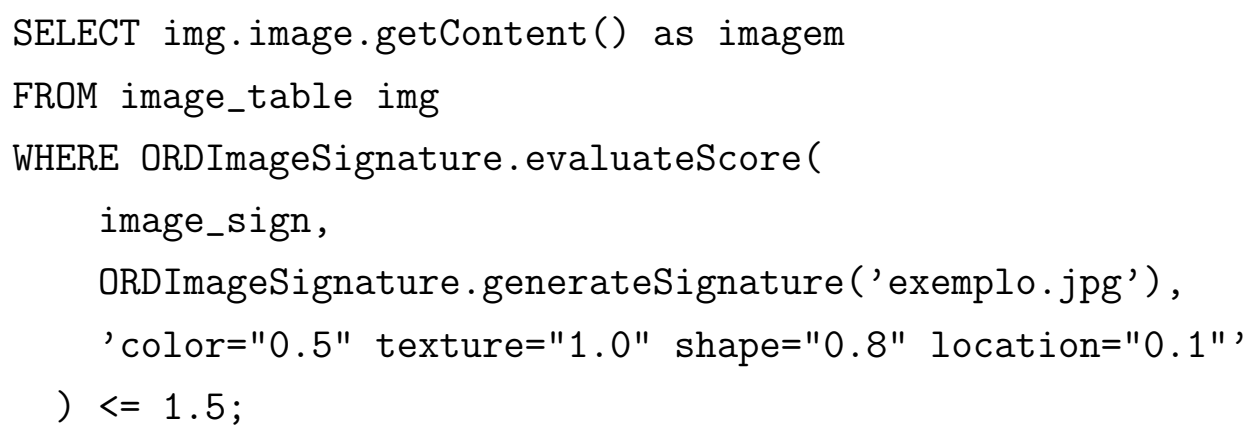

onde os parâmetros da função ORDImageSignature. evaluateScore são o nome do atributo que armazena as assinaturas das imagens, a assinatura de uma imagem de consulta (exemplo.jpg) e os pesos das características, e o limiar de dissimilaridade da Rq é 1.5.

Para acelerar o processamento da condição de busca por abrangência, o Oracle Multimedia dispõe de uma UDF específica, denominada IMGSimilar, que encapsula uma Rq e pode ser indexada utilizando um índice específico do tipo ORDImageIndex. O ORDImageIndex é formado por um conjunto de 64 índices bitmap que indexam assinaturas aproximadas das imagens, cuja intenção é fazer um filtragem inicial e reduzir ao máximo os cálculos de similaridade. A instrução a seguir cria um índice ORDImageIndex para acelerar as Rq:

\section{CREATE INDEX image_ix ON image_table(image_sign) \\ INDEXTYPE IS ORDImageIndex;}

Para que a consulta por abrangência utilize o índice criado, é preciso escrevê-la usando a função IMGSimilar, como segue: 


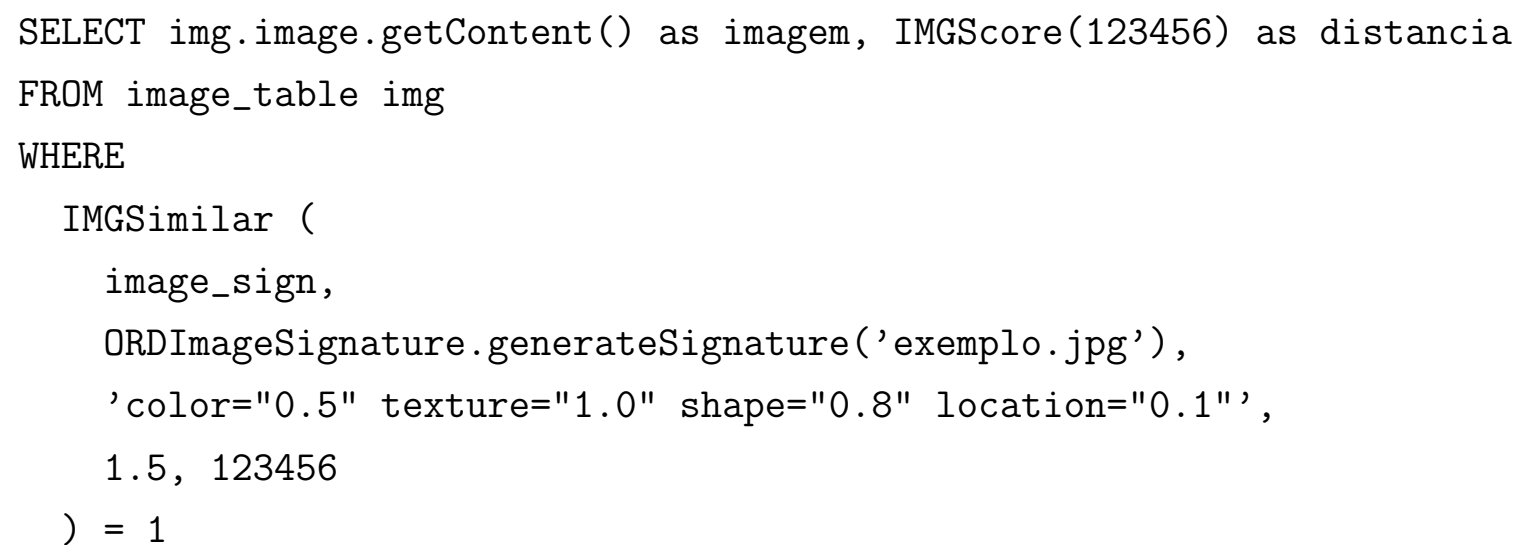

onde os primeiros parâmetros da função IMGSimilar são os mesmos da função ORDImageSignature.evaluateScore, e os dois últimos são o limiar de abrangência (1.5) e um identificador (123456), usado para associar as funções IMGSimilar e IMGScore. Uma função qualquer geralmente é executada duas vezes se for usada tanto na seleção quanto na projeção em uma consulta. Isso acontece com a função ORDImageSignature. evaluateScore. Como é comum o usuário solicitar que o resultado de uma busca por conteúdo inclua o valor de similaridade computado, a função IMGScore tem como objetivo retornar a similaridade calculada pela função IMGSimilar associada, evitando cálculos redundantes. O resultado da função IMGSimilar é comparado com o valor 1 (verdadeiro), seguindo a mesma sintaxe adotada para outras funções documentadas no padrão SQL/MM, como, por exemplo, a função Contains, usada para buscas em textos longos. Com estes recursos, o Oracle inclui a Rq no processo de otimização, porém, sempre que existir um índice ORDImageIndex ele é utilizado, o que indica que a previsão de seletividade não é adotada para a função IMGSimilar.

As $k$-NNq podem ser representadas no Oracle Multimedia utilizando funções de janela (window functions), incluídas no padrão SQL (ISO/IEC, 2003), conforme segue:

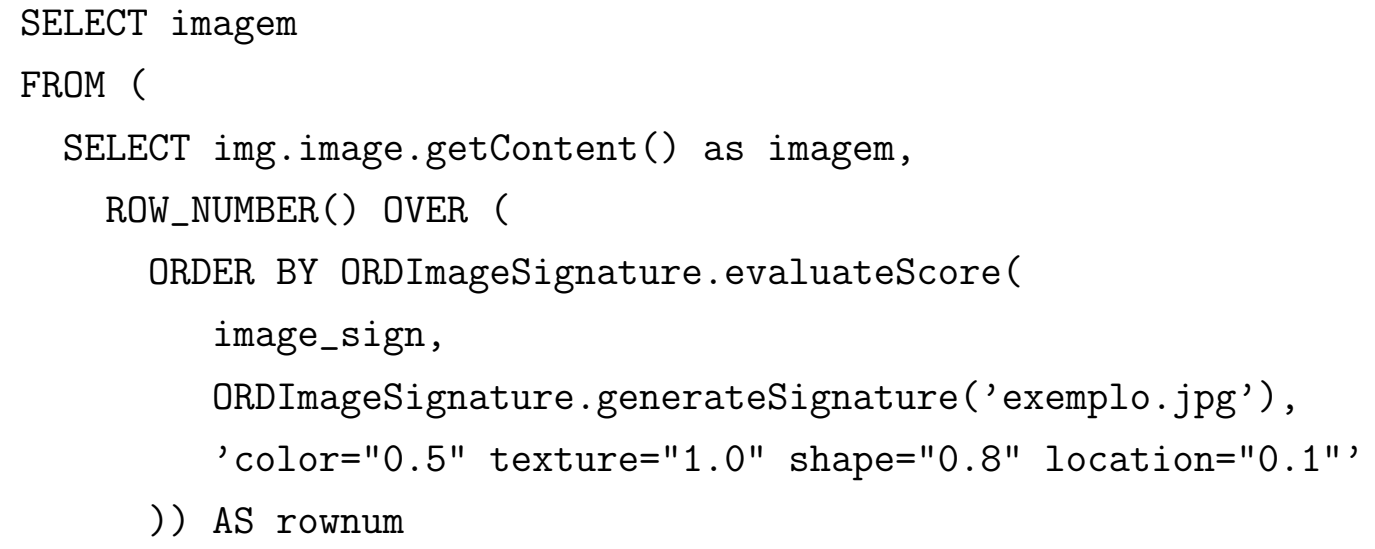

onde a função ROW_NUMBER atribui a um novo atributo a posição de cada tupla de acordo com a janela definida, que neste caso ordena as tuplas pela dissimilaridade entre a as- 
sinatura da imagem armazenada em cada tupla e a assinatura da imagem de consulta. Esse novo atributo é usado, então, para retornar apenas os $k$-vizinhos mais próximos. No Oracle, este tipo de consulta é sempre executado a partir de uma varredura sequencial da tabela de entrada. Entretanto, o otimizador detecta que o predicado de seleção da consulta externa (rownum $<=10$ ) pode ser usado para reduzir o custo da ordenação na definição da janela e executa a $k$-NNq em $O(n \cdot \log k)$ (Bellamkonda et al., 2003).

\subsubsection{Sistemas Acadêmicos de CBIR sobre SGBDs}

Além dos sistemas comerciais, existem sistemas acadêmicos que implementam extensões a SGBDs comerciais para realizar busca por conteúdo em imagens. Dois exemplos são o SIREN e o PostgreSQL-IE, descritos nesta subseção.

\section{SIREN}

O SIREN (Similarity Retrieval Engine) (Barioni et al., 2006) é um protótipo que implementa sobre os SGBDs Oracle e PostgreSQL um interpretador para uma extensão à linguagem SQL que permite a representação de consultas por similaridade, incluindo seleção e junção por similaridade.

O SIREN implementa um tipo de dados denominado StillImage, porém não aderente ao definido no SQL/MM. Este protótipo permite a associação de diversos extratores e funções de distância aos atributos de tipos complexos e agiliza as consultas através da indexação em métodos de acesso métricos. Ao contrário do Oracle Multimedia, o SIREN armazena os vetores de características extraídos das imagens em atributos em tabelas do catálogo do banco de dados, ocultando do usuário estes detalhes.

Uma Rq pode ser escrita no SIREN conforme exemplificado a seguir:

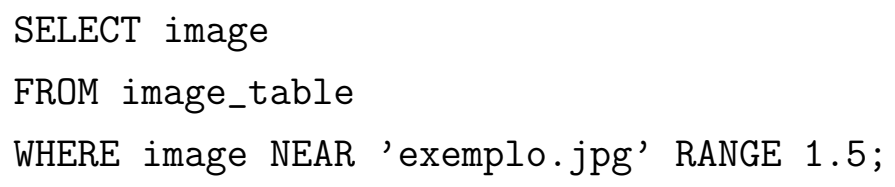

onde a palavra-chave NEAR indica que a consulta envolve operações por similaridade e a palavra-chave RANGE expressa uma Rq, com limiar de dissimilaridade 1.5. Observe que a representação de consultas no SIREN é bem mais simples do que nos SGBDs comerciais apresentados. Os extratores de características e as métricas utilizadas na análise de similaridade ficam associados ao tipo de dados definido para o atributo image. Desta forma, sua manipulação é transparente e não é necessário referenciá-los na consulta, pois o sistema detecta automaticamente esses detalhes na compilação da consulta.

Uma $k$-NNq pode ser representada no SIREN tal como a consulta que se segue: 
SELECT image

FROM image_table

WHERE image NEAR 'exemplo.jpg' STOP AFTER 10;

onde a palavra-chave STOP AFTER expressa uma $k$-NNq, com $k=10$ neste exemplo.

O SIREN executa tanto Rq quanto $k$-NNq fazendo uso de índices, de forma semelhante ao DB2. Entretanto, como o SIREN é uma camada de abstração sobre o SGBD que provê o suporte à consultas por similaridade, os operadores por similaridade não são tratados pelo otimizador de consultas do gerenciador. Contudo, é possível incluir estratégias de otimização envolvendo as operações por similaridade, antes de repassar o controle ao SGBD.

\section{PostgreSQL-IE}

O PostgreSQL-IE (PostgreSQL with Image-handling Extension) (Guliato et al., 2008) é um protótipo de extensão ao SGBD PostgreSQL, composto por um conjunto de UDFs para a extração de características e outro conjunto para a execução de consultas envolvendo seleção por similaridade.

O PostgreSQL-IE encapsula as imagens em um novo tipo de dados, o PGImage, que não é aderente ao padrão SQL/MM. As buscas por similaridade são implementadas em UDFs que são referenciadas como subconsultas. Essa abordagem é utilizada apenas pelo fato do PostgreSQL permitir invocar funções que podem retornar vários valores ou tuplas apenas na cláusula FROM.

Uma Rq pode ser expressa no PostgreSQL-IE como no exemplo a seguir:

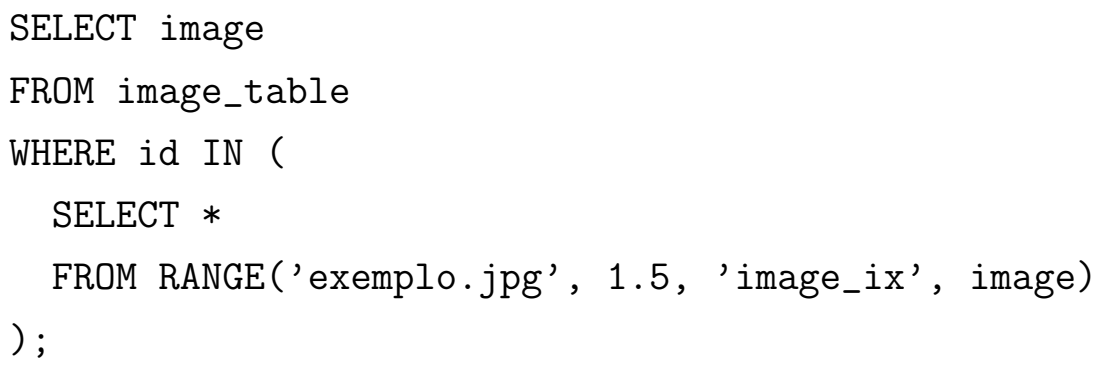

onde a função RANGE recebe como parâmetros a imagem de consulta, o limiar de dissimilaridade (1.5), o nome do índice previamente criado para indexar o conteúdo da imagem (image_ix) e o nome do atributo do tipo imagem (image). A função de distância e o extrator de características utilizado na avaliação de similaridade estão implícitos no índice fornecido na consulta.

De forma semelhante, uma $k$-NNq pode ser escrita conforme segue: 


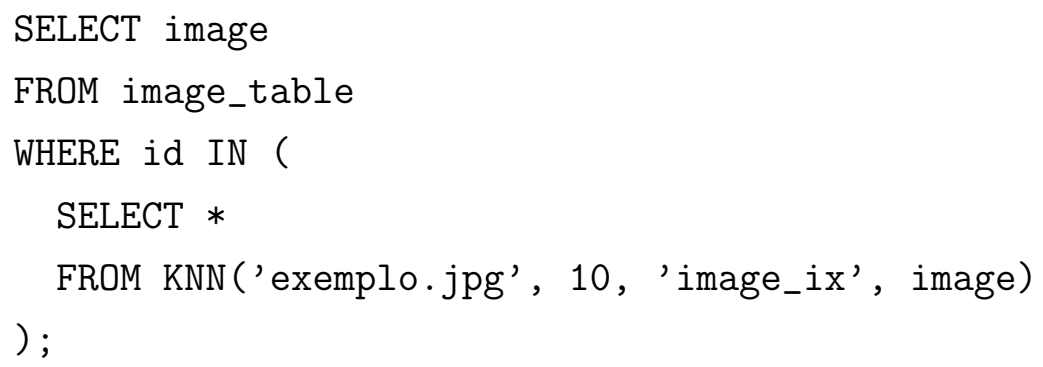

onde a diferença para a $\mathrm{Rq}$ é o que na $k$-NNq é fornecido o valor de $k(10)$.

Embora neste protótipo as consultas $\mathrm{Rq}$ e $k$-NNq também sejam executadas sobre índices métricos, ao contrário do SIREN, a arquitetura do PostgreSQL-IE não possibilita qualquer tipo de otimização de consultas sem recodificar o módulo otimizador do PostgreSQL.

\subsection{Considerações Finais}

Neste capítulo foi apresentada uma revisão das abordagens algébricas para representação de consultas por similaridade encontradas na literatura e a representação dos principais tipos de consultas por similaridade usando uma notação de álgebra relacional estendida para tratar operadores por similaridade. Também foram apresentados os principais algoritmos para execução de seleções por similaridade em métodos de acesso métricos, que são atualmente as estruturas mais adequadas para indexar dados complexos/multimídia. Por fim, este capítulo descreveu o suporte a CBIR oferecido por SGBDs comerciais e pelos principais sistemas acadêmicos de CBIR integrados a SGBDs, bem como suas limitações. Neste ponto, vale ressaltar que a partir da versão 9.1 do DB2, as extensões de audio, imagem e vídeo (Audio, Image, and Video (AIV) Extenders) não são mais suportadas e a implementação de funcionalidades para a manipulação desses tipos de dados passou a ser responsabilidade do usuário, a partir de UDTs/UDFs e de softwares de terceiros. Da mesma forma, a recuperação de imagens por conteúdo foi descontinuada na versão 11.1 do Oracle, embora os tipos de dados e funções usadas para esse fim ainda estejam disponíveis. Estas decisões podem ser explicadas pela dependência entre as aplicações de CBIR e os domínios específicos das imagens em questão. As abordagens generalistas não têm alcançado bons resultados e percebe-se que ainda há muito pesquisa a se fazer na área de CBIR, incluindo o processamento de consultas por similaridade antes que esse suporte genérico possa ser oferecido em um SGBD comercial.

O próximo capítulo apresenta um novo tipo de consulta por similaridade: a consulta aos vizinhos mais próximos estendida com condições. Este tipo de consulta permite acrescentar à consulta aos $k$-vizinhos mais próximos uma condição adicional, possibilitando responder a consultas até então não representáveis utilizando os operadores baseados em similaridade existentes. Juntamente com a definição desta consulta, são apresentados sua 
representação algébrica, regras de equivalência úteis para otimização de consultas envolvendo esta operação, os principais algoritmos para executar consultas $k$-NN estendidas com condições e experimentos avaliando o desempenho destes algoritmos. 


\section{Capítulo \\ 4 \\ Consulta aos Vizinhos mais Próximos com Condições}

Conforme visto nos capítulos anteriores, a consulta aos $k$-vizinhos mais próximos é uma das consultas por similaridade mais frequentemente utilizadas em aplicações sobre dados complexos. Entretanto, o número reduzido de propriedades algébricas envolvendo essa operação dificulta que o processador de consulta de um SGBDR possa integrá-la às demais operações de uma maneira otimizada. Desta forma, a busca aos vizinhos mais próximos limita-se a uma operação com pouca mobilidade no plano de execução. Além disso, existe uma variedade de consultas incluindo variações da busca aos vizinhos mais próximos que não são representáveis usando o operador de consulta $k$-NNq básico.

Este capítulo apresenta uma proposta de extensão do operador $k$-NNq incluindo condições adicionais que o resultado da busca deve satisfazer (Kaster et al., 2011b). Com isso, torna-se possível incorporar diversas condições da consulta em um único operador, as quais teoricamente deveriam ser representadas por diversos operadores algébricos. Seguindo a abordagem proposta, a otimização das consultas passa a poder ser feita internamente ao operador, o que leva a um efeito, no mínimo, tão eficiente quanto ao que poderia ser conseguido pela otimização pela reescrita de operadores elementares, além de permitir também uma grande integração dos algoritmos que executam as operações codificadas nesse operador único. A Seção 4.1 define a consulta aos vizinhos mais próximos com condições. A Seção 4.2 apresenta os tipos de condições aceitos por esta consulta e a Seção 4.3 apresenta as principais regras algébricas válidas para o operador proposto. Por fim, a Seção 4.4 mostra os algoritmos desenvolvidos para executar ${ }_{c} k$-NNq considerando 
tipos diferentes de condições e a Seção 4.5 apresenta resultados de experimentos realizados para avaliar os algoritmos propostos.

\subsection{Definição da Consulta}

A consulta aos $k$-vizinhos mais próximos pode ser estendida para incluir condições adicionais modificando a busca. Esta tese propõe uma nova operação de busca por similaridade que estende o operador $k$-NN básico, denominada consulta aos $k$-vizinhos mais próximos estendida com condições (condition-extended $k$-NN query $-{ }_{c} k$-NNq). Uma ${ }_{c} k$-NNq é uma busca exata que recupera os $k$ elementos mais próximos ao elemento de referência que satisfaçam a condição adicional $c$ fornecida.

Esta tese propõe representar algebricamente as consultas aos $k$-vizinhos mais próximos estendidas com condições de forma semelhante às $k$-NNq, também utilizando a operação de seleção por similaridade $(\ddot{\sigma})$. Contudo, para representar uma ${ }_{c} k$-NNq, o predicado da seleção por similaridade utiliza um novo operador por similaridade, denotado por ${ }_{c} k \mathrm{NN}$, que além da função de distância e do número de vizinhos a ser retornado, aceita uma condição envolvendo atributos da relação de entrada. Desta forma, uma consulta aos $k$-vizinhos mais próximos estendida com condições é representada conforme segue:

$$
\ddot{\sigma}_{S_{j} k \mathrm{NN}[\delta, \Delta, k, \text { cond }] Q}(R)
$$

onde $S_{j}$ é um atributo da relação de entrada $R$, cujo domínio é $\mathbb{S}, Q \subseteq \mathbb{S}$ é um conjunto de elementos de referência e ${ }_{c} k \mathrm{NN}[\delta, \Delta, k$, cond $]$ é o operador ${ }_{c} k$-NN, sendo que $\delta$ é uma função de distância definida sobre $\mathbb{S}, \Delta$ é uma função agregadora de distâncias, $k$ é o número de vizinhos e cond é a condição restringindo a busca. Se $Q$ é um conjunto unitário, contendo apenas um elemento $s_{q}$, ele pode ser denotado no predicado da $\ddot{\sigma}$ como $\left\{s_{q}\right\}$ ou, simplesmente, $s_{q}$. Além disso, neste caso, a função agregadora de distâncias pode ser omitida, assumindo-se que $\Delta$ é uma soma simples das distâncias que irá retornar o próprio valor $\delta\left(s, s_{q}\right)$, onde $s \in S_{j}$.

De uma forma geral, uma $k-\mathrm{NNq}$ tradicional pode ser resolvida ordenando os elementos armazenados de acordo com sua dissimilaridade ao elemento de referência e retornando os $k$ primeiros elementos desta lista. Seguindo o mesmo raciocínio, uma ${ }_{c} k$-NNq pode ser resolvida também ordenando os elementos armazenados, mas retornando os $k$ primeiros elementos que satisfaçam a condição adicional, que não necessariamente serão os $k$ primeiros da lista. Para definir formalmente o significado de uma ${ }_{c} k$-NNq, a seguir são apresentadas as definições necessárias, onde $\mathbb{S}$ é um domínio de dados complexos, $S \subseteq \mathbb{S}$ é um conjunto de elementos, $\delta$ é uma função de distância, $\Delta$ é uma função agregadora de distâncias, $Q \subseteq \mathbb{S}$ é um conjunto não vazio de elementos de referência e $c$ é uma condição definida sobre os elementos de $\mathbb{S}$. 
Definição 4.1 Um valor de dissimilaridade $v^{\Delta_{\delta}, Q}$ de um elemento $s \in \mathbb{S}$ é dado pela agregação das distâncias $\delta$ entre este elemento e os elementos do conjunto de elementos de referência $Q$, considerando uma função agregadora de distâncias $\Delta$. Isto é: s. $v^{\Delta_{\delta}, Q}=\Delta(s, Q)$, onde a distância entre o elemento $s$ e cada elemento de consulta $s_{q} \in Q$ é dada por $\delta\left(s, s_{q}\right)$.

Desta forma, um mesmo elemento pode ter vários valores de dissimilaridade, com diferentes instanciações de $\delta, \Delta$ e/ou $Q$. As definições a seguir são baseadas na noção de valor de dissimilaridade.

Definição 4.2 Um conjunto induzido por dissimilaridade $S^{\Delta_{\delta}, Q}$ é um conjunto formado por elementos sob a forma $s^{\prime}=\left\langle s, s . v^{\Delta_{\delta}, Q}\right\rangle$, onde $s$ é cada elemento de $S$ e $s . v^{\Delta_{\delta}, Q}$ é o valor de dissimilaridade do elemento s com relação a $\delta, \Delta$ e $Q$, sendo que $\left|S^{\Delta_{\delta}, Q}\right|=|S|$. Diz-se que $S^{\Delta_{\delta}, Q}$ é um conjunto por dissimilaridade induzido sobre $S$ por $\delta, \Delta$ e $Q$.

Definição 4.3 A dissimilaridade total de um conjunto induzido por dissimilaridade $S^{\Delta_{\delta}, Q}$ é o somatório dos valores de dissimilaridade dos seus elementos, ou seja:

$$
\text { dissimilaridade total }\left(S^{\Delta_{\delta}, Q}\right)=\sum_{s \in S^{\Delta_{\delta}, Q}} s \cdot v^{\Delta_{\delta}, Q}
$$

Se o conjunto de elementos de referência é unitário, por exemplo $Q=\left\{s_{q}\right\}$, podese omitir a função agregadora de distâncias, assumindo-se que é uma soma simples das distâncias, e denotar o conjunto induzido por dissimilaridade como $S^{\delta,\left\{s_{q}\right\}}$ ou, simplesmente, $S^{\delta, s_{q}}$. Para ilustrar o significado dessas definições será apresentado um exemplo. Seja $S$ o conjunto CidadesAmericanas apresentado na Figura 4.1, cujos elementos são cidades dos Estados Unidos. Os atributos de cada elemento deste conjunto são, respectivamente: o nome da cidade, o estado em que se localiza, sua população e suas coordenadas geográficas (latitude e longitude, delimitadas por colchetes). O conjunto $S^{L_{2}, \text { Bristol city }}$, mostrado na Figura 4.2, é o conjunto induzido sobre $S$ pela distância $L_{2}$ entre as coordenadas geográficas dos elementos e pelo elemento de referência Bristol city. Observe-se que a função agregadora de distâncias foi omitida neste caso, pois o conjunto de elementos de referência é unitário. O último atributo dos elementos do conjunto da Figura 4.2 é o valor de dissimilaridade dos elementos, com relação à distância $L_{2}$ e ao elemento de referência. A dissimilaridade total do conjunto induzido por dissimilaridade $S^{L_{2}, \text { Bristol city é }}$ 6.977401, que é a soma dos valores de dissimilaridade dos elementos do conjunto. Note-se que o elemento $s_{q}$ não precisa fazer parte do conjunto $S$, mas apenas pertencer ao domínio $\mathbb{S}$. No exemplo, como Bristol City faz parte do conjunto, seu valor de dissimilaridade é zero.

A definição a seguir estabelece um tipo particular de conjunto induzido por dissimilaridade, restrito por uma condição envolvendo atributos dos seus elementos. 


$$
\begin{aligned}
& S=\{\quad\langle\text { Wellford city, SC, 2030, [34, 9511, -82.0985]〉, } \\
& \text { 〈Nickelsville town, VA, 448, [36, 7519, -82.417]〉, } \\
& \text { 〈Forest Hills village, NC, 330, [35, 2972, -83.1937]〉, } \\
& \text { 〈Bristol city, VA, 17367, [36.6111, -82.1762]〉, } \\
& \langle\text { Bluff City city, TN, 1559, [36.4634, -82.275]〉, } \\
& \text { 〈Watauga city, TN, 403, [36.3673, -82.2913, 0.269604]〉, } \\
& \text { 〈Mooresville town, NC, 18823, [35.5843, -80.8201]〉, } \\
& \text { 〈Black Mountain town, NC, 7511, [35.6192, -82.3254]), } \\
& \text { 〈Abingdon town, VA, 7780, [36.7098, -81.9757]〉 \} }
\end{aligned}
$$

Figura 4.1: Conjunto CidadesAmericanas.

$$
\begin{aligned}
& S^{L_{2}, \text { Bristol city }}=\{\quad\langle\text { Wellford city, SC, 2030, [34, 9511, -82.0985], 1.66182〉, } \\
& \text { 〈Nickelsville town, VA, 448, [36, 7519, -82.417], 0.278942〉, } \\
& \text { 〈Forest Hills village, NC, 330, [35, 2972, -83.1937], 1.66182〉, } \\
& \langle\text { Bristol city, VA, 17367, [36.6111, -82.1762], 0〉, } \\
& \text { 〈Bluff City city, TN, 1559, [36.4634, -82.275], 0.177697〉, } \\
& \text { 〈Watauga city, TN, 403, [36.3673, -82.2913], 0.269604), } \\
& \text { 〈Mooresville town, NC, 18823, [35.5843, -80.8201], 1.70098〉, } \\
& \text { 〈Black Mountain town, NC, 7511, [35.6192, -82.3254], 1.00306〉, } \\
& \text { 〈Abingdon town, VA, 7780, [36.7098, -81.9757], 0.223478〉\} }
\end{aligned}
$$

Figura 4.2: Conjunto induzido sobre o conjunto de cidades americanas pela distância $L_{2}$ e pelo elemento de referência Bristol city.

Definição 4.4 Um conjunto restrito induzido por dissimilaridade $S_{c}^{\Delta_{\delta}, Q}$ é um subconjunto do conjunto induzido por similaridade $S^{\Delta_{\delta}, Q}$, tal que a condição c é satisfeita pelos elementos em $S_{c}^{\Delta_{\delta}, Q}$. Diz-se que $S_{c}^{\Delta_{\delta}, Q}$ é um conjunto por dissimilaridade restrito por $c e$ induzido sobre $S$ por $\delta, \Delta$ e $Q$.

Por exemplo, considere a condição $c=\left\langle\right.$ estado $\neq$ ' $\left.V A^{\prime}\right\rangle$, que é satisfeita pelas cidades que não pertencem ao estado da Virgínia. Um conjunto restrito por $c$ e induzido sobre o conjunto de cidades americanas por $L_{2}$ e pelo elemento de referência Bristol city é apresentado na Figura 4.3. A condição $\langle e s t a d o \neq ' V A$ ' $\rangle$ aplicada ao conjunto $S^{L_{2}, \text { Bristol city }}$ gera um único conjunto restrito induzido por dissimilaridade. Entretanto, outros tipos de condição (vide Seção 4.2) podem possibilitar a existência de vários conjuntos restritos diferentes a partir de um mesmo conjunto induzido por dissimilaridade.

Observando-se as duas definições 4.2 e 4.4, percebe-se que a Definição 4.2 é um caso particular da Definição 4.4, quando a condição $c$ é nula. As definições a seguir restringem 


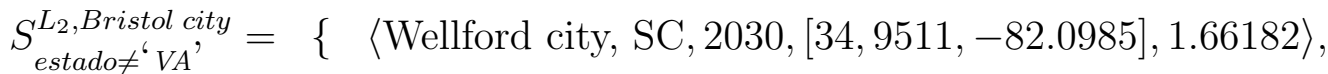

$$
\begin{aligned}
& \text { 〈Forest Hills village, NC, 330, [35, 2972, -83.1937], 1.66182〉, } \\
& \text { 〈Bluff City city, TN, 1559, [36.4634, -82.275], 0.177697〉, } \\
& \text { 〈Watauga city, TN, 403, [36.3673, -82.2913], 0.269604〉, } \\
& \text { 〈Mooresville town, NC, 18823, [35.5843, -80.8201], 1.70098〉, } \\
& \text { 〈Black Mountain town, NC, 7511, [35.6192, -82.3254], 1.00306〉\} }
\end{aligned}
$$

Figura 4.3: Conjunto restrito pela condição $\left\langle\right.$ estado $\neq \neq^{\prime} V A$ ' $\rangle$ e induzido sobre o conjunto de cidades americanas pela distância $L_{2}$ e pela referência Bristol city.

a noção de conjunto induzido por dissimilaridade com relação à quantidade de elementos e à dissimilaridade total do conjunto.

Definição 4.5 Um k-conjunto restrito induzido por dissimilaridade $S_{c, k}^{\Delta_{\delta}, Q}$ é um conjunto por dissimilaridade restrito por c e induzido sobre $S$ por $\delta, \Delta$ e $Q$ contendo $k$ elementos.

Definição 4.6 Um k-conjunto minimal por soma restrito induzido por dissimilaridade $\bar{S}_{c, k}^{\Delta_{\delta}, Q}$ é um k-conjunto por dissimilaridade restrito por c e induzido sobre $S$ por $\delta, \Delta$ e $Q$ cuja dissimilaridade total é minimal entre todos os $k$-conjuntos por dissimilaridade restritos por c e induzidos sobre $S$ por $\delta, \Delta e Q$.

Além da minimalidade por soma, há outras opções de minimização de um $k$-conjunto restrito induzido por similaridade, que serão apresentadas na Seção 4.2.2. Em geral, existem vários $k$-conjuntos restritos pela mesma condição $c$ e induzidos por dissimilaridade sobre um mesmo conjunto $S$ por uma distância $\delta$ e um conjunto de elementos $Q$. Além disso, mais de um desses conjuntos pode ser minimal. Retomando o exemplo, a Figura 4.4 mostra um $k$-conjunto minimal por soma, $k=4$, restrito pela condição $\langle$ estado $\neq$ 'VA' $\rangle$ e induzido sobre o conjunto de cidades americanas por $L_{2}$ e pelo elemento de referência Bristol city.

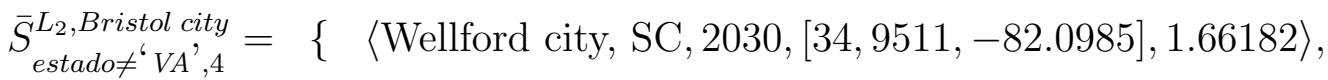

$$
\begin{aligned}
& \text { 〈Bluff City city, TN, 1559, [36.4634, -82.275], 0.177697〉, } \\
& \text { 〈Watauga city, TN, 403, [36.3673, -82.2913], 0.269604〉, } \\
& \text { 〈Black Mountain town, NC, 7511, [35.6192, -82.3254], 1.00306〉\} }
\end{aligned}
$$

Figura 4.4: Exemplo de um $k$-conjunto minimal por soma restrito induzido por similaridade $\bar{S}_{c, k}^{\delta, Q}$, onde $\delta=L_{2}, Q=\{$ Bristol city $\}, c=\left\langle\right.$ estado $\neq$ ' $\left.V A^{\prime}\right\rangle \mathrm{e}$ $k=4$.

Seja uma consulta $\ddot{\sigma}_{S_{j} k \mathrm{NN}[\delta, \Delta, k, c o n d]} Q(R)$, onde $S_{j}$ é um atributo complexo da relação $R$, cujo domínio é $\mathbb{S}$, e $Q \subseteq \mathbb{S}$ é o conjunto de elementos de referência. Com base nas 
definições apresentadas, o resultado desta consulta é uma relação $R^{\prime}$ tal que os valores de $S_{j}$ nas tuplas de $R^{\prime}$ formam um $k$-conjunto minimal restrito induzido por dissimilaridade $S_{\text {cond,k }}^{\Delta_{\delta}, Q}$, onde $S$ é o conjunto formado pelos valores de $S_{j}$ nas tuplas de $R$ e a opção de minimização é indiferente. Caso a condição cond seja nula, a ${ }_{c} k$-NNq torna-se uma $k$-NNq regular, cujo conjunto resposta é dado por $S_{k}^{\Delta_{\delta}, Q}$. Note que podem existir vários $k$-conjuntos minimais por soma restritos induzidos por dissimilaridade que definem corretamente o resultado de uma ${ }_{c} k-\mathrm{NNq}$ (ou de uma $k$-NNq). Essa propriedade é garantida pelo Teorema 4.1.

Teorema 4.1 Dois $k$-conjuntos minimais restritos induzidos por dissimilaridade distintos, $S_{1 c, k}^{\Delta_{\delta}, Q}$ e $S_{2 c, k}^{\Delta_{\delta}, Q}$, diferem apenas por elementos cujo valor de dissimilaridade é igual e maximal dentre os valores de dissimilaridade dos elementos de ambos os conjuntos.

Prova Se $S_{1 c, k}^{\Delta_{\delta}, Q}$ e $S_{2 c, k}^{\Delta_{\delta}, Q}$ são $k$-conjuntos minimais restritos induzidos por dissimilaridade distintos, existe, ao menos, um elemento $s_{1} \in\left(S_{1 c, k}^{\Delta_{\delta}, Q}-S_{2 c, k}^{\Delta_{\delta}, Q}\right)$ e um elemento $s_{2} \in\left(S_{2 c, k}^{\Delta_{\delta}, Q}-S_{1 c, k}^{\Delta_{\delta}, Q}\right)$, portanto $s_{1} \neq s_{2}$. Pela Definição 4.6, o valor de dissimilaridade $s_{1} \cdot v^{\Delta_{\delta}, Q}$ é menor ou igual ao valor de dissimilaridade $s \cdot v^{\Delta_{\delta}, Q}, \forall s \in\left(S_{c}^{\Delta_{\delta}, Q}-S_{1 c, k}^{\Delta_{\delta}, Q}\right)$, caso contrário a dissimilaridade total de $S_{1 c, k}^{\Delta_{\delta}, Q}$ não seria minimal. Isso implica que $s_{1} \cdot v^{\Delta_{\delta}, Q} \leq s_{2} \cdot v^{\Delta_{\delta}, Q}$, pois $s_{2} \in\left(S_{c}^{\Delta_{\delta}, Q}-S_{1 c, k}^{\Delta_{\delta}, Q}\right)$. Entretanto, $s_{1} \cdot v^{\Delta_{\delta}, Q}$ não pode ser menor que $s_{2} \cdot v^{\Delta_{\delta}, Q}$, ou $s_{1}$ poderia substituir $s_{2}$ em $S_{2 c, k}^{\Delta_{\delta}, Q}$, reduzindo a dissimilaridade total do conjunto, o que contrariaria a afirmação de que $S_{2 c, k}^{\Delta_{\delta}, Q}$ é minimal. Portanto, tem-se que $s_{1} \cdot v^{\Delta_{\delta}, Q}=s_{2} \cdot v^{\Delta_{\delta}, Q}$. Além disso, não pode haver um elemento $s_{1}^{\prime} \in S_{1 c, k}^{\Delta_{\delta}, Q}, s_{1}^{\prime} \neq s_{1}$, tal que $s_{1}^{\prime} \cdot v^{\Delta_{\delta}, Q}>s_{1} \cdot v^{\Delta_{\delta}, Q}$, ou $s_{2}$ poderia substituir $s_{1}^{\prime}$ em $S_{1 c, k}^{\Delta_{\delta}, Q}$, reduzindo a dissimilaridade total do conjunto e contrariando a afirmação de que este conjunto é minimal. Isto garante que o valor de dissimilaridade de $s_{1}$ é maximal dentre os valores de dissimilaridade dos elementos de $S_{1 c, k}^{\Delta_{\delta}, Q}$. Fazendo a mesma análise com relação a $s_{2}$, conclui-se que $s_{2} \cdot v^{\Delta_{\delta}, Q}$ é maximal dentre os valores de dissimilaridade dos elementos de $S_{2 c, k}^{\Delta_{\delta}, Q}$.

Em termos de consultas ${ }_{c} k$-NN, o Teorema 4.1 indica que uma ${ }_{c} k$-NNq pode ter múltiplas respostas corretas e que todos os elementos que diferenciam estas respostas têm distâncias iguais ao conjunto de elementos de referência. Por exemplo, considere a consulta a seguir:

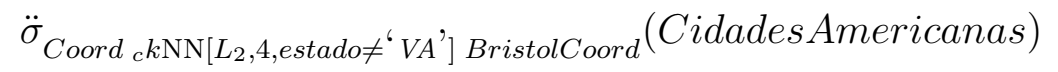

onde Coord é o atributo complexo que armazena as coordenadas geográficas das cidades, CidadesAmericanas é uma relação que contém os elementos do conjunto de cidades americanas e BristolCoord é uma constante que contém as coordenadas de Bristol city.

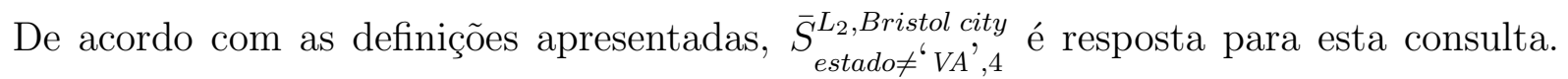
Um exemplo deste conjunto foi apresentado na Figura 4.4, cuja dissimilaridade total é 3.112181. Outro exemplo deste conjunto seria dado pela troca do elemento Wellford city 
pelo elemento Forest Hills village, mantendo a dissimilaridade total do conjunto, pois os valores de dissimilaridade destes elementos são iguais e maximais dentre todos os elementos do conjunto (observe-se o valor do último atributo destes elementos nas figuras 4.2 ou 4.3). Este segundo exemplo do conjunto $\bar{S}_{\text {estado } \neq^{6} V A^{\prime}, 4}^{L_{2}, B r i s t a t y}$ também é uma resposta correta à consulta apresentada.

A escolha de uma resposta correta em detrimento de outra geralmente é arbitrária. Uma alternativa para eliminar esta arbitrariedade seria fazer a união de todos os $k$ conjuntos minimais restritos induzidos por similaridade que respondem à consulta em um único conjunto resposta, contendo mais do que $k$ elementos. Entretanto, esta alternativa nem sempre é viável, pois, dependendo do tipo de condição fornecida à ${ }_{c} k$-NNq, a união dos conjuntos pode levar à violação da condição, gerando uma resposta inválida. Além disso, a possibilidade da existência de mais de uma resposta correta depende da cardinalidade do domínio do atributo. Para muitos domínios complexos, tais como características extraídas de dados multimídia, a chance de empates tende a ser pequena. Assim, esta alternativa não é tratada nesta tese.

\subsection{Tipos de Condições Aplicáveis a Consultas aos Vizi- nhos mais Próximos}

A condição indicada em um operador ${ }_{c} k$-NN pode ser nula ou pode ser uma condição (ou composição de condições) envolvendo atributos da relação de entrada. Se a condição for nula, assume-se que ela é avaliada como verdadeira para qualquer tupla, fazendo com que a ${ }_{c} k$-NNq recaia em uma $k$-NNq regular. Assim, o parâmetro cond pode ser omitido no operador ${ }_{c} k$-NN. Caso especificada, a condição cond pode ser baseada em tupla ou baseada em agregação, ou ainda pode ser uma composição destas condições. Esses tipos de condição são definidos a seguir. A Tabela 4.1 mostra os esquemas das relações usadas nos exemplos apresentados neste capítulo e suas descrições.

\section{Esquema e descrição}

CidadesAmericanas (nome, estado, pop, coord)

Cidades dos Estados Unidos: nome, estado, população e coordenadas geográficas das cidades

Hoteis(nome, numEstrelas, coord)

Hotéis: nome, número de estrelas (categoria) e coordenadas geográficas

Exames(idPaciente, idade, idImagem, imagem, idEstudo)

Imagens de exames médicos: identificador do paciente, idade do paciente, identificador da imagem, imagem e identificador do estudo do qual a imagem faz parte

PontosTuristicos(nome, categoria, taxaAcesso, tempo Visita, coord)

Pontos turísticos: nome do ponto turístico, categoria (museu, edificação, etc.), valor da taxa de acesso, tempo médio de visita e coordenadas geográficas

Tabela 4.1: Relações usadas nos exemplos do Capítulo 4. 
Definição 4.7 Uma condição baseada em tupla (tcond) é uma condição que pode ser verificada analisando-se individualmente cada elemento de um dominio de dados complexos. Em termos relacionais, é uma condição que pode ser verificada individualmente para cada tupla da relação de entrada, analisando-se apenas dados disponíveis na tupla.

De acordo com a Definição 4.7, termos comumente usados em predicados de seleção tradicional são condições baseadas em tupla. Por exemplo, $\langle$ estado $\neq$ ' $V A$ ' $\rangle$ e $\langle p o p \geq 5.000\rangle$ são tconds, considerando a relação CidadesAmericanas, pois podem ser avaliadas acessando cada tupla da relação de entrada individualmente. Há outros tipos de condição que não podem ser verificadas analisando tuplas individualmente. Tais condições dependem de um conjunto de tuplas para serem verificadas/satisfeitas. Um tipo de condição definida sobre o conjunto de tuplas que forma a relação resultante de uma ${ }_{c} k$-NNq são as condições baseadas em agregação, definidas a seguir.

Definição 4.8 Uma condição baseada em agregação (acond) é uma condição que inclui uma função de agregação filtrada, cujo valor é definido analisando-se em grupo todos os elementos de um domínio complexo que formam um conjunto induzido por similaridade restrito por esta condição. Em termos relacionais, é uma condição que só pode ser verificada agregando-se todos os elementos que formam a resposta de uma ${ }_{c} k-N N q$. As condiçôes baseadas em agregação têm a seguinte forma geral:

$$
f(\text { agAtr, min-op, tcond }) \theta c
$$

onde $f$ é o nome da função de agregação, agAtr é o atributo da relação de entrada utilizado no cálculo da função, min-op é a opção de minimização adotada, e tcond é uma condição baseada em tupla, opcionalmente utilizada para filtrar que tuplas devem ser consideradas na função de agregação, $\theta$ é um operador de comparação $\{=, \neq,<, \leq, \geq,>\}$ e c é um valor válido no contradomínio da função de agregação.

A Definição 4.8 indica que a função de agregação de uma acond é definida sobre o resultado da própria consulta aos $k$-vizinhos mais próximos estendida com condições. Além disso, o significado de uma acond depende da função de agregação adotada. As subseções que se seguem detalham aconds baseadas nas funções de agregação COUNT, SUM, AVG, MIN, MAX. Entretanto, a Definição 4.8 permite considerar também outras funções de agregação.

\subsubsection{Condições Baseadas em Agregação por Contagem}

Uma condição baseada em agregação por contagem, ou c-acond, é uma acond do tipo $\langle$ COUNT $(a g A t r, t c o n d) \theta c\rangle$ que garante que a quantidade de tuplas que satisfazem a condição tcond, e cujo valor do atributo agAtr não é nulo, seja $\theta c$. Note-se que a opção 
de minimização (parâmetro min-op da forma geral das condições baseadas em agregação) é omitida nas condições baseadas em agregação por contagem, pois essas condições são indiferentes a este fator, como será discutido na Seção 4.2.2. De forma semelhante ao que ocorre na função de agregação COUNT do padrão SQL, em uma c-acond o parâmetro agAtr pode ser substituído por um '*', indicando a contagem de todas as tuplas (e não de tuplas cujo valor de agAtr seja não nulo). Este tipo de condição baseada em agregação permite definir várias consultas, como, por exemplo, a consulta definida a seguir sobre o conjunto de cidades americanas.

Consulta 1: Retorne as 5 cidades que são as mais próximas a Bristol city, de forma que o resultado inclua ao menos 3 cidades com população maior ou igual a 5000 habitantes.

A Consulta 1 estabelece que o resultado satisfaça uma condição baseada em agregação por contagem. Ela pode ser escrita usando o operador por similaridade ${ }_{c} k \mathrm{NN}$ como:

$$
\ddot{\sigma}_{\text {coord }{ }_{c} k \mathrm{NN}\left[L_{2}, 5, \operatorname{COUNT}(*, p o p \geq 5000) \geq 3\right] \text { BristolCoord }}(\text { CidadesAmericanas })
$$

onde $L_{2}$ é a função de distância utilizada e BristolCoord é uma constante contendo as coordenadas geográficas de Bristol city. Observe que essa consulta pode descartar cidades mais próximas de Bristol city que tenham menos que 5000 habitantes para que o resultado satisfaça a condição baseada em agregação por contagem. Para ilustrar esta idéia, a Figura 4.5 mostra o conjunto por dissimilaridade induzido sobre o conjunto CidadesAmericanas por $L_{2}$ e Bristol city, ordenado conforme o valor de dissimilaridade dos elementos, isto é, a sua distância para o elemento de referência. A resposta para a Consulta 1 considerando o conjunto CidadesAmericanas como relação de entrada é dado pelo $k$-conjunto minimal restrito induzido por dissimilaridade apresentado na Figura 4.6. Observe-se que a resposta inclui a $6^{\mathrm{a}}$ cidade mais próxima a Bristol city, descartando a $5^{\mathrm{a}}$ cidade mais próxima, para satisfazer a c-acond apresentada.

A consulta apresentada a seguir é outro exemplo de consulta que utiliza uma c-acond, definida sobre a relação Hoteis.

Consulta 2: Retorne os 10 hotéis mais próximos ao local da conferência, tal que no máximo 2 deles estejam $10 \mathrm{~km}$ ou mais do aeroporto.

A Consulta 2 pode ser escrita conforme segue:

$$
\ddot{\sigma}_{\text {coord }}{ }_{c} k \mathrm{NN}\left[L_{2}, 10, \operatorname{COUNT}\left(*, L_{2}(\text { coord,aerCoord }) \geq 10 \mathrm{~km}\right) \leq 2\right] \text { confCoord }(\text { Hoteis })
$$

onde aerCoord e confCoord são, respectivamente, as coordenadas do aeroporto e do local da conferência e as distâncias são calculadas usando a função $L_{2}$. Note-se que apesar de 


$$
\begin{aligned}
& S^{L_{2}, \text { Bristol city }}=\{\quad\langle\text { Bristol city, VA, 17367, [36.6111, -82.1762], 0 }\rangle, \\
& \text { 〈Bluff City city, TN, 1559, [36.4634, -82.275], 0.177697〉, } \\
& \text { 〈Abingdon town, VA, 7780, [36.7098, -81.9757], 0.223478〉, } \\
& \text { 〈Watauga city, TN, 403, [36.3673, -82.2913], 0.269604), } \\
& \text { 〈Nickelsville town, VA, 448, [36, 7519, -82.417], 0.278942〉, } \\
& \text { 〈Black Mountain town, NC, 7511, [35.6192, -82.3254], 1.00306〉, } \\
& \text { 〈Wellford city, SC, 2030, [34, 9511, -82.0985], 1.66182〉, } \\
& \text { 〈Forest Hills village, NC, 330, [35, 2972, -83.1937], 1.66182〉, } \\
& \text { 〈Mooresville town, NC, 18823, [35.5843, -80.8201], 1.70098〉\} }
\end{aligned}
$$

Figura 4.5: Conjunto induzido sobre o conjunto CidadesAmericanas por $L_{2}$ e Bristol city, apresentado em ordem do valor de dissimilaridade.

$$
\begin{aligned}
& S_{c, 5}^{L_{2}, \text { Bristol city }}=\{\langle\text { Bristol city, VA, 17367, [36.6111, -82.1762], 0 }\rangle, \\
& \text { 〈Bluff City city, TN, 1559, [36.4634, -82.275], 0.177697〉, } \\
& \text { 〈Abingdon town, VA, 7780, [36.7098, -81.9757], 0.223478〉, } \\
& \text { 〈Watauga city, TN, 403, [36.3673, -82.2913], 0.269604), } \\
& \text { 〈Black Mountain town, NC, 7511, [35.6192, -82.3254], 1.00306〉\} }
\end{aligned}
$$

Figura 4.6: Conjunto resposta da Consulta 1, considerando o conjunto CidadesAmericanas como a instância da relação de entrada e $c=\langle\mathrm{COUNT}(*$, pop $\geq 5000) \geq 3\rangle$.

ser usada uma função distância como filtro, isso não apresenta conflito com o operador de busca por similaridade, uma vez que a condição $\left\langle L_{2}(\operatorname{coord}\right.$, aerCoord $\left.) \leq 10 \mathrm{~km}\right\rangle$ é uma condição baseada em tupla, e portanto pode ser usada tal como qualquer outra condição tradicional.

Uma variação da condição baseada em agregação por contagem consiste em adicionar o modificador DISTINCT à função de agregação COUNT, gerando uma condição baseada em agregação por contagem de distintos ( $c d$-acond). Uma $c d$-acond indica que o resultado da consulta deve incluir no máximo/mínimo $c$ tuplas que satisfazem tcond e que tenham valores distintos para o atributo agAtr. Para elucidar o significado das $c d$-aconds, considere-se a relação de imagens de exames médicos Exames, apresentada na Tabela 4.1. Em várias modalidades de exames de diagnóstico por imagem, tais como ressonância magnética e tomografia computadorizada, as imagens são agrupadas em estudos, que representam um único exame. Nesses casos, o conjunto de imagens que forma um estudo pode ser interpretado como uma (ou mais) imagem tridimensional da região do paciente que é alvo da investigação médica. Desta forma, em muitas situações não é interessante para o usuário de um sistema de CBIR da área médica que uma consulta por similaridade 
retorne mais de uma imagem de um mesmo estudo, pois geralmente as imagens de um estudo são analisadas em conjunto. Este tipo de situação é ilustrado pela consulta a seguir.

Consulta 3: Retorne as 10 imagens médicas que sejam as mais similares a uma dada imagem de referência $i_{q}$, sendo que cada imagem retornada seja de um estudo distinto.

Considerando a relação Exames, a Consulta 3 pode ser representada como:

$$
\ddot{\sigma}_{\text {imagem }_{c} k \mathrm{NN}\left[L_{2}, 10, \operatorname{COUNT}(\operatorname{DISTINCT}(i d E s t u d o)) \geq 10\right] i_{q}}(\text { Exames })
$$

Observando-se que o atributo idEstudo identifica o estudo do qual a imagem faz parte, esta consulta não permite que exista mais de uma imagem de um mesmo estudo no resultado, pois os valores de $c$ e $k$ são iguais $(c=10$ e $k=10)$. Essa consulta utiliza uma tcond nula, contudo é possível utilizar filtros à função de agregação em $c d$-aconds para responder a consultas como a Consulta 4.

Consulta 4: Retorne as 10 imagens médicas que são mais similares a uma dada imagem de referência $i_{q}$, sendo que, pelo menos, 8 delas sejam de exames distintos de idosos (65 anos ou mais).

A Consulta 4 pode ser representada utilizando a operação ${ }_{c} k$-NNq como segue:

$$
\ddot{\sigma}_{\text {imagem }} k \mathrm{NN}\left[L_{2}, 10, \mathrm{COUNT}(\operatorname{DISTINCT}(\text { idEstudo),idade } \geq 65) \geq 8] i_{q}(\text { Exames })\right.
$$

Note que a condição usada nessa consulta permite que o resultado inclua mais de uma imagem de um mesmo exame, pois $k>c$. Inclusive, mais de uma imagem de um mesmo exame de idoso pode fazer parte do resultado. Neste caso, apenas uma dessas imagens é considerada na função COUNT(DISTINCT), que é a imagem do exame em questão mais similar à imagem de referência. As imagens que não precisam ser de exames distintos de idosos são as mais similares à imagem de referência encontradas, descontando-se as imagens mais similares de exames distintos de idosos. Ou seja, uma vez encontrado um conjunto $C$, que contém as $c$ tuplas de exames distintos que são as mais similares à imagem de consulta, os demais elementos retornados são os $k-c$ elementos pertencentes a $\left(S^{\Delta_{\delta}, Q}-C\right)$ com menor valor de dissimilaridade, sendo $S^{\Delta_{\delta}, Q}$ o conjunto por dissimilaridade induzido sobre $S$ por $\delta, \Delta$ e $Q$, onde, no caso, $S$ é o conjunto formado pelos valores do atributo imagem nas tuplas da relação Exames, $\delta=L_{2}$ e $Q$ é o conjunto unitário $\left\{i_{q}\right\}$, portanto, $\Delta$ foi omitida. O significado deste tipo de condição é que deseja-se obter as $c$ imagens de exames distintos de idosos mais similares a $i_{q}$ e também as $k-c$ imagens mais similares à imagem de referência $i_{q}$, independentemente de serem de pacientes 
mais jovens, ou mesmo de pertencerem a um mesmo exame de idosos que outras imagens retornadas.

Para ilustrar o significado das principais variações de condições baseadas em agregação por contagem, a Figura 4.7 mostra resultados de consultas ${ }_{c} k$-NN restritas por estas variações sobre um conjunto de dados geográficos. A região mostrada nas figuras é a vizinhança da cidade de Bristol, localizada no estado da Virgínia, Estados Unidos, próxima à divisa com o estado do Tennessee. A referência de consulta é a própria cidade de Bristol, representada nas figuras pela estrela vermelha, que foi retirada do conjunto para tornar os exemplos mais claros. Os círculos sólidos são cidades com população de 100.000 ou mais habitantes, os círculos sem preenchimento são cidades ou vilarejos com população entre 10.000 e 99.999 habitantes e os pontos cinza são cidades ou vilarejos com menos de 10.000 habitantes. As consultas recuperam os 10 vizinhos mais próximos à cidade de referência que satisfazem a condição imposta. As cidades que compõem o resultado de cada consulta são aquelas marcadas com um " $\mathrm{x}$ " nas figuras.

- A Figura 4.7a mostra o resultado de uma $k$-NNq regular (ou seja, uma ${ }_{c} k$-NNq com condição nula).

- A c-acond da Figura 4.7b, $\langle\operatorname{COUNT}(*, p o p \geq 100.000) \geq 4\rangle$, indica que o resultado deve incluir ao menos 4 cidades com 100.000 habitantes ou mais. Visualmente, percebe-se que o resultado inclui 4 círculos sólidos (marcados com um "x" na figura), sendo 1 no estado do Tennessee (TN) e 3 na Carolina do Norte (NC). Note que tais cidades não faziam parte do resultado da $k$-NNq (Figure $4.7 \mathrm{a}$ ).

- A c-acond da Figura 4.7c, $\langle\operatorname{COUNT}(*, p o p<10.000) \leq 2\rangle$, indica que o resultado deve incluir, no máximo, 2 cidades com população menor que 10.000 habitantes. Observando esta figura, nota-se que o conjunto resposta inclui apenas as 2 cidades com menos de 10.000 habitantes mais próximas à cidade de consulta, sendo que as outras 8 cidades que compõem o resultado tem 10.000 ou mais habitantes.

- A c-acond da Figura 4.7d, 〈COUNT(DISTINCT(estado), pop $\geq 100.000) \geq 3\rangle$, indica que o resultado deve incluir ao menos 3 cidades de estados distintos com 100.000 habitantes ou mais. Desta forma, o resultado apresentado na figura inclui uma cidade com 100.000 habitantes ou mais do estado do Tennessee, uma da Carolina do Norte e outra do Kentucky (KY). Observe que a cidade com 100.000 habitantes ou mais do Kentucky que foi selecionada está mais distante que duas outras cidades da mesma faixa de população da Carolina do Norte (veja que tais cidades da Carolina do Norte foram selecionadas na consulta da Figura 4.7b). Porém, a cidade do Kentucky foi incluída no resultado por estar em um estado diferente.

- A cd-acond da Figura 4.7e, 〈COUNT(DISTINCT(estado), pop < 10.000) $\leq 1\rangle$, indica que a quantidade de cidades com menos de 10.000 habitantes de estados dis- 


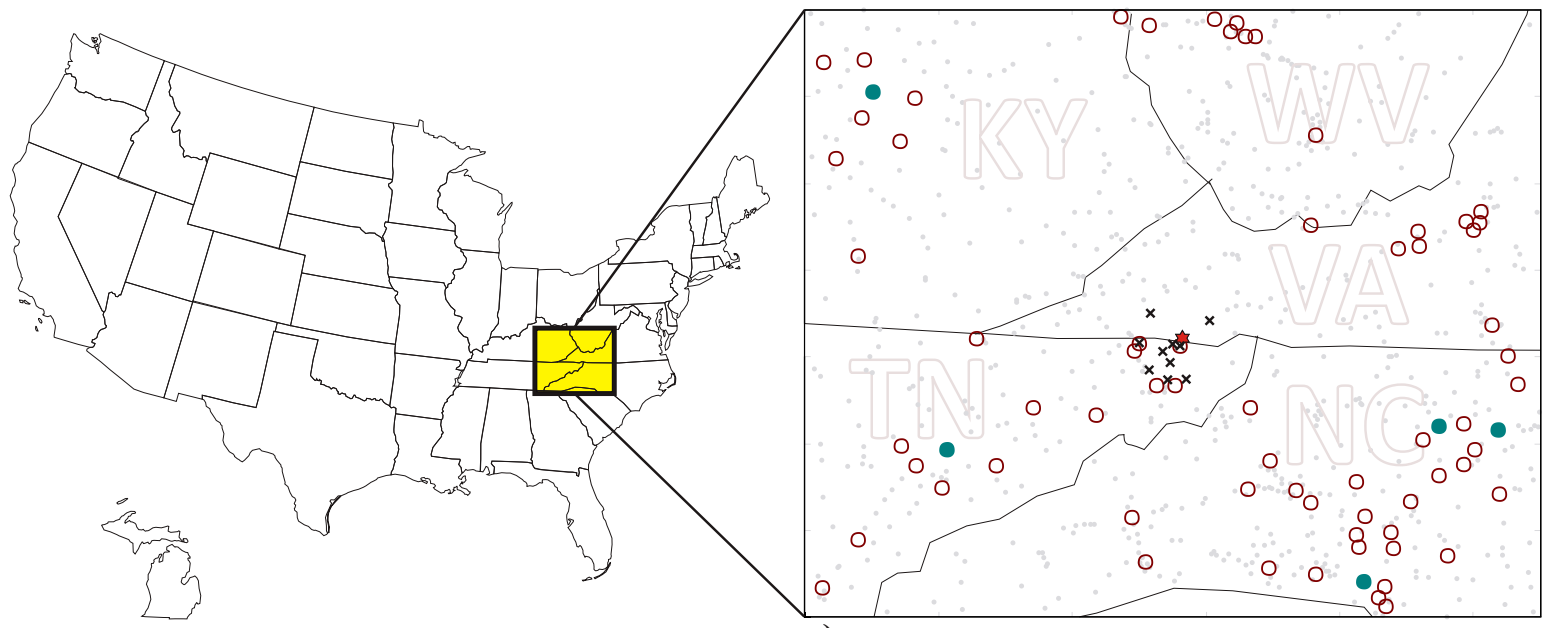

a)
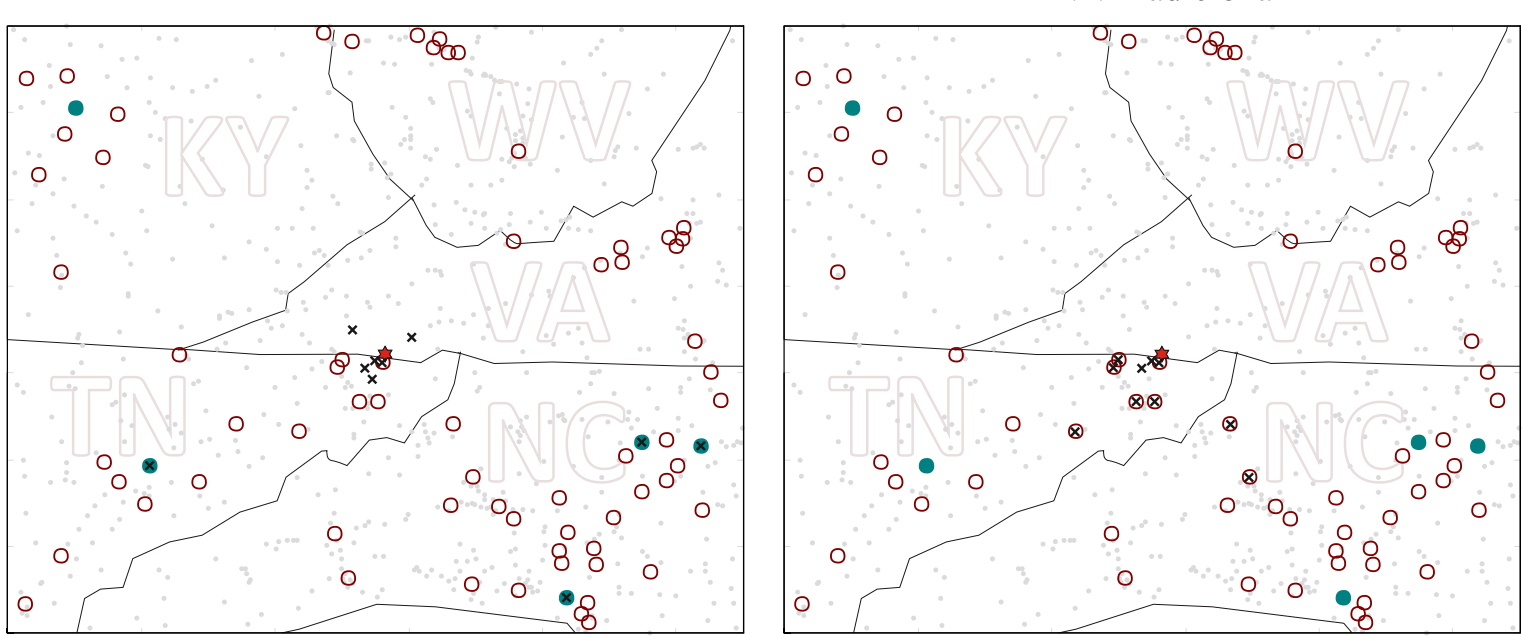

b) $\quad \operatorname{COUNT}(*, p o p \geq 100,000)) \geq 4$

c)
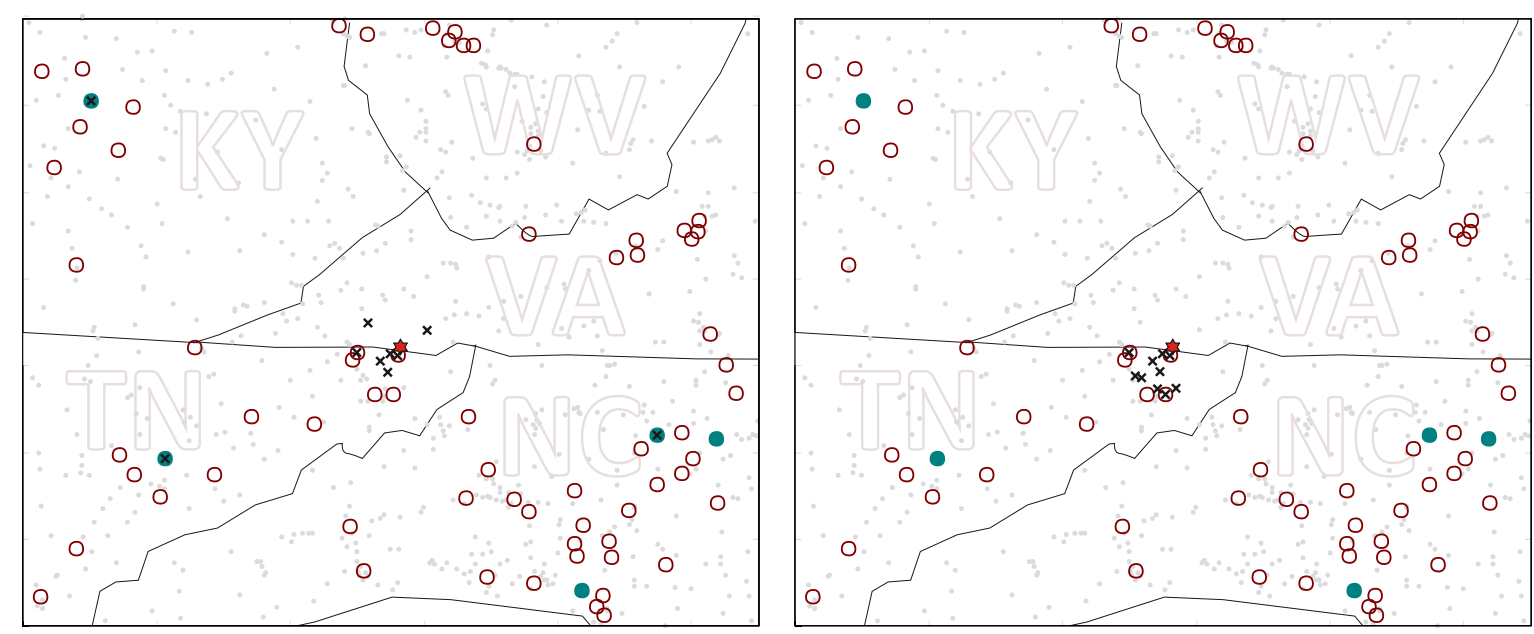

d)COUNT(DISTINCT (estado), pop $\geq 100,000) \geq 3$

e) $\operatorname{COUNT}(\mathrm{DISTINCT}($ estado), $\operatorname{pop}<10,000) \leq 1$

Figura 4.7: Comparação dos resultados de uma $k$-NNq e de consultas ${ }_{c} k$-NN com variações de condições baseadas em agregação por contagem. O elemento de consulta é a estrela no centro da figura, e as cidades retornadas são as marcadas com um "x". O número de vizinhos é $k=10$ e abaixo de cada figura está a $c d$-acond que gera o resultado apresentado na figura. 
tintos deve ser menor ou igual a 1. Uma interpretação errônea desta condição seria imaginar que o resultado só poderia incluir uma única cidade com menos de 10.000 habitantes. Na verdade, esta $c d$-acond permite que o resultado inclua várias cidades com menos de 10.000 habitantes, desde que sejam todas do mesmo estado. Isto se deve ao fato que apenas a cidade com menos de 10.000 habitantes mais próxima à cidade de consulta de cada estado é considerada na função de agregação COUNT(DISTINCT). Analisando a Figura 4.7a, nota-se a cidade com menos 10.000 habitantes mais próxima à cidade de referência está no estado do Tennessee, portanto, nenhuma cidade com menos de 10.000 habitantes de outro estado pode ser incluída no resultado, pois a $c d$-acond define $c=1$. Entretanto, outras cidades do Tennessee com menos de 10.000 habitantes podem ser incluídas no resultado, conforme mostra a figura, pois elas não alteram o valor da função COUNT(DISTINCT). Nota-se, ainda, que o resultado dessa consulta inclui 3 cidades com 10.000 habitantes ou mais, que também são do Tennessee. O fato de tais cidades serem do mesmo estado da cidade considerada na função COUNT(DISTINCT) foi uma coincidência neste exemplo, pois cidades com 10.000 habitantes não satisfazem o filtro da função de agregação e, portanto, não mudam o valor da contagem de distintos, independentemente do estado a que pertencem.

\subsubsection{Condições Baseadas em Agregação por Soma ou por Média}

Uma condição baseada em agregação por soma, denotada como sum-acond, é uma acond que utiliza uma função de agregação SUM filtrada. Este tipo de condição tem a forma $\langle\operatorname{SUM}(a g A t r$, min-op,tcond $) \theta c\rangle$, onde o valor da função SUM é dado pela soma dos valores do atributo agAtr das tuplas do resultado da ${ }_{c} k$-NNq que satisfazem a condição de filtragem tcond, e a escolha das tuplas do resultado considera a opção de minimização min-op. Existem três opções de minimização básicas que definem a escolha das tuplas que formarão a relação resultante de uma ${ }_{c} k$-NN restrita por uma sum-acond:

- minimização da soma das distâncias ao conjunto de elementos de consulta $Q$ (minsum);

- minimização da distância mínima a $Q$ (min-min); ou

- minimização da distância máxima a $Q$ (min-max).

sendo que a opção desejada é definida pelo parâmetro min-op da condição, cujo valor é um entre $\{$ min-sum, min-min, min-max $\}$, indicando, respectivamente, a minimização da soma das distâncias, a minimização da distância mínima e a minimização da distância máxima.

O resultado de uma ${ }_{c} k$-NNq restrita por uma sum-acond com minimização da soma das distâncias é um $k$-conjunto minimal por soma restrito induzido por dissimilaridade, 
nos termos da Definição 4.6. As opções de minimização min-min e min-max são baseadas nas definições a seguir, onde $\mathbb{S}$ é um domínio de dados complexos, $S \subseteq \mathbb{S}$ é um conjunto de dados, $\delta$ é uma função de distância definida sobre $\mathbb{S}, \Delta$ é uma função agregadora de distâncias e $Q \subseteq \mathbb{S}$ é um conjunto de elementos de referência, $c$ é uma condição e $k$ o número de elementos do conjunto.

Definição 4.9 Dados dois $k$-conjuntos restritos por c e induzidos sobre $S$ por $\delta, \Delta e$ $Q, S_{c, k}^{\Delta_{\delta}, Q}$ e $S_{c, k}^{\prime \Delta_{\delta}, Q}$, diz-se que $S_{c, k}^{\Delta_{\delta}, Q}$ é maior por distância mínima do que $S_{c, k}^{\prime \Delta_{\delta}, Q}$ se $s_{1} \cdot v^{\Delta_{\delta}, Q}>s_{1}^{\prime} \cdot v^{\Delta_{\delta}, Q}$, onde $s_{1} \in S_{c, k}^{\Delta_{\delta}, Q}$ e $s_{1}^{\prime} \in S_{c, k}^{\prime \Delta_{\delta}, Q}$, tais que $s_{1} \cdot v^{\Delta_{\delta}, Q}$ é menor ou igual que o valor de dissimilaridade de qualquer elemento de $S_{c, k}^{\Delta_{\delta}, Q}$ e $s_{1}^{\prime} \cdot v^{\Delta_{\delta}, Q}$ é menor ou igual que o valor de dissimilaridade de qualquer elemento de $S_{c, k}^{\prime \Delta_{\delta}, Q}$. Se $s_{1} \cdot v^{\Delta_{\delta}, Q}=s_{1}^{\prime} \cdot v^{\Delta_{\delta}, Q}, S_{c, k}^{\Delta_{\delta}, Q} e^{\prime}$ maior por menor distância do que $S_{c, k}^{\prime \Delta_{\delta}, Q}$ se $s_{2} \cdot v^{\Delta_{\delta}, Q}>s_{2}^{\prime} \cdot v^{\Delta_{\delta}, Q}$, onde $s_{2} \in\left(S_{c, k}^{\Delta_{\delta}, Q}-\left\{s_{1}\right\}\right)$ e $s_{2}^{\prime} \in\left(S_{c, k}^{\prime \Delta_{\delta}, Q}-\left\{s_{1}^{\prime}\right\}\right)$, tais que $s_{2} \cdot v^{\Delta_{\delta}, Q}$ é menor ou igual que o valor de dissimilaridade de qualquer elemento de $S_{c, k}^{\Delta_{\delta}, Q}-\left\{s_{1}\right\}$ e $s_{2}^{\prime} \cdot v^{\Delta_{\delta}, Q}$ é menor ou igual que o valor de dissimilaridade de qualquer elemento de $S_{c, k}^{\prime \Delta_{\delta}, Q}-\left\{s_{1}^{\prime}\right\}$, e assim sucessivamente.

Definição 4.10 Um k-conjunto minimal por distância mínima restrito induzido por dissimilaridade $\check{S}_{c, k}^{\Delta_{\delta}, Q}$ é um $k$-conjunto por dissimilaridade restrito por c e induzido sobre $S$ por $\delta, \Delta$ e $Q$ que não é maior por distância mínima que qualquer outro k-conjunto por dissimilaridade restrito por c e induzido sobre $S$ por $\delta, \Delta$ e $Q$.

O resultado de uma ${ }_{c} k$-NNq restrita por uma sum-acond com a opção de minimização min-min é dado por um $k$-conjunto minimal por menor distância restrito induzido por dissimilaridade, nos termos da Definição 4.10. As definições a seguir fundamentam a opção de minimização min-max de maneira análoga.

Definição 4.11 Dados dois $k$-conjuntos restritos por $c$ e induzidos sobre $S$ por $\delta, \Delta$ e $Q, S_{c, k}^{\Delta_{\delta}, Q}$ e $S_{c, k}^{\Delta_{\delta}, Q}$, diz-se que $S_{c, k}^{\Delta_{\delta}, Q}$ é maior por distância máxima do que $S_{c, k}^{\Delta_{\delta}, Q}$ se $s_{k} \cdot v^{\Delta_{\delta}, Q}>s_{k}^{\prime} \cdot v^{\Delta_{\delta}, Q}$, onde $s_{k} \in S_{c, k}^{\Delta_{\delta}, Q}$ e $s_{k}^{\prime} \in S_{c, k}^{\Delta_{\delta}, Q}$, tais que $s_{k} \cdot v^{\Delta_{\delta}, Q}$ é maior ou igual que o valor de dissimilaridade de qualquer elemento de $S_{c, k}^{\Delta_{\delta}, Q}$ e $s_{k}^{\prime} \cdot v^{\Delta_{\delta}, Q}$ é maior ou igual que o valor de dissimilaridade de qualquer elemento de $S_{c, k}^{\Delta_{\delta}, Q}$. Se $s_{k} \cdot v^{\Delta_{\delta}, Q}=s_{k}^{\prime} \cdot v^{\Delta_{\delta}, Q}$, $S_{c, k}^{\Delta_{\delta}, Q}$ é maior por maior distância do que $S_{c, k}^{\prime \Delta_{\delta}, Q}$ se $s_{k-1} \cdot v^{\Delta_{\delta}, Q}>s_{k-1}^{\prime} \cdot v^{\Delta_{\delta}, Q}$, onde $s_{k-1} \in$ $\left(S_{c, k}^{\Delta_{\delta}, Q}-\left\{s_{k}\right\}\right)$ e $s_{k}^{\prime} \in\left(S_{c, k}^{\prime \Delta_{\delta}, Q}-\left\{s_{k}^{\prime}\right\}\right)$, tais que $s_{k-1} \cdot v^{\Delta_{\delta}, Q}$ é maior ou igual que o valor de dissimilaridade de qualquer elemento de $S_{c, k}^{\Delta_{\delta}, Q}-\left\{s_{k}\right\}$ e $s_{k-1}^{\prime} \cdot v^{\Delta_{\delta}, Q}$ é maior ou igual que o valor de dissimilaridade de qualquer elemento de $S_{c, k}^{\prime \Delta_{\delta}, Q}-\left\{s_{k}^{\prime}\right\}$, e assim sucessivamente.

Definição 4.12 Um k-conjunto minimal por distância máxima restrito induzido por dissimilaridade $\hat{S}_{c, k}^{\Delta, Q}$ é um $k$-conjunto por dissimilaridade restrito por c e induzido sobre $S$ por $\delta, \Delta$ e $Q$ que não é maior por distância máxima que qualquer outro $k$-conjunto por dissimilaridade restrito por c e induzido sobre $S$ por $\delta, \Delta$ e $Q$. 
A Definição 4.12 estabelece qual é o resultado de uma ${ }_{c} k$-NNq restrita por uma sumacond e com a opção de minimização min-max. Observe-se que com relação às condições baseadas em agregação por contagem é indiferente escolher a opção de minimização. Quando se trata de contagem, toda tupla tem o mesmo impacto na função de agregação utilizada (incrementa/decrementa a contagem em 1 unidade). Portanto, ao escolher-se os elementos mais próximos ao elemento de referência, que satifaçam a tcond fornecida, se for o caso, simultaneamente minimiza-se a menor distância, a soma das distâncias e a maior distância. Sendo assim, o parâmetro min-op é omitido nas condições baseadas em agregação por contagem. Para ilustrar o significado das condições baseadas em agregação por soma e as diferentes opções de minimização, considere-se a consulta a seguir.

Consulta 5: Retorne as 3 cidades que sejam as mais próximas a Bristol city, de forma que o resultado inclua cidades cuja soma das suas populações seja menor ou igual a 19300 habitantes e que a cidade mais próxima retornada tenha a menor distância possível de Bristol city.

A Consulta 5 estabelece que a opção de minimização deve ser a opção min-min, pois indica que a cidade mais próxima retornada deve ter a menor distância possível da referência. Desta forma, esta deverá ser representada conforme segue:

$$
\ddot{\sigma}_{\text {Coord }}{ }_{c} \mathrm{NN}\left[L_{2}, 3, \operatorname{SUM}(\text { pop,min-min }) \leq 19300\right] \text { BristolCoord }_{\text {Cidades Americanas })}
$$

onde o parâmetro tcond foi omitido, pois a condição de filtragem da função de agregação é nula. O resultado desta consulta é dado pelo $k$-conjunto minimal por menor distância restrito pela condição $\langle\mathrm{SUM}($ pop, min-min $) \leq 19300\rangle$ induzido sobre o conjunto CidadesAmericanas por $L_{2}$ e BristolCoord, mostrado na Figura 4.8. Nesse conjunto, a menor distância é 0 (Bristol city), a maior distância é 1.66182 (Forest Hills village) e a soma das distâncias é 1.839517. Se a opção de minimização indicada na consulta fosse min-sum, o valor do parâmetro min-op da min-acond seria min-sum e o resultado da consulta seria o conjunto apresentado na Figura 4.9, cuja menor distância é 0 (Bristol city), a maior distância é 0.278942 (Nickelsville town) e a soma das distâncias é 0.548546 . Note-se que, embora este conjunto também inclua a cidade mais próxima ao elemento de referência, ele não é uma resposta válida considerando-se a opção de minimização minmin, pois o valor de dissimilaridade do segundo elemento mais próximo deste conjunto é maior que o do conjunto da Figura 4.8. Por fim, se a opção de minimização indicada na consulta fosse min-max, o parâmetro min-op deveria ter o valor min-max e a consulta produziria o resultado apresentado na Figura 4.10, cuja menor distância é 0.177697 (Bluff City), a maior distância é 0.269604 (Watauga city) e a soma das distâncias é 0.670779 . 


$$
\begin{aligned}
\check{S}_{\mathrm{SUM}(\text { pop }) \leq 19300,3}^{L_{2}, \text { Bristol city }}=\{ & \langle\text { Bristol city, VA, 17367, }[36.6111,-82.1762], 0\rangle, \\
& \langle\text { Bluff City city, TN, 1559, [36.4634, -82.275], 0.177697〉, } \\
& \langle\text { Forest Hills village, NC, 330, [35, 2972, -83.1937], 1.66182〉\} }
\end{aligned}
$$

Figura 4.8: Conjunto resposta da Consulta 5 com opção de minimização min-min.

$$
\begin{aligned}
& \bar{S}_{\mathrm{SUM}(\text { pop }) \leq 19300,3}^{L_{2}, \text { Bristol city }}=\{\quad\langle\text { Bristol city, VA, 17367, [36.6111, -82.1762], 0 }\rangle, \\
& \text { 〈Watauga city, TN, 403, [36.3673, -82.2913], 0.269604〉, } \\
& \text { 〈Nickelsville town, VA, 448, [36, 7519, -82.417], 0.278942〉\} }
\end{aligned}
$$

Figura 4.9: Conjunto resposta da Consulta 5 com opção de minimização min-sum.

$$
\begin{aligned}
& \hat{S}_{\mathrm{SUM}(\text { pop }) \leq 19300,3}^{L_{2}, \text { Bristol city }}=\{\quad\langle\text { Bluff City city, TN, 1559, [36.4634, -82.275], 0.177697〉, } \\
& \text { 〈Abingdon town, VA, 7780, [36.7098, -81.9757], 0.223478〉, } \\
& \text { 〈Watauga city, TN, 403, [36.3673, -82.2913], 0.269604〉\} }
\end{aligned}
$$

Figura 4.10: Conjunto resposta da Consulta 5 com opção de minimização min-max.

Outro exemplo de consulta que usa uma condição baseada em agregação por soma é apresentado a seguir, considerando uma relação de pontos turísticos PontosTuristicos, apresentada na Tabela 4.1.

Consulta 6: Retorne os 3 pontos turísticos mais próximos ao local em que me encontro no momento, sendo que a soma das taxas de acesso a eles seja menor ou igual a $\mathrm{R} \$ 100,00$ e que o ponto turístico mais distante retornado seja o mais próximo possível.

A consulta 6 permite selecionar um conjunto de pontos turísticos para visitação restringindo a distância do local em que me encontro e o gasto total com as visitas. A opção de minimização estabelecida é a minimização da distância máxima ("[...] sendo que o ponto turístico mais distante retornado seja o mais próximo possível"), portanto, esta consulta é representada da seguinte forma:

$$
\ddot{\sigma}_{\text {coord }}{ }_{c} k \mathrm{NN}\left[L_{2}, 3, \operatorname{SUM}(\text { taxaAcesso,min-max }) \leq R \$ 100,00\right] \text { minhaCoord }(\text { PontosTuristicos) }
$$

onde, minhaCoord é a coordenada da minha localização atual. Para facilitar a visualização do resultado desta consulta, considere a instância da relação PontosTuristicos ilustrada na Figura 4.11, onde os pontos turísticos são identificados por letras, o valor indicado acima de cada ponto turístico é o valor da taxa de acesso e os valores indicados 
nas linhas são as distâncias dos pontos turísticos à localização de referência. Considerando estes dados, como a opção de minimização indicada na Consulta 6 é a minimização da distância máxima, o resultado da consulta é a relação $R_{\min \_ \text {max }}=\{A, D, F\}$. Entretanto, se a opção de minimização fosse min-min, o resultado da consulta seria a relação $R_{\text {min_min }}=\{B, E, G\}$ e se a opção fosse minimizar a soma das distâncias, o resultado seria a relação $R_{\text {min_soma }}=\{C, F, G\}$.

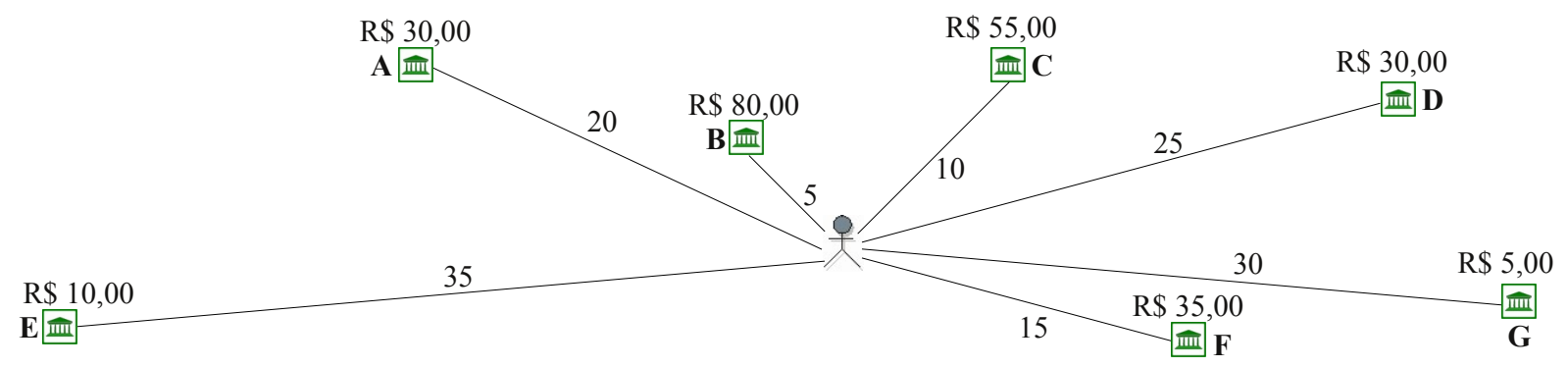

Figura 4.11: Representação visual de uma instância da relação PontosTuristicos.

As condições baseadas em agregação por média, ou avg-aconds, baseiam-se em uma função de agregação AVG filtrada, e têm a forma $\langle$ AVG (agAtr, min-op,tcond) $\theta c\rangle$. O significado deste tipo de condição é semelhante ao da sum-acond, mas calculando a média dos valores do atributo agAtr das tuplas do resultado que satisfazem a condição de filtragem tcond. Consultas ${ }_{c} k$-NN restritas por avg-aconds também exigem definir a opção de minimização da busca. Um exemplo de consulta que pode ser respondida utilizando esse tipo de condição é apresentado a seguir.

Consulta 7: Retorne os 5 pontos turísticos mais próximos ao local em que me encontro no momento, minimizando a soma das distâncias, sendo que, se o resultado incluir museus, o tempo médio de visita a eles seja, no máximo, 2 horas.

A Consulta 7 define que o resultado deve respeitar a minimização da soma das distâncias, sendo representada conforme segue:

$$
\ddot{\sigma}_{\text {coord }{ }_{c} k \mathrm{NN}\left[L_{2}, 5, \mathrm{AVG}\left(\text { tempoVisita,min-sum,categoria= ' }{ }_{\text {museu' }}\right) \leq 2 h\right] \text { minhaCoord }}(\text { PontosTuristicos })
$$

onde a avg-acond utilizada é baseada em uma função de agregação por média filtrada pela tcond $\langle$ categoria $=$ 'museu' . Esta consulta retorna o conjunto de pontos turísticos mais próximos ao local em que me encontro, minimizando a soma das distâncias e restringindo o tempo médio de visita a museus. Ao restringir o tempo médio de visita, a consulta permite que o resultado inclua museus cujos tempos de visita sejam maiores que 2 horas, desde que o resultado também inclua museus cujos tempos de espera sejam menores que 2 horas, compensando os tempos de visita maiores. 


\subsubsection{Condições Baseadas em Agregação por Mínimo ou por Máximo}

Uma condição baseada em agregação por mínimo (min-acond) utiliza em sua definição uma função de agregação mínimo filtrada, sendo denotada como $\langle\operatorname{MIN}(a g A t r$, tcond $) \theta c\rangle$. Uma condição baseada em agregação por máximo (maxacond) tem forma análoga, mas utilizando uma função máximo (MAX) filtrada. Estas condições permitem restringir o resultado de uma ${ }_{c} k$-NNq com base, respectivamente, nos limites inferior e superior de um dado atributo das tuplas que satisfazem a tcond de filtragem fornecida.

Da mesma forma que as condições baseadas em agregação por contagem, as condições baseadas em agregação por mínimo e máximo não são afetadas pela opção de minimização na construção do resultado e, portanto, o parâmetro min-op é omitido na definição da condição. Para verificar esse fato, sem perda de generalidade, considere uma min-acond $\langle\operatorname{MIN}($ agAtr, tcond $) \theta c\rangle$. Se $\theta$ é '=', o resultado deverá incluir ao menos uma tupla que satisfaça tcond, tal que $\langle a g A t r=c\rangle$, sendo que o restante das tuplas não devem satisfazer tcond ou devem satisfazer tcond e também $\langle a g A t r \geq c\rangle$. Caso $\theta$ seja ' $\neq$ ', o resultado tem que incluir uma tupla que satisfaça tcond e também $\langle a g A t r<c\rangle$, caso contrário, todas as tuplas do resultado que satisfaçam tcond devem satisfazer também $\langle a g A t r>c\rangle$, sendo que o resultado tem que incluir pelo menos uma tupla que satisfaça estas duas condições. Se $\theta \in\{\geq,>\}$, podem ser incluídas no resultado tuplas que não satisfazem tcond ou tuplas que satisfazem tcond e também satisfazem a condição $\langle\operatorname{agAtr} \theta c\rangle$. Em todos esses casos, inclui-se no resultado as tuplas de forma que sejam as mais próximas ao elemento de consulta, fazendo com que a opção de minimização seja indiferente. Por outro lado, se $\theta \in\{<, \leq\}$, o resultado deve incluir ao menos uma tupla que satisfaz as condições tcond e $\langle$ agAtr $\theta$ c $\rangle$. Desta forma, o resultado é formado pela tupla mais próxima ao elemento de consulta que satisfaz estas duas condições e pelas $k-1$ tuplas mais próximas ao elemento de consulta, independentemente de satisfazerem ou não tais condições (note que o resultado pode incluir mais tuplas que satisfaçam as duas condições), tornando novamente a opção de minimização indiferente.

A Consulta 8 apresentada a seguir é um exemplo de ${ }_{c} k$-NNq restrita por uma condição baseada em agregação por mínimo. Esta consulta considera que a relação CidadesAmericanas também inclui o atributo usaTransportePublico, que armazena a porcentagem da população da cidade que utiliza transporte público.

Consulta 8: Retorne as 20 cidades mais próximas de Bristol city, de forma que o resultado inclua cidades com 100 mil habitantes ou mais, ou cidades com menos de 100 mil habitantes cuja porcentagem de habitantes que usa transporte público seja, no mínimo, $5 \%$. 
A Consulta 8 pode ser representada utilizando uma min-acond, como segue.

$\ddot{\sigma}_{\text {coord }}{ }_{c} k \mathrm{NN}\left[L_{2}, 20, \operatorname{MIN}(\right.$ usaTransportePublico,pop $\left.<100000) \geq 5 \%\right]$ BristolCoord $($ CidadesAmericanas $)$

Consultas ${ }_{c} k$-NNq com condições baseadas em agregação por máximo são aplicáveis a situações semelhantes. Por exemplo, caso a Consulta 8 restringisse a porcentagem máxima da população que usa transporte público, a condição utilizada seria uma max-acond.

\subsection{Regras Algébricas}

Esta seção apresenta regras algébricas válidas em expressões que envolvem o operador de consulta aos $k$-vizinhos mais próximos estendido com condições. As regras apresentadas nesta seção, consideram uma relação $R$, um atributo $S$ de $R$, no domínio complexo $\mathbb{S}$, uma função de distância $\delta$ definida sobre $\mathbb{S}$ e um conjunto não vazio de elementos de referência $Q \subseteq \mathbb{S}$.

\subsubsection{Regras Algébricas Envolvendo Condições em Geral Restrin- gindo o Operador ${ }_{c} k \mathrm{NN}$}

Esta seção apresenta as principais regras algébricas envolvendo condições baseadas em tupla e condições baseadas em agregação em geral.

Regra 4.1 (Condição nula) Um operador ${ }_{c} k \mathrm{NN}$ com condição nula é equivalente ao operador $k \mathrm{NN}$ convencional em uma seleção por similaridade agregada, isto é:

$$
\ddot{\sigma}_{S c k \mathrm{NN}[\delta, \Delta, k, N U L L] Q}(R) \Leftrightarrow \ddot{\sigma}_{S k \mathrm{NN}[\delta, \Delta, k] Q}(R)
$$

A regra da condição nula é a propriedade fundamental do operador ${ }_{c} k \mathrm{NN}$ como uma extensão do operador $k \mathrm{NN}$. Desta forma, o operador ${ }_{c} k \mathrm{NN}$ é capaz de responder a consultas aos $k$-vizinhos mais próximos agregados, e também a consultas aos $k$-vizinhos mais próximos convencionais, quando o conjunto de elementos de referência é unitário e omitese a função agregadora de distâncias $\Delta$.

Regra 4.2 (Antecipação de condições baseadas em tupla) Uma seleção por similaridade envolvendo um operador ${ }_{c} k \mathrm{NN}$, cuja condição é uma condição baseada em tupla tcond, pode ser antecipada por uma seleção convencional cuja expressão condicional é tcond, ou seja:

$$
\ddot{\sigma}_{S_{c} k \mathrm{NN}[\delta, \Delta, k, t \text { cond }]} Q(R) \Leftrightarrow \ddot{\sigma}_{S_{c} k \mathrm{NN}[\delta, \Delta, k]} Q\left(\sigma_{\text {tcond }}(R)\right)
$$

A Regra 4.2 possibilita explorar planos alternativos de consulta, com base na seletividade de tcond e na existência de estruturas de indexação que permitam agilizar o acesso 
aos dados com base nesta condição. Esta regra não se aplica se a condição do operador ${ }_{c} k \mathrm{NN}$ é uma acond, pois condições baseadas em agregação não são válidas como expressão condicional de uma seleção convencional. As regras a seguir tratam da antecipação de tconds em conjunções e disjunções de condições.

Regra 4.3 (Antecipação de tcond em conjunções de tconds) Uma seleção por similaridade envolvendo um operador ${ }_{c} k \mathrm{NN}$, cuja condição é uma expressão conjuntiva envolvendo duas condições quaisquer baseadas em tupla tcond $d_{1}$ e tcond $d_{2}$, pode ser antecipada por uma seleção convencional cuja expressão condicional é qualquer uma dessas condições, conforme estabelecem as duas equivalências a seguir:

$$
\begin{aligned}
& \ddot{\sigma}_{S_{c} k \mathrm{NN}\left[\delta, \Delta, k, \text { tcond }_{1} \wedge \text { tcond }_{2}\right] Q}(R) \Leftrightarrow \ddot{\sigma}_{S_{c} k \mathrm{NN}\left[\delta, \Delta, k, \text { tcond }_{1}\right] Q}\left(\sigma_{\text {tcond }_{2}}(R)\right) \\
& \ddot{\sigma}_{S_{c} k \mathrm{NN}\left[\delta, \Delta, k, \text { tcond }_{1} \wedge t \text { cond }_{2}\right] Q}(R) \Leftrightarrow \ddot{\sigma}_{S_{c} k \mathrm{NN}\left[\delta, \Delta, k, \text { tcond }_{2}\right] Q}\left(\sigma_{\text {tcond }_{1}}(R)\right)
\end{aligned}
$$

A combinação das equivalências 4.3 e 4.4 permite gerar uma sequência de seleções convencionais antecipadas à seleção por similaridade, derivando, por consequência, a Equivalência 4.5 .

$$
\ddot{\sigma}_{S_{c} k \mathrm{NN}\left[\delta, \Delta, k, \text { tcond }_{1} \wedge t c o n d_{2}\right] Q}(R) \Leftrightarrow \ddot{\sigma}_{S_{c} k \mathrm{NN}[\delta, \Delta, k] Q}\left(\sigma_{\text {tcond }_{1} \wedge t \text { cond }_{2}}(R)\right)
$$

Caso uma ${ }_{c} k$-NNq seja restrita por uma conjunção de uma condição baseada em tupla tcond e de uma condição baseada em agregação acond, vale a regra a seguir.

\section{Regra 4.4 (Antecipação de tcond em conjunções de tconds com aconds)}

Uma seleção por similaridade envolvendo um operador ${ }_{c} k \mathrm{NN}$, cuja condição é uma expressão conjuntiva envolvendo uma condição baseada em tupla tcond e uma condição baseada em agregação acond, pode ser antecipada por uma seleção convencional cuja expressão condicional é a condição tcond, isto é:

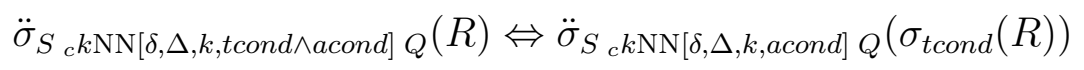

Caso a condição do operador ${ }_{c} k$-NN seja uma disjunção de condições, as propriedades válidas são diferentes. Se cond é uma uma disjunção de duas condições tcond e $c$, sendo que tcond é uma condição baseada em tupla e $c$ é uma condição de qualquer tipo (baseada em tupla ou baseada em agregação), não se pode antecipar à seleção por similaridade uma seleção convencional tendo apenas tcond como predicado, como mostra a Expressão 4.7.

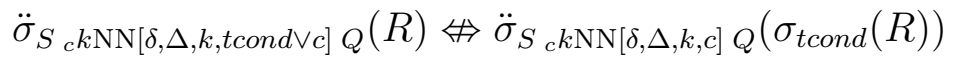

Entretanto, se cond for uma disjunção de duas condições baseadas em tupla, embora as condições baseadas em tupla não possam ser antecipadas isoladamente, é possível fazer 
a antecipação considerando a expressão disjuntiva como um todo, como enuncia a regra a seguir.

Regra 4.5 (Antecipação de disjunções de tconds) Uma seleção por similaridade envolvendo um operador ${ }_{c} k \mathrm{NN}$, cuja condição é uma expressão disjuntiva envolvendo quaisquer duas condições baseadas em tupla tcond e $_{1}$ tcond $_{2}$, pode ser antecipada por uma seleção convencional cuja expressão condicional é a expressão disjuntiva, conforme estabelece a equivalência a seguir:

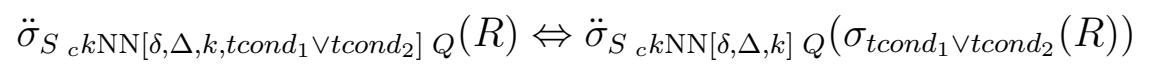

A aplicação da Regra 4.5 pode ser extrapolada para conjunções de condições, quando uma expressão disjuntiva de condições baseadas em tupla pode ser tratada como uma condição composta, como mostra a Equivalência 4.9:

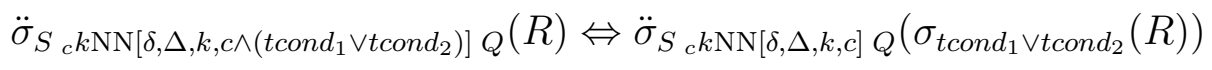

onde $c$ é uma condição de qualquer tipo (baseada em tupla ou baseada em agregação). Neste caso, a expressão disjuntiva pode ser movimentada pois é uma condição composta, delimitada por parênteses.

Vale ressaltar que não se pode transformar uma conjunção de duas condições no operador ${ }_{c} k \mathrm{NN}$ de uma seleção por similaridade em uma interseção de duas seleções por similaridade, cada uma com uma das condições, independentemente do tipo das condições. Da mesma forma, uma disjunção de condições no operador ${ }_{c} k \mathrm{NN}$ não pode ser transformada em uma união de seleções. Ou seja, uma seleção por similaridade envolvendo um operador ${ }_{c} k \mathrm{NN}$, cuja condição é uma expressão conjuntiva, ou disjuntiva, de condições simples, não é equivalente à interseção, ou à união, de seleções por similaridade envolvendo o operador ${ }_{c} k \mathrm{NN}$, cujas condições são partes partes da expressão original da consulta, independentemente dos tipos das condições. Esta observação é expressa algebricamente por meio das expressões 4.10 e 4.11, sendo $c_{1}$ e $c_{2}$ duas condições quaisquer (baseadas em tupla ou baseadas em agregação).

$$
\begin{aligned}
& \ddot{\sigma}_{S_{c} k \mathrm{NN}\left[\delta, \Delta, k, c_{1} \wedge c_{2}\right] Q}(R) \nRightarrow \ddot{\sigma}_{S_{c} k \mathrm{NN}\left[\delta, \Delta, k, c_{1}\right] Q}(R) \cap \ddot{\sigma}_{S_{c} k \mathrm{NN}\left[\delta, \Delta, k, c_{2}\right]} Q(R) \\
& \ddot{\sigma}_{S_{c} k \mathrm{NN}\left[\delta, \Delta, k, c_{1} \vee c_{2}\right]} Q(R) \leftrightarrow \ddot{\sigma}_{S_{c} k \mathrm{NN}\left[\delta, \Delta, k, c_{1}\right]} Q(R) \cup \ddot{\sigma}_{S_{c} k \mathrm{NN}\left[\delta, \Delta, k, c_{2}\right]} Q(R)
\end{aligned}
$$

Isso explicita que a interpretação que uma seleção conjuntiva/disjuntiva pode ser expressa por uma interseção/união de seleções, válida para a seleção tradicional, não se aplica à seleção por similaridade $\ddot{\sigma}$ com um operador ${ }_{c} k \mathrm{NN}$. As seções a seguir apresentam regras de equivalência para os diferentes tipos de condições baseadas em agregação propostos. 


\subsubsection{Regras Algébricas Envolvendo Condições Baseadas em Agregação por Contagem}

Esta seção apresenta as regras algébricas da seleção por similaridade tendo um termo utilizando o operador ${ }_{c} k$-NN com uma condição baseada em agregação por contagem. Como visto anteriormente, a função de agregação neste tipo de condição pode assumir duas formas: COUNT(atr,tcond), na qual o valor da função é dado pela contagem de valores não nulos no atributo de agregação agAtr das tuplas do resultado da consulta que satisfazem tcond; ou COUNT(*,tcond), na qual o valor da função de agregação é dado simplesmente pela contagem de tuplas do resultado que satisfazem tcond. Entretanto, a segunda forma é mais geral, pois a primeira forma sempre pode ser convertida na segunda, como define a Regra 4.6 .

Regra 4.6 (Generalidade da contagem de tuplas) Uma condição baseada em agregação por contagem que indica a contagem de valores não nulos no atributo de agregação pode ser transformada em uma condição baseada em agregação por contagem de tuplas em uma seleção por similaridade envolvendo o operador ${ }_{c} k \mathrm{NN}$, isto é:

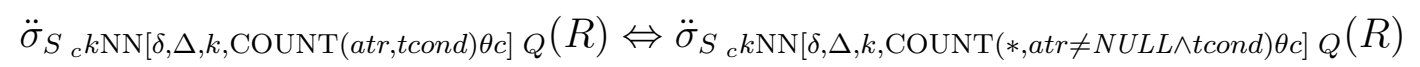

A regra da generalidade da contagem de tuplas baseia-se na observação que uma agregação por contagem de valores não nulos pode ser transformada em uma agregação por contagem de tuplas que inclui uma verificação de nulidade do atributo de agregação na condição de filtragem da função, como mostra a Equivalência 4.12. Note-se que nem sempre é possível transformar uma agregação por contagem de tuplas em uma agregação por contagem de valores não nulos. Uma agregação por contagem de tuplas só pode ser transformada em uma agregação por contagem de valores não nulos se houver algum atributo garantidamente não nulo na relação de entrada. Baseando-se nesta regra, sem perda de generalidade, as demais regras apresentadas nesta seção consideram a agregação por contagem de tuplas. A regra a seguir considera a possibilidade de inconsistência entre os valores $c$ e $k$.

Regra 4.7 (Inconsistência da contagem) Uma seleção por similaridade sobre uma relação com $k$ tuplas ou mais envolvendo o operador ${ }_{c} k \mathrm{NN}$ com uma condição baseada em agregação por contagem c-acond, cujo valor de c é inconsistente com o valor de $k$, produz um resultado vazio. Se a c-acond não é filtrada, isto é, tcond é nula, c é inconsistente com $k$ quando: $\theta$ é ' $=$ ' e $c \neq k$; ou $\theta$ é 'fl' e $c=k$; ou $\theta$ é '> e $c \geq k$; ou $\theta$ é $\geq$ ' e $c>k$; ou $\theta$ é ' $\leq$ ' e c $<k$; ou $\theta$ é $<e c \leq k$. Nesses casos, a expressão a seguir é válida:

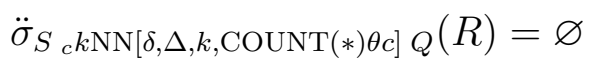


Caso a c-acond seja filtrada, $c$ é inconsistente com $k$ quando: $\theta$ é '=' e $c>k$; ou $\theta$ é '>' e c $\geq k$; ou $\theta$ é $\geq$ ' e $c>k$; ou $\theta$ é ' $\leq$ ' e $c<0$; ou $\theta$ é $<$ e $c \leq 0$. Nesses casos, a expressão a seguir é válida:

$$
\ddot{\sigma}_{S}{ }_{c} k \mathrm{NN}[\delta, \Delta, k, \operatorname{COUNT}(*, \operatorname{tcond}) \theta c] Q(R)=\varnothing
$$

A Regra 4.7 é baseada no fato que não existe um $k$-conjunto minimal restrito induzido por dissimilaridade $\bar{S}_{c a-c o n d, k}^{\delta, Q}$ que seja restrito por uma $c$-acond cujo valor de $c$ é inconsistente com o valor de $k$.

Regra 4.8 (Redundância da contagem) Uma condição baseada em agregação por contagem não filtrada, cujo valor de c é sobreposto pelo valor de $k$, não acrescenta significado ao operador ${ }_{c} k \mathrm{NN}$ de uma seleção por similaridade sobre uma relação com $k$ tuplas ou mais e pode ser eliminada. Em c-conds não filtradas, o valor de c é sobreposto por $k$ quando: $\theta$ é ' $=$ ' e $c=k$; ou $\theta$ é 'f' e $c \neq k$; ou $\theta$ é ' $>$ ' e $c<k$; ou $\theta$ é ' $\geq$ ' e $c \leq k$; ou $\theta$ $e^{e}$ ' $\leq$ ' e $c \geq k$; ou $\theta$ é '<' e $c>k$. Nesses casos, é válida a expressão a seguir:

$$
\ddot{\sigma}_{S}{ }_{c} k \mathrm{NN}[\delta, \Delta, k, \operatorname{COUNT}(*) \theta c] Q(R) \Leftrightarrow \ddot{\sigma}_{S_{c} k \mathrm{NN}[\delta, \Delta, k] Q}(R)
$$

A Regra 4.8 não se aplica caso a c-acond seja filtrada. Entretanto, existem casos particulares de sobreposição entre $c$ e $k$ que são interessantes para a reescrita de consultas, pois permitem antecipar à seleção por similaridade uma seleção convencional e eliminar a c-acond, conforme mostram as regras 4.9 e 4.10 apresentadas a seguir.

Regra 4.9 (Conversão de $\boldsymbol{c}$-conds com sobreposição em $\boldsymbol{t}$-conds) Uma seleção por similaridade envolvendo um operador ${ }_{c} k \mathrm{NN}$, cuja condição é uma condição baseada em agregação por contagem filtrada por uma condição tcond, pode ser antecipada por uma seleção convencional cuja expressão condicional é tcond se o valor de c for sobreposto pelo valor de $k$. Em c-aconds filtradas, o valor de c é sobreposto por $k$ quando: $\theta$ é ' $\geq$ ' $e$ $c=k$; ou $\theta$ é '>' e c $=k-1$. Nesses casos, é válida a expressão a seguir:

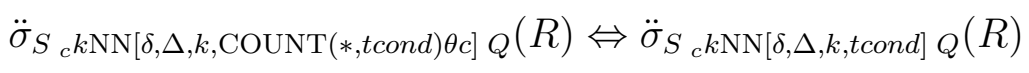

Regra 4.10 (Conversão de $\boldsymbol{c}$-conds filtrantes em $\boldsymbol{t}$-conds) Uma seleção por similaridade envolvendo um operador ${ }_{c} k \mathrm{NN}$, cuja condição é uma condição baseada em agregação por contagem filtrada por uma condição tcond, pode ser antecipada por uma seleção convencional cuja expressão condicional é a negação de tcond se a ca-cond for filtrante e se a condição de filtragem tcond for avaliada como verdadeira ou falsa para todas as tuplas da relação de entrada. Uma ca-cond é filtrante quando tcond não é nula, 
$\theta \in\{=, \leq\}$ e $c=0$ ou quando tcond não é nula, $\theta={ }^{\prime}<$ ' e $c=1$. Nesses casos, é válida a expressão a seguir:

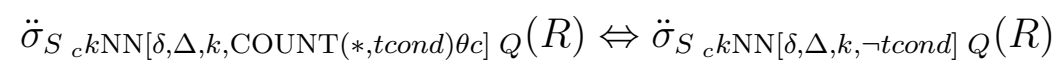

Note-se que a Regra 4.10 não é válida se existir a possibilidade da condição tcond ser avaliada como unknown (desconhecido) para alguma tupla, o que pode ocorrer se a condição envolver atributos que aceitam valores nulos. A regra seguir trata da negação de $c$-conds.

Regra 4.11 (Negação de $\boldsymbol{c}$-conds) $U m a_{c} k$-NNq restritra por uma condição baseada em agregação por contagem, cuja condição de filtragem tcond é avaliada como verdadeira ou falsa para todas as tuplas da relação de entrada ${ }^{1}$, pode ser transformada em uma ${ }_{c} k-N N q$ restrita pela negação dessa condição. A negação de c-conds é dada pela equivalência a seguir:

$$
\ddot{\sigma}_{S_{c} k \mathrm{NN}[\delta, \Delta, k, \operatorname{COUNT}(*, t c o n d) \geq c]} Q(R) \Leftrightarrow \ddot{\sigma}_{S_{c} k \mathrm{NN}[\delta, \Delta, k, \operatorname{COUNT}(*, \neg t \text { cond })<(k-c+1)] Q}(R)
$$

De forma geral, não existem equivalências das regras apresentadas nesta subseção para o operador ${ }_{c} k$-NN quando a condição é baseada em agregação por contagem de distintos ( $c d$-acond). Seleções por similaridade envolvendo um operador ${ }_{c} k \mathrm{NN}$ restrito por uma $c d$-acond têm pouquíssimas propriedades para reescrita de consultas. Uma exceção é se o atributo agAtr é uma chave candidata da relação de entrada, o que torna o modificador DISTINCT dispensável. Este caso particular é enunciado na regra a seguir.

Regra 4.12 (Redundância da contagem de distintos) Uma ${ }_{c} k-N N q$ restrita por uma condição baseada em agregação por contagem de distintos não filtrada, cujo atributo de agregação agAtr é uma chave candidata da relação de entrada, pode ser transformada em uma ${ }_{c} k-N N q$ restrita por uma condição baseada em agregação por contagem, pois, garantidamente, todas as tuplas de $R$ tem valores diferentes para agAtr. Neste caso, é válida a expressão a seguir:

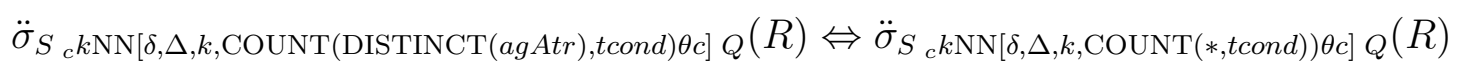

Vale ressaltar que, nos casos em que a regra da redundância da contagem de distintos é válida, por transitividade as regras válidas envolvendo $c$-aconds, apresentadas anteriormente, também são válidas. O modificador DISTINCT também altera o significado da negação de uma condição baseada em agregação por contagem. Em se tratando de cd-aconds, não é válida uma regra semelhante à Regra 4.11, a menos que o atributo de

\footnotetext{
${ }^{1}$ Note-se que se tcond for nula, ela será avaliada como verdadeira para todas as tuplas.
} 
agregação seja chave candidata da relação de entrada. Esta observação é fundamentada na Expressão 4.20:

$$
\begin{gathered}
\ddot{\sigma}_{S}{ }_{c} k \mathrm{NN}[\delta, \Delta, k, \operatorname{COUNT}(\operatorname{DiSTINCT}(\text { agAtr }), t \text { tcond }) \geq c] Q \\
\left.\Leftrightarrow \quad \ddot{\sigma}_{S}{ }_{c k} \operatorname{NN}[\delta, \Delta, k, \operatorname{COUNT}(\operatorname{DiSTINCT}(\text { agAtr }), \neg t \text { tcond })<(k-c+1))\right] Q
\end{gathered}
$$

pois o lado esquerdo da expressão indica que o resultado deve incluir ao menos $c$ tuplas que satisfazem tcond e tenham valores distintos para agAtr, enquanto o lado direito da expressão apenas impõe que o resultado deve ter menos de $(k-c+1)$ tuplas que não satisfazem tcond e que tem valores distintos para agAtr. Ou seja, o lado direito da expressão não trata da quantidade de tuplas satisfazendo tcond e com valores distintos para agAtr, podendo até mesmo não retornar nenhuma tupla que satisfaz tcond, contradizendo a condição indicada no lado esquerdo da expressão.

\subsubsection{Regras Algébricas Envolvendo Condições Baseadas em Agregação por Soma ou por Média}

As consultas aos vizinhos mais próximos estendidas com condições baseadas em agregação por soma e média têm poucas propriedades que podem ser utilizadas para reescrita de consultas. A única regra relevante para estes tipos de condições, definida a seguir, é baseada na observação que as definições de média e soma são correlacionadas ( média $=$ soma/contagem), se a condição de agregação não é filtrada.

Regra 4.13 (Equivalência entre agregação por soma e por média não filtradas) Uma condição baseada em agregação por média não filtrada pode ser transformada em uma condição baseada em agregação por soma não filtrada, e vice-versa, em uma seleção por similaridade sobre uma relação com $k$ tuplas ou mais envolvendo o operador ${ }_{c} k \mathrm{NN}$, isto é:

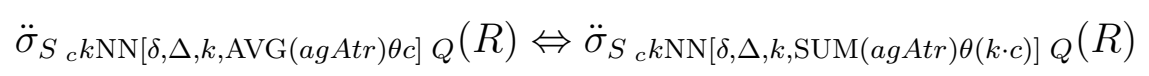

Note-se que, se a condição baseada em agregação por média (ou por soma) é filtrada (tcond não nula), a Regra 4.13 não é válida. O motivo é que não se sabe a priori o valor da contagem de tuplas que satisfazem tcond no resultado da consulta. Sabe-se, apenas, que esse valor é menor ou igual a $k$, o que não é suficiente para tornar a regra válida.

\subsubsection{Regras Algébricas Envolvendo Condições Baseadas em Agregação por Mínimo ou por Máximo}

Esta seção apresenta as regras algébricas para a seleção por similaridade envolvendo um operador ${ }_{c} k \mathrm{NN}$ restrito por uma condição baseada em agregação por mínimo ou por máximo. 
Regra 4.14 (Conversão de min-acond em tcond) Uma condição baseada em agregação por mínimo, cujo operador $\theta$ é ' $>$ ' ou ' $\geq$ ', pode ser transformada em uma condição baseada em tupla em uma seleção por similaridade. Isto é, são válidas as equivalências 4.22 e 4.23, respectivamente se tcond é nula na min-acond e se tcond não é nula na min-acond:

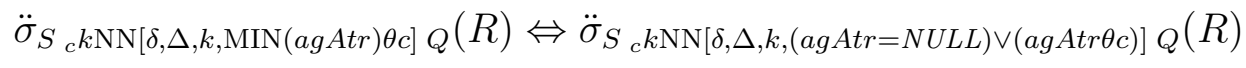

$\ddot{\sigma}_{S}{ }_{c} k \mathrm{NN}[\delta, \Delta, k, \operatorname{MIN}($ agAtr,tcond $) \theta c] Q(R) \Leftrightarrow \ddot{\sigma}_{S_{c} k \mathrm{NN}[\delta, \Delta, k,(t \operatorname{cond} d \wedge((\operatorname{agAtr}=N U L L) \vee(\text { agAtr } \theta c))) \vee(\neg t c o n d)] Q}(R)$

Observe-se que na Equivalência 4.22 a condição equivalente à minacond é uma disjunção de duas condições baseadas em tupla: a primeira $\langle$ tcond $\wedge((a g A t r=N U L L) \vee(a g A t r \theta c))\rangle$ que considera as tuplas que satisfazem a condição de filtragem tcond e, portanto, cujo mínimo valor para o atributo agAtr deve ser $c$ (ou então agAtr é nulo); e a segunda $\langle\neg t c o n d\rangle$ para incluir as tuplas que não satisfazem a condição de filtragem da função de agregação. Uma observação semelhante pode ser feita considerando-se a Equivalência 4.23. Uma exceção à Regra 4.14, considerando a Equivalência 4.22, ocorre se o valor do atributo agAtr for nulo para todas as tuplas da relação de entrada. Neste caso, a ${ }_{c} k$-NNq com a condição baseada em agregação por mínimo retorna uma relação vazia e a relação retornada pela ${ }_{c} k-\mathrm{NNq}$ com condição baseada em tupla não é vazia. Outra exceção à Regra 4.14 considera a Equivalência 4.23, caso todas as tuplas da relação de entrada que satisfazem a condição de filtragem tcond tenham valor nulo para o atributo agAtr.

Uma propriedade interessante da regra da conversão de min-acond em tcond é que uma seleção por similaridade envolvendo o operador ${ }_{c} k \mathrm{NN}$ restrito por uma min-acond pode ser convertida em uma seleção convencional, cuja expressão condicional é a condição baseada em tupla equivalente à min-acond, seguida por uma seleção por similaridade com

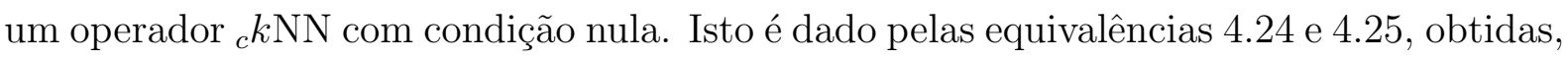
respectivamente, a partir das equivalências 4.22 e 4.23 , por transitividade pela Regra 4.5.

$$
\begin{aligned}
& \ddot{\sigma}_{S}{ }_{c k \mathrm{NN}[\delta, \Delta, k, \operatorname{MIN}(a g A t r) \theta c]} Q(R) \Leftrightarrow \ddot{\sigma}_{S}{ }_{c k \mathrm{NN}[\delta, \Delta, k]} Q\left(\sigma_{(\operatorname{agAtr}=N U L L) \vee(\operatorname{agAtr} \theta c)}(R)\right)
\end{aligned}
$$

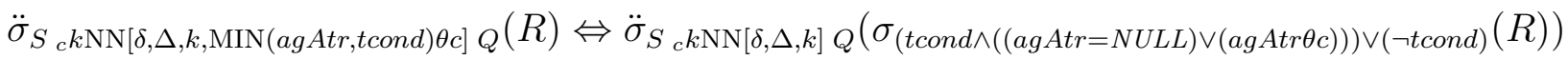

Regra 4.15 (Conversão de min-acond em $\boldsymbol{c}$-acond) Uma condição baseada em agregação por mínimo, cujo operador $\theta$ é ' $\leq$ ' ou ' $<$ ', pode ser transformada em uma condição baseada em agregação por contagem em uma seleção por similaridade. Isto é, 
são válidas as equivalências 4.26 e 4.27, respectivamente se a condição tcond é nula na min-acond e se tcond não é nula na min-acond:

$$
\begin{gathered}
\ddot{\sigma}_{S_{c} k \mathrm{NN}[\delta, \Delta, k, \operatorname{MIN}(\text { agAtr }) \theta c] Q}(R) \Leftrightarrow \ddot{\sigma}_{S_{c} k \mathrm{NN}[\delta, \Delta, k, \operatorname{COUNT}(*, a g A t r \theta c) \geq 1] Q}(R) \\
\ddot{\sigma}_{S_{c} k \mathrm{NN}[\delta, \Delta, k, \operatorname{MIN}(\text { agAtr,tcond }) \theta c] Q}(R) \Leftrightarrow \ddot{\sigma}_{S_{c} k \mathrm{NN}[\delta, \Delta, k, \operatorname{COUNT}(*, \operatorname{tcond} \wedge(\operatorname{ag} A \operatorname{Atr} \theta c)) \geq 1] Q}(R)
\end{gathered}
$$

Analisando-se a Equivalência 4.26, nota-se que a $c$-acond do operador ${ }_{c} k \mathrm{NN}$ da seleção por similaridade à direita na equivalência indica que o resultado deve incluir ao menos uma tupla cujo valor de agAtr seja maior (ou igual) a $c$. É essa observação que garante que o valor mínimo para agAtr no resultado seja maior (ou igual) a $c$, como especificado na min-acond da consulta à esquerda na equivalência. Um raciocínio semelhante aplica-se à Equivalência 4.27. A regras 4.16 e 4.17, apresentadas a seguir, são equivalentes às regras 4.14 e 4.15, mas considerando condições baseadas em agregação por máximo.

Regra 4.16 (Conversão de max-acond em tcond) Uma condição baseada em agregação por máximo, cujo operador $\theta$ é ' $<$ ' ou ' $\leq$ ', pode ser transformada em uma condição baseada em tupla em uma seleção por similaridade. Isto é, são válidas as equivalências 4.28 e 4.29, respectivamente se tcond é nula na max-acond e se tcond não é nula na max-acond:

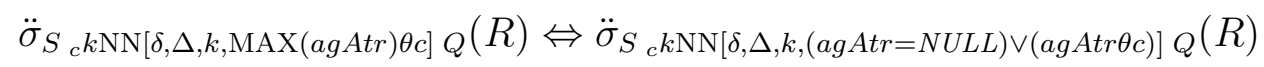

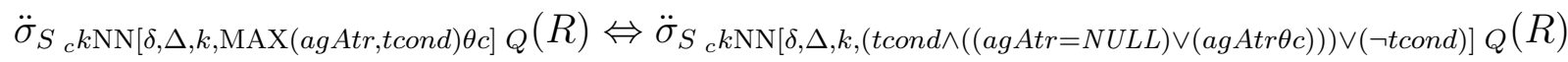

Regra 4.17 (Conversão de max-cond em $\boldsymbol{c}$-acond) Uma condição baseada em agregação por máximo, cujo operador $\theta$ é ' $\geq$ ' ou ' $>$ ', pode ser transformada em uma condição baseada em agregação por contagem em uma seleção por similaridade. Isto é, são válidas as equivalências 4.30 e 4.31, respectivamente se tcond é nula na max-acond e se tcond não é nula na max-acond:

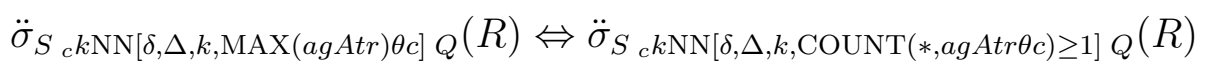

$$
\ddot{\sigma}_{S}{ }_{c} k \mathrm{NN}[\delta, \Delta, k, \operatorname{MAX}(\text { agAtr,tcond }) \theta c] Q(R) \Leftrightarrow \ddot{\sigma}_{S_{c} k \mathrm{NN}[\delta, \Delta, k, \operatorname{COUNT}(*, t \operatorname{tcond} \wedge(\operatorname{agAtr} \theta c)) \geq 1] Q}(R)
$$

As regras 4.14, 4.15, 4.16 e 4.17 mostram que as principais variações de min-aconds e max-aconds podem ser representadas utilizando outros tipos de condições restringindo o operador ${ }_{c} k \mathrm{NN}$ em uma seleção por similaridade. Os casos que escapam a essas regras são as exceções citadas e as consultas que utilizam min-aconds ou max-aconds, cujo operador $\theta$ é ' $=$ ' ou ' $\neq$ ', que têm aplicação prática limitada. Desta forma, as condições baseadas em agregação por mínimo e máximo são convenientes para representar consultas, contudo pouco aumentam o poder de expressividade do operador ${ }_{c} k \mathrm{NN}$. 


\subsection{Algoritmos}

Esta seção apresenta algoritmos desenvolvidos para executar consultas aos $k$-vizinhos mais próximos estendidas com condições. Os algoritmos desenvolvidos estendem os algoritmos para execução de consultas $k$-NN regulares sob alguns aspectos, como descrito a seguir.

Em primeiro lugar, o conjunto resposta de uma consulta $k$-NN regular é formado estritamente pelos elementos mais próximos ao(s) elemento(s) de consulta. Desta forma, não há diferenciação entre elementos do conjunto de dados, portanto todos são tratados de maneira igual nos algoritmos. Por outro lado, o conjunto resposta de uma ${ }_{c} k$-NN também tem que satisfazer a condição imposta na consulta. Além disso, a condição pode utilizar um filtro condicional, tanto em condições baseadas em tupla quanto em condições baseadas em agregação que utilizam funções de agregação filtradas. Essa característica exige diferenciar os elementos que satisfazem a condição de filtragem dos elementos que não a satisfazem.

Em segundo lugar, na execução de consultas ${ }_{c} k$-NN, o raio dinâmico passa a ser reduzido quando encontra-se um conjunto de $k$ elementos que satisfaz a condição imposta. Portanto, o conjunto resposta tem que ser controlado durante a execução dos algoritmos para garantir que os elementos que o compõem sejam escolhidos de forma que a condição imposta seja satisfeita.

Por fim, uma consulta ${ }_{c} k$-NN depende de outros atributos da relação de entrada para verificar a condição imposta, além do atributo complexo utilizado no cálculo de dissimilaridade. Entretanto, os métodos de acesso utilizados para responder a consultas por similaridade não prevêm atributos adicionais nas suas estruturas. Desta maneira, os algoritmos para consultas ${ }_{c} k$-NN que utilizam métodos de acesso para acelerar a busca devem considerar alternativas para armazenar e/ou recuperar os atributos adicionais necessários à execução da consulta.

\subsubsection{Fundamentos e Complexidade dos Algoritmos}

As consultas aos $k$-vizinhos mais próximos estendidas com condições demandam encontrar, dentre os $k$-conjuntos restritos pela condição imposta e induzidos por dissimilaridade sobre a relação de entrada, um conjunto que seja minimal. Entretanto, fazer a escolha das tuplas que compõem a resposta a uma consulta ${ }_{c} k$-NN restrita por uma condição baseada em agregação não é uma tarefa simples, pois nem sempre é trivial manter a lista de candidatos no decorrer do processamento das tuplas da relação de entrada. As definições 4.6, 4.10 e 4.12 estabelecem quais devem ser os resultados de ${ }_{c} k$-NNq restritas por condições baseadas em agregação considerando, respectivamente, a minimização da soma das distâncias, a minimização da menor distância e a minimização da maior distância. Note-se que as ${ }_{c} k$-NNq restritas por condições baseadas em agregação por contagem, 
por contagem de distintos, por mínimo ou por máximo podem escolher qualquer uma das opções de minimização, pois são indiferentes a esse fator. A partir dessas definições é possível definir algoritmos que respondam a ${ }_{c} k$-NNq restritas por esses tipos de condições, conforme segue:

1. identifique os $k$-conjuntos induzidos por dissimilaridade sobre a relação de entrada que satisfaçam a condição apresentada;

2. retorne um desses conjuntos que seja minimal, considerando a opção de minimização escolhida.

Embora esta solução retorne soluções exatas para as consultas, sua complexidade é muito alta. Dado que a cardinalidade da relação de entrada é $n$, há $C_{n, k}=n ! /(k ! \cdot(n-k) !)$ combinações de $k$ elementos possíveis. Este é o número de $k$ conjuntos induzidos por dissimilaridade sobre a relação de entrada. O teste da condição baseada em agregação sobre um $k$-conjunto induzido por dissimilaridade tem custo $O(k)$. O custo de calcular a dissimilaridade total de um conjunto (Definição 4.3), necessário para construir a resposta com base na minimização por soma das distâncias, também é $O(k)$. Da mesma forma, verificar se um $k$-conjunto é maior por menor/maior distância que outro (definições 4.9 e 4.11), necessário para as opções de minimização da menor distância ou de minimização da maior distância, tem um custo $O(k)$. Portanto, a complexidade desses algoritmos é $O\left(n^{k}\right)$, considerando que, em geral, $n \gg k$ em consultas ${ }_{c} k$-NN.

Contudo, para as consultas ${ }_{c} k$-NN restritas por condições baseadas em tupla, é possível encontrar uma solução eficiente fazendo uma adaptação simples no algoritmo de execução de consultas $k$-NN convencionais. Observe-se que a resposta de uma ${ }_{c} k$-NNq restrita por uma condição baseada em tupla pode ser dada por uma $k$-NNq convencional sobre as tuplas que satisfazem a condição imposta. Desta forma, a adaptação proposta consiste em fazer uma verificação dupla sobre as tuplas da relação de entrada. A primeira verificação testa se a tupla é candidata à resposta de acordo com o critério de distância, isto é, se a tupla corrente é mais próxima do elemento de referência do que o $k$-ésimo elemento do conjunto resposta. Se a tupla for candidata à resposta de acordo com o critério de distância, a segunda verificação testa se a tupla satisfaz a condição imposta. Caso afirmativo, o $k$-ésimo elemento é descartado do resultado, se for o caso, e a tupla corrente é inserida no resultado. Considerando-se que a verificação da condição baseada em tupla é realizada em tempo constante, a complexidade desse algoritmo, no pior caso, é:

- $O(n)$, em termos de cálculos de distância;

- $O(k)$, em termos de consumo de memória;

- $O(n \cdot \log k)$, em termos do número de comparações; 
onde $n$ é o tamanho da relação de entrada e $k$ o número de vizinhos. Esta solução é utilizada no Algoritmo 4.1 (Seção 4.4.2), desenvolvido neste trabalho para responder à ${ }_{c} k$-NNq restritas por $t$-conds. Embora a ordem das verificações seja irrelevante para a resposta, optou-se por fazer a verificação do critério de distância primeiro para tirar proveito da organização dos métodos de acesso métricos para reduzir o espaço de busca nas variações do algoritmo implementadas sobre essas estruturas, descritas na Seção 4.4.4.

Neste trabalho também foram desenvolvidas soluções eficientes para resolução de ${ }_{c} k-\mathrm{NNq}$ com condições baseadas em agregação por contagem, que possuem uma lógica mais elaborada do que a lógica do algoritmo proposto para ${ }_{c} k$-NNq com condições baseadas em tupla, mas com complexidades semelhantes. Os algoritmos propostos para a execução de ${ }_{c} k$-NNq com $c$-aconds ou com $c d$-aconds são apresentados na Seção 4.4.3. Estes algoritmos utilizam uma estrutura de dados auxiliar para armazenar o resultado parcial da consulta e controlar o descarte de candidatos. A estrutura utilizada é uma combinação de três listas de prioridade ordenadas segundo a distância do elemento armazenado ao(s) elemento(s) de consulta:

satisfyList: contém os elementos do resultado que satisfazem a condição de filtragem (tcond) da função de agregação e estão sendo contados para satisfazer a condição baseada em agregação definida na consulta;

notSatisfyList: contém os elementos que fazem parte do resultado, mas que não satisfazem a condição de filtragem;

resultList: contém todos os elementos do resultado, contados ou não na verificação da condição definida.

Esta organização permite realizar eficientemente o descarte de candidatos ao encontrar-se elementos mais próximos ao(s) elemento(s) de consulta, que satisfazem ou não a condição de filtragem, garantindo que após o descarte o resultado parcial como um todo satisfaça a condição baseada em agregação por contagem. Cada elemento armazenado é compartilhado entre duas listas de prioridade: a lista resultList, contendo todos os elementos, e a lista em que o elemento é categorizado (satisfyList ou notSatisfyList). Em algumas situações, um elemento considerado para garantir a satisfação da condição indicada na consulta pode passar a não ser mais considerado para garantir a condição. Nestes casos, o elemento pode ser descartado do resultado, ou então mantido, caso seja próximo o suficiente do(s) elemento(s) de consulta, mas agora como um elemento que não é considerado para satisfazer a condição da consulta.

Observe-se que as consultas ${ }_{c} k$-NN com condições baseadas em agregação por mínimo e por máximo mais frequentes podem ser transformadas em ${ }_{c} k$-NNq com condições baseadas em tupla ou com condições baseadas em agregação por contagem, conforme estabelecem 
as regras 4.14, 4.15, 4.16 e 4.17, apresentadas na Seção 4.3.4. Desta forma, essas consultas também podem ser resolvidas de forma eficiente, fazendo chamadas aos algoritmos propostos para ${ }_{c} k$-NN com condições baseadas em tupla ou com condições baseadas em contagem.

As subseções a seguir apresentam os algoritmos desenvolvidos durante o projeto de doutoramento. Os algoritmos propostos consideram que cada dado complexo é armazenado em uma tabela contendo o(s) vetor(es) de características e outros atributos descritivos a respeito do dado complexo. Por simplicidade, os algoritmos consideram que a consulta possui apenas um elemento de referência.

\subsubsection{Algoritmo Sequencial para Consultas ${ }_{c} k$-NN com Condições Baseadas em Tupla}

O algoritmo para execução de consultas aos $k$-vizinhos mais próximos estendidas com condições baseadas em tupla é bastante semelhante ao algoritmo para execução de $k$-NNq regulares. A diferença fundamental é que uma tupla é incluída no resultado não só se sua distância ao elementos de referência é menor do que o raio dinâmico de consulta (maxDist), mas também se a tupla satisfaz a condição baseada em tupla tcond.

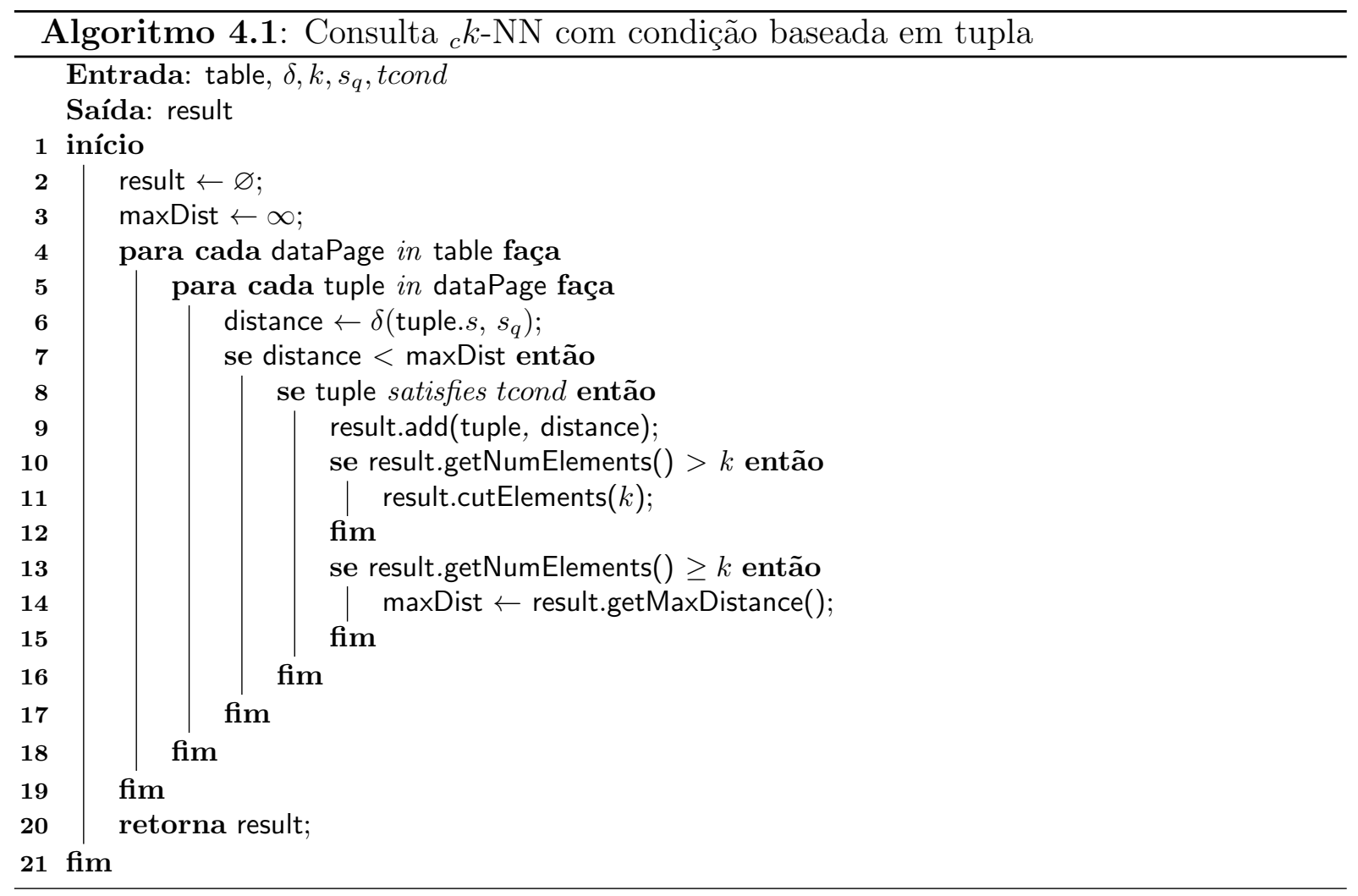

O Algoritmo 4.1 mostra a solução sequencial desenvolvida para execução de consultas ${ }_{c} k$-NN com condições baseadas em tupla. O algoritmo começa inicializando a estrutura de dados que armazena o resultado com vazio e o raio dinâmico de consulta com infinito 
(linhas 2-3). Para cada tupla, de cada página de dados, o algorimo calcula a distância entre a tupla e o elemento de consulta (linhas 4-6). Se a distância for menor que o raio dinâmico de consulta, o algoritmo testa se a tupla satisfaz a condição baseada em tupla tcond fornecida na consulta (linhas 7-8). Caso afirmativo, a tupla é inserida no resultado (linha 9). A inserção da nova tupla pode fazer com que o resultado fique com mais de $k$ elementos. Neste caso, o algoritmo invoca a função cutElements com o parâmetro $k$, que elimina os elementos mais distantes do elemento de referência em excesso, fazendo com que o resultado corrente fique com $k$ elementos (linhas 10-11). Se o resultado corrente já possuir $k$ elementos, o raio dinâmico de consulta é atualizado com a maior distância no resultado corrente, que é dada pela distância entre o elemento de referência e o $k$-ésimo elemento corrente (linhas 13-14). Após processar todas as tuplas da relação de entrada, o algoritmo retorna o resultado obtido (linha 20).

\subsubsection{Algoritmos Sequenciais para Consultas ${ }_{c} k-\mathrm{NN}$ com Condições Baseadas em Agregação por Contagem}

Esta seção apresenta os algoritmos com execução sequencial desenvolvidos para executar consultas ${ }_{c} k$-NN com condições baseadas em agregação por contagem ( $c$-aconds) e ${ }_{c} k$-NNq com condições baseadas em agregação por contagem de distintos ( $c$-aconds).

\section{Algoritmo Sequencial para ${ }_{c} k-\mathrm{NNq}$ com c-aconds}

$\mathrm{Na}$ maior parte das consultas aos $k$-vizinhos mais próximas que utilizam $c$-aconds $\langle$ COUNT(agAtr, tcond $) \theta c\rangle$, o operador $\theta$ é um entre $\{<, \leq, \geq,>\}$. Como o valor de $c$ é inteiro, uma condição $\langle\operatorname{COUNT}($ agAtr,tcond $)<c\rangle$ pode ser representada como $\langle$ COUNT $($ agAtr, tcond $) \leq c-1\rangle$. De maneira análoga, uma condição com $\theta=$ ' $>$ ' pode ser representada utilizando $\theta=$ ' $\geq$ '. Assim, é suficiente definir algoritmos para condições $\operatorname{com} \theta \in\{\leq, \geq\}$. Além disso, considerando uma ${ }_{c} k$-NNq restrita por uma condição baseada em agregação por contagem (sem o modificador DISTINCT), é possível definir facilmente a inversa da condição imposta, conforme mostra a Equivalência 4.18, apresentada na Seção 4.3.2. Desta forma, um algoritmo é o suficiente para responder a consultas ${ }_{c} k$-NN com $c$-aconds.

O Algoritmo 4.2 é a solução baseada em busca sequencial proposta nesta tese para executar consultas ${ }_{c} k$-NN com $c$-aconds, considerando $\theta=$ ' $\geq$ '. O algoritmo inicializa a estrutura de dados usada para armazenar o resultado parcial da consulta e define o raio dinâmico de consulta (maxDist) como infinito, impedindo inicialmente qualquer descarte de candidatos (linhas 2-3). Para cada tupla nas páginas de dados da relação de entrada, a distância entre a tupla armazenada e o elemento de consulta é calculada e, se a distância é menor que o raio dinâmico atual, a tupla é qualificada para ser incluída no resultado da consulta, considerando-se apenas o critério de dissimilaridade (linhas 4-7). Então, 


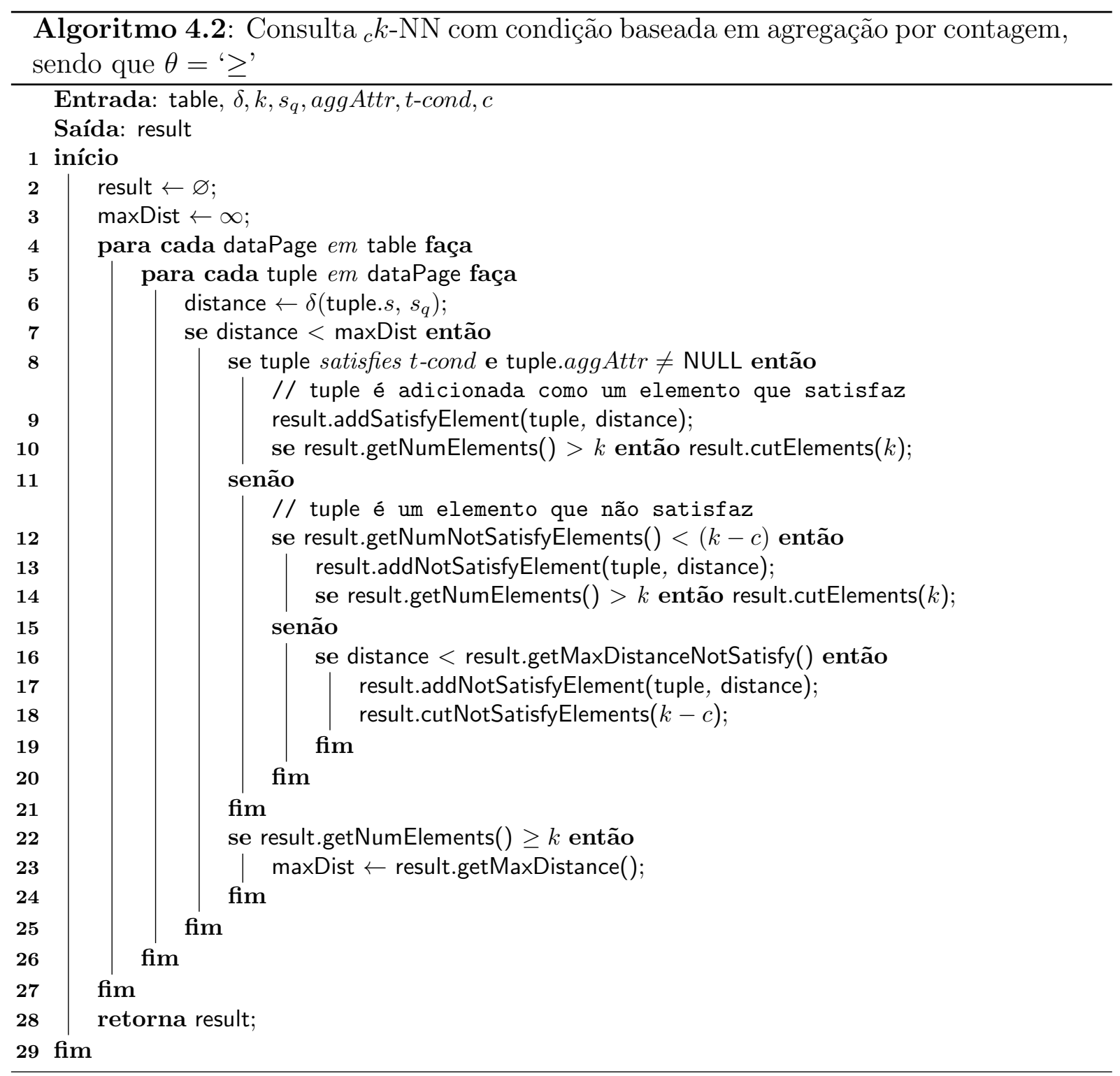

o algoritmo verifica se a tupla satisfaz a condição de filtragem fornecida tcond e se o valor do atributo de agregação agAtr não é nulo (teste desnecessário se foi solicitada a contagem de tuplas - COUNT $(*$, tcond $))$, para decidir se a tupla deve ser considerada na contagem ou não (linha 8). Se a tupla atende a estes requisitos, ela é incluída no resultado, na lista satisfyList, que contém os elementos que estão sendo contados para satisfazer a condição da consulta (linha 9). Se a inserção da tupla no resultado faz com que o resultado passe a ter mais que $k$ tuplas, o elemento mais distante no resultado é descartado, mantendo exatamente $k$ elementos no resultado, como informado no parâmetro da função cutElements (linha 10). Caso a tupla não satisfaça tcond, ou se o atributo de agregação seja nulo, quando for o caso, a tupla não é considerada na contagem e, portanto, é um elemento que não satisfaz a condição. Neste caso, o algoritmo verifica se a tupla pode ser adicionada ao resultado sem violar a condição baseada na contagem, que define que o resultado deve conter ao menos $c$ elementos que satisfazem tcond, o que implica que o 
resultado pode incluir, no máximo, $k-c$ elementos que não satisfazem tcond (linha 12). Se a tupla pode ser adicionada ao resultado, ela é adicionada na lista notSatisfyList (linha 13). Se após esta operação o resultado possuir mais do que $k$ elementos, isto significa que há mais do que $c$ tuplas na lista satisfyList, portanto, o elemento mais distante do elemento de consulta pode ser seguramente descartado do resultado, independentemente de ser um elemento que satisfaz tcond ou não (linha 14). Entretanto, se o teste da linha 12 não é verdadeiro, não é possível acrescentar ao resultado novos elementos que não satisfazem tcond sem ferir a condição baseada na contagem. Assim sendo, a tupla corrente somente poderá ser incluída no resultado no lugar de outra tupla que também não satisfaz tcond e é mais distante do elemento de consulta do que a tupla corrente. Se a distância da tupla corrente ao elemento de consulta é menor do que a maior distância dentre as tuplas da lista notSatisfyList, a tupla corrente é incluída no resultado e a tupla mais distante em notSatisfyList é removida, mantendo esta lista com $k-c$ elementos (linhas 16-18). Finalmente, o algoritmo verifica se o resultado contém $k$ elementos e, neste caso, atualiza o raio dinâmico de consulta com a maior distância no resultado, que é a distância da tupla no resultado parcial mais distante do elemento de consulta (linhas 22-23). Ao final do processamento de todas as tuplas da relação, o resultado gerado é retornado (linha 28).

\section{Algoritmo Sequencial para ${ }_{c} k-\mathrm{NNq}$ com cd-aconds}

O Algoritmo 4.3 foi desenvolvido para responder a consultas ${ }_{c} k$-NN com condições baseadas em agregação por contagem de distintos ( $c$-aconds), $\operatorname{com} \theta={ }^{\prime} \geq$ '. As primeiras 8 linhas são exatamente iguais às respectivas linhas no algoritmo para executar ${ }_{c} k$-NNq com $c$-aconds, apresentado na subseção anterior. A partir deste ponto, os algoritmos passam a ser consideravelmente diferentes. Na linha 9, o algoritmo percorre o resultado procurando por um elemento duplicado que satisfaça a condição de filtragem, ou seja, um elemento na lista satisfyList que tem o mesmo valor de agAtr que a tupla corrente que, neste ponto do algoritmo, sabe-se que também satisfaz tcond. Se é encontrado um elemento duplicado, o algoritmo testa se a tupla corrente é mais próxima ao elemento de consulta do que o duplicado (linhas 10-11). Caso afirmativo, a tupla corrente é incluída em satisfyList, para substituir o duplicado (linha 12). Em seguida, o algoritmo verifica se o elemento duplicado ainda deve ser mantido no resultado, mas agora tratado como uma tupla que não satisfaz a condição de filtragem, pois não é mais contada na função de agregação. Uma tupla que não satisfaz a condição de filtragem somente é incluída no resultado se houver espaço para mais tuplas que não satisfazem tal condição ou em substituição a outra tupla que também não satisfaz a condição. Desta forma, o algoritmo verifica se há menos que $k-c$ tuplas que não satisfazem tcond no resultado (linha 13). Neste caso, o elemento duplicado é retirado da lista satisfyList e movido para a lista notSatisfyList (linha 14). Se após esta operação o resultado ficar com mais de $k$ elementos, a tupla mais distante é descartada, independentemente de estar sendo contada na função de agregação ou não, 


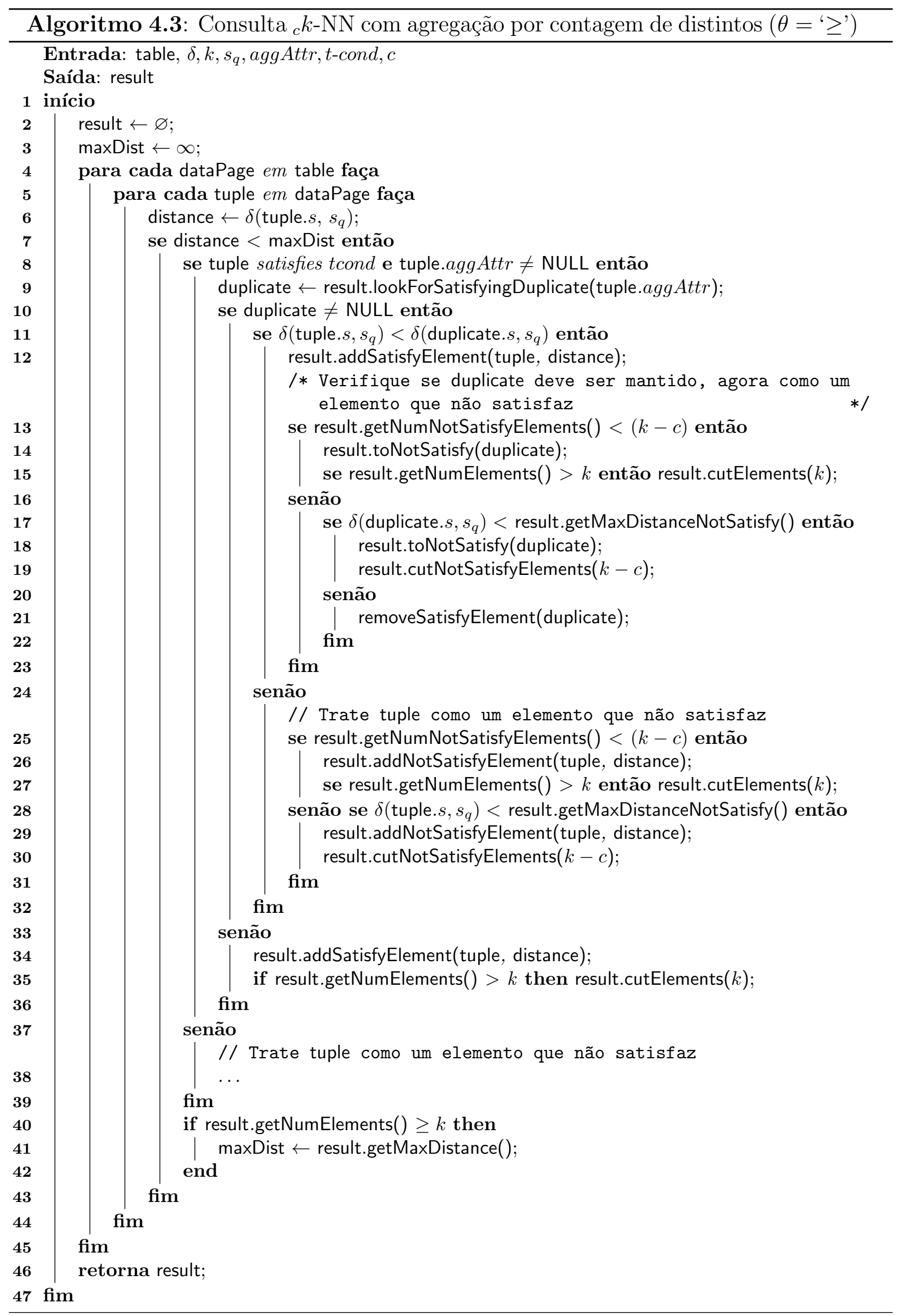


pois sabe-se neste ponto do algoritmo que o resultado contém mais do que $c$ tuplas que satisfazem tcond e que têm valores distintos para agAtr (linha 15). Por outro lado, se já existem $k-c$ elementos que não estão sendo contados na função de agregação, testa-se se o duplicado é mais próximo do elemento de consulta do que alguma tupla em notSatisfyList (linha 17). Caso esse teste seja verdadeiro, o duplicado é movido para a lista notSatisfyList e a tupla mais distante desta lista é descartada, mantendo $k-c$ elementos na lista (linhas 18-19). Caso contrário, o duplicado é removido do resultado (21). No caso da tupla corrente (satisfazendo tcond) ser mais distante do elemento de consulta do que o duplicado encontrado, isto é, o teste da linha 10 retorna falso, o algoritmo verifica se a tupla deve ser inserida no resultado como um elemento que não satisfaz a condição de filtragem, seguindo uma lógica semelhante àquela utilizada anteriormente para verificar se o duplicado mais distante deveria ser mantido no resultado ou não (linhas 25-30). As linhas 34-35 tratam do caso em que a tupla corrente satisfaz tcond e não possui duplicação com relação ao atributo agAtr no resultado. Neste caso, a tupla é inserida no resultado e, caso esta operação deixe o resultado com mais de $k$ tuplas, a tupla mais distante é descartada, independentemente de estar sendo contada ou não na função de agregação, pois é certo que com a inserção da tupla corrente o resultado passou a ter uma contagem de distintos satisfazendo tcond maior ou igual a $c+1$. Se a tupla corrente não satisfaz tcond a inserção ou não dela no resultado segue a lógica já apresentada para elementos tratados como não satisfazendo a condição. Por fim, se o resultado possui $k$ elementos, o raio dinâmico de consulta é atualizado com a maior distância dentre as tuplas no resultado (linhas 40-41), e a execução continua até que o resultado final seja obtido.

Caso $\theta$ seja $\leq$, outro algoritmo faz-se necessário, pois uma consulta ${ }_{c} k$-NN restrita por uma $c d$-acond $\operatorname{com} \theta=$ ' $\leq$ ', não pode ser convertida diretamente em uma ${ }_{c} k$-NNq com uma $c d$-acond tal que $\theta=$ ' $\geq$ ' (vide Equivalência 4.20 na Seção 4.3.2). No algoritmo para execução ${ }_{c} k$-NNq restritas por $c d$-aconds $\operatorname{com} \theta=$ ' $\leq$ ', o tratamento de elementos que satisfazem a condição de filtragem da função de agregação é um pouco diferente do apresentado no Algoritmo 4.3, pois exige manter listas adicionais de candidatos ao resultado da consulta. A intuição desta idéia é a seguinte. Uma ${ }_{c} k$-NNq com uma $c d$ acond $\langle$ COUNT(DISTINCT(aggAttr), t-cond) $\leq c\rangle$, tal que $c<k$, permite mais de uma tupla com o mesmo valor para agAtr no resultado, embora apenas uma delas é considerada na contagem de distintos. Durante a execução da consulta, se o número de elementos distintos que satisfazem a condição de filtragem da $c d$-acond está no limite (ou seja, já é igual a c) e o algoritmo encontra outra tupla mais próxima que o raio dinâmico de consulta, tal que essa tupla satisfaça a condição de filtragem e cujo valor de agAtr seja diferente dos valores das tuplas que fazem parte do resultado "corrente", esta nova tupla deve ser incluída no resultado. Ao incluir a nova tupla, outra tupla que estava sendo considerada anteriormente na contagem de distintos deve ser removida do resultado. Entretanto, pode ser que o resultado inclua outras tuplas cujo valor de agAtr seja igual 
ao valor da tupla a ser removida e, portanto, também tenham que ser removidas do resultado "em cascata". Desta forma, a inclusão de uma nova tupla pode substituir mais de uma tupla no resultado. Isso requer que sejam mantidas listas adicionais para cada valor distinto considerado na contagem, para fazer a escolha da(s) tupla(s) "duplicada(s)" mais próxima(s) do elemento de referência para inclusão no resultado.

\subsubsection{Algoritmos Utilizando o Método de Acesso Métrico Slim-tree}

Esta seção apresenta a implementação de duas variações dos algoritmos para ${ }_{c} k$-NNq com condições baseadas em tupla e para ${ }_{c} k$-NNq com condições baseadas em agregação por contagem, apresentados anteriormente, sobre o método de acesso métrico Slim-tree. A escolha deste método de acesso para implementação dos algoritmos foi devido a ser uma estrutura que está entre as de melhor desempenho encontradas na literatura, e que está bem consolidada para indexação de dados complexos. O algoritmo para execução de uma $k$-NN regular em uma Slim-tree, apresentado na Seção 3.3.4, utiliza a estratégia de visita de nós Best-First e realiza a poda de subárvores com base na propriedade de desigualdade triangular. Uma diferença fundamental deste algoritmo para os algoritmos propostos nesta tese para responder a consultas $k$-NN estendidas com condições é que as ${ }_{c} k$-NNq utilizam, além do vetor de características do dado complexo, atributos adicionais na definição das condições.

Os algoritmos para ${ }_{c} k$-NNq sobre a Slim-tree desenvolvidos nesta tese seguem a lógica de gerenciamento do resultado parcial da consulta dos algoritmos baseados em busca sequencial apresentados na seção anterior, diferenciando tuplas que satisfazem à condição de filtragem da função de agregação e controlando a inclusão e descarte de elementos no resultado. Além disso, os algoritmos incluem a lógica da poda de subávores e de elementos baseada na propriedade de desigualdade triangular e também a estratégia de visita de nós Best-First, da mesma forma que o algoritmo para execução de $k$-NN tradicionais da Slimtree. Contudo, a Slim-tree foi concebida para armazenar apenas vetores de características, portanto, os algoritmos propostos utilizam duas estratégias para acesso aos atributos adicionais, compreendendo duas variações dos algoritmos.

Para implementar estas variações de algoritmos, foi desenvolvida uma abstração para armazenamento de tabelas em disco e uma camada de acesso a páginas de dados, denominada Gerenciador de Blocos de Dados. Na abstração implementada, cada tabela é armazenada em um arquivo e o identificador de linha (rowId) é formado pelo identificador da página de disco e a pela posição da tupla dentro da página, que é utilizada para indexar o cabeçalho da página e recuperar o deslocamento da tupla dentro da página. A seguir, são descritas as duas variações desenvolvidas.

A primeira variação, denominada Table-Slim, utiliza uma Slim-tree convencional, armazenando o vetor de características e o identificador da linha (rowId) de cada tupla 
indexada. Para cada nó folha visitado segundo a ordem definida pela estratégia BestFirst, os algoritmos verificam se os elementos armazenados são candidatos a compor o resultado da consulta segundo o critério de dissimilaridade. Ou seja, verifica-se, para cada elemento armazenado, se ele está mais próximo do elemento de consulta do que algum elemento que faz parte do resultado parcial. Para verificar o critério de similaridade, apenas os vetores de caracteríticas são necessários. Portanto, nesta fase o algoritmo utiliza apenas dados existentes na estrutura. Caso algum elemento avaliado satisfaça o critério de dissimilaridade, o algoritmo precisa verificar se o elemento é candidado à resposta segundo a condição imposta à consulta ${ }_{c} k$-NN. Para fazer esta verificação, o algoritmo recupera a tupla apontada pelo rowId armazenado no elemento e procede conforme a lógica apresentada nos algoritmos baseados em busca sequencial. A variação Table-Slim tende a demandar um grande número de acessos a páginas de dados. Entretanto, é uma alternativa genérica que permite utilizar um índice Slim-tree existente em atributo contendo um vetor de características de um dado complexo para responder a uma ${ }_{c} k$-NNq cuja condição envolve qualquer outro atributo da tabela que armazena o dado complexo. Além disso, dependendo da consulta e dos volumes de dados filtrados pelas várias condições, esta variação pode ser muito mais eficiente do que a busca sequencial.

A segunda variação, denominada Covering-Slim, define a Slim-tree como um índice de cobertura de consultas ${ }_{c} k$-NN. Isto significa que a Slim-tree armazena atributos adicionais da tabela de origem, que são usados na condição restringindo a seleção por similaridade envolvendo o operador ${ }_{c} k \mathrm{NN}$, além do rowId associado a cada vetor de características indexado. A estrutura continua organizada segundo o espaço de busca definido pelo vetor de características, porém, ao encontrar um determinado elemento em uma página folha da estrutura, obtém-se o rowId e os demais atributos associados ao elemento. Desta forma, se existe um índice de cobertura Slim-tree que contém o(s) atributo(s) usados na condição de uma consulta ${ }_{c} k$-NN, os algoritmos desenvolvidos realizam o processo de identificação do conjunto resposta utilizando apenas este índice. Tendo definido o conjunto resposta, os algoritmos requisitam ao Gerenciador de Blocos de Dados as tuplas para retornar o resultado final da consulta. Portanto, o número de acessos a páginas de dados é minimal, pois apenas páginas de dados contendo tuplas do resultado da consulta são recuperadas, o que torna esta variação bastante eficiente.

\subsection{Experimentos}

Esta seção apresenta resultados de experimentos avaliando o desempenho dos algoritmos desenvolvidos para a execução de consultas ${ }_{c} k$-NN. Foram testadas a versão sequencial dos algoritmos propostos e as duas variações de implementação sobre o MAM Slim-tree. As subseções a seguir descrevem os conjuntos de dados utilizados, a metodologia de teste e os resultados obtidos. 


\subsubsection{Conjuntos de Dados e Descrição dos Experimentos}

Foram executados experimentos sobre os algoritmos desenvolvidos sobre conjuntos de dados georeferenciados e conjuntos de imagens. Esta seção apresenta resultados obtidos sobre dois desses conjuntos, descritos a seguir.

\section{Conjunto CidadesAmericanas}

O primeiro conjunto de dados é o conjunto CidadesAmericanas, que contém o nome, o estado, as coordenadas geográficas e mais 97 atributos de dados demográficos de 25.374 cidades dos Estados Unidos. Este conjunto foi obtido por meio da combinação de dados demográficos das cidades, referentes ao censo americano de 2000, e as coordenadas geográficas do sistema Tiger, ambos disponibilizados pelo U.S. Census Bureau. Para avaliar os algoritmos que executam consultas ${ }_{c} k$-NN restritas por condições baseadas em agregação por contagem, é preciso verificar como o desempenho de uma ${ }_{c} k$-NNq é afetado pelo número de vizinhos $(k)$, pelo valor de $c$ e pela seletividade da condição de filtragem da condição baseada em agregação fornecida. Observe-se que uma ${ }_{c} k$-NNq restrita por uma $c$-acond, tal que $\theta=$ ' $\geq$ ' e que a condição de filtragem tcond que é satisfeita por apenas $1 \%$ das tuplas da relação de entrada (o que corresponde a uma seletividade de $99 \%$ ), tende a ser mais custosa do que uma ${ }_{c} k-\mathrm{NNq}$ restrita por uma $c$-acond semelhante, mas cuja condição de filtragem é satisfeita por $20 \%$ das tuplas da relação de entrada (seletividade de 80\%). No caso de ${ }_{c} k$-NNq restritas por condições baseadas em tupla, o desempenho dos algoritmos é afetado apenas pelo número de vizinhos e pela seletividade da condição. Desta forma, para permitir avaliar o impacto desses parâmetros, as consultas deste teste foram definidas como segue:

Consulta 9: Retorne as $k$ cidades que são as mais próximas à cidade de referência, de forma que o resultado inclua ao menos $c$ cidades com população maior ou igual a $x$ habitantes.

Consulta 10: Retorne as $k$ cidades que são as mais próximas à cidade de referência, de forma que o resultado inclua ao menos $c$ cidades, de estados distintos, com população maior ou igual a $x$ habitantes.

Consulta 11: Retorne as $k$ cidades que são as mais próximas à cidade de referência que tenham população maior ou igual a $x$ habitantes.

onde a Consulta 9 é a uma ${ }_{c} k$-NNq restrita por uma $c$-acond, a Consulta 10 é uma ${ }_{c} k$-NNq com uma $c d$-acond e a Consulta 11 é uma ${ }_{c} k$-NNq restrita por uma tcond. Com respeito às ${ }_{c} k-\mathrm{NNq}$ com condições baseadas em agregação por contagem, foram executadas três 
baterias de 500 consultas, cada uma com uma cidade de referência sorteada aleatoriamente e usando a distância $L_{2}$ sobre as coordenadas das cidades como função de dissimilaridade, sendo:

$\mathbf{1}^{\text {a }}$ bateria: variando-se $c$ entre 1 e 100 para a Consulta 9 e entre 1 e 10 para a Consulta 10 e, para ambas as consultas, fixando-se $k=100$ e fixando-se a seletividade da tcond em $95 \%$ (dada por $x=29674$ );

$2^{\text {a }}$ bateria: fixando-se $c=20$ para a Consulta 9 e $c=5$ para a Consulta 10 e, para ambas as consultas, variando-se $k$ entre 20 e 400 e fixando-se a seletividade da tcond em $95 \%$;

$3^{\text {a }}$ bateria: fixando-se $c=20$ para a Consulta 9 e $c=5$ para a Consulta 10 e, para ambas as consultas, fixando-se $k=100$ e variando-se a seletividade da tcond entre $50 \%$ e $99 \%$.

Para as ${ }_{c} k$-NNq com condições baseadas em tupla, foram executadas duas baterias de 500 consultas, sendo:

$1^{\text {a }}$ bateria: variando-se $k$ entre 1 e 400 e fixando-se a seletividade da tcond em 95\%;

$2^{\text {a }}$ bateria: fixando-se $k=100$ e variando-se a seletividade da tcond entre $50 \%$ e $99 \%$.

\section{Conjunto DICOM_HC200k}

O segundo conjunto de dados, denominado DICOM_HC200k ${ }^{2}$, foi obtido a partir de uma coleção de 200 mil imagens DICOM, do Hospital das Clínicas da Faculdade de Medicina de Ribeirão Preto da USP (HCFMRP-USP). De cada imagem, foi extraído o histograma normalizado de 256 níveis de cinza e 13 atributos do cabeçalho da imagem, incluindo a descrição do exame, a idade do paciente e outras informações. As consultas executadas sobre este conjunto de dados utilizaram a distância $L_{1}$ e foram enunciadas como segue:

Consulta 12: Retorne as $k$ imagens que são as mais próximas à imagem de referência, de forma que ao menos $c$ delas sejam de pacientes com $x$ anos de idade ou mais.

Consulta 13: Retorne as $k$ imagens que são as mais próximas à imagem de referência, de forma que ao menos $c$ delas sejam de exames/estudos distintos de pacientes com $x$ anos de idade ou mais.

\footnotetext{
${ }^{2}$ Este conjunto de dados é uma parte do conjunto DICOM_HC, utilizado nos experimentos apresentados na Seção 5.4.
} 
Consulta 14: Retorne as $k$ imagens que são as mais próximas à imagem de referência que sejam de pacientes com $x$ anos de idade ou mais.

Para as consultas baseadas em agregação por contagem sobre este conjunto (consultas 12 e 13), também foram executadas três baterias de consultas, mas considerando a média de 50 consultas com imagens de referência aleatórias, a saber:

$\mathbf{1}^{\text {a }}$ bateria: variando-se $c$ entre 1 e 100 para a Consulta 12 e entre 1 e 35 para a Consulta 13 e, para ambas as consultas, fixando-se $k=100$ e fixando-se a seletividade da tcond em $93.75 \%$ (dada por $x=77$ );

$2^{\text {a }}$ bateria: fixando-se $c=20$ para a Consulta 12 e $c=15$ para a Consulta 13 e, para ambas as consultas, variando-se $k$ entre 20 e 400 e fixando-se a seletividade da tcond em $93.75 \%$;

$\mathbf{3}^{\mathbf{a}}$ bateria: fixando-se $c=20$ para a Consulta 12 e $c=15$ para a Consulta 13 e, para ambas as consultas, fixando-se $k=100$ e variando-se a seletividade da tcond entre $50 \%$ e $99 \%$.

Para as ${ }_{c} k-\mathrm{NNq}$ com condições baseadas em tupla (Consulta 14), foram executadas duas baterias de consultas, sendo:

$\mathbf{1}^{\text {a }}$ bateria: variando-se $k$ entre 1 e 400 e fixando-se a seletividade da tcond em $93.75 \%$;

$2^{\mathbf{a}}$ bateria: fixando-se $k=100$ e variando-se a seletividade da tcond entre $50 \%$ e $99 \%$.

Os experimentos foram executados em uma máquina equipada com um processador Intel Core 2 Quad 2.83GHz, 4GB de memória RAM e um disco rígido SATA2 de 2TB e 7.200RPM, sobre o sistema operacional Kubuntu GNU/Linux 10.04 64bit. Os algoritmos foram implementados em $\mathrm{C}++$, utilizando a biblioteca Arboretum ${ }^{3}$, uma biblioteca de métodos de acesso, desenvolvida em $\mathrm{C}++$ pelo Grupo de Bases de Dados e Imagens do Instituto de Ciências Matemáticas e de Computação da Universidade de São Paulo (GBdI-ICMC-USP), e compilados com o GCC 4.4.3 para GNU/Linux.

\subsubsection{Resultados e Discussão}

A seguir são apresentados os resultados dos experimentos realizados, considerando os algoritmos que respondem à consultas ${ }_{c} k$-NN com os três tipos de condições restringindo uma ${ }_{c} k$-NNq testados: $c$-aconds, $c d$-aconds e tconds.

\footnotetext{
${ }^{3}$ http://gbdi.icmc.usp.br/arboretum
} 


\section{Algoritmos para ${ }_{c} k$-NNq com Condições Baseadas em Agregação por Contagem}

As figuras 4.12 e 4.13 mostram, respectivamente, os resultados da execução das consultas 9 sobre o conjunto CidadesAmericanas e 12 sobre o conjunto DICOM_HC200k. Os gráficos da primeira coluna das figuras mostram o comportamento dos algoritmos desenvolvidos com respeito à variação do parâmetro $c$, enquanto os gráficos da segunda e da terceira colunas mostram, respectivamente, os comportamentos dos algoritmos com relação à variação de $k$ e da seletividade da condição de filtragem. Note-se que os gráficos da terceira coluna são apresentados em escala logarítmica, para facilitar a legibilidade. Os gráficos da primeira linha das figuras mostram o tempo total de execução dos algoritmos sobre os conjuntos de dados, de acordo com as variações dos parâmetros, sumarizando o comportamento das outras variáveis observadas: número médio de cálculos de distância, número médio de comparações envolvendo os atributos tradicionais usados na condição da ${ }_{c} k$-NNq, número médio de acessos a disco e número médio de operações na lista de prioridade que armazena o resultado.

Com respeito à Consulta 9 ( ${ }_{c} k$-NNq com uma $c$-acond sobre o conjunto CidadesAmericanas), analisando o gráfico da Figura 4.12a, pode ser visto que tanto o algoritmo Sequencial quanto o algoritmo Covering-Slim apresentaram um comportamento praticamente constante com relação à variação de $c$, tendo o Covering-Slim sido até 4 vezes mais rápido do que o Sequencial. Observando os outros gráficos da primeira coluna, pode ser percebido que as variáveis analisadas que apresentaram um comportamento crescente - número de comparações (Fig. 4.12d), para o algoritmo Sequencial, e número de cálculos de distância (Figura 4.12d) e número de comparações (Figura 4.12g) para o algoritmo Covering-Slim - foram compensados pelo comportamento decrescente do número de operações sobre a lista de prioridade (Figura 4.12m). Por outro lado, o algoritmo Table-Slim apresentou um comportamento linear com relação ao tempo de execução, tendo desempenho inferior ao algoritmo Covering-Slim para todos os valores de $c$, e inferior ao algoritmo Sequencial para $c>30$. Embora para a maioria das variáveis o algoritmo Table-Slim foi mais eficiente do que o Covering-Slim, o Table-Slim teve um custo muito alto de acessos a disco (Figura 4.12j), degradando o tempo total de execução. A Figura 4.12b mostra que os tempos de execução dos três algoritmos apresentaram um comportamento linear com relação à variação de $k$. Novamente, o algoritmo Covering-Slim foi o mais rápido, tendo sido até 6 vezes mais rápido que o Sequencial e até 5 vezes mais rápido que o Table-Slim. Contudo, com relação à variação de $k$, o algoritmo Table-Slim foi até $20 \%$ mais rápido do que o Sequencial, pois o número superior de acessos a disco demandados pelo Table-Slim (Figura 4.12k) foi compensado pelo seu desempenho muito superior ao Sequencial nas outras variáveis (figuras 4.12e, 4.12h e 4.12n). O gráfico da Figura 4.12c mostra que somente o algoritmo Table-Slim apresentou uma degradação aguda no tempo de execução, para altas seletividades da condição de filtragem. Mais uma vez, o desempenho inferior do al- 

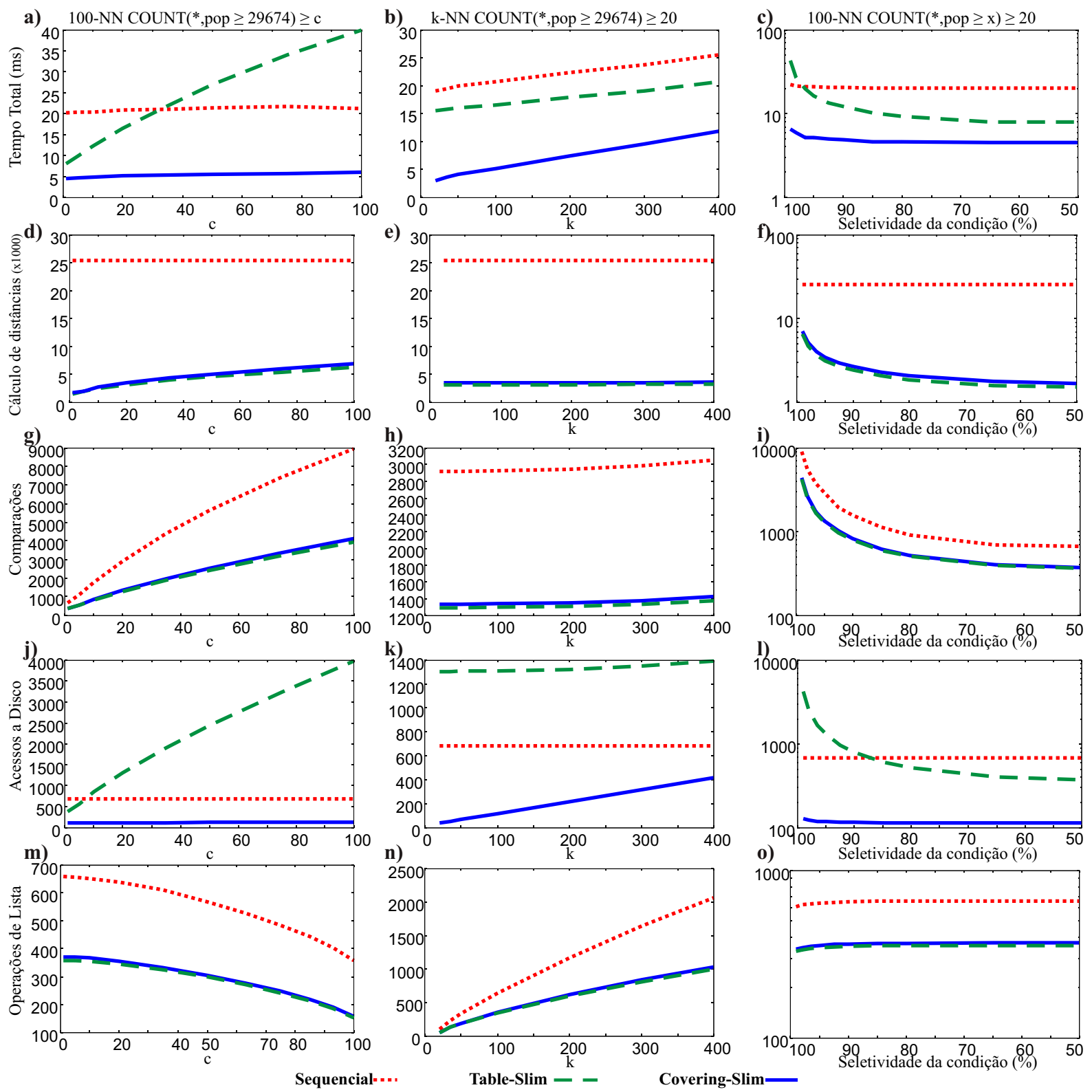

Figura 4.12: Resultados da execução da Consulta 9 sobre o conjunto de dados CidadesAmericanas, comparando o comportamento dos algoritmos Sequencial, Table-Slim e Covering-Slim com relação à variação de $c$ (coluna à esquerda), de $k$ (coluna central) and da seletividade da condição de filtragem (coluna à direita).

goritmo Table-Slim foi devido ao alto número de acessos a disco (Figura 4.121). Os tempos de execução dos algoritmos Covering-Slim e Sequencial apresentaram um comportamento praticamente constante com relação à variação de seletividade da condição de filtragem, tendo um crescimento sutil para seletividades maiores que 97\%. Esse crescimento foi resultado do aumento do número de comparações (Figura 4.12i), para o algoritmo Sequencial, e do aumento tanto do número de comparações (Figura 4.12i) quanto do número de cálculos de distância (Figura 4.12f), para o Covering-Slim. O Covering-Slim foi o mais rápido de todos, tendo sido em torno de 4 vezes mais rápido do que o Sequencial e até 6.5 vezes 
mais rápido do que o Table-Slim. O Table-Slim foi mais eficiente que o Sequencial para seletividades menores do que $97 \%$, chegando a ser até 2.5 vezes mais rápido. Por fim, a Figura 4.12o mostra que o número de operações na lista de prioridade dos três algoritmos foi praticamente indiferente à variação da seletividade da condição de filtragem.
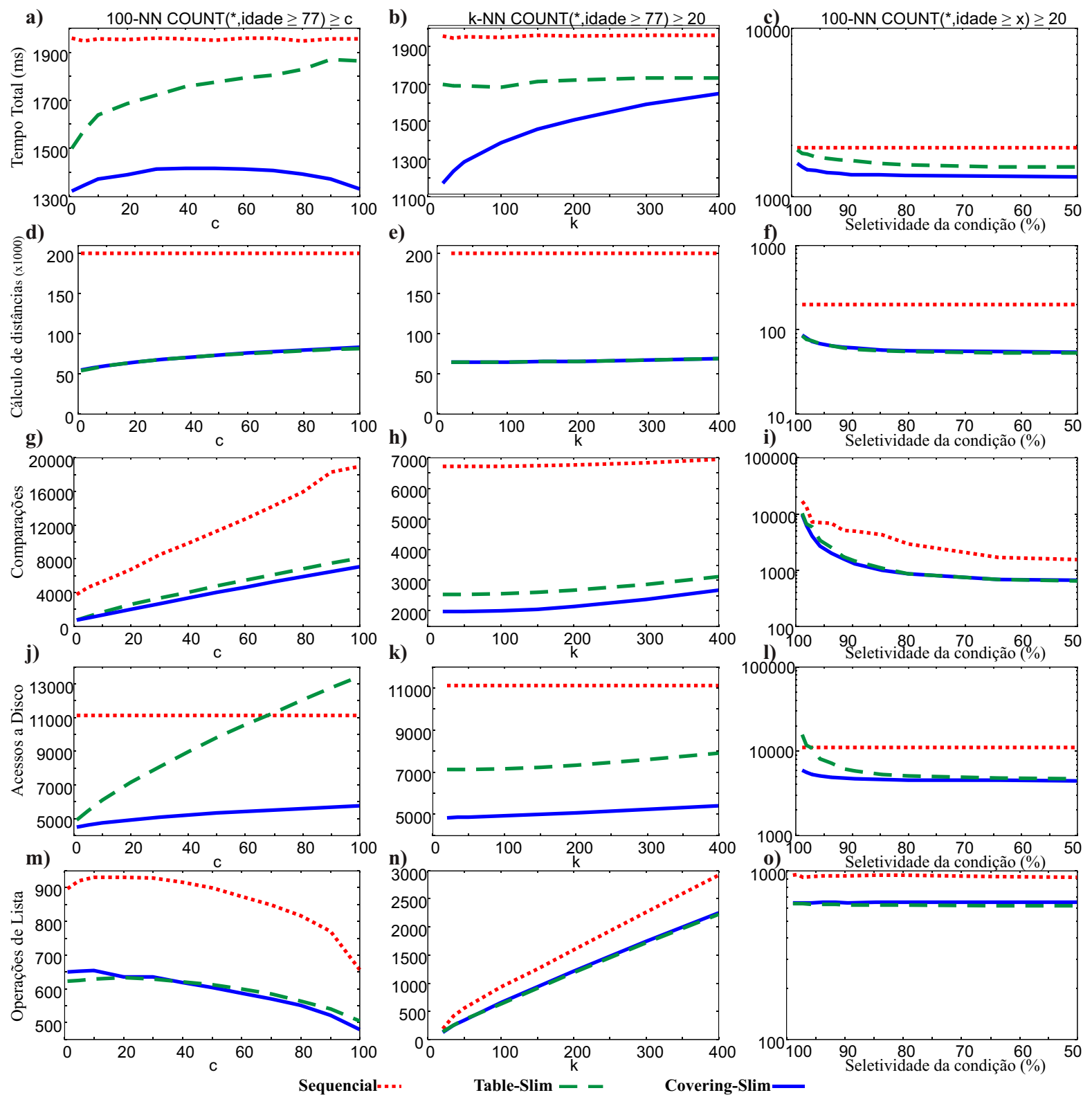

Figura 4.13: Resultados da execução da Consulta 12 sobre o conjunto DICOM_HC200k, comparando o comportamento dos algoritmos desenvolvidos com relação à variação de $c$ (coluna à esquerda), de $k$ (coluna central) e da seletividade da condição de filtragem (coluna à direita).

Com respeito à execução da Consulta $12\left({ }_{c} k\right.$-NNq com uma $c$-acond sobre o conjunto DICOM_HC200k), a Figura 4.13a mostra que o algoritmo Sequencial teve o pior desempenho dentre os três algoritmos com relação à variação de $c$, apresentando um comportamento praticamente constante. Diferentemente do que ocorreu com o conjunto CidadesAmericanas, o tempo de execução do algoritmo Table-Slim sobre o conjunto DI- 
COM_HC200k apresentou um comportamento sublinear frente à variação de $c$, tendo sido mais rápido do que o Sequencial para todos os valores de $c$. O algoritmo Covering-Slim foi até $29 \%$ mais rápido do que o Table-Slim e até 33\% mais rápido do que o Sequencial, enquanto o Table-Slim foi até $23 \%$ mais rápido do que o Sequencial. O desempenho superior do algoritmo Table-Slim comparado ao Sequencial foi porque ele teve um ganho considerável com respeito ao número de cálculos de distância (Figura 4.13d), ao número de comparações envolvendo os atributos tradicionais da condição (Figura 4.13g) e ao número de operações na lista de prioridade (Figura 4.13m), e também porque o número de acessos a disco do Table-Slim foi menor que o do Sequencial para $c<70$ e apenas $20 \%$ maior no pior caso. Além disso, nota-se na figura que o tempo de execução, com relação à variação de $c$, do algoritmo Covering-Slim apresentou uma curva interessante, tendo o ponto de máximo no meio da curva. A redução do tempo de execução a partir da metade da curva foi puxada pela redução do número de operações na lista de prioridades (Figura 4.13m), que neste conjunto de dados teve um impacto maior no desempenho global dos algoritmos, pois o vetor de características do conjunto DICOM_HC200k é muito maior do que o vetor do conjunto CidadesAmericanas. Com relação à variação de $k$, a Figura 4.13b mostra que os tempos de execução tanto do algoritmo Sequencial quanto do Table-Slim apresentaram comportamentos quase constantes, ao passo que o tempo de execução do Covering-Slim teve um comportamento sublinear. Entretanto, o Covering-Slim ainda foi o mais eficiente, tendo sido até $67 \%$ mais rápido do que o Sequencial e até $45 \%$ mais rápido do que o Table-Slim. O algoritmo Table-Slim foi até $24 \%$ mais rápido do que o Sequencial, tendo sido melhor do que o Sequencial em todas as variáveis analisadas, até mesmo em número de acessos a disco (figuras 4.13e, 4.13h, 4.13k e 4.13n). Com respeito à variação da seletividade da condição de filtragem, a Figura 4.13c mostra que os tempos de execução dos dois algoritmos indexados foram menores que o do algoritmo Sequencial, para todas as seletividades testadas. O algoritmo Covering-Slim foi até 33\% mais rápido do que o Sequencial e até $20 \%$ mais rápido do que o Table-Slim, que, por sua vez, foi até $25 \%$ mais rápido do que o Sequencial. Percebe-se, também, que o tempo de execução do algoritmo Sequencial teve um comportamento praticamente constante com relação à variação da seletividade da condição de filtragem, que foi resultado do comportamento quase constante com relação às demais variáveis, excetuando-se o número de comparações (Figura 4.13i). Por outro lado, os algoritmos indexados apresentaram um comportamento quase constante apenas com relação ao número de operações na lista de prioridade (Figura 4.13o), tendo seus desempenhos com relação às demais variáveis degradados para altas seletividades. Os algoritmos indexados apresentaram curvas similares com respeito ao número de cálculos de distância (Figura 4.13f) e ao número de comparações (Figura 4.13i), contudo, o Table-Slim teve um crescimento acentuado no número de acessos a disco para seletividades acima de $90 \%$, enquanto o Covering-Slim teve um crescimento sutil e para seletividades maiores que $97 \%$ (Figura 4.131). 


\section{Algoritmos para ${ }_{c} k$-NNq com Condições Baseadas em Agregação por Contagem de Distintos}

Com relação ao desempenho das consultas ${ }_{c} k$-NN com condições baseadas em agregação por contagem de distintos, a Figura 4.14 apresenta os tempos totais de execução dos algoritmos, sumarizando os desempenhos das variáveis analisadas. Os gráficos apresentados na primeira linha da figura mostram os resultados da execução da Consulta 10 sobre o conjunto de dados CidadesAmericanas e a segunda linha de gráficos da figura mostram os resultados da execução da Consulta 13 sobre o conjunto DICOM_HC200k.

$$
\text { a) }
$$

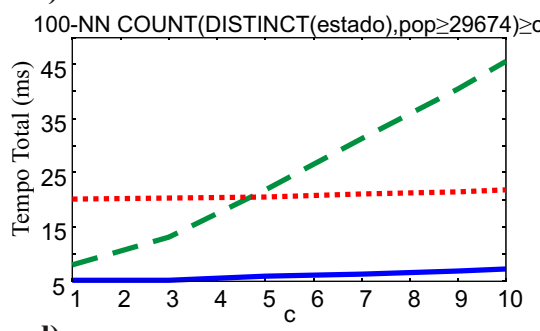

$$
\text { d) }
$$

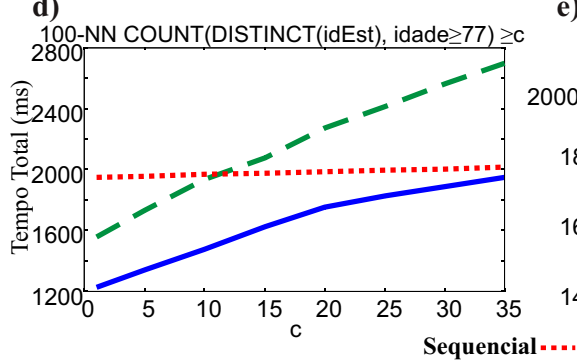

b)

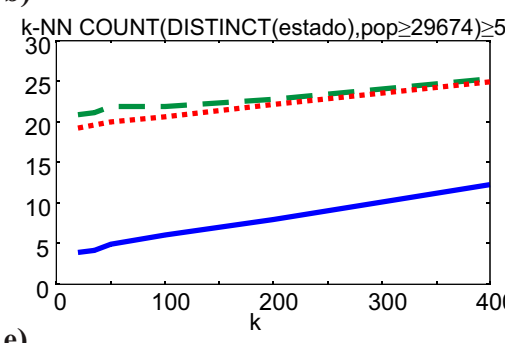

e)

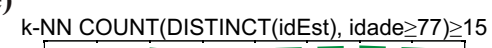

c)

100-NN COUNT(DISTINCT(estado),pop $\geq x$ ) $\geq 5$

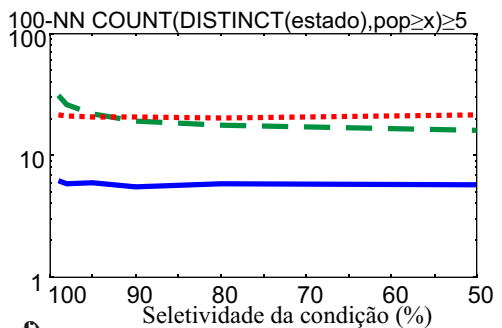

f)

100-NN COUNT(DISTINCT(idEst), idade $\geq x$ ) $\geq 15$

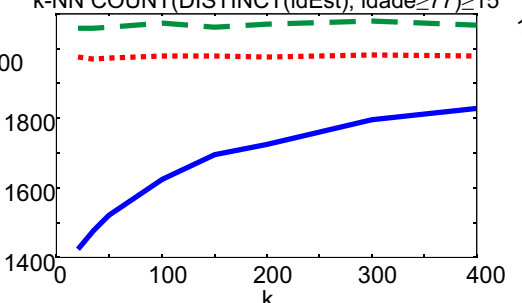
10000

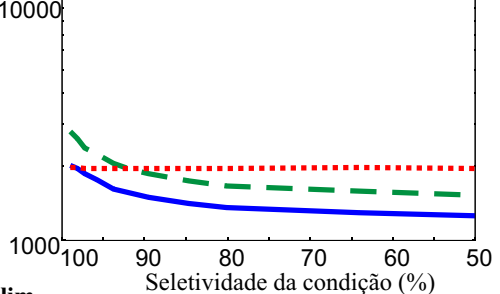

Figura 4.14: Resultados de experimentos avaliando os algoritmos para execução de ${ }_{c} k$-NNq restritas por $c d$-aconds sobre os conjuntos CidadesAmericanas (linha de cima) e DICOM_HC200k (linha de baixo), considerando a variação de $c$ (coluna à esquerda), de $k$ (coluna central) e da seletividade da condição de filtragem (coluna à direita).

Considerando a Consulta 10, com relação à variação de $c$, o comportamento dos três algoritmos de ${ }_{c} k$-NNq com $c d$-aconds executando esta consulta (Figura 4.14a) foi similar ao comportamento dos algoritmos correspondentes de ${ }_{c} k$-NNq com $c$-aconds executando a Consulta 9 (compare-se com a Figura 4.12a). Com relação à variação de $k$ (Figura 4.14b), o comportamento dos algoritmos de ${ }_{c} k$-NNq com $c d$-aconds foi linear, tendo o algoritmo Covering-Slim sido o mais eficiente, assim como ocorreu com os algoritmos de ${ }_{c} k$-NNq com c-aconds. Entretanto, para a Consulta 10, o algoritmo Table-Slim foi sensivelmente mais lento do que o Sequencial, devido ao fato do número de acessos a disco realizados pelo Table-Slim ter sido relativamente maior que o número de acessos do Sequencial para esta consulta do que para a Consulta 9. Com relação à variação da seletividade da condição de filtragem, o tempo de execução do algoritmo Table-Slim aproximou-se do tempo do algorimo Sequencial, como mostra a Figura 4.14c. O desempenho do TableSlim foi degradado pelo aumento do número de acessos a disco, tendo sido apenas até 
25\% mais rápido do que o Sequencial na execução da Consulta 10 (o Table-Slim foi até 2.5 vezes mais rápido que o Sequencial para a Consulta 9). O algoritmo Covering-Slim manteve-se com um desempenho consideravelmente superior aos demais com relação à variação da seletividade da condição de filtragem, tendo sido até 3.5 vezes mais rápido que o Sequencial neste caso.

Considerando a Consulta 13, pode ser visto na Figura 4.14d que os dois algoritmos indexados para ${ }_{c} k$-NNq com $c d$-aconds apresentaram um comportamento sublinear com relação à variação de $c$, enquanto o tempo de execução do algoritmo Sequencial mostrou-se invariante a este aspecto. O Covering-Slim foi o mais rápido, mas tendo o desempenho muito próximo do Sequencial para valores altos de c. Já o Table-Slim foi mais rápido que o Sequencial apenas para $c \leq 10$. Com relação à variação de $k$, a Figura 4.14e mostra o Covering-Slim foi o mais rápido, tendo sido até $30 \%$ mais rápido que o Sequencial e apresentando um comportamento sublinear. O Table-Slim apresentou um comportamento praticamente constante, porém seu desempenho foi, em média, $4.5 \%$ pior que o desempenho do Sequencial, que novamente foi degradado pelo excessivo número de acessos a disco. Finalmente, com respeito à variação da seletividade da condição de filtragem, pode-se notar na Figura $4.14 \mathrm{f}$ que o comportamento dos algoritmos de ${ }_{c} k$-NNq com $c d$-aconds respondendo à Consulta 13 foi similar ao comportamento dos algoritmos de ${ }_{c} k$-NNq com $c$-aconds respondendo à Consulta 12 (compare-se com a Figura 4.13c). Entretanto, o impacto da alta seletividade da condição de filtragem no desempenho dos algoritmos indexados de ${ }_{c} k$-NNq com $c d$-aconds foi mais visível. O algoritmo CoveringSlim teve um desempenho equivalente ao Sequencial para a seletividade de 99\%, contudo ele foi até $37 \%$ mais rápido considerando-se seletividades mais baixas. Comparando-se com o Table-Slim, o Covering-Slim foi mais eficiente para todas as seletividades analisadas. O Table-Slim foi até $23 \%$ mais rápido do que o Sequencial para seletividades mais baixas, mas chegou a ser pior que o Sequencial para seletividades maiores que $92 \%$.

\section{Algoritmos para ${ }_{c} k-\mathrm{NNq}$ com Condições Baseadas em Tupla}

Por fim, a Figura 4.15 mostra os comportamentos dos algoritmos de ${ }_{c} k$-NNq com condições baseadas em tupla, sumarizados pelo tempo total de execução. Na figura, a linha de cima mostra o desempenho da Consulta 11 sobre o conjunto CidadesAmericanas enquanto a linha de baixo mostra o desempenho da Consulta 14 sobre o conjunto DICOM_HC200k, sendo que os gráficos da coluna à esquerda apresentam o impacto da variação de $k$ e os gráficos da coluna à direita mostram o impacto da variação da seletividade da condição.

Com respeito à Consulta 11, como pode ser visto na Figura 4.15a, enquanto os algoritmos Sequencial e Covering-Slim apresentaram um crescimento moderado com o aumento de $k$, o desempenho do Table-Slim degradou rapidamente, tendo passado a ser pior que o do algoritmo Sequencial para $k$ próximo de 30 e tendo chegado a ser mais de 4 vezes mais lento para $k=400$. Esse comportamento se deve ao fato que o algoritmo 

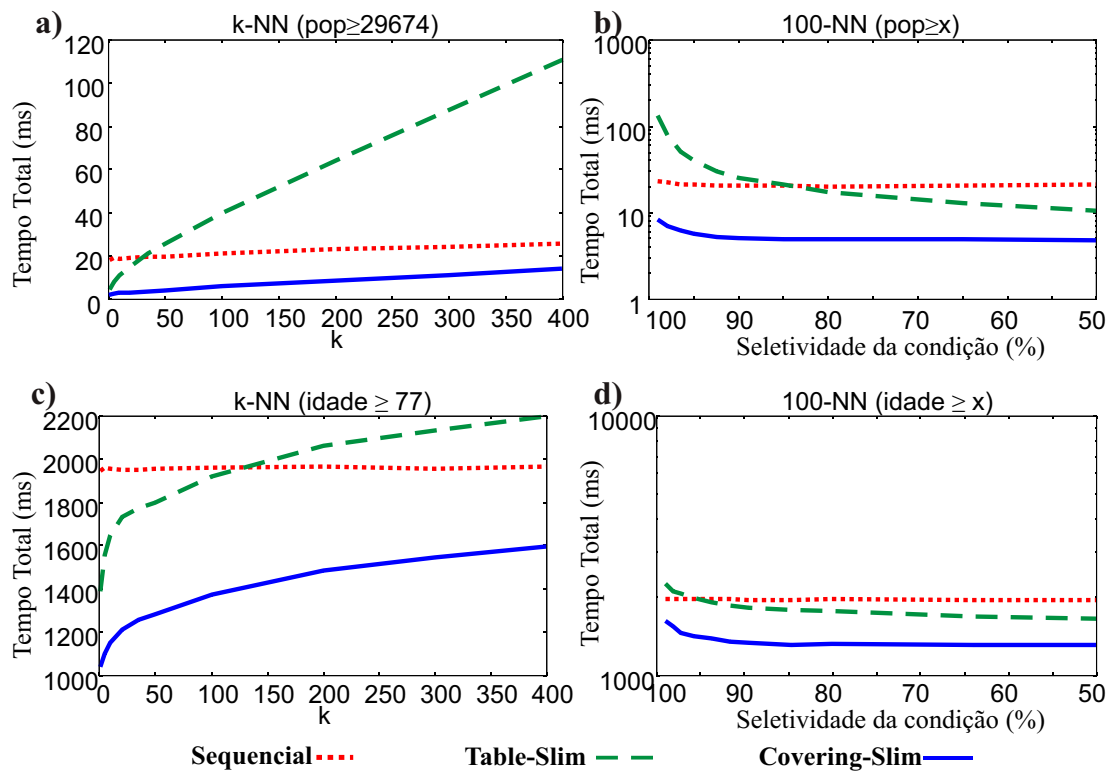

Figura 4.15: Resultados de experimentos avaliando os algoritmos para execução de ${ }_{c} k$-NNq com condições baseadas em tupla sobre os conjuntos CidadesAmericanas (linha de cima) e DICOM_HC200k (linha de baixo), considerando a variação de $k$ (coluna à esquerda) e a variação da seletividade da condição de filtragem (coluna à direita).

só começa a reduzir o espaço de busca ao encontrar 100 elementos que satisfaçam a condição. Como a seletividade da condição foi estabelecida em 5\%, a capacidade de poda do algoritmo ficou bastante reduzida. Embora o algoritmo Covering-Slim também tenha tido a capacidade de poda reduzida, seu desempenho ainda foi o melhor de todos considerando a variação de $k$, tendo sido mais de 5 vezes mais rápido que o Sequencial, em média, e até mais de 8 vezes mais rápido que o Table-Slim. Considerando a variação da seletividade da condição nesta consulta, a Figura 4.15b mostra que o algoritmo TableSlim apresentou um desempenho superior ao Sequencial para seletividades menores que $85 \%$, tendo sido até quase 2 vezes mais rápido, mas apresentou um aumento acentuado no tempo de execução para seletividades mais altas, tendo chegado a ser quase 6 vezes mais lento para a seletividade de $99 \%$. Já o Covering-Slim foi mais eficiente que os demais algoritmos para todas as seletividades testadas, tendo chegado a ser até mais de 4 vezes mais rápido que o Sequencial e até mais de 15 vezes mais rápido que o Table-Slim (observese que os gráficos considerando a variação da seletividade da condição aparecem em escala logarítmica).

Com relação à Consulta 14, analisando a Figura 4.15c, nota-se que os dois algoritmos indexados apresentaram um comportamento sublinear com o aumento de $k$. Assim como ocorreu com a consulta anterior, o algoritmo Table-Slim teve desempenho inferior ao Sequencial para valores grandes de $k$, embora a degradação do desempenho tenha sido menor (o Table-Slim foi, no máximo, $11 \%$ mais lento que o Sequencial), pois o valor de $k$ é proporcionalmente menor que o número de tuplas da relação de entrada que satisfazem 
a condição apresentada. O Covering-Slim novamente obteve o melhor desempenho, tendo sido 40\% mais rápido que o Table-Slim em média e até $87 \%$ mais rápido que o Sequencial. Considerando a variação da seletividade da condição, observa-se na Figura 4.15d que o algoritmo Table-Slim foi mais eficiente que o Sequencial para seletividades menores que 95\%, com ganhos médios de aproximadamente $10 \%$, e que a degradação do desempenho do Table-Slim foi mais suave para seletividades mais altas, tendo sido apenas $8 \%$ mais lento que o Sequencial para a seletividade de 98\%. O Covering-Slim foi mais eficiente para todas as seletividades, tendo sido até 1 vez e meia mais rápido que o Sequencial e que o Table-Slim.

Analisando os resultados obtidos, pode-se concluir que os algoritmos desenvolvidos nesta tese aprimoraram consideravelmente o desempenho da execução de consultas ${ }_{c} k$-NN restritas por condições baseadas em agregação por contagem e por contagem de distintos e por condições baseadas em tupla. Em especial, os algoritmos da variação Covering-Slim apresentaram-se como uma alternativa eficiente para executar esses tipos de consultas.

\subsection{Considerações Finais}

Este capítulo apresentou a proposta de um novo tipo de consulta por similaridade, denominada consulta aos $k$-vizinhos mais próximos estendida com condições $\left({ }_{c} k\right.$-NNq). Foram identificados dois tipos básicos de condições restringindo as ${ }_{c} k$-NNq: as condições baseadas em tupla e as condições baseadas em agregação. Além de não existirem trabalhos na literatura que propõem formalmente uma extensão ao operador de consulta $k$-NN para aceitar condições adicionais à busca, as condições baseadas em agregação propostas nesta tese são inovadoras e permitem expressar consultas aos $k$-vizinhos mais próximos com condições complexas, que não eram representáveis até então. Foram apresentadas as principais regras algébricas envolvendo o novo operador proposto, bem como algoritmos para executar algumas das principais variações das consultas ${ }_{c} k$-NN e experimentos, que mostraram que as consultas são exequíveis eficientemente sobre métodos de acesso métricos.

O próximo capítulo apresenta um módulo de banco de dados desenvolvido para executar consultas por similaridade integradas às demais operações oferecidas pelos SGBDs existentes no mercado. Este módulo provê funcionalidades para extração de características, para análise de similaridade entre vetores de características e para execução eficiente de buscas por similaridade sobre estruturas de indexação para dados complexos. O capítulo também apresenta uma extensão desse módulo para recuperação de imagens médicas no formato DICOM, capaz de executar consultas combinando condições baseadas no conteúdo das imagens e nos metadados do cabeçalho das imagens de forma eficiente sobre grandes bancos de imagens. São discutidos os principais aspectos de implementação dos módulos, como as principais consultas por similaridade podem ser representadas usando 
os módulos e também experimentos avaliando a efetividade dos módulos nas tarefas que se propõem realizar. 


\section{Capítulo \\ 5 \\ FMI-SiR: Um Módulo de Banco de Dados para Consultas por Similaridade}

Os SGBDs existentes atualmente são carentes de funcionalidades para a recuperação por similaridade de dados complexos. Muitos esforços têm sido direcionados para desenvolver algoritmos e estruturas de dados para suportar consultas por similaridade. Entretanto, os sistemas desenvolvidos para responder a consultas por similaridade são fracamente acoplados aos SGBDs, o que limita o aproveitamento dos recursos oferecidos nativamente pelos SGBDs.

Este capítulo apresenta o FMI-SiR (user-defined $\boldsymbol{F}$ eatures, Metrics and Indexes for Similarity $\boldsymbol{R}$ etrieval - características, métricas e índices definidos pelo usuário para recuperação por similaridade). O FMI-SiR é um módulo que é executado acoplado a um SGBD, concebido para ser um subsistema especializado para recuperação por similaridade acessível ao processador de consultas do SGBD. Ele provê operadores, extratores de características, funções de distância e métodos de acesso para responder eficientemente a consultas por similaridade integradas às demais operações de busca disponibilizadas pelo SGBD. Por ser de código aberto, o FMI-SiR permite acrescentar novos extratores de características, funções de distância ou estruturas de indexação, o que facilita a integração de novos resultados de pesquisa a um SGBD do mercado. Em particular, o FMI-SiR implementa em um ambiente homogêneo os operadores definidos no capítulo anterior. $\mathrm{O}$ FMI-SiR foi concebido de maneira independente do SGBD ao qual deve ser acoplado, portanto ele deve ser instanciado para cada SGBD ao qual deva ser integrado.

A Seção 5.1 descreve o FMI-SiR $O$ (Kaster et al., 2009, 2010), uma implementação do FMI-SiR sobre o SGBD Oracle. A Seção 5.2 apresenta o MedFMI-SiR (Kaster et 
al., 2011a), que é uma extensão do $\mathrm{FMI}_{-} \mathrm{SiR}_{O}$ para manipulação de imagens médicas no formato DICOM. Finalmente, a Seção 5.3 apresenta experimentos avaliando o FMI-SiR $O$ e a Seção 5.4 apresenta experimentos sobre o MedFMI-SiR, ambos utilizando conjuntos de dados reais.

\subsection{O Módulo FMI-SiR}

Esta seção descreve o FMI-SiR $O$, uma implementação do FMI-SiR sobre o SGBD Oracle, utilizando as interfaces da arquitetura extensível do Oracle (Oracle Extensible Architecture Framework). Por implementar os requisitos definidos pela arquitetura extensível do Oracle, o FMI-SiR $O$ é integrado homogeneamente às demais funcionalidades do SGBD, enriquecendo-o com funções para recuperação de dados complexos por similaridade.

O FMI-SiR $O$ é implementado como uma biblioteca compartilhada dinâmica em $\mathrm{C} / \mathrm{C}++$, composta por um conjunto de funções para extração de características, funções de distância e funções de gerenciamento de índices para dados complexos, particularmente métodos de acesso métricos. As funcionalidades do $\mathrm{FMI}_{-} \mathrm{SiR}_{O}$ são integradas ao SGBD por meio de novos tipos de dados e conjuntos de funções SQL, que invocam as funções da biblioteca compartilhada dinâmica.

As funções de distância e os métodos de acesso são providos pela biblioteca Arboretum, desenvolvida pelo GBdI-ICMC-USP. Os extratores de características também são organizados em bibliotecas portáveis, o que facilita a inclusão de novos extratores. As operações de busca por similaridade são disponibilizadas por novos operadores incorporados pelo FMI-SiR à linguagem SQL, que permitem a representação de operações por similaridade em sentenças SELECT padrão.

Com o FMI-SiR $O$, as principais etapas de um processo de recuperação por similaridade são atendidas. Por exemplo, considere-se o fluxo de dados de um sistema de CBIR, ilustrado na Figura 2.9 da Seção 2.4.4. A aquisição de imagens, anotação e interação e a seleção da imagem de consulta são realizadas usando funções do SGBD. A extração de características é feita por meio de duas novas funções, generateSignature e readSignatureFromFile, sendo que os vetores de características gerados são armazenados em atributos binários no banco de dados. A indexação das características é suportada por novos tipos de índices, Slim_<distance_name>, que são métodos de acesso métricos acoplados ao SGBD para indexar dados complexos. O cálculo de similaridade é realizado usando novas funções de cálculo de distância, <distance_name>_distance, e novos operadores para execução indexada de buscas por similaridade, <distance_name>_dist e <distance_name>_knn. Com o uso dessas funções e operadores, torna-se possível representar os principais tipos de consultas por similaridade usando a sintaxe SQL padrão. Por fim, as tarefas de apresentação e realimentação são suportadas indiretamente, pois as primitivas fornecidas pelo $\mathrm{FMI}_{-} \mathrm{SiR}_{O}$ facilitam a implementação destas funcionalidades 
sobre o SGBD. A Tabela 5.1 resume as funcionalidades implementadas pelo FMI-SiR ${ }_{O}$, relacionando-as com as tarefas de recuperação por similaridade diretamente suportadas.

\begin{tabular}{ll}
\hline Tarefa & Funcionalidade \\
\hline Extração de características & $\begin{array}{l}\text { Funções generateSignature e } \\
\text { readSignatureFromFile }\end{array}$ \\
\hline Indexação das características & Novos tipos de índice Slim_<distance_name> \\
\hline Cálculo de similaridade & $\begin{array}{l}\text { UDFs }<\text { distance_name>_dist e operadores para } \\
\text { execução indexada }<\text { distance_name>dist } \\
\text { e }<\text { distance_name>_kNN }\end{array}$ \\
\hline
\end{tabular}

Tabela 5.1: Funcionalidades implementadas no FMI-SiR $O$ para suporte à recuperação por conteúdo.

Para explicar a implementação do FMI-SiR $O$, esta seção utiliza um exemplo que considera a existência de uma tabela chamada image_table, contendo um identificador id, um atributo image contendo uma imagem digital e um atributo image_sign, do tipo BLOB, para armazenar o vetor de características utilizado para descrever o conteúdo da imagem, que é utilizado nas consultas envolvendo similaridade.

\subsubsection{Extração de Características}

A primeira tarefa realizada pelo $\mathrm{FMI}_{-} \mathrm{SiR}_{O}$ é gerar vetores de características descrevendo o conteúdo do dado complexo armazenado. O dado complexo em si é carregado e gerenciado pelo SGBD utilizando funções de manipulação de BLOBs. Isto permite que procedimentos eficientes de carga de grandes volumes de dados providos pelo SGBD sejam utilizados. Tendo o dado complexo (binário) carregado, a geração de vetores de características para este dado é realizada utilizando uma nova função definida pelo FMI-SiR ${ }_{O}$, chamada generateSignature, que tem a forma:

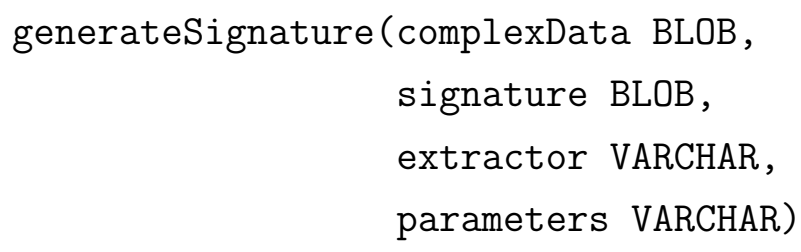

onde o parâmetro complexData recebe o dado complexo de entrada, signature é o BLOB que irá armazenar o vetor de características gerado, extractor é o nome do extrator desejado e parameters é uma string contendo os parâmetros passados para o extrator de características. Esta função pode ser invocada em uma sentença SQL, como exemplificado a seguir:

FOR csr IN (SELECT image, image_sign FROM image_table FOR UPDATE) LOOP generateSignature(csr.image, csr.image_sign, 'Histogram', '256'); 


\section{END LOOP;}

onde csr é um cursor iterando sobre as tuplas da relação image_table, csr.image e csr.image_sign são os atributos da tupla corrente do cursor que armazenam, respectivamente, a imagem de entrada e o vetor de características gerado, Histogram indica que está sendo solicitado o histograma de cores da imagem de entrada e o parâmetro 256 é o número desejado de bins do histograma.

A função SQL generateSignature mapeia para uma função $\mathrm{C}++$ na biblioteca compartilhada, cuja execução é ilustrada na Figura 5.1. Quando esta função é chamada, o processador de consultas invoca a função $\mathrm{C}++$ fornecendo como parâmetros: os localizadores de LOB (LobLocators) para os atributos BLOB que armazenam o dado complexo e o vetor de características, o identificador do extrator de características desejado e seus parâmetros (Passo 1). Em seguida, são carregados a imagem e o dado binário do vetor de características apontados pelos respectivos LobLocators (Passo 2). A função identifica qual é o extrator de características desejado e quais os seus parâmetros de configuração, informados nos dois últimos parâmetros da função, e invoca este extrator sobre o dado complexo de entrada (Passo 3). O vetor de características retornado é serializado em formato binário e armazenado no atributo BLOB que armazena as características (Passo 4). Por fim, a função retorna o controle para o processador de consultas, informando o código de retorno da operação (Passo 5). Observe que o vetor de características é um parâmetro de saída, portanto, é necessário acessar este atributo utilizando um bloqueio exclusivo, expresso no exemplo pela cláusula FOR UPDATE.

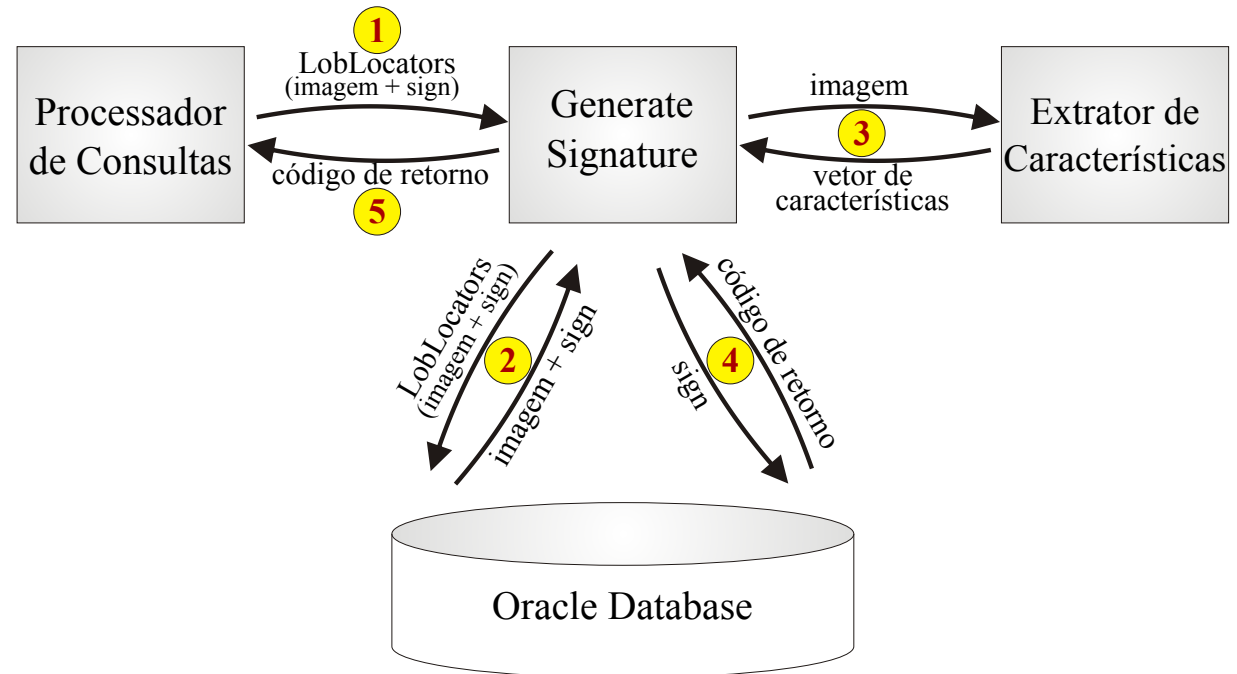

Figura 5.1: Passos da execução da função generateSignature.

A implementação atual do FMI-SiR $O$ contém apenas extratores de características para imagens. Entretanto, a arquitetura do módulo permite incluir novos extratores de características, bastando acrescentar a chamada do extrator de características no código fonte 
do módulo e recompilando a biblioteca compartilhada dinâmica (não é preciso nenhuma modificação nas funções SQL que associam o FMI-SiR $O$ ao Oracle).

O FMI-SiR $O$ também oferece uma função que permite carregar características geradas por extratores de características externos, denominada readSignatureFromFile. Esta função tem a forma:

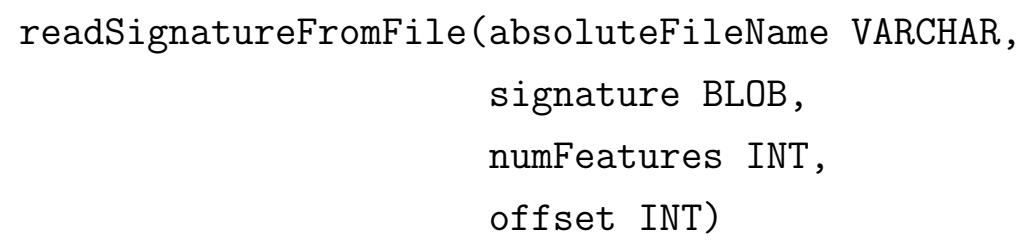

onde absoluteFileName é o caminho absoluto para o arquivo contendo as características, signature é o BLOB que irá guardar o vetor de características, numFeatures é a quantidade de características a serem lidas do arquivo de entrada e offset é a quantidade de campos do arquivo de entrada a serem desconsiderados antes de começarem as características desejadas. O arquivo de entrada é um arquivo texto simples, contendo os valores das características separados por espaços. A função readSignatureFromFile é invocada em sentenças SQL, serializando as características lidas do arquivo de entrada em formato binário no BLOB informado no parâmetro signature. Desta forma, esta função também exige um bloqueio exclusivo da relação que contém o atributo que irá armazenar os vetores de características lidos, se for o caso.

\subsubsection{Seleções por Similaridade com Execução Sequencial}

Tendo computado os vetores de características, os dados complexos estão aptos para ser comparados por similaridade. Para isso, o FMI-SiR $O$ fornece funções de distância, que retornam o valor de dissimilaridade entre dois vetores de características e podem ser chamadas em consultas SQL. As funções de distância são definidas no FMI-SiR ${ }_{O}$ por meio de funções definidas pelo usuário (UDFs) da seguinte forma:

<distance_name>_distance(signature1 BLOB, signature2 BLOB)

onde <distance_name> é o nome da função de distância implementada. FMI-SiR $O$ implementa várias funções de distância, tais como a Manhattan_distance, a Euclidean_distance e a Canberra_distance. Além disso, novas funções de distância podem ser incluídas de acordo com os requisitos das aplicações. As funções de distância do FMI-SiR $O$ podem ser utilizadas para formular consultas por similaridade, com execução sequencial, utilizando a sintaxe SQL padrão, como apresentado a seguir.

As consultas por similaridade por abrangência utilizam condições simples baseadas em uma função de distância. Por exemplo, a consulta a seguir é uma consulta por abrangência (Rq), utilizando a função de distância Manhattan $\left(L_{1}\right)$ : 


\section{SELECT image}

FROM image_table

WHERE Manhattan_distance(image_sign, center_sign) $<=0.5$;

onde center_sign é um BLOB contendo o vetor de características da imagem de consulta e o valor 0.5 é o limiar de dissimilaridade.

A consulta pontual $(\mathrm{Pq})$ e a consulta por abrangência reversa $\left(\mathrm{Rq}^{-1}\right)$ seguem a mesma sintaxe da consulta por abrangência, mas alterando o operador de comparação e/ou o limiar de dissimilaridade. Seguindo o exemplo de consulta $\mathrm{Rq}$ apresentado, uma consulta pontual utilizaria a condição Manhattan_distance(image_sign, center_sign) = 0 e uma consulta por abrangência reversa utilizaria a condição Manhattan_distance(image_sign, center_sign) > 0.5.

As consultas aos $k$-vizinhos mais próximos $(k-\mathrm{NNq})$ são representadas utilizando funções de janela (window functions) do padrão SQL, como no exemplo a seguir:

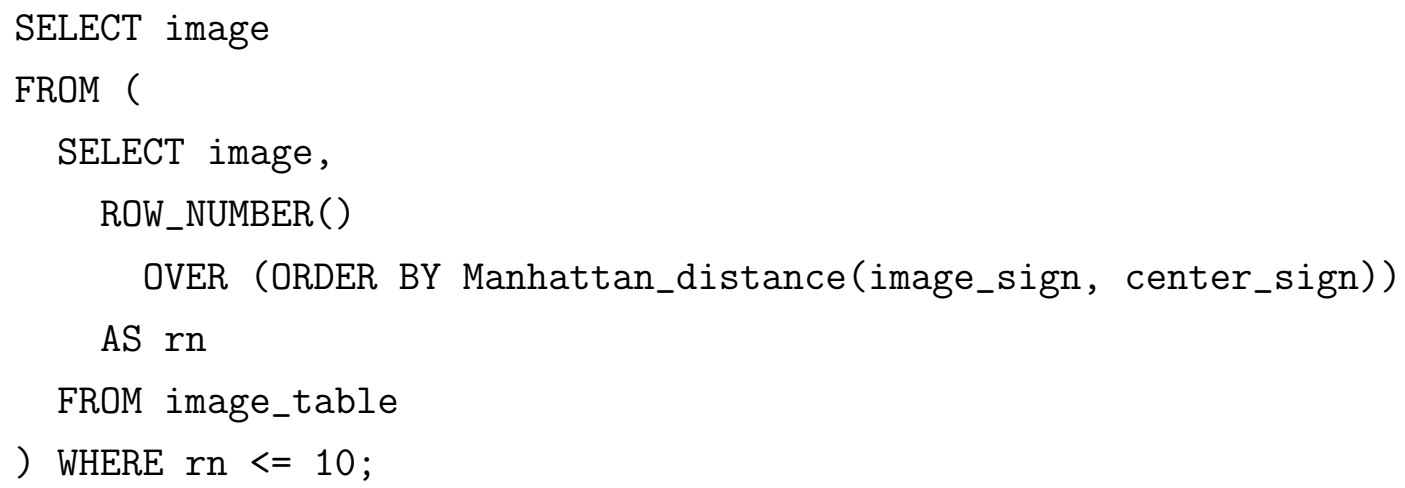

onde a função ROW_NUMBER atribui a um novo atributo (rn) a posição de cada tupla de acordo com a janela definida, que neste caso ordena as tuplas pelo valor da distância Manhattan entre o vetor de características da imagem armazenada e o vetor de características da imagem de consulta (center_sign). O atributo rn é, então, usado na condição de filtragem consulta externa, para retornar apenas os $k$-vizinhos mais próximos (no exemplo, $k=10)$.

As consultas aos $k$-vizinhos mais distantes ( $k$-FNq) com execução sequencial também usam esta sintaxe, porém invertendo a ordenação da janela de consulta. A consulta aos $k$-vizinhos mais próximos apresentada seria transformada em uma consulta aos $k$-vizinhos mais distantes, $k=10$, sendo escrita da seguinte maneira: 


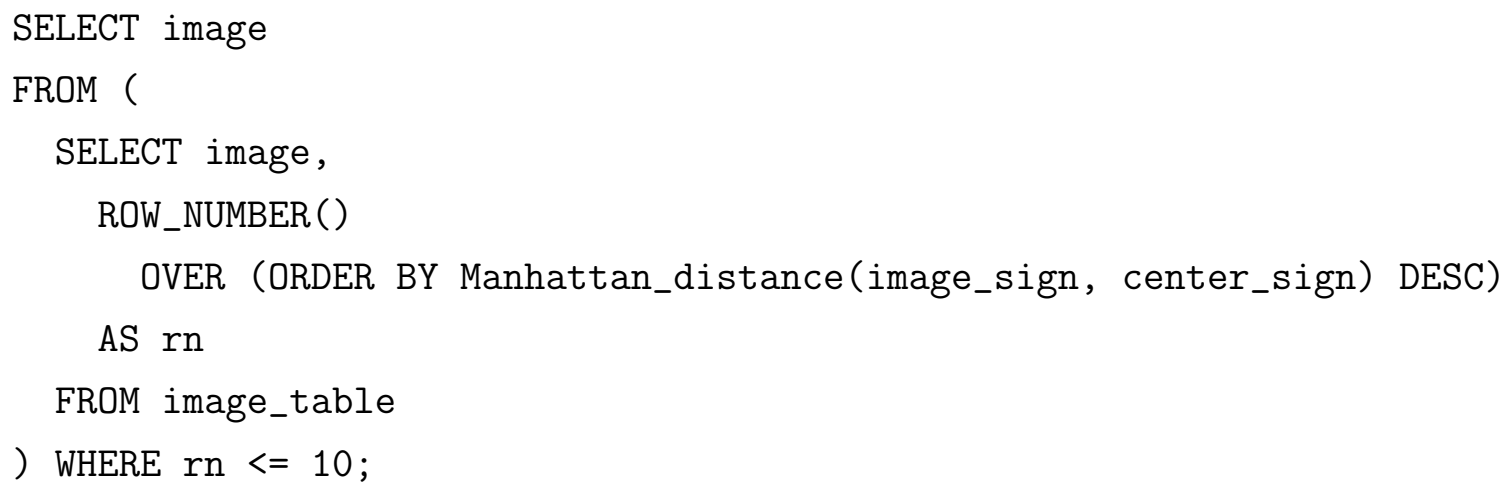

As consultas apresentadas nesta seção são executadas por meio de uma varredura sequencial na tabela de entrada. Para melhorar o desempenho de execução, o FMI-SiR $O$ oferece índices para responder a buscas por similaridade, apresentados na próxima seção.

\subsection{3 Índices para Consultas por Similaridade}

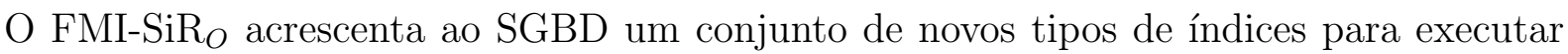
consultas por similaridade, utilizando a interface de indexação da arquitetura extensível do Oracle. Esta interface permite definir os métodos necessários para implementar os novos tipos de índices. Estes métodos são encapsulados em um tipo de dados que define uma classe de objetos, que possui a seguinte interface:

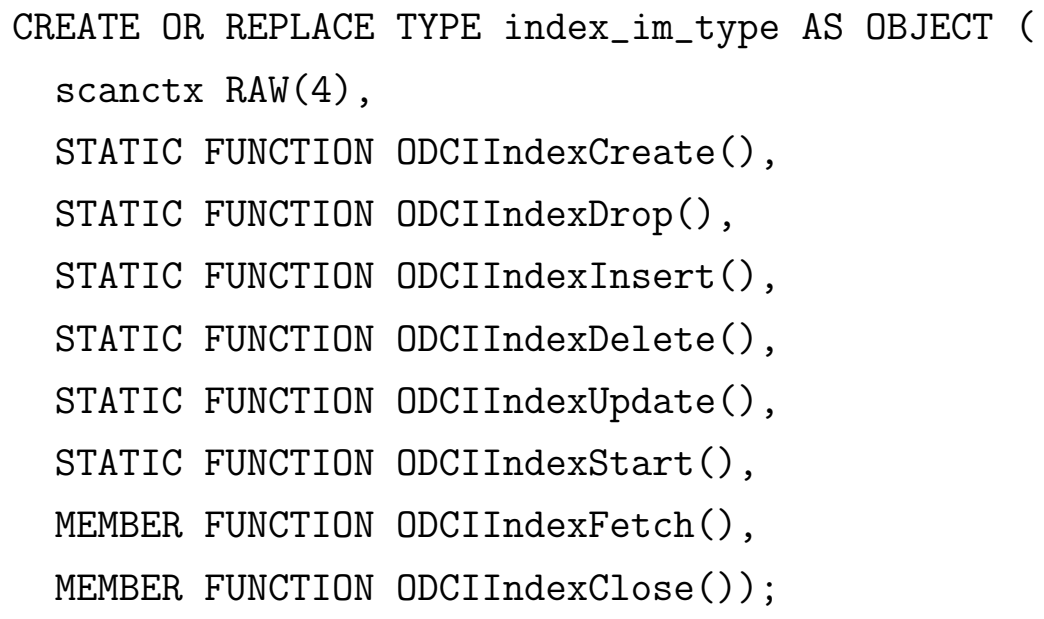

A implementação deste novo tipo de dados mapeia as funções declaradas para funções externas $\mathrm{C}++$, da biblioteca compartilhada dinâmica. A versão corrente do $\mathrm{FMI}_{-} \mathrm{SiR}_{O}$ define um novo tipo de índices utilizando a implementação do MAM Slim-tree (Seção 3.3.2) na biblioteca Arboretum. Na verdade, o FMI-SiR $O$ define um conjunto de novos tipos de índices baseados na Slim-tree, pois os MAMs são dependentes da função de distância utilizada para definir o espaço métrico onde os dados são representados. Então, há um novo tipo de índice Slim-tree para cada distância implementada no $\mathrm{FMI}_{-} \mathrm{SiR}_{O}$ : Slim_Manhattan, Slim_Canberra, etc. Além disso, um mesmo atributo armazenando um vetor de características pode possuir mais de um índice Slim-tree, desde que utilizando 
funções de distância diferentes. Esta abordagem permite efetuar buscas indexadas mediante diferentes combinações de vetores de características e funções de distância.

Novos tipos de índices no Oracle exigem a declaração de operadores para disparar as buscas sobre o índice. Na concepção da Oracle, um operador associa uma função definida pelo usuário a um tipo de índice. Por isso, o FMI-SiR ${ }_{O}$ define um operador para a consulta por abrangência e um operador para a consulta aos $k$-vizinhos mais próximos para cada função de distância implementada. Por exemplo, o operador de consulta por abrangência para a distância Manhattan é definido como:

\section{CREATE OPERATOR Manhattan_dist BINDING (BLOB, BLOB) \\ RETURN FLOAT USING Manhattan_distance;}

onde Manhattan_distance é a função definida pelo usuário que implementa o cálculo desta função de distância. $\mathrm{O}$ operador de consulta aos $k$-vizinhos mais próximos (Manhattan_kNN) é definido de forma semelhante. Os novos tipos de índices essencialmente estabelecem a associação entre os operadores e os tipos de dados que definem as classes que contêm os métodos para manipular os índice. Por exemplo, a instrução a seguir cria o tipo de índice Slim_Manhattan, associando os operadores Manhattan_dist e Manhattan_kNN ao tipo de dados index_im_type:

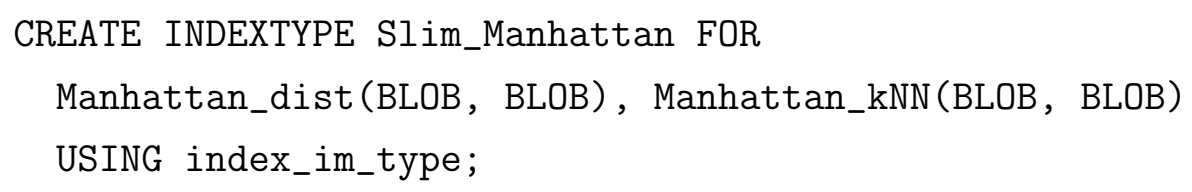

Com a definição do novo tipo de índice, o processador de consultas do SGBD passa a aceitar a criação de índices usando este novo tipo. A sintaxe para criar índices utilizando os novos tipos de índices disponibilizados pelo $\mathrm{FMI}_{-S} \mathrm{R}_{O}$ é a mesma usada para criar índices de outros tipos. Por exemplo, a instrução a seguir cria um índice do tipo Slim_Manhattan sobre o atributo image_sign da tabela image_table:

\section{CREATE INDEX image_sign_Slim_Manhattan_ix ON image_table(image_sign) INDEX TYPE IS Slim_Manhattan PARAMETERS ('8192');}

onde o único parâmetro considerado na implementação corrente do FMI-SiR $O$ é o tamanho em bytes das páginas do índice (8192).

A criação de um índice dispara o processo ilustrado na Figura 5.2. O processador de consultas invoca a função ODCIIndexCreate, definida no tipo de dados que implementa o índice, passando as informações a respeito do índice a ser criado, tais como o nome da tabela e o nome do atributo a ser indexado (Passo 1). A função ODCIIndexCreate requisita à Arboretum a criação de uma Slim-tree vazia (Passo 2). Em seguida, a função consulta os dados (vetor de características e rowId) armazenados na tabela (Passo 3). 
Utilizando os LobLocators dos vetores de características, a função recupera os dados dos BLOBs (Passo 4) e insere os vetores de características com os respectivos rowIds na Slimtree (Passo 5). Por fim, a função retorna o controle ao processador de consultas (Passo 6). Observe que os índices do FMI-SiR $O$ são armazenados em arquivos de dados externos ao SGBD, gerenciados por meio da biblioteca Arboretum, que implementa acesso paginado aos dados e com controle de cache.

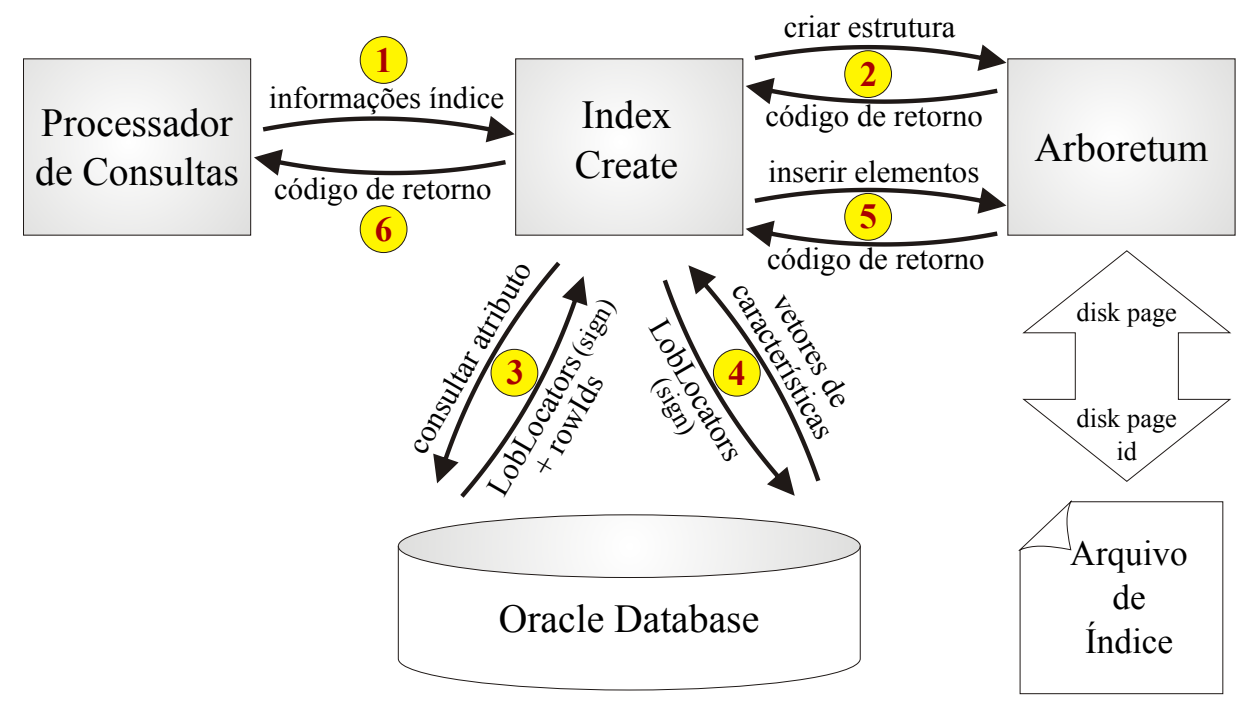

Figura 5.2: Passos executados pela função ODCIIndexCreate.

Os índices criados são dinamicamente atualizados quando ocorrem inserções (INSERT), remoções (DELETE) ou atualizações (UPDATE) nas tabelas indexadas. As funções que implementam estas operações nos índices (ODCIIndexInsert, ODCIIndexDelete e ODCIIndexUpdate) executam os passos 4-6 do processo de criação do índice, utilizando o LobLocator e o rowId da tupla atualizada, que são fornecidos pelo processador de consultas como parâmetros. Quando um índice é removido (via DROP INDEX, DROP TABLE, etc.), o processador de consultas invoca a função ODCIIndexDrop, que elimina o arquivo externo que armazenava o índice, e, em seguida, remove do catálogo do banco as informações a respeito do índice.

A próxima seção mostra como os novos tipos de índices do $\mathrm{FMI}_{-} \mathrm{SiR}_{O}$ são usados para executar seleções por similaridade.

\subsubsection{Seleções por Similaridade com Execução Indexada}

Para utilizar os novos tipos de índices oferecidos pelo FMI-SiR $_{O}$ é preciso utilizar os operadores associados nas consultas, pois os operadores definidos pelo $\mathrm{FMI}^{-\mathrm{SiR}_{O}}$ são os elementos de ligação entre as funções de distância e os novos tipos de índices.

As consultas por abrangência devem ser escritas utilizando os operadores <distance_name>_dist no lugar das funções <distance_name>_distance para pode- 
rem fazer uso de índices na sua execução. Por exemplo, para que a Rq apresentada na Seção 5.1.2 possa ter uma execução indexada, ela tem que ser reescrita conforme segue:

\section{SELECT * FROM image_table}

WHERE Manhattan_dist(image_sign, center_sign) $<=0.5$;

O comportamento do processador de consultas ao avaliar esta consulta é o seguinte. Ao encontrar o operador Manhattan_dist, o processador de consultas tenta invocar uma consulta por abrangência no índice Slim_Manhattan construído sobre o atributo image_sign. Caso este índice não exista, o processador de consultas invoca a função Manhattan_distance para cada tupla da relação de entrada, efetuando uma execução sequencial da operação. Observe-se que se existir um índice no atributo do vetor de características, mas que utiliza outra função de distância (por exemplo, um índice Slim_Euclidean) ele também não pode ser usado para executar a consulta. A ordem dos parâmetros dos operadores também é importante para o processador de consultas. O primeiro parâmetro sempre deve ser o atributo indexado, caso contrário o índice não é invocado e o processador de consultas realiza a execução sequencial da consulta. Ou seja, mesmo que exista um índice Slim_Manhattan no atributo image_sign, ele não será utilizado se a consulta for escrita usando Manhattan_dist (center_sign, image_sign), pois o atributo indexado é o segundo parâmetro.

Vale observar que um operador pode ser utilizado em um ponto da cláusula SELECT que não corresponde a uma busca, ou até mesmo em instruções SQL que não consultam o banco de dados. Por exemplo, pode-se utilizar um operador <distance_name>_dist na lista de atributos da projeção, para obter-se o valor da distância entre os elementos armazenados e o elemento de consulta. Ou então, pode-se utilizar o valor da distância para efetuar uma inserção ou uma atualização. Nestes casos, não faz sentido tentar fazer uma busca indexada, pois não é esse o significado do uso do operador na instrução SQL. Portanto, o processador de consultas naturalmente irá executar a função de distância referente ao operador para cada tupla da relação de entrada, independentemente de existir índice associado ao operador ou não.

As consultas pontuais e as consultas por abrangência reversa também precisam usar os operadores <distance_name>_dist para poderem ser executadas utilizando índices. Contudo, as consultas pontuais utilizam o operador de comparação '=' na condição de busca e as consultas por abrangência reversa utilizam o operador de comparação '>'.

As consultas aos $k$-vizinhos mais próximos com execução indexada no FMI-SiR ${ }_{O}$ utilizam uma sintaxe semelhante às consultas por similaridade por abrangência, porém usando os operadores <distance_name>_kNN. Por exemplo, a consulta a seguir é uma $k$-NNq com execução indexada: 
SELECT * FROM image_table

WHERE Manhattan_kNN(image_sign, center_sign) $<=10$;

onde são retornados os 10 vizinhos mais próximos ao vetor de características de consulta center_sign, considerando a distância Manhattan.

Observe que a sintaxe para a execução de $k$-NNq indexadas no FMI-SiR $_{O}$ não utiliza funções de janela, como ocorre com as $k$-NNq com execução sequencial (vide Seção 5.1.2). Esta é uma restrição imposta pela interface de indexação da arquitetura extensível do Oracle. Um efeito colateral desta restrição é que ao escrever uma $k$-NNq utilizando a sintaxe da execução indexada, se não existe um índice para executar esta operação, o FMI-SiR $O$ solicita ao processador de consultas que aborte a execução, emitindo uma mensagem de erro ao usuário. Isto porque o $\mathrm{FMI}_{-} \mathrm{SiR}_{O}$ não é capaz de reescrever automaticamente a consulta segundo a sintaxe da execução sequencial, pois no contexto da função não há informação suficiente para isso.

As consultas aos $k$-vizinhos mais distantes com execução indexada também usam os operadores <distance_name>_kNN. Contudo, elas devem utilizar o operador de comparação '>' no lugar do operador '<=' na condição de busca. Ao ser invocado pelo processador de consultas por meio de um operador <distance_name>_kNN, o FMI-SiR $O$ verifica qual o operador de comparação utilizado. Caso o operador de comparação seja '<=', o módulo executa uma $k$-NNq na Slim-tree, e caso o operador seja '>', o módulo executa uma $k$-FNq. Note que esta é uma convenção utilizada na versão corrente do FMI-SiR $O$, pois a construção "<distance_name>_kNN > k" não é intuitiva para representar uma $k$-FNq.

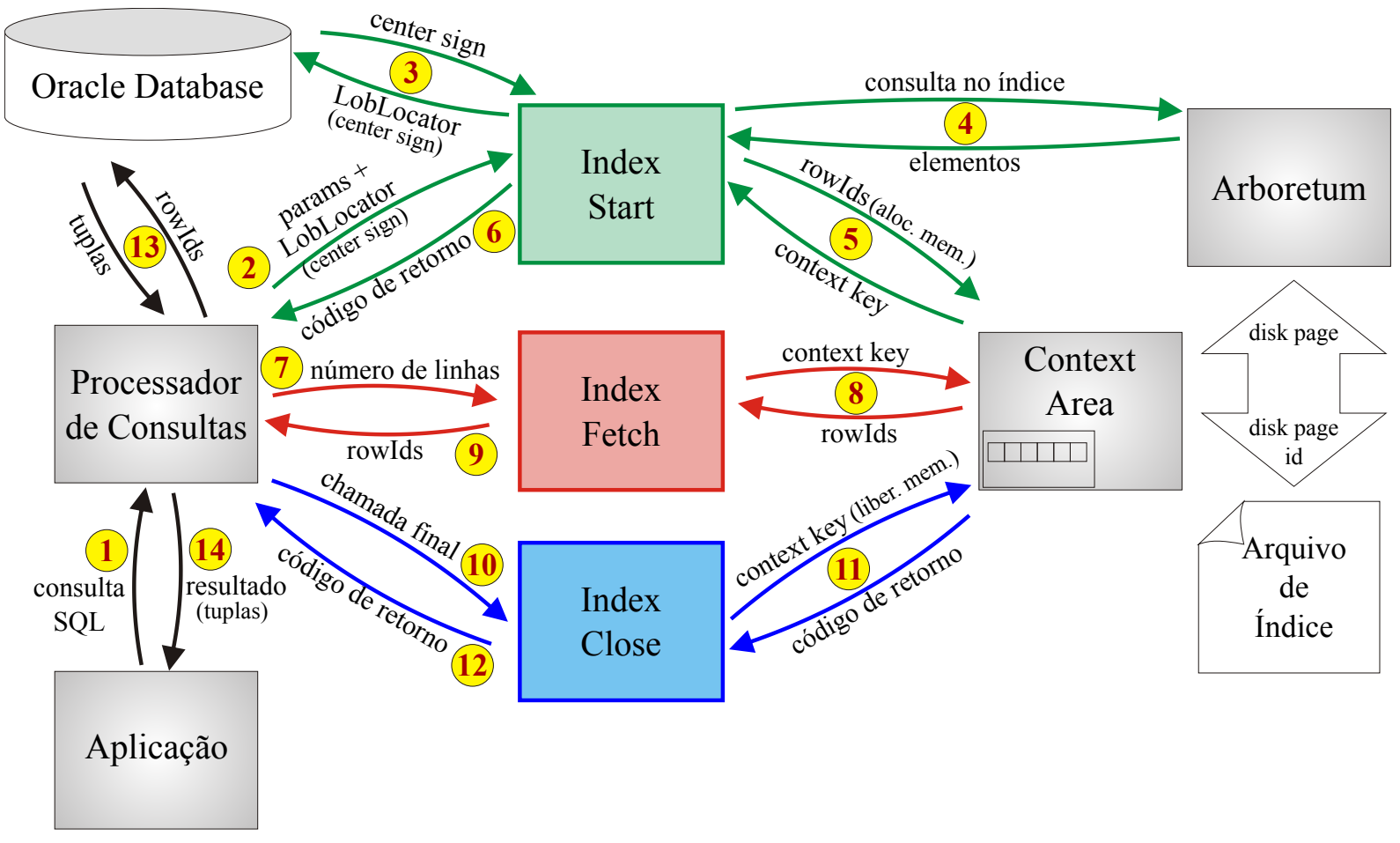

Figura 5.3: Execução de uma consulta por similaridade indexada no FMI-SiR . 
A execução de uma busca indexada no FMI-SiR $O$ ocorre como ilustrado na Figura 5.3. A aplicação envia uma consulta SQL para o SGBD (Passo 1). Quando o processador de consultas do SGBD identifica um operador por similaridade (<distance_name>_dist ou <distance_name>_kNN), ele consulta o catálogo do banco procurando por um índice associado a este operador para executar a operação de busca. Se o índice é encontrado, o processador de consultas chama a função ODCIIndexStart, passando informações sobre o operador, sobre o índice e sobre o predicado utilizado, e também o LobLocator do vetor de características de consulta e o limitante da busca (o limiar de dissimilaridade, para consultas baseadas em abrangência, ou o número de vizinhos, para consultas aos vizinhos mais próximos/distantes) (Passo 2). A função ODCIIndexStart carrega o vetor de características apontado pelo LobLocator do elemento de consulta (Passo 3) e executa a consulta indicada sobre o índice na biblioteca Arboretum (Passo 4). Então, a função armazena os rowIds dos elementos retornados pelo índice na área de contexto da sessão corrente do usuário, identificando área de memória por uma chave única (Passo 5). A chave de identificação da área de contexto é armazenada na variável scanctx do objeto do tipo de dados que implementa o índice, para ser utilizada nas próximas funções invocadas (fetch e close). A função, então, retorna o controle ao processador de consultas (Passo 6).

Em seguida, o processador de consulta invoca a função ODCIIndexFetch, fornecendo o número de linhas $n_{\text {rows }}$ a serem recuperadas (Passo 7). A função ODCIIndexFetch obtém a chave de identificação da área de contexto, acessando na variável scanctx do objeto que implementa o índice, e recupera os primeiros $n_{\text {rows }}$ rowIds armazenados na área de contexto (Passo 8), retornando-os ao processador de consultas (Passo 9). Se houverem mais rowIds no resultado, o processador de consultas faz novas chamadas à função ODCIIndexFetch, até que o conjunto de resultados seja completado.

Quando a fase de recuperação do resultado é finalizada, o processador de consultas chama a função ODCIIndexClose para encerrar a busca (Passo 10). A função ODCIIndexClose recupera a chave da área de contexto, libera a memória alocada para armazenar os resultados da busca (Passo 11) e retorna o controle ao processador de consultas (Passo 12).

Como o FMI-SiR $O$ utiliza as interfaces da arquitetura extensível do Oracle, o otimizador de consultas é ciente das buscas por similaridade indexadas. Desta forma, ele é capaz de intercalar a execução de buscas por similaridade com as demais operações suportadas pelo SGBD, de forma a identificar os caminhos de acesso mais eficientes aos dados. No plano de execução gerado pelo processador de consultas do Oracle, uma busca por similaridade indexada é identificada como uma varredura em um índice de domínio (DOMAIN INDEX). A listagem a seguir mostra o plano de execução gerado para a $k$-NNq apresentada nesta seção: 


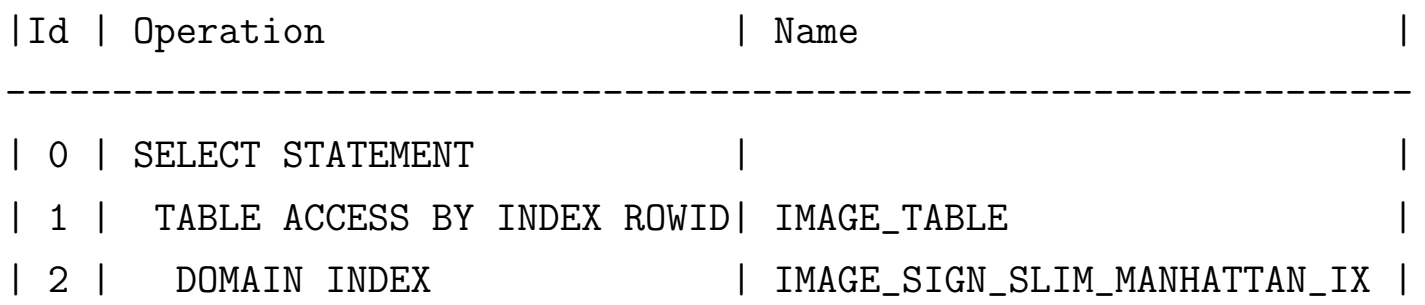

\subsubsection{Junções por Similaridade}

As junções por similaridade também são representáveis no FMI-SiR $O$. As construções utilizadas para representar as junções por similaridade são derivadas das construções usadas para representar as seleções por similaridade. Os exemplos apresentados nesta seção consideram que existe uma segunda tabela image_table2, cuja estrutura é idêntica à estrutura da tabela image_table.

As junções por abrangência $\left(\star_{\mathrm{Rq}}\right)$ são representadas no $\mathrm{FMI}_{-} \mathrm{SiR}_{O}$ utilizando os operadores <distance_name>_dist, ou as suas respectivas funções de distância <distance_name>_distance, na condição de junção. A consulta a seguir é uma junção por abrangência entre estas duas tabelas, cuja condição de junção é baseada na distância Manhattan entre os atributos das duas tabelas que armazenam os vetores de características das imagens:

SELECT out.image AS out_image, inn.image AS inn_image

FROM image_table out, image_table2 inn

WHERE Manhattan_dist(inn.img_sign, out.img_sign) $<=0.5$;

onde 0.5 é o limiar de dissimilaridade da condição de junção.

O FMI-SiR $O$ não implementa nenhum operador especial para junções por similaridade. Entretanto, as junções por abrangência podem ser executadas no FMI-SiR usando duas estratégias clássicas: a junção por laços aninhados (nested-loop join) e a junção baseada em índice (index-based join).

A junção por abrangência por laços aninhados é a estratégia trivial para efetuar este tipo de junção. O algoritmo de junção por laços aninhados, em cada iteração, carrega uma tupla da relação externa (ou um conjunto de tuplas) e, em seguida, percorre a relação interna, concatenando as tuplas que satisfazem a condição de junção. O algoritmo termina quando todas as tuplas da relação externa foram analisadas. Usualmente, a menor das duas relações é definida como sendo a relação externa, para tirar proveito do gerenciamento de memória do SGBD e obter melhor desempenho. Para duas relações $R$ e $S$, este método efetua $|R| *|S|$ cálculos de distância.

A junção por abrangência baseada em índice depende da existência de um índice em um dos atributos complexos de junção, que seja baseado na mesma função de distância utilizada na condição de junção. O algoritmo de junção baseada em índice percorre as 
tuplas da relação externa e, para cada tupla, executa uma consulta por abrangência, centrada no atributo de junção desta tupla e com limiar de dissimilaridade igual ao limiar indicado na condição de junção por abrangência, utilizando o índice do atributo de junção da relação interna. Portanto, para habilitar o uso deste algoritmo, necessariamente a consulta deve ser expressa utilizando um operador <distance_name>_dist, sendo que o nome do atributo de junção que possui índice deve ser o primeiro parâmetro do operador. Observe que, na consulta apresentada, a relação image_table2 é definida como sendo a relação interna (inn), pois inn.img_sign é o primeiro parâmetro do operador. O algoritmo de junção baseada em índice permite reduzir o espaço de busca, pois, para cada tupla da relação externa, a busca por abrangência indexada fica restrita apenas à região delimitada pela bola centrada no elemento de consulta e com raio igual ao limiar de abrangência da condição de junção. O custo deste algoritmo é $|R| *$ custo_Rq_indexada $(\xi)$, onde custo_Rq_indexada $(\xi)$ é o custo médio de execução de consultas por abrangência com limiar de dissimilaridade $\xi$ sobre o índice utilizado.

Percebe-se que o custo do algoritmo de junção por abrangência baseada em índice depende diretamente do limiar de abrangência definido na condição de junção. Na maioria das consultas, este limiar é pequeno o suficiente para que este algoritmo seja mais rápido do que o algoritmo por laços aninhados, mas nem sempre isto é verdadeiro. Além disso, caso existam índices nos dois atributos de junção, que sejam baseados na mesma função de distância utilizada na condição de junção, a escolha da relação interna afeta o desempenho do algoritmo. Se uma das relações é consideravelmente menor do que a outra, definir a menor relação como a relação externa, em geral, é uma boa alternativa. Entretanto, se as relações têm tamanhos semelhantes, o desempenho das buscas nos índices é o fator determinante na escolha da melhor opção, e este desempenho depende de uma série de fatores (distribuição dos dados, grau de sobreposição entre nós do índice, etc.). Como não foi avaliado um modelo de seletividade para operações de busca por similaridade, a versão atual do FMI-SiR $O$ não é capaz de escolher qual algoritmo é mais eficiente para cada caso. É responsabilidade do usuário escrever a consulta de forma que o algoritmo mais eficiente será usado.

A junção dos $k$-pares de vizinhos mais próximos $\left(\bowtie_{k \mathrm{CN}}\right)$ utiliza funções de janela do padrão SQL, de forma semelhante às seleções aos $k$-vizinhos mais próximos. A diferença é que a janela é definida pelas tuplas concatenadas pelo produto cartesiano das duas relações de entrada e ordenada segundo a distância entre os atributos de junção. A consulta a seguir expressa uma junção dos $k$-pares de vizinhos mais próximos no $\mathrm{FMI}_{-\mathrm{SiR}}$, considerando a distância Manhattan: 


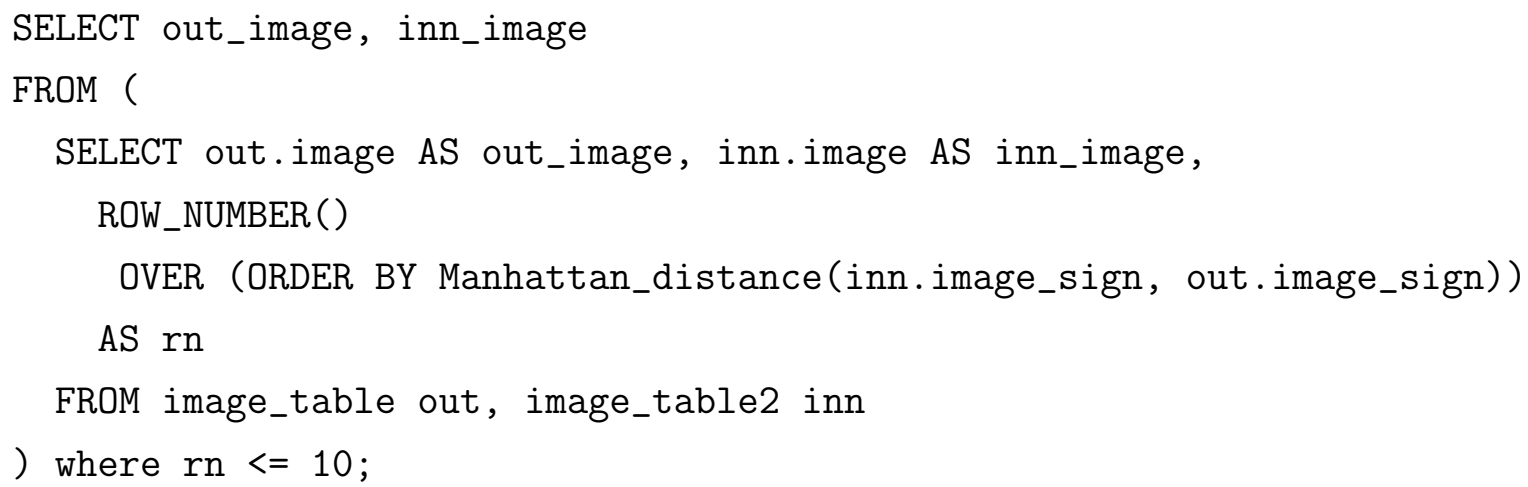

onde $k=10$ é o número de pares de vizinhos retornados. Na versão atual do FMI-SiR ${ }_{O}$, esta operação só possui a opção de execução sequencial.

As junções pelos k-vizinhos mais próximos $\left(\star_{k \mathrm{NN}}\right)$ também utiliza funções de janela. Porém, a definição da janela utiliza o modificador PARTITION BY, que organiza a janela de consulta em partições. O valor da função de janela é computado para cada partição. Desta forma, definindo as partições pelo identificador de cada tupla da primeira relação (lembre-se que a $\rtimes_{k N N}$ não é comutativa) é possível selecionar os $k$ vizinhos mais próximos a esta tupla na segunda relação. A consulta que se segue é um exemplo de junção pelos $k$-vizinhos mais próximos:

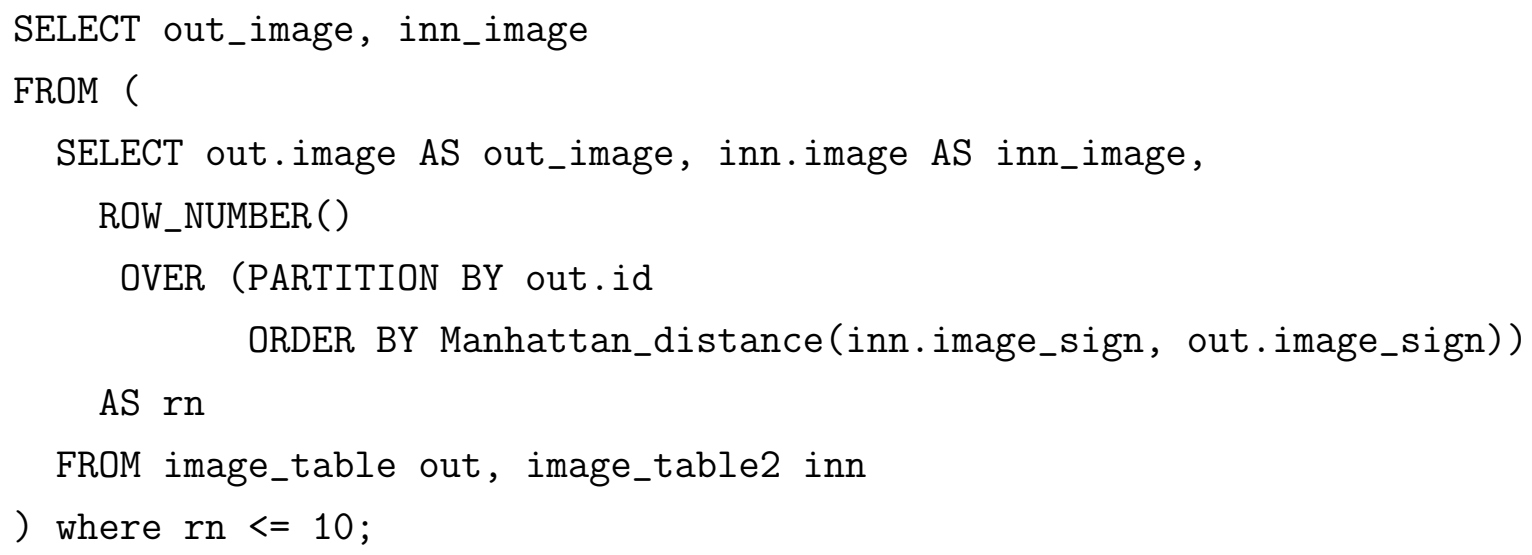

onde $k=10$ e a relação resultante possui $k * \mid$ image_table $\mid$ tuplas. Note que a partição foi definida pelo atributo id da relação image_table. Desta forma, para cada valor de image_table.id, as tuplas da relação image_table2 são ordenadas conforme a distância entre o atributo image_table.image_sign da tupla correspondente ao valor de image_table.id e o atributo image_table2.image_sign. Além disso, o valor do atributo rn gerado pela função de janela ROW_NUMBER é reiniciado a cada partição. Portanto, o filtro usado na consulta externa ( $r n<=10$, no exemplo) é satisfeito por 10 tuplas de cada partição, que são exatamente a concatenação da tupla de image_table que define a partição com as tuplas de image_table2 que correspondem aos seus 10 vizinhos mais próximos. Observe que no exemplo apresentado foi utilizado um atributo que identifica as tuplas da relação que contém o atributo complexo para definir a partição 
(image_table.id). A consulta foi montada desta forma porque o Oracle não permite particionar uma janela por um atributo do tipo BLOB, que é o tipo de dados tipicamente usado para armazenar dados complexos. Entretanto, como a grande maioria das aplicações mantém um identificador, geralmente numérico, para cada dado complexo armazenado, nestes casos esta restrição não é um limitante para definir a consulta. Esta operação também só é executada no $\mathrm{FMI}_{-} \mathrm{SiR}_{O}$ por meio de uma varredura sequencial.

\subsubsection{Seleções por Similaridade Agregada}

O FMI-SiR ${ }_{O}$, em sua versão atual, não tem tratamento específico para seleções por similaridade agregada. Contudo, estas consultas também são representadas no FMI-SiR $O$ utilizando instruções SQL nativas do SGBD Oracle. A expressão de consulta deve ser montada de forma a representar a função de distância agregada através de funções matemáticas.

Conforme apresentado na Seção 2.3.3, um exemplo interessante de função agregadora de distâncias é dado por: $\left.d_{g}(s, Q)=\sqrt[g]{\sum_{s_{q} \in Q}\left(\delta\left(s, s_{q}\right)^{g} * w_{q}\right.}\right)$. Para ilustrar a representação das seleções por similaridade agregada usando esta função, os exemplos desta seção consideram que o conjunto de elementos de consulta possui três elementos: $Q=\{$ center_sign1, center_sign2, center_sign3\}, que são BLOBs contendo vetores de características. Consideram, também, que a distância Manhattan é a função utilizada para calcular as dissimilaridades parciais $\left(\delta=L_{1}\right)$ e que os pesos ds dissimilaridades parciais é dado pelo conjunto de pesos $W=\{3,1.5,4\}$, onde o primeiro elemento de $W$ é o peso referente ao primeiro elemento de $Q$, o segundo elemento de $W$ é o peso referente ao segundo elemento de $Q$, e assim por diante.

As seleções por similaridade agregada utilizam a mesma sintaxe das seleções por similaridade simples, mas expressando a medida de dissimilaridade por meio da função de distância agregada $d_{g}$ desejada. O fator de agregação $g$ determina a forma de representar a função de distância agregada. Se $g=1$, a função de distância agregada é representada por uma soma ponderada. Quando $g=\infty$, o resultado de $d_{g}$ é o valor da maior dissimilaridade (ponderada) parcial. Portanto, se $g=\infty$, a função de distância agregada é representada utilizando a função GREATEST, que retorna o maior valor dentre os valores passados como parâmetros para a função. No outro extremo, se $g=-\infty$, o resultado de $d_{g}$ é o valor da menor dissimilaridade parcial. Assim, se $g=-\infty$, a função LEAST é utilizada para representar $d_{g}$, pois retorna o menor valor dentre todos os parâmetros fornecidos. Para os demais valores de $g$, a função de distância agregada utiliza a função de potenciação POWER.

As consultas por abrangência agregada são representadas conforme segue. A consulta a seguir expressa uma consulta por abrangência agregada pela função agregadora de distâncias citada com $g=1$ : 
SELECT image

FROM image_table

WHERE ((Manhattan_distance(image_sign, center_sign1) * 3) +

(Manhattan_distance (image_sign, center_sign2) * 1.5) +

(Manhattan_distance (image_sign, center_sign3) $* 4$ )) $<=4.5$;

onde 4.5 é limiar de dissimilaridade. Por outro lado, se $g=\infty$, uma consulta por abrangência agregada com os mesmos parâmetros é representada como:

SELECT image

FROM image_table

WHERE GREATEST((Manhattan_distance(image_sign, center_sign1) * 3),

(Manhattan_distance (image_sign, center_sign2) * 1.5),

(Manhattan_distance (image_sign, center_sign3) $* 4$ )) $<=4.5$;

onde a função GREATEST retorna o valor da menor distância. Consultas por abrangência agregada com $g=-\infty$ utilizam uma construção idêntica à da última consulta, porém utilizando a função LEAST no lugar da função GREATEST. Se $g \neq 1, g \neq \infty$ e $g \neq-\infty$, as consultas por abrangência agregada utilizam a função POWER, conforme segue:

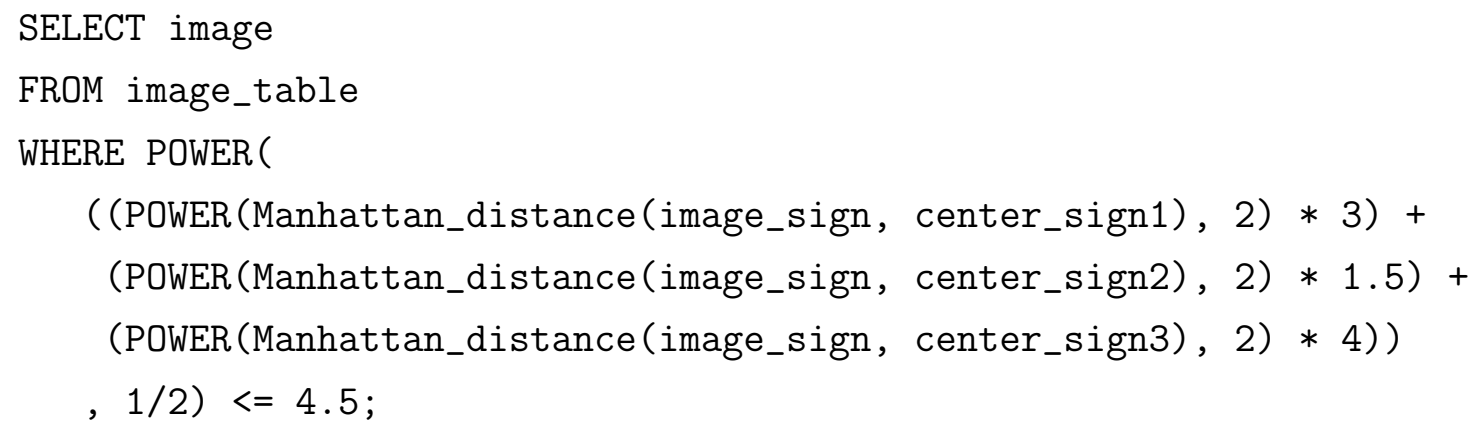

onde $g=2$, neste exemplo. A função POWER mais externa corresponde à $\sqrt[g]{ }$, por isso o valor do primeiro parâmetro da função, que é o resultado do somatório, é elevado a $1 / g$ (1/2, no exemplo).

As consultas aos $k$-vizinhos mais próximos agregados são representadas seguindo a mesma construção das $k$-NNq, utilizando funções de janela, mas representando a função de distância agregada da mesma forma que as consultas por abrangência agregada. Por exemplo, a consulta a seguir mostra uma consulta aos $k$-vizinhos mais próximos agregados, com os mesmos parâmetros da última consulta por abrangência agregada apresentada $(g=2)$ : 


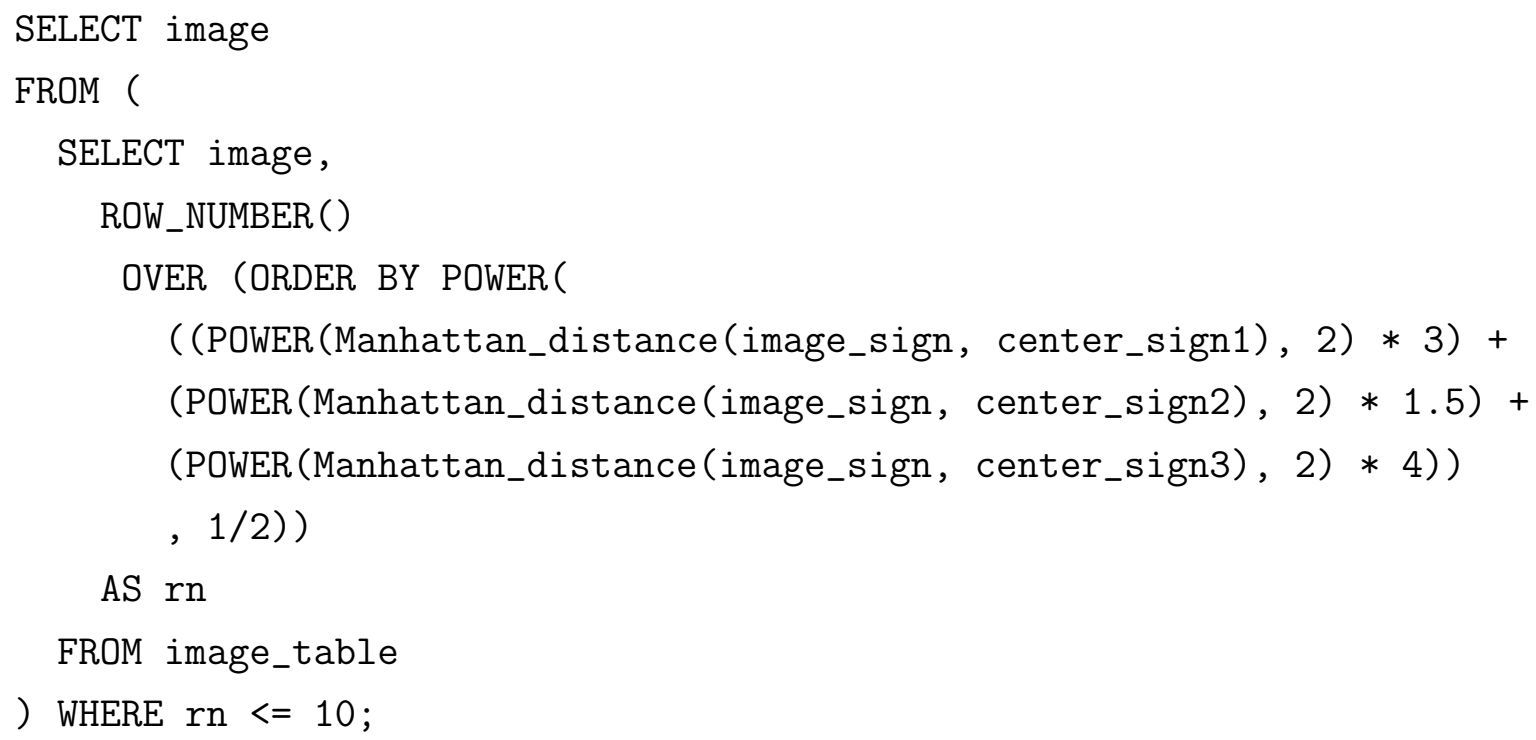

onde $k=10$.

As seleções por similaridade agregada são executadas por meio de varredura sequencial da relação de entrada. Entretanto, não é difícil acrescentar suporte à execução indexada deste tipo de consultas ao FMI-SiR ${ }_{O}$. Existem algoritmos funcionais para execução de consultas por abrangência agregada e de consultas aos $k$-vizinhos mais próximos agregados implementados sobre a Slim-tree da biblioteca Arboretum, cujas execuções são muito mais eficientes do que a varredura sequencial. Para isso, seria preciso acrescentar novos operadores ao $\mathrm{FMI}_{-} \mathrm{SiR}_{O}$, que recebessem todos os parâmetros necessários e fizessem a ligação com os respectivos algoritmos da Slim-tree.

\subsubsection{Seleções aos $k$-Vizinhos Mais Próximos com Condições}

As consultas aos $k$-vizinhos mais próximos estendidas com condições $\left({ }_{c} k\right.$-NNq), propostas no Capítulo 4 desta tese, também são suportadas pelo FMI-SiR $O$. Para representar as ${ }_{c} k$-NNq, foi incluído um novo operador ao FMI-SiR $O$ para cada função de distância disponível, com a forma:

<distance_name>_ckNN(signature1 BLOB, signature2 BLOB, cond VARCHAR)

onde o primeiro parâmetro é o nome do atributo da relação de entrada que armazena o vetor de características a ser usado na operação, o segundo parâmetro é o vetor de características de consulta e o terceiro parâmetro é uma string que define a condição que restringe a ${ }_{c} k$-NNq. Os formatos aceitos para o parâmetro cond são os mesmos das condições do operador ${ }_{c} k$-NN, apresentadas no Capítulo 4. Uma string vazia no parâmetro cond corresponde a uma condição nula, fazendo com que a operação executada pelo operador <distance_name>_ckNN seja uma consulta aos $k$-vizinhos mais próximos comum. 
Os operadores <distance_name>_ckNN mapeiam para funções $\mathrm{C}++$ da biblioteca dinâmica compartilhada que implementa o FMI-SiR $O$. Estas funções utilizam os algoritmos desenvolvidos sobre o MAM Slim-tree, descritos na Seção 4.4. Como estes algoritmos utilizam atributos adicionais para representar as condições aplicadas à busca, foi incluída no FMI-SiR ${ }_{O}$ uma segunda categoria de novos tipos de índice: os índices de cobertura para consultas por similaridade. A implementação destes tipos de índice utiliza a Slim-tree modificada para implementar os algoritmos para execução de consultas ${ }_{c} k$-NN das variações Table-Slim e Covering-Slim, apresentados na Seção 4.4.4. Os novos tipos de índice de cobertura têm a forma cov_slim_<distance_name> e recebem como parâmetro, além o tamanho da página de disco, a lista de atributos adicionais que formam o índice de cobertura.

Estes novos tipos de índices podem ser usados para a criação de índices para responder a consultas $k$-NN estendidas com condições. Por exemplo, considere que é acrescentado à relação image_table um novo atributo, denominado date_taken, populado com a data em que a imagem foi obtida. A instrução a seguir cria um índice de cobertura para o atributo image_sign desta tabela, considerando a distância Manhattan e incluindo o atributo date_taken:

\section{CREATE INDEX image_sign_cov_Slim_Manhattan ON image_table(image_sign) INDEXTYPE IS cov_Slim_Manhattan PARAMETERS ('8192 date_taken');}

onde 8192 é o tamanho da página de disco do índice. A lista de atributos adicionais contém os nomes dos atributos separados por espaços. Apenas atributos da mesma tabela do atributo complexo indexado são aceitos na lista de atributos adicionais e estes atributos têm que ser de tipos de dados simples (números, strings e datas ${ }^{1}$ ).

Embora os índices de cobertura sejam projetados para responder a consultas ${ }_{c} k-\mathrm{NN}$, uma vez criados eles também podem ser usados para responder a consultas por abrangência. Por isso, o FMI-SiR $O$ também implementa operadores de busca por abrangência com condições, com a forma:

<distance_name>_cdist(signature1 BLOB, signature2 BLOB, cond VARCHAR)

onde, neste caso, o parâmetro condition só aceita uma condição baseada em tupla, ou uma condição vazia/nula, que corresponde a uma consulta por abrangência convencional.

Uma ${ }_{c} k$-NNq com uma condição baseada em tupla pode ser representada com os operadores <distance_name>_ckNN. Por exemplo, a consulta "retorne as 10 imagens mais similares à imagem de consulta, representada pelo vetor de características center_sign, que tenham sido tiradas a partir de 11 de janeiro de 2011" é uma ${ }_{c} k$-NNq com uma condição baseada em tupla. Esta consulta pode ser representada algebricamente como:

$$
\ddot{\sigma}_{\text {image_sign }_{c} k \mathrm{NN}\left[L_{1}, 10, \text { date_taken } \geq\right.} \geq^{\left.\prime 01 / 01 / 2011^{\prime}\right]} \text { center_sign }(\text { image_table) }
$$

\footnotetext{
${ }^{1}$ Atributos do tipo DATE são convertidos em strings no formato 'YYYYMMDD'.
} 
onde a função de distância utilizada é a Manhattan $\left(L_{1}\right)$. No FMI-SiR $O$, esta consulta pode ser representada conforme segue:

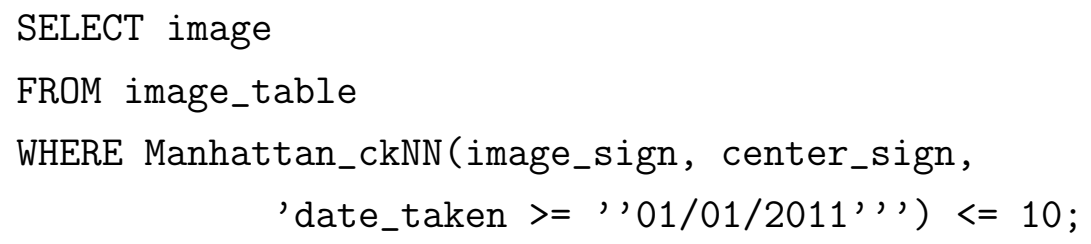

onde Manhattan_ckNN é o operador de consulta aos $k$-vizinhos mais próximos estendido com condições para a função de distância Manhattan, a condição baseada em tupla imposta é date_taken $>=$ '01/01/2011' (os caracteres ' ' ' adicionais são usados para escape), o operador de comparação '<=' indica que a busca é aos vizinhos mais próximos e 10 é o número de vizinhos.

Relembrando, a Regra 4.2, apresentada na Seção 4.3.1, indica que uma condição baseada em tupla restingindo uma ${ }_{c} k$-NNq pode ser utilizada em uma seleção convencional antecipada à seleção por similaridade. Portanto, as ${ }_{c} k$-NNq com condições baseadas em tupla podem ser representadas utilizando funções de janela, seguindo a sintaxe apresentada na Seção 5.1.2 para execução sequencial de consultas aos $k$-vizinhos mais próximos. Desta forma, a consulta anterior pode ser alternativamente escrita como:

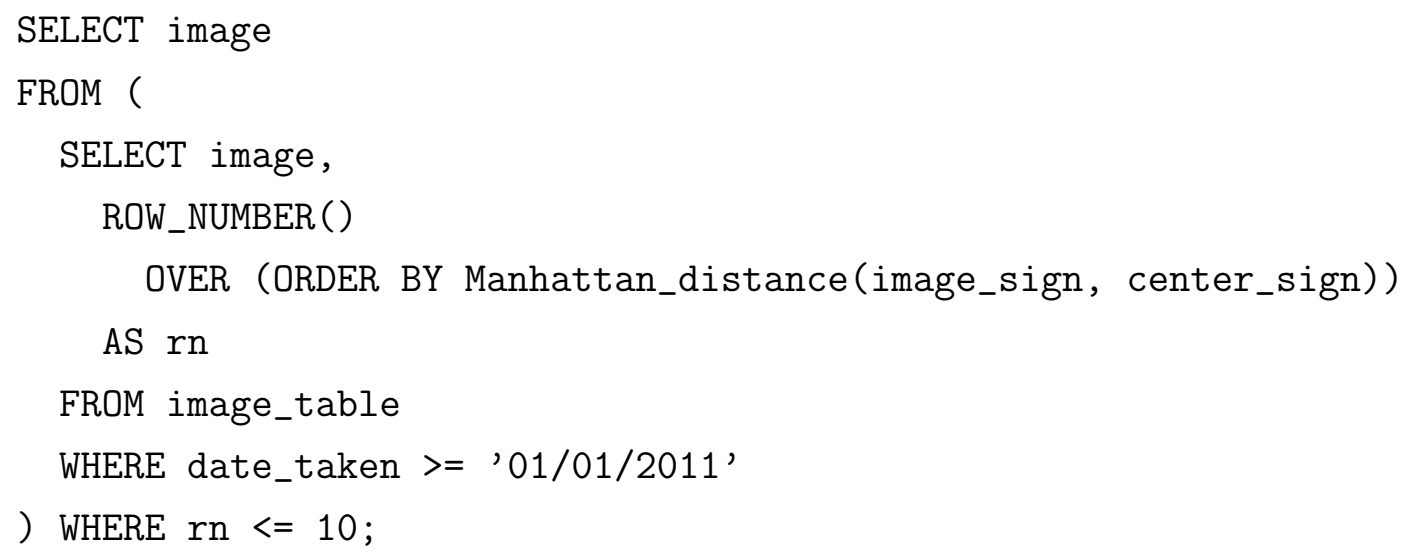

onde a condição restringindo a busca encontra-se na cláusula WHERE da subconsulta interna, filtrando as tuplas cujas imagens foram obtidas a partir de 01/01/2011. Esta construção sintática é interessante quando a seletividade da condição da ${ }_{c} k$-NNq é alta, especialmente se existe um índice no atributo date_taken que pode ser usado para agilizar a execução da consulta.

Por outro lado, as ${ }_{c} k-\mathbf{N N q}$ com condições baseadas em agregação só podem ser expressas fazendo uso dos operadores ${ }_{c} k$-NN (<distance_name>_ckNN). Isto porque a condição baseada em agregação afeta o funcionamento da busca, que não é representável por meio de operadores de consulta existentes no SGBD. Portanto, antes de executar qualquer ${ }_{c} k$-NNq no FMI-SiR $O$ com uma condição baseada em agregação, é necessário 
criar um índice de cobertura sobre o atributo complexo, baseado na mesma função de distância usada na consulta.

Por exemplo, a consulta "Retorne as 10 imagens mais similares à imagem de consulta, representada pelo vetor de características center_sign, sendo que, ao menos, 5 delas tenham sido tiradas antes de 31 de dezembro de 2010" é uma ${ }_{c} k$-NNq com uma condição baseada em agregação por contagem. Esta consulta é representada algebricamente como:

$$
\ddot{\sigma}_{\text {image_sign } c k N N\left[L_{1}, 10, \operatorname{COUNT}\left(*, \text { date_taken }^{\prime} 31 / 12 / 2010^{\prime}\right) \geq 5\right] \text { center_sign }}(\text { image_table })
$$

considerando que a dissimilaridade é calculada pela distância Manhattan. Supondo que existe um índice de cobertura sobre o atributo image_sign organizado segundo a distância Manhattan, esta consulta é representada no FMI-SiR $O$ pela expressão SQL a seguir:

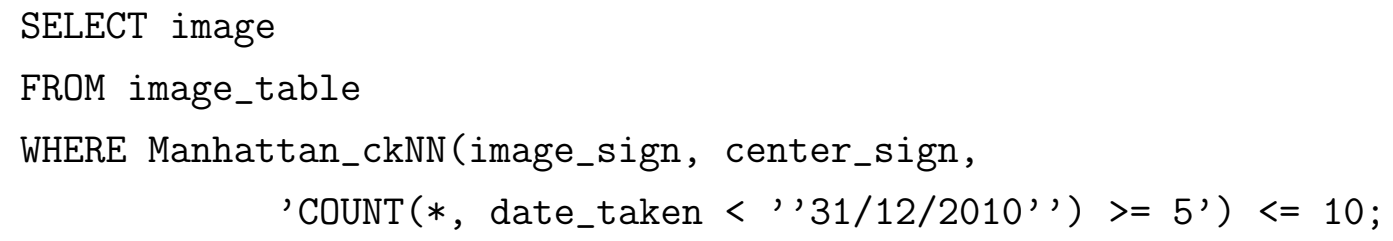

A execução da operação disparada por um operador <distance_name>_ckNN inicialmente verifica se o(s) atributo(s) utilizado(s) na condição da ${ }_{c} k$-NN está(ão) presente(s) no índice de cobertura. Note que uma condição de agregação por contagem de distintos (COUNT(DISTINCT)) requer dois atributos para ser computada. Se todos os atributos necessários encontram-se no índice, o algoritmo referente à condição imposta à ${ }_{c} k$-NNq da variação Covering-Slim é chamado para executar a busca. Caso contrário, é invocado o algoritmo da variação Table-Slim, acessando as tuplas da relação de entrada a partir dos rowIds armazenados nas entradas do índice.

A versão atual do FMI-SiR $O$ aceita apenas condições baseadas em tupla e condições baseadas em agregação por contagem. Para acrescentar suporte às condições baseadas em agregação por soma e por média é preciso implementar algoritmos eficientes para responder a consultas com essas condições. Com respeito às condições baseadas em agregação por mínimo e por máximo, seria preciso alterar o parsing da condição, dentro da função que implementa os operadores <distance_name>_ckNN, e invocar os algoritmos correspondentes, que, por sua vez, são baseados nos algoritmos de ${ }_{c} k$-NNq com condições baseadas em tuplas e com condições baseadas em agregação por contagem.

É fundamental observar que, embora as consultas apresentadas na descrição do FMI-SiR $_{O}$ considerem operações baseadas em similaridade, estas operações podem ser utilizadas em conjunto com as demais operações de consulta fornecidas pelo SGBD. Desta forma, é possível executar consultas complexas envolvendo operações baseadas em similaridade e operações relacionais tradicionais, utilizando a sintaxe SQL apresentada. 


\subsection{A Extensão MedFMI-SiR}

Uma das principais áreas de aplicação das pesquisas desenvolvidas nesta tese é a área médica. Conforme apresentado na Seção 2.4.1, os sistemas de apoio à área médica em geral manipulam uma diversidade de tipos de dados. Em especial, os sistemas existentes carecem de soluções eficientes para integração de dados tradicionais e dados de exames de radiologia, particularmente, no gerenciamento de bancos de imagens médicas no padrão DICOM (descrito na Seção 2.4.2).

Os PACS (Picture Archiving and Communications Systems - sistemas de arquivamento e comunicação de imagens), usados para gerenciar os bancos de imagens em instituições médicas, em geral não suportam recuperação de imagens por conteúdo (ContentBased Image Retrieval - CBIR). As buscas nos PACS são feitas apenas com base nos metadados armazenados nas tags do cabeçalho das imagens DICOM. Entretanto, muitos esforços de pesquisa têm sido direcionados para desenvolver novas técnicas e sistemas de CBIR para o gerenciamento de imagens médicas por conteúdo (vide Seção 2.4). As imagens médicas naturalmente possuem vários atributos descritivos associados, contudo a riqueza do conteúdo retratado na imagem em si é uma fonte fundamental de informação para o processo de busca. Desta forma, inúmeras aplicações médicas demandam soluções que permitam recuperar imagens médicas combinando condições baseadas em metadados e condições baseadas em similaridade do conteúdo das imagens.

Esta seção descreve o MedFMI-SiR (Medical user-defined Features, Metrics and Indexes for Similarity Retrieval - caraterísticas, métricas e índices para recuperação por similaridade de dados médicos), que é uma extensão do módulo FMI-SiR $O$ para manipular imagens médicas no formato DICOM por conteúdo. O MedFMI-SiR foi concebido para ser usado em conjunto com os mecanismos de busca baseada em metadados DICOM, providos pelo módulo Multimedia DICOM do SGBD Oracle(Oracle Corporation, 2007a), para suportar recuperação combinando metadados e similaridade em grandes bancos de imagens médicas.

\subsubsection{A Arquitetura do MedFMI-SiR}

A Figura 5.4 mostra a arquitetura do MedFMI-SiR. O MedFMI-SiR estende as funcionalidades do FMI-SiR $O$ (extratores de características, métricas e índices para dados complexos) para imagens no formato DICOM. Para suportar imagens DICOM, o MedFMI-SiR interage com uma Biblioteca de Gerenciamento de DICOM, que na versão corrente é a DICOM Toolkit (DCMTK)2 ${ }^{2}$ A DCMTK é uma coleção de rotinas C++ que implementam várias partes do padrão DICOM, incluindo funções para visualizar, construir e converter arquivos de imagens no formato DICOM. Assim, o MedFMI-SiR é capaz de

\footnotetext{
${ }^{2}$ http://dicom.offis.de/dcmtk.php.en
} 
manipular uma grande variedade de modalidades de imagens DICOM, incluindo imagens comprimidas, e de efetuar operações de processamento destas imagens para extração de características. O MedFMI-SiR é acoplado ao SGBD Oracle através das interfaces da arquitetura extensível do Oracle. Desta forma, ele é controlado pelo processador de consultas do SGBD e integrado às demais funcionalidades do SGBD, permitindo executar eficientemente consultas combinando condições baseadas em metadados e condições baseadas em conteúdo em bancos de imagens DICOM.

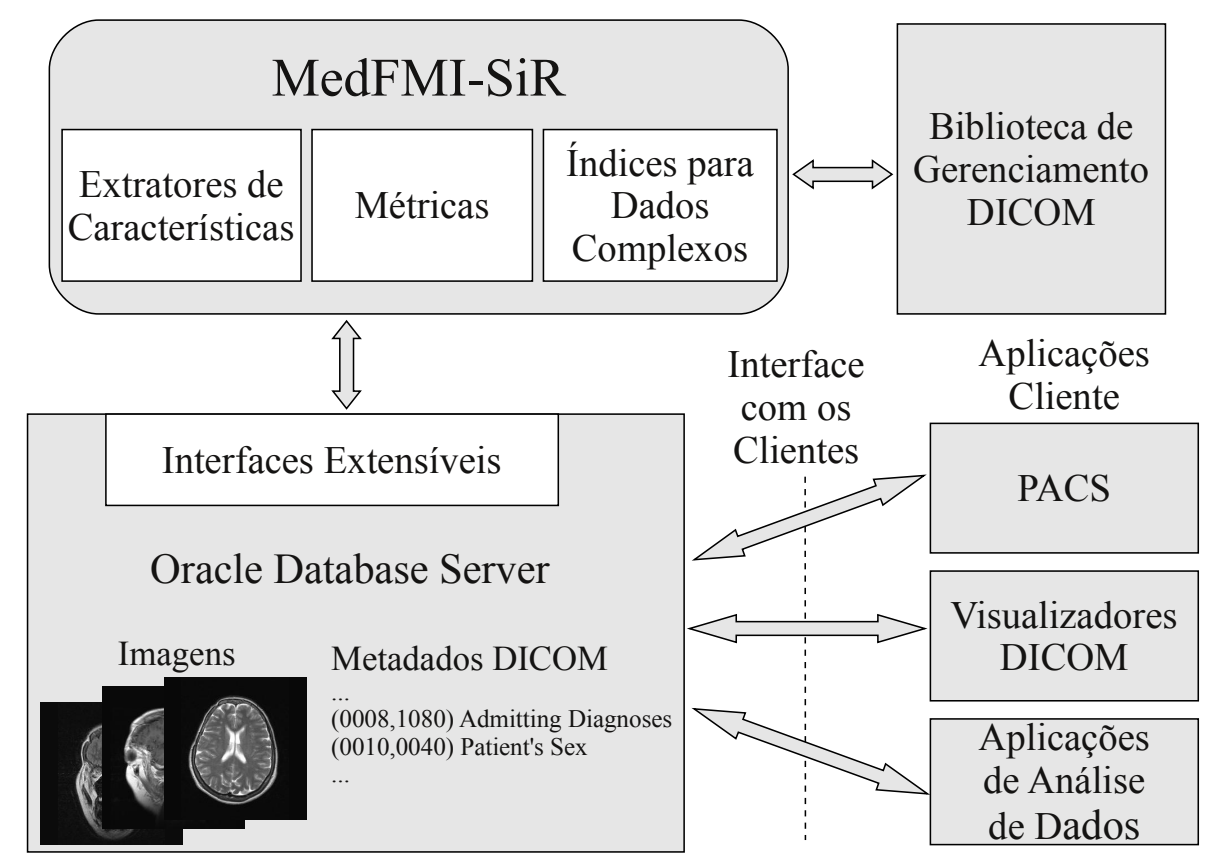

Figura 5.4: Arquitetura do MedFMI-SiR.

Todas as informações sobre as imagens são armazenadas no banco de dados de forma integrada, incluindo os metadados DICOM, os vetores de características descrevendo o seus conteúdos e as imagens em si. As aplicações cliente utilizam as funcionalidades do MedFMI-SiR acessando diretamente a interface do SGBD, sem a necessidade de bibliotecas adicionais. Isto permite que aplicações desenvolvidas em qualquer linguagem sejam capazes de recuperar imagens DICOM por conteúdo por meio de uma conexão simples com o SGBD. Assim, múltiplas aplicações médicas, tais como PACS, visualizadores de DICOM e outras aplicações de análise de dados, podem fazer uso compartilhado de um repositório centralizado de imagens, com integridade e segurança reforçadas e com funcionalidades de recuperação por conteúdo.

\subsubsection{Extração de Características}

O MedFMI-SiR inclui funcionalidades para extração de características diretamente das imagens DICOM armazenadas no banco de dados. O padrão DICOM permite o uso de várias codificações diferentes para as imagens, incluindo diferentes técnicas de compressão 
e variação na ordem de bytes das palavras de memória (por exemplo, big-endian, onde os primeiros bytes são os mais significativos, e little-endian, onde os últimos bytes são os mais significativos). Dentre as bibliotecas para dados DICOM estudadas, a DCMTK mostrou-se a mais completa, oferecendo funções para manipular uma grande diversidade de modalidades de imagens DICOM, sendo adotada como a Biblioteca de Gerenciamento de DICOM do MedFMI-SiR.

Os extratores de características de imagens disponíveis no MedFMI-SiR são genéricos, ou seja, não há extratores específicos para as diferentes modalidades de imagens médicas. Entretanto, a inclusão de novos extratores exige apenas manipular as matrizes de pixels da imagem, pois, depois de abertas, as imagens são encapsuladas em um tipo de dados genérico, independente da codificação da imagem. Além disso, a Biblioteca de Gerenciamento de DICOM permite manipular diretamente os metadados do cabeçalho das imagens. Esta funcionalidade permite utilizar dados do cabeçalho das imagens para guiar o processo de extração de características. Embora este recurso ainda não seja aproveitado na versão corrente do MedFMI-SiR, os metadados das imagens DICOM poderiam ser utilizados para selecionar automaticamente o extrator de características e/ou os seus parâmetros, de forma a gerar vetores de características que melhor descrevam o conteúdo das imagens de cada modalidade de exame.

Os extratores de características do MedFMI-SiR também são encapsulados na função generateSignature, que invoca os extratores por meio de funções $\mathrm{C}++$ da biblioteca compartilhada dinâmica que implementa o módulo. Esta função é chamada em sentenças SQL, conforme apresentado na Seção 5.1.1.

\subsubsection{Recuperação Combinando Metadados e Conteúdo de Imagens DICOM}

As versões mais recentes do SGBD Oracle possuem suporte a dados DICOM, por meio do módulo Oracle Multimedia DICOM (introduzido na Seção 3.4.2). O módulo Multimedia DICOM permite que as imagens DICOM sejam armazenadas no banco de dados utilizando um tipo de dados especial, que extrai os metadados do cabeçalho da imagem e os armazena em formato XML, utilizando o subsistema de gerenciamento de dados XML nativo do SGBD Oracle. Tendo os dados DICOM armazenados no banco de dados, as aplicações médicas que manipulam os bancos de imagens podem se beneficiar de todos os recursos providos pelo SGBD, tais como controle de acesso e segurança, execução concorrente, garantia de integridade, entre outros. Além disso, armazenando o cabeçalho das imagens DICOM em XML, é possível efetuar buscas baseadas em metadados diretamente em sentenças SQL. 
Para ilustrar a recuperação de imagens combinando metadados e conteúdo de imagens médicas no MedFMI-SiR, considere uma relação para armazenar imagens DICOM definida como segue:

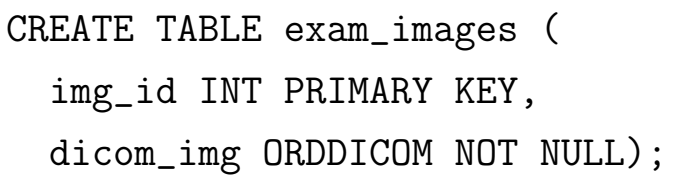

onde o atributo img_id é um identificador único e o atributo dicom_img armazena as imagens DICOM no tipo proprietário ORDDICOM, fornecido pelo Oracle Multimedia DICOM. Considere, também, que existe uma outra relação associada à relação exam_images que guarda os vetores de características das imagens, definida como:

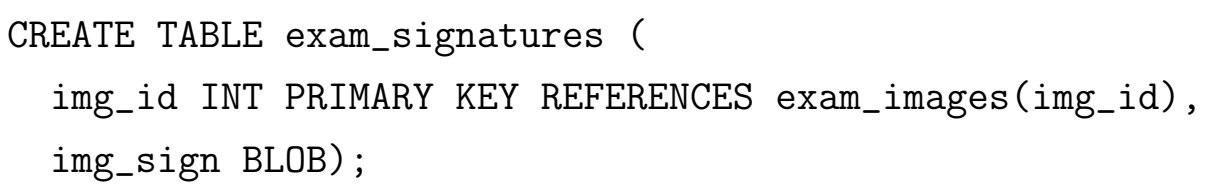

onde img_sign é o atributo usado para armazenar os vetores de características das imagens. Neste exemplo, utilizam-se duas relações separadas para guardar os dados relativos às imagens armazenadas. Embora possa ser utilizada apenas uma relação, a abordagem adotada de usar duas delas é melhor porque em uma instituição médica normalmente o banco de imagens é compartilhada entre várias aplicações usadas na rotina da instituição, sendo que muitas delas não fazem uso de recuperação por conteúdo, e que a quantidade de imagens armazenadas é tipicamente grande (da ordem de milhões de imagens).

Inicialmente, as imagens DICOM devem ser carregadas no banco de dados. Em seguida, são invocadas a função para extração de características do MedFMI-SiR e a função para extração dos metadados do cabeçalho das imagens (função setProperties() do tipo ORDDICOM). Depois disso, é possível consultar o banco de imagens utilizando operações baseadas em metadados e operações baseadas em similaridade.

A operações de consulta baseadas em metadados utilizam os operadores SQL de consulta sobre dados XML do Oracle. Já as operações baseadas em similaridade utilizando os operadores fornecidos pelo MedFMI-SiR, sob as diversas formas apresentadas na seção que descreve o FMI-SiR $O$. Por exemplo, considere a Consulta 15, definida como segue.

Consulta 15: Dentre as 50 imagens de exames mais similares à imagem de consulta, representada pelo vetor de características center_sign, retorne aquelas que sejam de séries de protocolos de epilepsia de rotina (Routine Epilepsy Protocol).

A Consulta 15 utiliza uma condição baseada em metadados (a descrição da série deve ser Routine Epilepsy Protocol) e uma condição baseada em similaridade (consulta aos $k$-vizinhos mais próximos). Esta consulta pode ser expressa no MedFMI-SiR como: 
SELECT e.dicom_img

FROM exam_images i, exam_signatures s

WHERE i.img_id $=$ s.img_id

AND Manhattan_kNN(s.img_sign, center_sign) $<=50$

AND extractValue(i.dicom_img.metadata,

'/DICOM_OBJECT/LONG_STRING[Qtag="0008103E"]/text()')

= 'Routine Epilepsy Protocol';

onde Manhattan_kNN é o operador de consulta aos $k$-vizinhos mais próximos do MedFMI-SiR para a função de distância Manhattan, retornando os 50 vizinhos mais próximos a center_sign dentre os valores de img_sign, e extractValue é uma função que percorre um "arquivo" XML, no caso, a propriedade metadata do atributo dicom_img (definida no tipo ORDDICOM), retornando os valores que casam com a expressão de caminho fornecida ('/DICOM_OBJECT/LONG_STRING [@tag="0008103E"]/text()'). A descrição da série (Series Description) de uma imagem é armazenada na tag DICOM (0008,103E), informada na expressão de caminho da consulta. Toda tupla da relação exam_images cujo valor de retorno da função extractValue seja igual à string de comparação ('Routine Epilepsy Protocol') satisfaz a condição baseada em metadados fornecida.

As consultas com condições baseadas em metadados DICOM são bastante custosas, pois exigem recuperar cada tupla da tabela de entrada e processar o arquivo XML contendo os metadados. Entretanto, é possível agilizar muito o processo de busca definindo um índice baseado em função sobre o resultado da função extractValue. A instrução a seguir define um índice sobre o conteúdo da tag DICOM (0008,103E), para acelerar a consulta apresentada no exemplo:

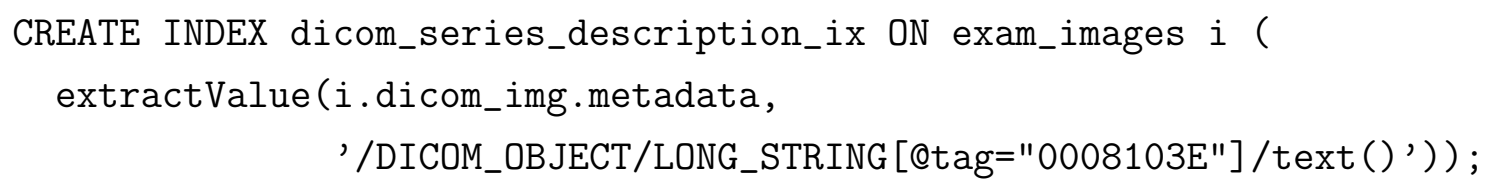

indexando o resultado da função extractValue para a tag DICOM Series Description. Na verdade, esta instrução adiciona um atributo oculto à relação exam_images para armazenar o resultado da função e cria um índice (B-tree) sobre este atributo. Com a criação deste índice, a verificação da condição baseada em metadados é verificada diretamente no índice, evitando o processamento do arquivo XML.

No exemplo, como trata-se de uma busca combinando duas condições, se houver um índice no atributo image_sign, este índice também poderá ser usado na execução da consulta. O MedFMI-SiR permite gerar planos de execução alternativos para a consulta, que podem ser explorados para otimizar o desempenho da execução, dependendo das operações existentes na consulta e das seletividades das condições de busca. Esta é uma característica herdada do módulo $\mathrm{FMI}_{-} \mathrm{SiR}_{O}$. Esta potencialidade é particularmente útil 
para aplicações sobre grandes bancos de dados complexos, que demandem consultas envolvendo condições baseadas em metadados e baseadas em similaridade, como é o caso de aplicações médicas com suporte a recuperação por conteúdo. Infelizmente, o módulo não é capaz de guiar o processador de consultas na tarefa de otimização, ficando a cargo do programador a escrita da consulta em sua forma mais eficiente.

\subsection{Experimentos Sobre o Módulo FMI-SiR ${ }_{O}$}

O módulo FMI-SiR foi testado sobre várias conjuntos de imagens. Esta seção apresenta resultados de experimentos comparando a recuperação de imagens por conteúdo no SGBD Oracle usando o módulo FMI-SiR $O$ e usando o módulo padrão de CBIR do Oracle interMedia (introduzido na Seção 3.4.2), referenciado nesta seção como Oracle padrão.

O conjunto de imagens utilizada nestes experimentos foi a $\mathrm{ALOI}^{3}$ (Amsterdam Library of Object Images - biblioteca Amsterdam de imagens de objetos) (Geusebroek et al., 2005), que é uma coleção de imagens coloridas de mil pequenos objetos, com 108 imagens de cada objeto, variando a cor de iluminação, o ângulo de iluminação e o ponto de vista, totalizando 108.000 imagens. A Figura 5.5 apresenta uma amostra das imagens deste conjunto.

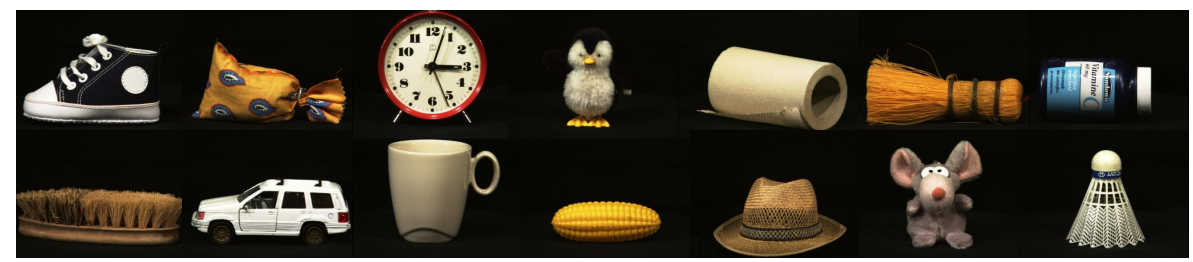

Figura 5.5: Amostra das imagens do conjunto ALOI.

O conjunto de imagens foi carregada no banco de dados utilizando os mecanismos de carga em lote. Para cada imagem foram gerados quatro vetores de características:

1. Oracle padrão: vetor de características OrdImageSignature, do módulo de CBIR do Oracle, que inclui as características de Cor, Forma e Textura utilizadas pelo módulo da Oracle;

2. Histograma: histograma de cores de 256 bins, utilizado pelo FMI-SiR $O$ como vetor de características de Cor;

3. Zernike: vetor contendo os primeiros 256 momentos de Zernike, utilizado pelo FMI-SiR $O$ como descritor de Forma; e

4. Haralick: vetor com descritores de Haralick, totalizando 140 características, utilizado pelo FMI-SiR $O$ como descritor de Textura.

\footnotetext{
${ }^{3} \mathrm{http}: / /$ staff.science.uva.nl/ aloi/
} 
Em seguida, foram realizados vários testes em um SGBD Oracle Database 11g Enterprise Edition Release 11.1.0.6.0 64bit, sobre o sistema operacional Kubuntu GNU/Linux 8.10 64bit, executado em uma máquina equipada com um processador Intel Core 2 Quad 2.83GHz, 4GB of memória RAM e um disco rígido SATA2 de 750GB e 7.200RPM. As próximas seções apresentam os resultados destes experimentos.

\subsubsection{Avaliação de Qualidade dos Resultados}

O primeiro conjunto de experimentos realizado teve por objetivo comparar a qualidade dos resultados gerados pelo Oracle padrão e pelo FMI-SiR $O$. Para avaliar a qualidade dos resultados foram utilizados gráficos de precisão versus revocação $(\mathrm{P} \times \mathrm{R})($ Baeza-Yates e Ribeiro-Neto, 1999). A precisão dos resultados de uma consulta é a fração dos elementos recuperados que são relevantes para a consulta, dada por $\operatorname{Prec}=\frac{|R a|}{|A|}$, onde $|R a|$ é o número de elementos relevantes recuperados e $|A|$ é o número de elementos do conjunto resposta da consulta. A revocação dos resultados de uma consulta é a fração do total de elementos relevantes que foram recuperados pela consulta, definida como Revoc $=\frac{|R a|}{|R|}$, onde $|R a|$ é o número de elementos relevantes recuperados e $|R|$ é o número total de elementos relevantes que deveriam ser recuperados. Desta forma, quanto mais próxima do topo estiver uma curva de $P \times R$, melhor é a qualidade dos resultados.

Inicialmente, para cada vetor de características usado pelo $\mathrm{FMI}_{-} \mathrm{SiR}_{O}$, foram avaliadas as precisões obtidas por várias funções de distância diferentes, para identificar qual função de distância gera o melhor resultado para o vetor de características. As funções de distância escolhidas foram: $L_{1}$ (Manhattan) para os vetores de características Histograma e Zernike e a distância Canberra para o vetor de características Haralick. A função de distância usada pelo Oracle padrão foi a função fornecida juntamente com o tipo OrdImageSignature. Em seguida foram gerados os gráficos de $P \times R$ para cada classe de vetor de características (cor, forma e textura), obtidos pela média das precisões de 50 consultas, cada uma com um elemento de referência distinto, escolhido aleatoriamente dentre os armazenados no banco de imagens. Para avaliar separadamente as características de cor, forma e textura no vetor de características Oracle padrão, as consultas foram definidas atribuindo peso 1 para a característica avaliada e 0 para as demais características.

A Figura 5.6 mostra os gráficos de $\mathrm{P} \times \mathrm{R}$ comparando a qualidade da recuperação obtida

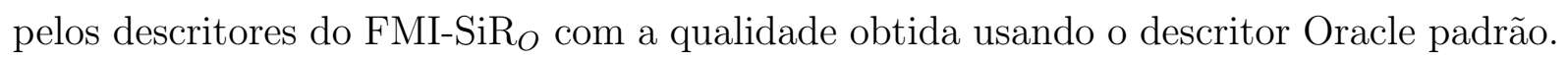
Analisando os gráficos da Figura 5.6, pode ser observado que o FMI-SiR $O$ foi superior em termos de precisão dos resultados em todos os casos. Considerando o descritor de Cor, a precisão obtida pelo $\mathrm{FMI}_{-} \mathrm{SiR}_{O}$ foi até $50 \%$ superior à precisão do Oracle padrão. Com relação ao descritor de Forma, o FMI-SiR $O$ também foi visivelmente superior, obtendo ganho de $92 \%$ para o valor de revocação de $5 \%$. O descritor de Textura do FMI-SiR $O$ apresentou um ganho notável de precisão sobre o descritor Oracle padrão, atingindo $171 \%$ 
de ganho também para o valor de revocação de 5\%. É importante enfatizar que buscas por similaridade tipicamente retornam uma pequena fração da relação de entrada. Portanto, em geral, as precisões dos valores de revocação pequenos são as mais revelantes, o que reitera a superioridade da qualidade dos resultados gerados pelo FMI-SiR . $_{\text {. }}$
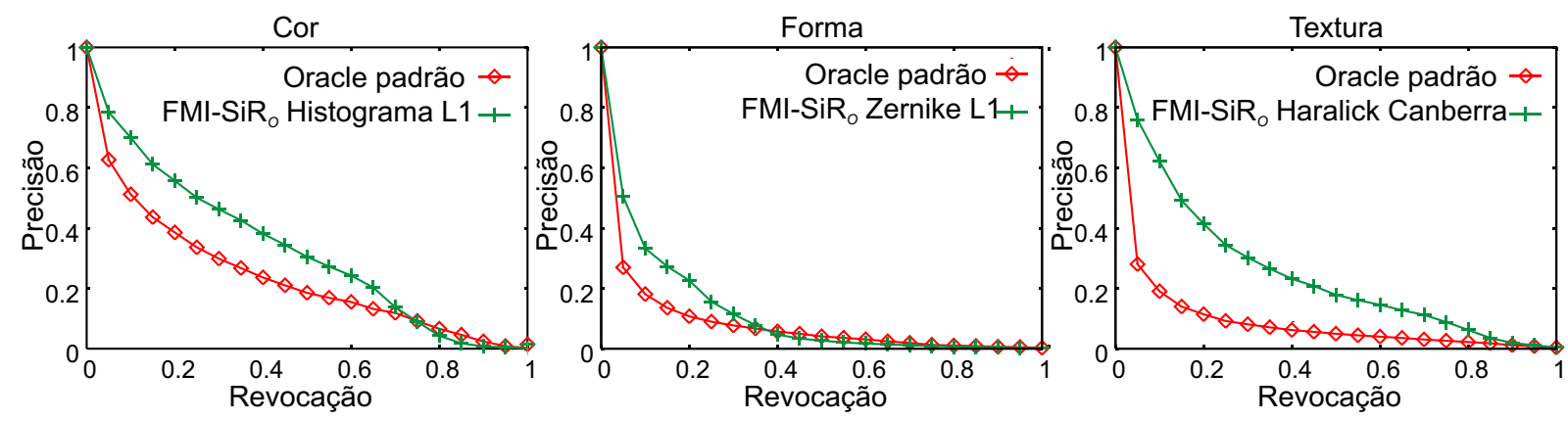

Figura 5.6: Gráficos de $\mathrm{P} \times \mathrm{R}$ comparando a qualidade dos resultados do $\mathrm{FMI}_{-} \mathrm{SiR}_{O}$ e do Oracle padrão.

\subsubsection{Desempenho de Execução de Seleções por Similaridade}

O segundo conjunto de experimentos teve por meta avaliar o desempenho de execução de operações de seleção por similaridade. Para isto foram executadas baterias de consultas, com elementos de referência aleatórios, para cada algoritmo disponível para execução de consultas $k$-NN e por abrangência no FMI-SiR $O$ e no Oracle padrão, considerando isoladamente os descritores de Cor, Forma e Textura. Os resultados apresentados nesta seção foram obtidos pela média de 500 consultas. As funções de distância usadas para os vetores de características foram as mesmas utilizadas na seção anterior. É importante enfatizar que não foi possível utilizar a função de distância fornecida pelo Oracle padrão para os vetores de características do $\mathrm{FMI}_{-} \mathrm{SiR}_{O}$, ou vice-versa, o que faria a comparação de desempenho dos algoritmos mais justa, pois as estruturas do vetor de características e da função de distância do Oracle padrão são proprietárias e não há documentação disponível. Além disso, também não foi possível usar o descritor do Oracle padrão nos algoritmos do FMI-SiR $_{O}$, pois a função do Oracle padrão não é uma métrica (viola a propriedade de desigualdade triangular) e, portanto, não pode ser usada para indexar os dados nos índices do FMI-SiR .

A Figura 5.7 mostra o tempo necessário para executar consultas $k$-NN, com $k$ variando entre 1 e 100. Note que o eixo do tempo está em escala logarítmica. Na figura pode-se observar que o algoritmo de varredura sequencial do $\mathrm{FMI}_{-} \mathrm{SiR}_{O}$ foi em torno de duas vezes mais lento do que o algoritmo de varredura sequencial do Oracle padrão, para todos os descritores, sendo que ambos tiveram comportamento constante com relação ao aumento de $k$. Isto pode ser explicado pelo maior atraso do FMI-SiR $O$ para computar as funções de distância, pois são executadas por meio de funções $\mathrm{C}++$ embutidas em uma biblioteca 
compartilhada dinâmica. Foi verificado que o custo das operações aritméticas sobre os vetores de características foi praticamente irrelevante se comparado ao custo total de uma chamada de função de distância, consumindo menos de $5 \%$ do tempo total da execução função. O maior custo computacional está na conexão entre o Oracle e a biblioteca dinâmica externa e nas funções para manipular os BLOBs passados como parâmetros para as funções de distância, sendo que a manipulação de BLOBs foi responsável por mais de $60 \%$ do custo das funções.

O Oracle padrão não suporta consultas $k$-NN indexadas, assim, somente o comportamento do algoritmo de busca indexada aos $k$-vizinhos mais próximos do FMI-SiR $O$ aparece nos gráficos da figura. Considerando o descritor de Cor, o algoritmo de busca indexada do FMI-SiR $_{O}$ foi até 116 vezes mais rápido que o algoritmo sequencial do Oracle padrão. Notáveis ganhos também foram obtidos para os outros descritores, sendo que o algoritmo indexado do FMI-SiR foi até 71 mais rápido que o algoritmo sequencial do Oracle padrão para o descritor de Forma e até 175 vezes mais rápido para o descritor de Textura.
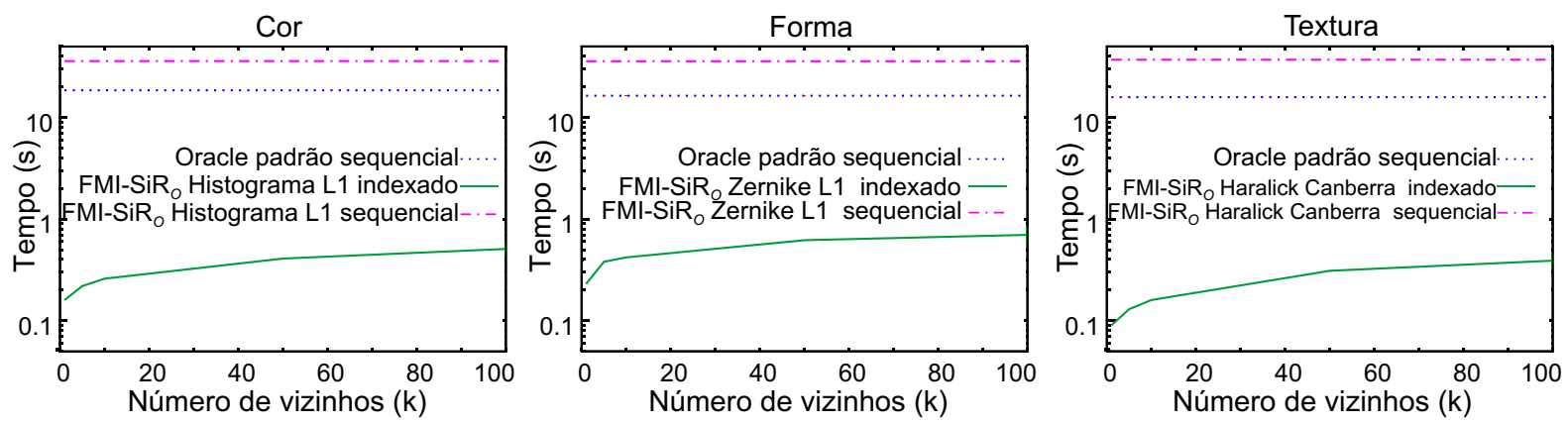

Figura 5.7: Comparativo do tempo de execução de consultas $k$-NN no FMI-SiR $O$ e no Oracle padrão.

Com relação a consultas por abrangência, foram executadas consultas variando a cardinalidade de seleção da condição por similaridade, definida pelo limiar de abrangência da consulta. Para cada elemento de referência selecionado aleatoriamente, o limiar de abrangência foi definido pela distância entre este elemento e o seu $k$-ésimo vizinho mais próximo no conjunto, fazendo que a consulta por abrangência retornasse exatamente $k$ tuplas. A Figura 5.8 mostra o desempenho dos algoritmos de seleção por abrangência. Da mesma forma como ocorreu com as consultas $k$-NN, os algoritmos sequenciais tiveram comportamento constante com relação à seletividade da condição, sendo que o algoritmo sequencial do $\mathrm{FMI}_{-} \mathrm{SiR}_{O}$ foi aproximadamente duas vezes mais lento do que o algoritmo sequencial do Oracle padrão, considerando todos os descritores. Entretanto, analisando o comportamento do desempenho dos algoritmos indexados nota-se que o algoritmo indexado do $\mathrm{FMI}_{-} \mathrm{SiR}_{O}$ foi até 2.7 vezes mais rápido que o algoritmo indexado do Oracle padrão para o descritor de Cor. Considerando Forma, o algoritmo indexado do FMI-SiR $\mathrm{F}_{O}$ também foi mais eficiente que o algoritmo indexado do Oracle padrão, tendo sido até 3.5 vezes mais rápido. Para o descritor de Textura, os dois algoritmos indexados tiveram 
desempenho idêntico para a cardinalidade de seleção menor ou igual a 5 , sendo que o do Oracle padrão foi mais rápido que o algoritmo do FMI-SiR $_{O}$ para resultados com cardinalidades maiores. Contudo, este resultado favorável ao algoritmo indexado do Oracle padrão em termos de desempenho é discutível, pois o resultado do algoritmo indexado é diferente do resultado do algoritmo sequencial equivalente.
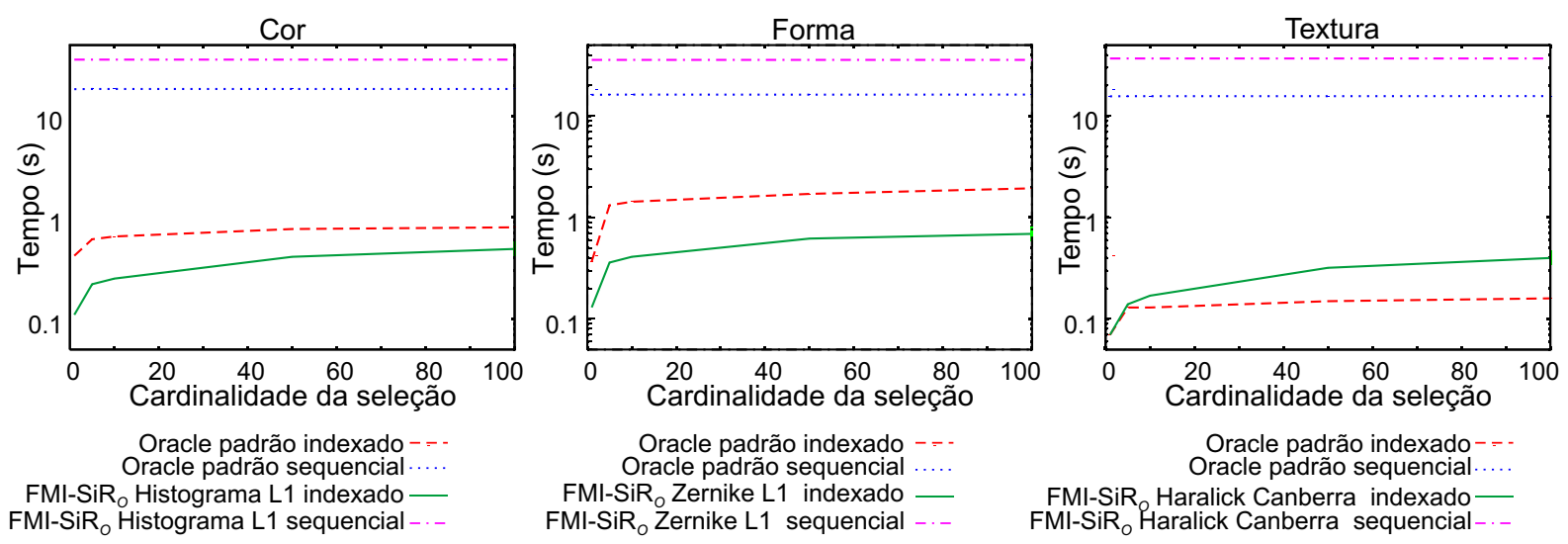

Figura 5.8: Comparativo do tempo de execução de consultas por abrangência no FMI-SiR $_{O}$ e no Oracle padrão.

Para ilustrar o problema detectado no algoritmo indexado de busca por abrangência do Oracle padrão, foram analisados os resultados gerados pelos algoritmos. A Figura 5.9 mostra que o algoritmo indexado do Oracle padrão produz uma grande quantidade de falsos negativos, ou seja, elementos que deveriam fazer parte do resultado são erroneamente podados durante a busca. Desta forma, o algoritmo indexado do Oracle padrão retorna menos tuplas do que deveria, se comparado com o algoritmo sequencial. Para o descritor de Cor, o algoritmo indexado do Oracle padrão deixa de retornar até $47 \%$ das tuplas que formam a relação resultante da consulta. Considerando o descritor de Forma, nota-se que também há falsos negativos, porém com uma taxa bem menor. Já para o descritor de Textura, no qual o algoritmo indexado do Oracle padrão teve desempenho superior ao algoritmo indexado do FMI-SiR $O$, a taxa de falsos negativos foi muito grande, chegando a podar erroneamente $98 \%$ das tuplas do conjunto resposta, para grandes limiares de abrangência. Não foi possível verificar o porquê desse problema, pois o código fonte do Oracle interMedia é proprietário. Por outro lado, a Figura 5.9 mostra que o algoritmo indexado do FMI-SiR $O$ não produz falsos negativos.

É importante ressaltar que se um algoritmo de consulta gera falsos negativos, as respostas produzidas por este algoritmo não são confiáveis. Desta forma, o algoritmo indexado de consulta por abrangência do FMI-SiR $O$ só deveria ser comparado ao algoritmo sequencial de busca por abrangência do Oracle padrão. Neste caso, o desempenho do algoritmo indexado do $\mathrm{FMI}_{-\mathrm{SiR}}$ foi até 165 vezes mais rápido que o algoritmo sequencial do Oracle padrão considerando o descritor de Cor, 210 vezes mais rápido para o descritor de Forma 
e 123 vezes mais rápido para o descritor de Textura. Em todos os casos a resposta foi a mesma, ou seja, não ocorreram nem falsos positivos nem falsos negativos.
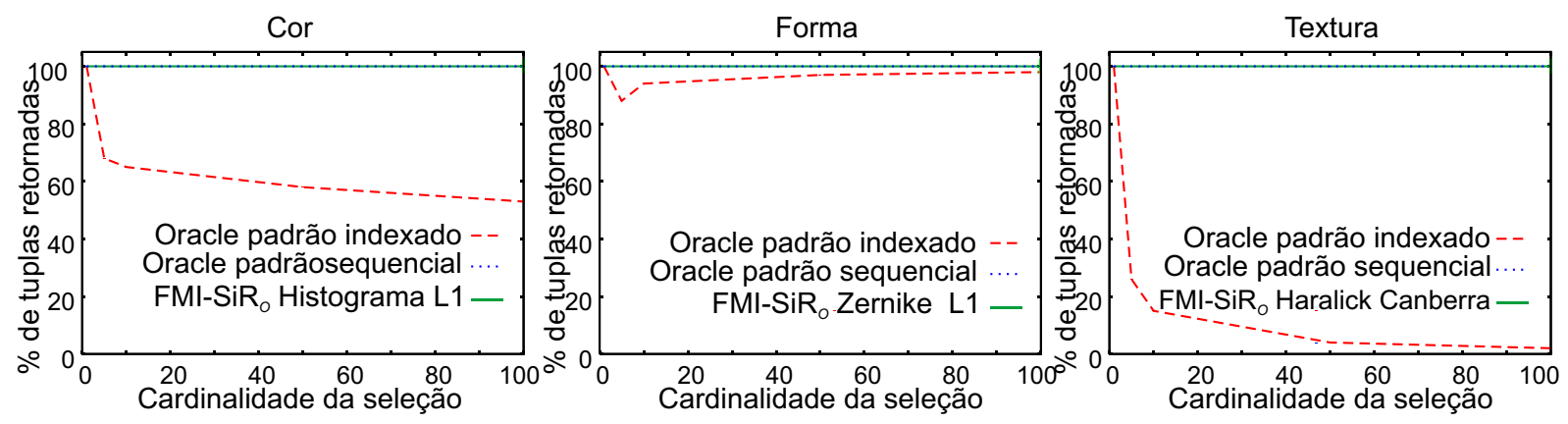

Figura 5.9: Avaliação de falsos negativos gerados pelos algoritmos de busca por abrangência.

A última parte deste conjunto de experimentos teve por objetivo avaliar quanto tempo é gasto pelo processador de consultas do Oracle em uma busca em um índice do FMI-SiR $\mathrm{F}_{O}$ e quanto tempo é gasto efetivamente percorrendo o índice. Para executar este experimento, o FMI-SiR $O$ foi compilado comentando as linhas do código fonte que executam os percursos nos índice, fazendo com que as buscas gerassem um conjunto de resultados vazio. As consultas usando esta "falsa" busca indexada levaram, em média, 0.07 segundos para ser executadas, que pode ser considerado como o tempo consumido pelo processador de consultas para invocar os algoritmos nos índices do FMI-SiR ${ }_{O}$. Analisando novamente a Figura 5.7, pode-se perceber que este tempo corresponde a aproximadamente de $16 \%$ a $44 \%$ do tempo demandado para executar as consultas 10-NN sobre os índices do FMI-SiR $O$ e de $10 \%$ a $18 \%$ do tempo demandado para executar as consultas $100-\mathrm{NN}$.

\subsubsection{Desempenho de Junções por Similaridade por Abrangência}

O último conjunto de experimentos apresentado nesta seção tem por objetivo analisar o desempenho e a escalabilidade de junções por similaridade. Nesta tese foi mostrado como representar os três principais tipos de junções por similaridade usado a sintaxe SQL e os as funções/operadores adicionais de distância. Como visto na Seção 5.1.5, o FMI-SiR $O$ é capaz de executar junções por abrangência seguindo duas estratégias: junção por laços aninhados e junção baseada em índice. Por outro lado, as junções pelos $k$-vizinhos mais próximos e as junções dos $k$-pares de vizinhos mais próximos só podem ser executadas no FMI-SiR $_{O}$ usando o algoritmo de laços aninhados. Com relação ao Oracle padrão, como a sua busca indexada por abrangência gera falsos negativos, considera-se que as junções por similaridade sempre são executadas usando a estratégia de laços aninhados no Oracle padrão. Os comportamentos relativos entre o FMI-SiR $O$ e o Oracle padrão com respeito aos algoritmos de laços aninhados dos três tipos de junções são semelhantes. Desta forma, 
apenas os testes sobre os algoritmos de junção por abrangência são apresentados nesta seção.

O primeiro experimento teve por objetivo avaliar como a cardinalidade de junção afeta o desempenho dos algoritmos. Para isso, foram criadas duas relações disjuntas a partir do conjunto de imagens ALOI, uma com 1.000 tuplas e outra com 10.000 tuplas. A Figura 5.10 mostra o comportamento dos algoritmos de junção por abrangência mediante a variação da cardinalidade do resultado. Analisando a figura, percebe-se que os algoritmos de laços aninhados apresentaram um comportamento constante com relação ao aumento da cardinalidade de junção, pois o número de comparações é sempre igual (10 milhões de comparações). A figura também mostra que algoritmo de laços aninhados do $\mathrm{FMI}^{-\mathrm{SiR}_{O}}$ foi aproximadamente duas vezes mais lento do que o algoritmo de laços aninhados do Oracle padrão. Por outro lado, o algoritmo de junção baseada em índice do FMI-SiR $O$ teve um desempenho muito superior aos algoritmos de laços aninhados. Note que o eixo do tempo é apresentado em escala logarítmica. O algoritmo baseado em índice do FMI-SiR $O$ foi até 252 vezes mais rápido que o algoritmo de laços aninhados do Oracle padrão, considerando o descritor de Cor. Com respeito aos outros descritores, o desempenho da junção baseada em índice do FMI-SiR $O$ também obteve ótimos resultados, sendo até 135 vezes mais rápido do que o algoritmo de laços aninhados do Oracle padrão para o descritor de Forma e até 360 vezes mais rápido para o descritor de Textura.
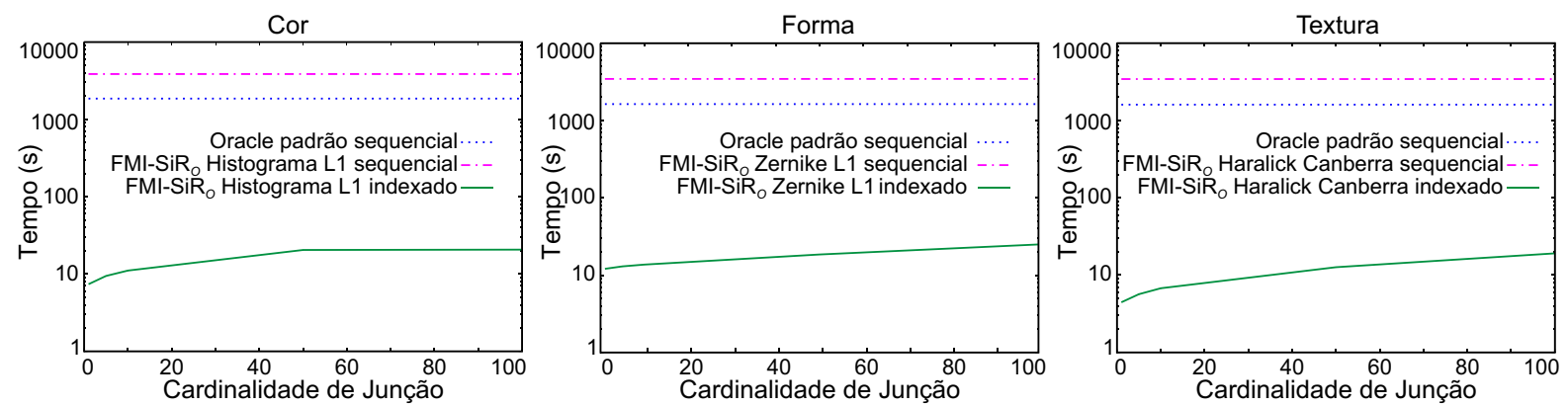

Figura 5.10: Comparativo de tempo de execução dos algoritmos junção baseada em laços aninhados do Oracle padrão e do FMI-SiR $O$ e o algoritmo de junção baseada em índice do FMI-SiR $O$, variando a cardinalidade de junção.

O segundo experimento teve como propósito avaliar a escalabilidade do algoritmo de junção por abrangência baseada em índice do FMI-SiR $O$. Os algoritmos de laços aninhados não foram avaliados neste quesito, devido ao seu alto custo. Foram realizados dois testes, variando os tamanhos das relações de entrada do algoritmo. No primeiro teste de escalabilidade, foi executada uma bateria de consultas utilizando o algoritmo de junção baseada em índice fixando-se o tamanho da relação externa e a cardinalidade de junção e variando-se o tamanho da relação interna, que é a relação onde é feita a busca indexada para verificar a condição de junção por abrangência. A relação externa foi fixada em 1.000 tuplas, a cardinalidade de junção foi fixada em 10.000 tuplas e o 
tamanho da relação interna variou entre 1.000 e 108.000 tuplas, variando o custo da busca indexada. Como pode ser visto na Figura 5.11, o algoritmo de junção baseada em índice do FMI-SiR $O$ apresentou um comportamento sub-linear com o crescimento do tamanho da relação interna, considerando todos os descritores.
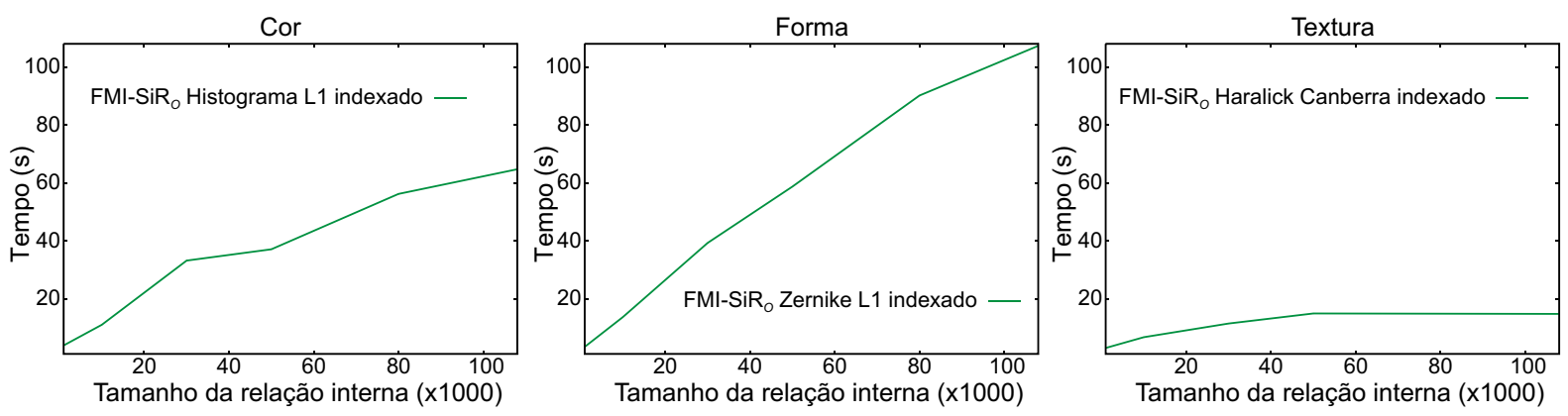

Figura 5.11: Avaliação de escalabilidade do algoritmo de junção baseada em índice do FMI-SiR $_{O}$, variando o tamanho da relação interna.

No segundo teste de escalabilidade, a variável analisada foi o tamanho da relação externa, e consequentemente a quantidade de buscas indexadas realizadas. Para isto, o tamanho da relação externa foi variado entre 1.000 e 10.000 tuplas, o tamanho da relação externa foi fixado em 10.000 tuplas e a cardinalidade da junção foi novamente fixada em 10.000 tuplas. Os tempos de execução do algoritmo de junção baseada em índice do FMI-SiR $_{O}$ variando-se o tamanho da relação externa são mostrados na Figura 5.12. Analisando a figura, pode-se notar que o algoritmo novamente apresentou um comportamento sub-linear, considerando todos os descritores. Estes testes mostram que o algoritmo de junção baseada em índice do FMI-SiR $O$ é adequado para executar junções por abrangência envolvendo grandes relações de entrada. Além disso, comparando os resultados das figuras 5.11 e 5.12, pode-se verificar que o aumento da relação externa causa mais impacto no desempenho do algoritmo do que o aumento da relação interna. Note que nos gráficos da Figura 5.11 a relação interna chegou a 108.000 tuplas, enquanto nos gráficos da Figura 5.12 a relação externa foi até 10.000 tuplas, sendo que os tempos de execução foram semelhantes.
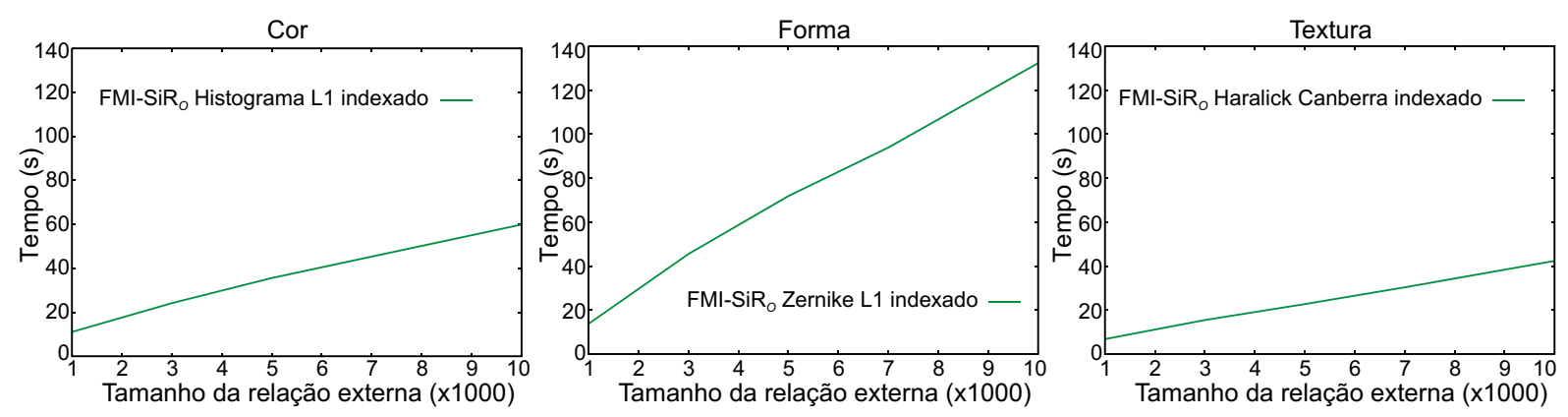

Figura 5.12: Escalabilidade do algoritmo de junção baseada em índice do FMI-SiR $O$, variando o tamanho da relação externa. 


\subsection{Experimentos Sobre a Extensão MedFMI-SiR}

Esta seção apresenta experimentos sobre o MedFMI-SiR sobre um grande conjunto de imagens médicas. Esta conjunto de imagens, denominado DICOM_HC, é formado por 14 milhões de imagens DICOM, obtidas no Hospital das Clínicas da Faculdade de Medicina de Ribeirão Preto da USP (HCFMRP-USP).

O banco de dados foi organizado utilizando duas relações, exam_images e exam_signatures, definidas como apresentado na Seção 5.2.3, para armazenar, respectivamente, as imagens médicas e os vetores de características extraídos das imagens. A relação exam_images ocupou um total de 1.7TB de espaço em disco, cujas imagens correspondem a aproximadamente 18 meses de atividades passadas do hospital. De cada imagem, foi extraído o histograma normalizado de 256 níveis de cinza, a uma taxa média de extração de 102 histogramas por segundo, totalizando 13.4GB de dados na relação exam_signatures. Nestes testes, foi utilizado o histograma normalizado pois o objetivo principal foi verificar se o MedFMI-SiR é capaz de suportar grandes volumes de dados, comuns em aplicações médicas, e não concentrar-se em alguma especialidade médica específica. Embora a capacidade de identificação do histograma de níveis de cinza seja limitada, este vetor de características é uma das técnicas mais frequentemente usadas para representar imagens médicas de qualquer especialidade. A extração de características inicial levou aproximadamente 28 horas para ser completada. Contudo, o processamento de novas imagens é praticamente imperceptível para os especialistas, pois a extração é feita gradativamente, à medida que as imagens são inseridas no banco de dados.

Os testes foram executados sobre o MedFMI-SiR instalado em um Oracle Database 11g Enterprise Edition Release 2 no sistema operacional Ubuntu Server GNU/Linux 9.10 64bits, sobre uma máquina equipada com um processador Intel Core 2 Quad 2.66GHz, 4GB de memória RAM e quatro discos rígidos SATA2 de 1TB e 7.200rpm. As subseções a seguir descrevem os principais resultados obtidos.

\subsubsection{Escalabilidade da Construção dos Índices para Consultas por Similaridade}

Os primeiros experimentos realizados tiveram como meta avaliar a escalabilidade dos índices sobre os vetores de características, analisando o comportamento apresentado pelos índices com o aumento do conjunto de dados indexados. Para atingir esse objetivo, foram criadas várias relações adicionais, com tuplas escolhidas aleatoriamente da relação exam_signatures, contendo 1.000, 10.000, 100.000, 1.000 .000 e 10.000 .000 de tuplas. Foi criado um índice Slim-tree sobre o atributo contendo o vetor de características de cada uma destas relações. Em seguida, foi executada uma bateria de 50 consultas $k$-NN 
sobre cada uma das relações, medindo-se o tempo de execução, sendo que o elemento de referência de cada consulta foi uma imagem sorteada aleatoriamente.
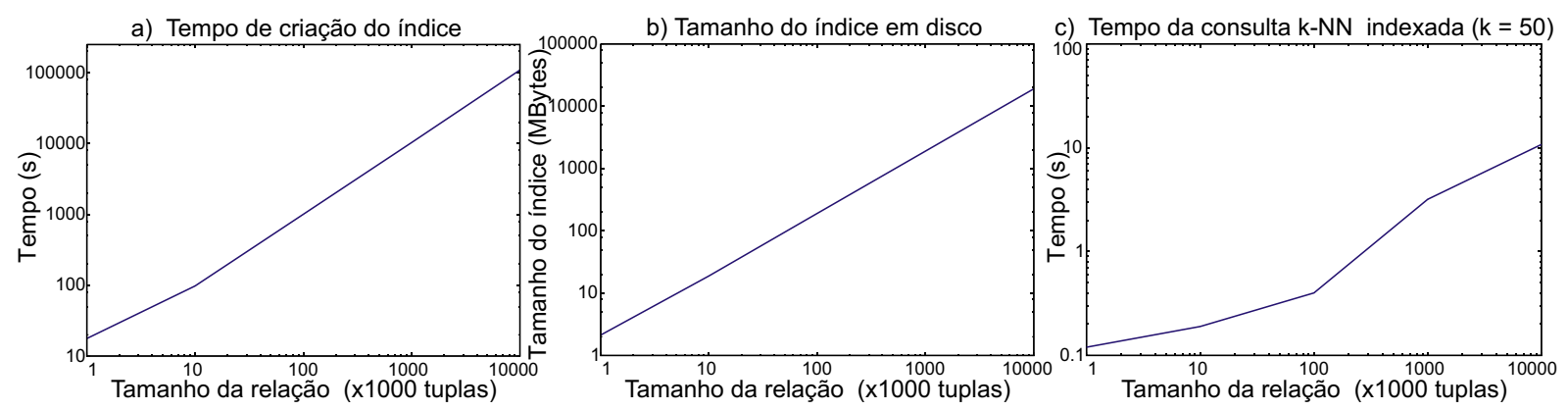

Figura 5.13: Análise de escalabilidade do MedFMI-SiR.

(a) Tempo de criação de índices. (b) Espaço de armazenamento para os índices. (c) Tempo para responder a consultas $k$-NN.

A Figura 5.13 mostra os resultados destes experimentos. Analisando a Figura 5.13a, pode-se perceber que o tempo necessário para criação dos índices teve um crescimento proporcional ao tamanho da relação. Note-se que todos os gráficos da Figura 5.13 estão em escalas log-log e que o coeficiente angular das retas que aproximam as curvas mostradas nos gráficos é menor do que 1, o que indica um crescimento linear. Os índices também escalaram linearmente com relação ao espaço de armazenamento demandado pelos índices (Figura 5.13b). Por fim, a Figura 5.13c mostra que o tempo total médio para execução das consultas $k$-NN, $k=50$, apesar de ter apresentado algumas oscilações, cresceu linearmente com o tamanho da relação de entrada. Esses resultados comprovam a escalabilidade dos índices do MedFMI-SiR, tendo apresentado custos lineares em todos os aspectos avaliados.

\subsubsection{Desempenho de Consultas Combinando Condições Baseadas em Similaridade e Condições Baseadas em Metadados}

Esta seção apresenta testes de execução de consultas sobre imagens DICOM integrando condições baseadas em similaridade e condições baseadas em metadados. A consulta utilizada como base foi a Consulta 15, apresentada na Seção 5.2.3. Uma das vantagens do MedFMI-SiR é que sua arquitetura permite gerar planos de execução alternativos, explorando as seletividades das condições envolvidas em uma consulta com múltiplos critérios. Desta forma, as consultas executadas variaram a seletividade das condições utilizadas, sendo que a condição baseada em similaridade teve $k$ variando entre 1 e 200 e a condição baseada em metadados teve duas seletividades analisadas: 99,95\%, que corresponde a pouco mais de 5.000 tuplas que satisfazem a condição, e 95\%, que corresponde a aproximadamente 500.000 tuplas que satisfazem a condição. Os resultados mostrados nesta seção foram obtidos pela média do tempo de execução de 50 consultas com imagens de referência diferentes, para cada combinação das seletividades. 
a) kNN-ind-Meta-seq

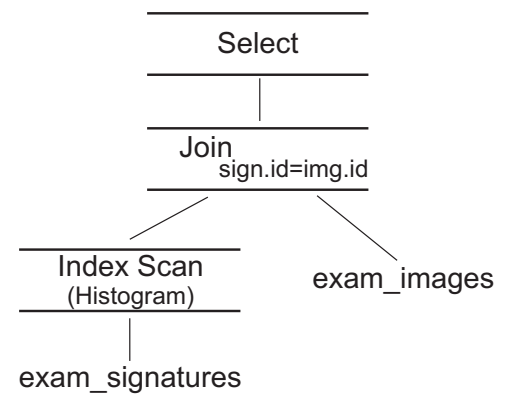

b) kNN-ind-Meta-ind

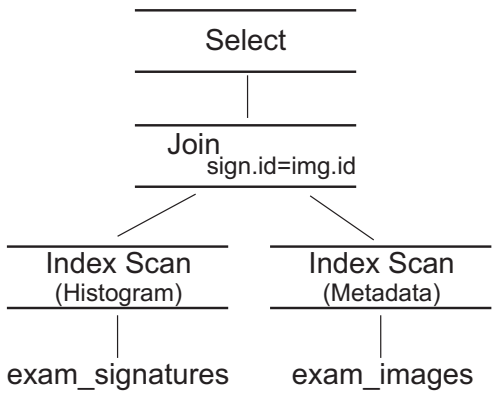

c) kNN-seq-Meta-ind

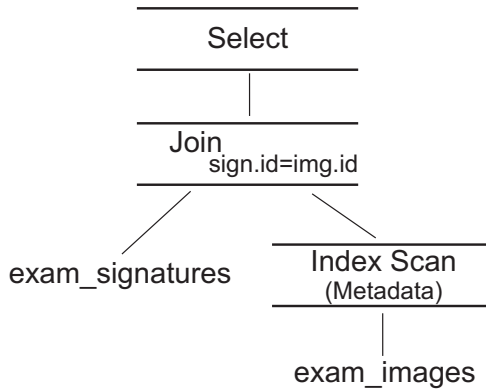

Figura 5.14: Planos de execução gerados sobre o MedFMI-SiR. (a, b) Planos alternativos referentes à Consulta 15 (Seção 5.2.3). (c) Plano para um consulta sensivelmente diferente, que executa uma busca indexada sobre a condição baseada em metadados seguida por uma $k$-NNq executada sequencialmente em memória.

Foram testados dois planos de execução alternativos para a Consulta 15, mostrados nas figuras 5.14a e 5.14b. O plano de execução knn_ind_meta_seq, apresentado na Figura 5.14a, executa uma busca indexada sobre a relação que contém os vetores de características (exam_signatures), usando a condição por similaridade $k$-NN, e efetua a junção do resultado retornado com as tuplas correspondentes da relação que armazena as imagens (exam_images) que satisfazem a condição baseada em metadados. O plano knn_ind_meta_ind, mostrado na Figura 5.14b, executa uma busca $k$-NN indexada sobre a relação exam_signatures e outra busca indexada sobre a relação exam_images, utilizando o índice baseado em função definido sobre a tag DICOM utilizada na condição baseada em metadados, fazendo, em seguida, a junção dos resultados retornados. Para completar a avaliação, foi testado um terceiro plano de execução knn_seq_meta_ind, mostrado na Figura $5.14 \mathrm{c}$, que primeiro executa uma busca indexada sobre a relação exam_images usando a condição baseada em metadados, faz a junção do resultado com as respectivas tuplas da relação exam_signatures e, então, computa a $k$-NNq sequencialmente sobre as tuplas da relação gerada pela junção. Observe-se que embora os planos de execução apresentados sejam semelhantes, o plano knn_seq_meta_ind responde a uma consulta diferente da que é respondida pelos outros planos. A consulta respondida pelos planos knn_ind_meta_seq e knn_ind_meta_ind retorna dentre as $k$ imagens de exames mais similares à imagem de referência aquelas que satisfazem a condição baseada em metadados. Por outro lado, o plano knn_seq_meta_ind refere-se a uma consulta que retorna as $k$ imagens mais similares à imagem de referência que satisfazem a condição baseada em metadados. Nos três planos de execução, o processador de consultas do SGBD utiliza os índices nas chaves primárias das relações para acelerar a execução de junção, reduzindo o impacto desta operação no custo total da consulta. 

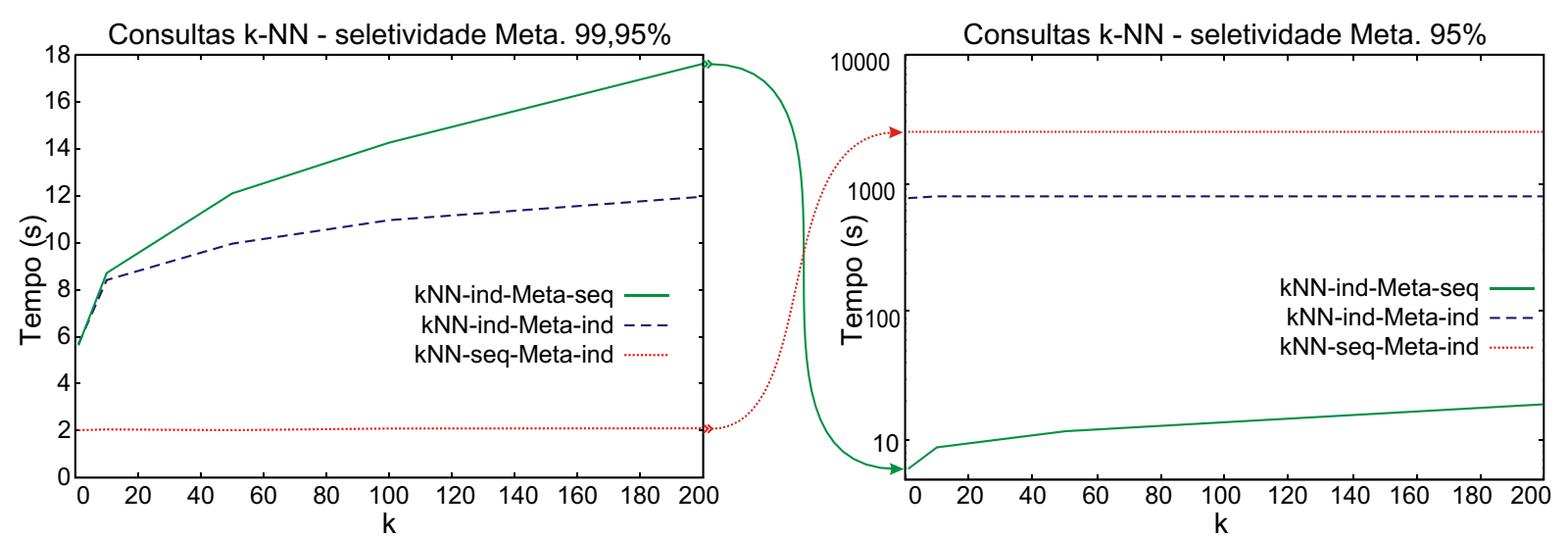

Figura 5.15: Comparativo dos tempos de execução dos diferentes planos gerados usando o MedFMI-SiR. (a) Consulta combinando uma condição $k$-NN e uma condição baseada em metadados com seletividade de 99,95\%. (b) Consulta combinando uma condição $k$-NN e uma condição baseada em metadados com seletividade de $95 \%$.

A Figura 5.15 mostra os tempos médios de execução dos planos de execução avaliados, variando o valor de $k$ e a seletividade da condição baseada em metadados. A Figura 5.15a mostra os resultados obtidos considerando a seletividade de 99,95\% para a condição baseada em metadados e a Figura 5.15b mostra os resultados considerando a seletividade de $95 \%$ para esta condição. Analisando a Figura 5.15a, nota-se que os planos de execução knn_ind_meta_seq e knn_ind_meta_ind apresentaram comportamentos sublineares com relação à variação de $k$, sendo que o plano knn_ind_meta_ind foi até $32 \%$ mais rápido que o knn_ind_meta_seq. Já o plano knn_seq_meta_ind teve um comportamento praticamente constante, mostrando que o teste da condição $k$-NN em memória foi indiferente ao valor de $k$, pois o custo das operações sobre a lista de prioridade que armazena os $k$ elementos atuais é irrelevante perto do custo total da consulta. Além disso, o knn_seq_meta_ind foi até 6 vezes mais rápido que o $\mathrm{knn}$ ind_meta_ind e até 9 vezes mais rápido que o knn_ind_meta_seq, pois a seletividade da condição baseada em metadados considerada é bem alta $(99,95 \%)$. Por outro lado, para a seletividade da condição baseada em metadados de 95\%, que também é uma seletividade alta, os comportamentos dos planos de execução foram bastante diferentes, como destacado pelas setas conectando as curvas dos planos knn_ind_meta_seq e knn_seq_meta_ind dos dois gráficos da Figura 5.15b. Neste caso, o plano knn_seq_meta_ind, que foi o mais eficiente para a seletividade de 99,95\%, teve o pior desempenho para a seletividade de 95\%, levando em média mais de 40 minutos para responder à consulta (o tempo demandado por este plano para a seletividade de 99,95\% foi de aproximadamente 2 segundos em média). O tempo de execução do plano knn_ind_meta_ind também subiu muito, apresentando um comportamento praticamente constante, pois o custo da busca indexada sobre a condição baseada em metadados, que é indiferente ao valor de $k$, dominou o custo total da consulta. Mesmo assim, o plano knn_ind_meta_ind foi quase 4 vezes mais rápido do que o knn_seq_meta_ind (note-se 
que o eixo do tempo na Figura 5.15b é apresentado em escala logarítmica). O plano knn_ind_meta_seq novamente apresentou um comportamento sublinear e mostrou-se a opção mais eficiente considerando-se a seletividade da condição baseada em metadados de $95 \%$, tendo sido, no seu pior caso $(k=200)$, mais de 40 vezes mais rápido do que o knn_ind_meta_ind e mais de 130 vezes mais rápido que o knn_seq_meta_ind.

Este experimento mostra que, além dos índices do MedFMI-SiR serem escaláveis, é de suma importância permitir gerar planos de execução alternativos para consultas complexas envolvendo condições baseadas em similaridade e condições envolvendo atributos tradicionais, por exemplo as condições baseadas em metadados de imagens DICOM. Esta possibilidade é um grande diferencial do módulo desenvolvido com relação a outras soluções de CBIR para a área médica apresentadas na literatura.

\subsection{Considerações Finais}

A recuperação de dados complexos por similaridade é um tópico de pesquisa que tem sido investigado por vários anos. Entretanto, existem poucas ferramentas que ofereçam suporte à consultas por similaridade para a produção de sistemas que manipulam dados complexos. Este capítulo apresentou o FMI-SiR, um novo módulo de banco de dados para consultas por similaridade eficiente e extensível. Foi apresentada a implementação deste módulo sobre o SGBD Oracle, denominada FMI-SiR. Também foi apresentada a extensão MedFMI-SiR, que acrescenta ao FMI-SiR o suporte a manipulação por conteúdo de imagens médicas no formato DICOM. A arquitetura do módulo permite realizar consultas complexas combinando condições baseadas em similaridade e condições baseadas em metadados e gerar planos de execução alternativos para as consultas. Com estes módulos, pode-se representar os diversos tipos de consultas por similaridade em sentenças SQL, permitindo que as aplicações cliente façam uso dos recursos de recuperação por similaridade por meio de uma conexão com o SGBD, sem a necessidade de componentes e bibliotecas adicionais. Além disso, os experimentos apresentados no capítulo mostram que as soluções desenvolvidas são eficientes e escaláveis a grandes bancos de dados complexos. 


\section{Capítulo \\ 6 \\ Conclusão}

Com a disponibilização de equipamentos de captura de dados cada vez mais potentes e presentes no dia-a-dia das pessoas, o volume de dados gerado é crescente, demandando novas soluções para gerenciamento destes dados. A complexidade dos dados armazenados em grandes bancos de dados aumenta cada vez mais, criando a necessidade de novas operações de consulta. Uma classe de operações que tem apresentado interesse crescente são as chamadas consultas por similaridade, aplicáveis a inúmeras áreas de estudo, com destaque ao gerenciamento de dados complexos e multimídia por conteúdo.

Esta tese teve como objetivo principal propor alternativas algébricas, estruturas e algoritmos para permitir o uso abrangente e a execução eficiente de consultas por similaridade integradas às demais operações de busca atendidas pelos SGBDs relacionais. Em especial, foi dado um enfoque particular à operação de consulta aos $k$-vizinhos mais próximos $(k-\mathrm{NNq})$, que, na sua forma canônica, tem a integração com outras operações e com condições de filtragem complementares dificultada em uma expressão de busca com múltiplos critérios. Consequentemente, esta operação vinha sendo tratada, de uma forma geral, como uma operação isolada, dissociada das demais formas de busca oferecidas pelos SGBDRs.

Além disso, foi explorado como enriquecer os SGBDs existentes com operações baseadas em similaridade. Neste sentido, a meta foi integrar estas operações ao ambiente de consultas do SGBD, de forma que as consultas por similaridade pudessem ser disponibilizadas para múltiplas aplicações cliente por meio de um subsistema especializado, eficiente e extensível. Tendo as operações baseadas em similaridade reconhecidas pelo processador de consultas, torna-se possível explorar planos de execução alternativos, apri- 
morando o desempenho de consultas envolvendo múltiplos critérios de busca. A seguir são sintetizadas as principais contribuições do trabalho.

\subsection{Principais Contribuições}

As principais contribuições deste tese podem ser divididas em duas linhas, descritas a seguir.

1. Definição de uma nova consulta por similaridade, a consulta aos $k$-vizinhos mais próximos estendida com condições (condition-extended $k N N$ query $-{ }_{c} k-\mathrm{NNq}$ ). Como visto, esta consulta é uma extensão da consulta $k$-NN, que possibilita modificar o comportamento da busca aos vizinhos mais próximos, de forma que atenda uma restrição definida sobre propriedades adicionais dos dados complexos consultados. Esta característica aumenta muito a quantidade de consultas que podem ser representadas, o que permite aproximar significativamente o resultado das consultas do interesse do usuário. A ${ }_{c} k$-NNq permite expressar consultas sobre bancos de dados complexos que não eram representáveis até então, oferecendo a possibilidade de integrar homogeneamente condições de filtragem complementares à busca aos $k$-vizinhos mais próximos. A nova consulta proposta foi definida incluindo:

- a definição formal da consulta, expressando o seu significado e apresentando exemplos de utilização;

- a apresentação das principais regras algébricas envolvendo o operador ${ }_{c} k \mathrm{NN}$, considerando os diferentes tipos de condição aceitas pelo operador;

- o desenvolvimento de algoritmos para execução de variantes das buscas habilitadas com o uso do operador proposto, com execução sequencial e utilizando duas estratégias de execução sobre métodos de acesso métricos.

2. Desenvolvimento de um módulo de banco de dados, denominado FMI-SiR (userdefined Features, Metrics and Indexes for Similarity Retrieval - características, métricas e índices definidos pelo usuário para recuperação por similaridade), que implementa os principais recursos necessários para a representação e execução eficiente de consultas por similaridade integradas às demais operações existentes no SGBD. A proposta apresentada inclui:

- o implementação do FMI-SiR sobre o SGBD Oracle, integrado ao ambiente de consultas pelo uso da estrutura extensível do Oracle Database;

- a representação dos principais tipos de consultas por similaridade usando a sintaxe SQL padrão e a execução destas consultas de forma eficiente, permitindo explorar planos de consulta alternativos; 
- o desenvolvimento da extensão MedFMI-SiR, que acrescenta funcionalidades para o gerenciamento de imagens médicas no formato DICOM;

\subsection{Contribuições Complementares}

Além das contribuições principais citadas, o projeto de doutoramento alcançou contribuições complementares, derivadas de contribuições com outros colegas do grupo de pesquisa, de maneira a aproveitar esses resultados para o desenvolvimento da linha principal deste projeto e também repassar resultados do projeto para os demais. Dentre as contribuições complementares mais relevantes, destacam-se as seguintes.

- Colaboração no desenvolvimento de algoritmos de remoção de elementos em métodos de acesso métricos e de estratégias de redução de sobreposição e de otimização destas estruturas. Esse trabalho contribuiu para melhorar o desenvolvimento da extensão feita sobre a Slim-tree para a criação dos índices de cobertura.

- Colaboração na proposta do espaço métrico-temporal, que é um modelo de representação de dados métricos com informação temporal associada, cuja similaridade entre elementos considera as características extraídas do conteúdo do dado e o dado temporal em conjunto. Esse trabalho contribuiu para a definição de métricas para o FMI-SiR, bem como permitiu utlizar resultados deste trabalho no aprimoramento do espaço métrico-temporal.

- Colaboração na concepção de um método não supervisionado de balanceamento de múltiplos vetores de características, baseado no conceito de dimensão de correlação fractal, em buscas por similaridade sobre bancos de imagens médicas. Este trabalho contribuiu para a explorar a generalização das consultas por similaridade considerando múltiplos critérios, auxiliando na definição da consulta aos $k$-vizinhos mais próximos estendida com condições.

- Colaboração no desenvolvimento de técnicas de visualização de dados métricos com informação temporal associada e de análise visual do efeito do balanceamento de múltiplos vetores de características na distribuição e idenficação de dados complexos. Este trabalho contribuiu na exploração de técnicas análise de dados complexos considerando múltiplos critérios.

- Colaboração na proposta de um mecanismo para responder a consultas por similaridade, considerando diferentes percepções de usuários, com base em seus perfis de acesso. Este trabalho teve como benefício a utilização de dados complexos e de dados de tipos tradicionais de forma integrada, além de destacar a necessidade de dinamicidade da escolha da função de distância nas consultas por similaridade, explorada pelas funções desenvolvidas no FMI-SiR. 
- Colaboração no desenvolvimento de uma ferramenta de recuperação de imagens médicas por conteúdo, desenvolvida com base no FMI-SiR, que está sendo utilizada, dentre outras coisas, para fazer uma análise de viabilidade de sistemas de CBIR em um ambiente real, através da cooperação com profissionais do Hospital das Clínicas da Faculdade de Medicina de Ribeirão Preto da USP (HCFMRP-USP). Este trabalho contribuiu para a avaliação da efetividade do FMI-SiR em um ambiente real da área clínica e deverá abrir novas frentes de pesquisa e desenvolvimento junto ao HCFMRP-USP.

\subsection{Publicações}

Os trabalhos a seguir contêm partes das contribuições principais e complementares geradas durante o doutoramento.

1. Kaster, D. S., Oliveira, W. D., Bueno, R., Traina, A. J. M. e Traina Jr, C. Nearest Neighbor Queries with Counting Aggregate-based Conditions. Journal of Information and Data Management, volume 2, número 3, páginas 401-416, 2011.

2. Kaster, D. S., Bugatti, P. H., Ponciano-Silva, M., Traina, A. J. M., Marques, P. M. A., Santos, A. C. e Traina Jr, C. MedFMI-SiR: A Powerful DBMS Solution for Large-Scale Medical Image Retrieval. In: 2nd International Conference on Information Technology in Bio- and Medical Informatics (ITBAM), Toulouse, FR. Lecture Notes in Computer Science (LNCS). Berlin/Heidelberg : Springer, volume 6865. páginas 16-30, 2011.

3. Barioni, M. C. N., Kaster, D. S., Razente, H. L., Traina, A. J. M. e Traina Jr, C. Querying Multimedia Data by Similarity in Relational DBMS. In: YAN, Li; MA, Zongmin. (Org.). Advanced Database Query Systems: Techniques, Applications and Technologies. Hershey, Pennsylvania, USA: IGI Global, 2011.

4. Bugatti, P. H., Kaster, D. S., Ponciano-Silva, M., Traina, A. J. M. e Traina Jr, C. Integrating User Profile in Medical CBIR Systems to Answer Perceptual Similarity Queries. In: SPIE Medical Imaging Conference, Lake Buena Vista, Orlando, USA. Proceedings of the SPIE Medical Imaging 2011. Los Angeles : SPIE, volume 1, páginas 1-12, 2011.

5. Bueno, R., Kaster, D. S., Razente, H. L., Barioni, M. C. N., Traina, A. J. M. e Traina Jr, C. Using Visual Analysis to Weight Multiple Signatures to Discriminate Complex Data. In: 15th International Conference on Information Visualization (IV), London, England. Proceedings of the IV 2011, Los Alamitos : IEEE Computer Society, páginas 1-6, 2011. 
6. Kaster, D. S., Bugatti, P. H., Traina, A. J. M. e Traina Jr, C. FMI-SiR: A Flexible and Efficient Module for Similarity Searching on Oracle Database. Journal of Information and Data Management, volume 1, número 2, páginas 229-244, 2010.

7. Bueno, R., Razente, H. L., Kaster, D. S., Barioni, M. C. N., Traina, A. J. M. e Traina Jr, C. Metric Data Analysis Enhanced through Temporal Visualization. In: 14th International Conference on Information Visualisation (IV), London, UK. Proceedings of the IV 2010, Los Alamitos : IEEE Computer Society, páginas 116$121,2010$.

8. Kaster, D. S., Bugatti, P. H., Traina, A. J. M. e Traina Jr, C. Incorporating Metric Access Methods for Similarity Searching on Oracle Database. In: XXIV Simpósio Brasileiro de Banco de Dados (SBBD), Fortaleza, CE, Brasil. Anais do SBBD 2009. Porto Alegre : SBC, páginas 196-210, 2009.

9. Bueno, R., Kaster, D. S., Traina, A. J. M. e Traina Jr, C. Time-Aware Similarity Search: A Metric-Temporal Representation for Complex Data. In: 11th Int. Symposium on Spatial and Temporal Databases (SSTD), Aalborg, Denmark. Lecture Notes in Computer Science (LNCS). Berlin/Heidelberg : Springer, volume 5644, páginas 302-319, 2009.

10. Bueno, R., Kaster, D. S., Paterlini, A. A., Traina, A. J. M. e Traina Jr, C. Unsupervised Scaling of Multi-Descriptor Similarity Functions for Medical Image Datasets. In: 22nd IEEE Symposium on Computer-Based Medical Systems (CBMS), Albuquerque, New Mexico, USA. Proceedings of the CBMS 2009. Los Alamitos: IEEE Computer Society, páginas 1-8, 2009.

11. Bueno, R., Kaster, D. S., Traina, A. J. M. e Traina Jr, C. A New Approach for Optimization of Dynamic Metric Access Methods Using an Algorithm of Effective Deletion. In: 20th International Conference on Scientific and Statistical Database Management (SSDBM), 2008, Pokfulam, Hong Kong. Lecture Notes in Computer Science (LNCS). Berlin/Heidelberg : Springer, volume 5069, páginas 366-383, 2008.

12. Kaster, D. S., Cordeiro, R. L. F. e Fortes, R. P. M. Uma Arquitetura Web Colaborativa Baseada em Ontologias para Recuperação e Descoberta de Conhecimento em Imagens Médicas. In: XIII Simpósio Brasileiro de Sistemas Multimídia e Web (WebMedia), Gramado, RS. Anais do WebMedia 2007. Porto Alegre : SBC, páginas $1-8,2007$. 


\subsection{Trabalhos Futuros}

O trabalho desenvolvido nesta tese abre um leque de possibilidades de pesquisas futuras. Dentre elas, pode-se destacar as seguintes.

- Concepção de algoritmos eficientes para responder a consultas ${ }_{c} k$-NN envolvendo as condições basedas em agregação por soma e por média.

- Desenvolvimento de algoritmos para consultas ${ }_{c} k$-NNq utilizando mais de uma estrutura de indexação de maneira simultânea (por exemplo, uma Slim-tree e uma $\mathrm{B}+$-tree), para que seja possível resolver uma ${ }_{c} k$-NNq utilizando os índices existentes nos atributos referenciados na consulta, sem a necessidade de haver um índice de cobertura que contenha todos os atributos necessários à busca.

- Implementação de estratégias de reescrita de consultas utilizando as regras algébricas identificadas para o operador ${ }_{c} k \mathrm{NN}$, para enumerar planos de execução alternativos no processo de otimização de consultas.

- Desenvolvimento de novas estruturas de dados, que sejam capazes de responder mais eficientemente a variações das consultas ${ }_{c} k$-NN.

- Definição de um modelo de custo para as consultas ${ }_{c} k$-NN, que contemple os diferentes tipos de condições que são aceitas por esta operação.

- Desenvolvimento de um modelo de previsão de seletividade de consultas por similaridade, que auxilie o modelo de custo do item anterior.

- Tratamento de atributos contínuos que possam ser ordenados, tais como atributos que representem dimensões temporais, em consultas ${ }_{c} k$-NN, que tanto pode ser considerada como uma condição especial de filtragem quanto pode influenciar na medida de dissimilaridade entre elementos, com base nos conceitos do espaço métrico-temporal.

- Inclusão de novos operadores por similaridade ao módulo FMI-SiR, para acelerar a execução de consultas por similaridade agregada e junções por similaridade, através do uso de algoritmos que resolvem estas operações sobre estruturas de indexação.

- Desenvolvimento de aplicações avançadas sobre dados complexos com base no módulo desenvolvido, acrescentando extratores de características especializados e/ou novas medidas de dissimilaridade.

- Exploração de novas técnicas para o desenvolvimento de algoritmos eficientes para operações baseadas em similaridade, como, por exemplo, paralelismo e métodos inteligentes. 
- Avaliação dos resultados da cooperação com o HCFMRP-USP para o ajuste e desenvolvimento do módulo FMI-SiR, de maneira a torná-lo o mais adequado possível às necessidades das aplicações em medicina. 


\section{Referências Bibliográficas}

Adali, S.; Bonatti, P. A.; Sapino, M. L.; Subrahmanian, V. S. A multisimilarity algebra. In: ACM SIGMOD International Conference on Management of Data, Seattle, USA: ACM Press, 1998, p. 402-413.

Adali, S.; Bufi, C.; SApino, M.-L. Ranked relations: Query languages and query processing methods for multimedia. Multimedia Tools and Applications Journal, v. 24, n. 3, p. 197-214, 2004.

Adali, S.; Sapino, M. L.; Marshall, B. A rank algebra to support multimedia mining applications. In: 8th international workshop on Multimedia Data Mining (MDM) (associated with the ACM SIGKDD 2007), New York, NY, USA: ACM, 2007, p. 1-9.

Akgül, C.; Rubin, D.; Napel, S.; Beaulieu, C.; Greenspan, H.; Acar, B. Content-based image retrieval in radiology: Current status and future directions. Journal of Digital Imaging, v. 24, p. 208-222, 2011.

Atnafu, S.; Brunie, L.; Kosch, H. Similarity-based operators and query optimization for multimedia database systems. In: International Database Engineering and Applications Symposium (IDEAS), Grenoble, France: IEEE Computer Society, 2001, p. 346-355.

Atnafu, S.; Chbeir, R.; Coquil, D.; Brunie, L. Integrating similarity-based queries in image dbmss. In: ACM Symposium on Applied computing (SAC), Nicosia, Cyprus: ACM Press, 2004, p. 735-739.

Bach, J. R.; Fuller, C.; Gupta, A.; Hampapur, A.; Horowitz, B.; Humphrey, R.; JAIn, R.; Shu, C.-F. Virage image search engine: An open framework for image management. In: Storage and Retrieval for Image and Video Databases (SPIE), 1996, p. $76-87$. 
Baeza-Yates, R. A.; Cunto, W.; Manber, U.; Wu, S. Proximity matching using fixed-queries trees. In: Combinatorial Pattern Matching (CPM), Asilomar, CA: Springer Verlag, 1994, p. 198-212 (Lecture Notes in Computer Science, v.807).

Baeza-Yates, R. A.; Ribeiro-Neto, B. A. Modern information retrieval. Wokingham, UK: Addison-Wesley, 1999.

Balan, A. G. R.; Traina, A. J. M.; Ribeiro, M. X.; Marques, P. M. D. A.; Traina, Caetano, J. HEAD: the human encephalon automatic delimiter. In: 20th IEEE Intl Symposium on Computer-Based Medical Systems (CBMS), Maribor, Slovenia: IEEE Computer Society, 2007, p. 171-176.

Baluja, S.; Covell, M. Waveprint: Efficient wavelet-based audio fingerprinting. Pattern Recognition, v. 41, n. 11, p. 3467-3480, 2008.

Barioni, M. C. N.; Kaster, D. S.; Razente, H. L.; Traina, A. J. M.; Traina JR, C. Advanced database query systems: Techniques, applications and technologies, cáp. Querying Multimedia Data by Similarity in Relational DBMS Hershey, Pennsylvania, USA: IGI Global, 2011.

Barioni, M. C. N.; Razente, H. L.; Traina, A. J. M.; Traina, Caetano, J. Siren: A similarity retrieval engine for complex data. In: 32nd Intl Conference on Very Large Data Bases (VLDB 06), Seoul, South Korea: ACM Press, 2006, p. 1155-1158.

Barioni, M. C. N.; Razente, H. L.; Traina, A. J. M.; Traina Jr., C. Seamlessly integrating similarity queries in SQL. Software, Practice Experience, v. 39, n. 4, p. 355$384,2009$.

Barrios, J. M.; Bustos, B. Automatic weight selection for multi-metric distances. In: 4th International Conference on Similarity Search and Applications (SISAP), New York, NY, USA: ACM, 2011, p. 61-68.

Beckmann, N.; Kriegel, H.-P.; Schneider, R.; Seeger, B. The R*-tree: An efficient and robust access method for points and rectangles. In: ACM SIGMOD International Conference on Management of Data, 1990, p. 322-331.

Bellamkonda, S.; Ghosh, B.; Witkowski, A. Method and apparatus for optimizing computation of OLAP ranking functions. United States Patent No. 6,222,138 B1, 2003.

Belohlávek, R.; Vychodil, V. Query systems in similarity-based databases: logical foundations, expressive power, and completeness. In: 17th ACM Symposium on Applied Computing (SAC), ACM, 2010, p. 1648-1655. 
BelohláveK, R.; Opichal, S.; Vychodil, V. Relational algebra for ranked tables with similarities: Properties and implementation. In: 7th International Symposium on Intelligent Data Analysis (IDA), Springer, 2007, p. 140-151 (Lecture Notes in Computer Science, v.4723).

Blanken, H. M.; De Vries, A. P.; Blok, H. E.; Feng, L., eds. Multimedia retrieval. Data-Centric Systems and Applications, 1 ed. Springer, 2007.

Bozkaya, T.; Özsoyoglu, Z. M. Distance-based indexing for high-dimensional metric spaces. In: ACM SIGMOD International Conference on Management of Data, Tucson, AZ: ACM Press, 1997, p. 357-368.

Bueno, J. M.; Chino, F. J. T.; Traina, A. J. M.; Traina Jr., C.; Marques, P. M. D. A. How to add content-based image retrieval capability in a PACS. In: IEEE International Conference on Computer Based Medical Systems (CBMS), Maribor, Slovenia: IEEE Computer Society, 2002, p. 321-326.

Bueno, R.; Kaster, D. S.; Paterlini, A. A.; Traina, A. J. M.; Jr., C. T. Unsupervised scaling of multi-descriptor similarity functions for medical image datasets. In: $C B M S$, Albuquerque, New Mexico, USA: IEEE, 2009, p. 1-8.

Bueno, R.; Kaster, D. S.; Traina, A. J. M.; Traina JR., C. A new approach for optimization of dynamic metric access methods using an algorithm of effective deletion. In: 20th International Conference on Scientific and Statistical Database Management, 2008, p. 366-383.

Bufi, C.; AdAli, S. A declarative language for similarity queries. In: Workshop on Knowledge and Data Engineering Exchange, IEEE, 1999, p. 107 - 113.

Bugatti, P. H.; Ribeiro, M. X.; Traina, A. J. M.; Traina Jr., C. Feature selection guided by perception in medical CBIR systems. In: 1st IEEE International Conference on Healthcare Informatics, Imaging and Systems Biology (HISB), IEEE, 2011, p. 323-330.

Bugatti, P. H.; Traina, A. J. M.; Traina Jr., C. Assessing the best integration between distance-function and image-feature to answer similarity queries. In: Symposium on Applied Computing, Fortaleza, CE, Brazil: ACM, 2008, p. 1225-1230.

Burkhard, W. A.; Keller, R. M. Some approaches to best-match file searching. Communications of the ACM (CACM), v. 16, n. 4, p. 230-236, 1973.

Bustos, B.; Keim, D.; Saupe, D.; Schreck, T.; Vranic, D. Automatic selection and combination of descriptors for effective $3 \mathrm{~d}$ similarity search. In: Multimedia Software Engineering, Miami, FL, USA: IEEE, 2004, p. 514-521. 
Böнm, C.; Berchtold, S.; Keim, D. A. Searching in high-dimensional spaces - index structures for improving the performance of multimedia databases. ACM Computing Surveys, v. 33, n. 3, p. $322-373,2001$.

Böhm, C.; Krebs, F. High performance data mining using the nearest neighbor join. In: 2002 IEEE International Conference on Data Mining (ICDM), Maebashi City, Japan: IEEE Computer Society, 2002, p. 43-50.

Cary, A.; Wolfson, O.; Rishe, N. Efficient and scalable method for processing top-k spatial boolean queries. In: 22nd International Conference on Scientific and Statistical Database Management (SSDBM), Springer, 2010, p. 87-95 (Lecture Notes in Computer Science, v.6187).

Chávez, E.; Navarro, G.; Baeza-Yates, R. A.; Marroquín, J. L. Searching in metric spaces. ACM Computing Surveys, v. 33, n. 3, p. 273-321, 2001.

Ciaccia, P.; Montesi, D.; Penzo, W.; Trombetta, A. Imprecision and user preferences in multimedia queries: A generic algebraic approach. In: Foundations of Information and Knowledge Systems: First International Symposium, FoIKS 2000, Burg, Germany: Springer, 2000 (Lecture Notes in Computer Science, v.1762).

Ciaccia, P.; Patella, M.; Zezula, P. M-tree: An efficient access method for similarity search in metric spaces. In: International Conference on Very Large Databases (VLDB), Athens, Greece: Morgan Kaufmann, 1997, p. 426-435.

Cong, G.; Jensen, C. S.; Wu, D. Efficient retrieval of the top-k most relevant spatial web objects. Proceedings of the VLDB Endowment, v. 2, n. 1, p. 337-348, 2009.

Datta, R.; Joshi, D.; Li, J.; WAng, J. Z. Image retrieval: Ideas, influences, and trends of the new age. ACM Computing Surveys, v. 40, n. 2, p. 1-60, 2008.

De Felipe, I.; Hristidis, V.; Rishe, N. Keyword search on spatial databases. In: 24th International Conference on Data Engineering (ICDE), IEEE, 2008, p. 656-665.

Depeursinge, A.; Foncubierta-Rodriguez, A.; Ville, D. V. D.; Müller, H. Lung texture classification using locally-oriented riesz components. In: Medical Image Computing and Computer-Assisted Intervention (MICCAI) - Part III, Springer, 2011, p. 231-238 (Lecture Notes in Computer Science, v.6893).

Deppisch, U. S-tree: A dynamic balanced signature index for office retrieval. In: 9th Annual International ACM SIGIR Conference on Research and Development in Information Retrieval, ACM, 1986, p. 77-87.

Deselaers, T.; Keysers, D.; Ney, H. Features for image retrieval: an experimental comparison. Information Retrieval, v. 11, n. 2, p. 77-107, 2008. 
Deserno, T. M.; Antani, S.; Long, R. Ontology of gaps in content-based image retrieval. Journal of Digital Imaging, v. 22, n. 2, p. 202-215, 2009.

Dhawan, A. P. Medical image analysis. 2 ed. Wiley-IEEE Press, 2011.

Doulamis, N.; Doulamis, A. Evaluation of relevance feedback schemes in contentbased in retrieval systems. Signal Processing: Image Communication, v. 21, n. 4, p. 334-357, 2006.

Eakins, J.; Graham, M. Content-based image retrieval. Relatório Técnico 39, University of Northumbria at Newcastle, 1999.

Fayyad, U. M.; Uthurusamy, R. Evolving data into mining solutions for insights. Communications of the ACM (CACM), v. 45, n. 8, p. 28-31, 2002.

Felipe, J. C.; JR., C. T.; Traina, A. J. M. A new family of distance functions for perceptual similarity retrieval of medical images. Journal of Digital Imaging, v. 22, n. 2, p. 183-201, 2009.

Ferreira, M. R. P.; Santos, L. F. D.; Traina, A. J. M.; Dias, I.; Chbeir, R.; JR., C. T. Algebraic properties to optimize kNN queries. Journal of Information and Data Management, v. 2, n. 3, p. 385-400, 2011.

Ferreira, M. R. P.; Traina, A. J. M.; Dias, I.; Chbeir, R.; Jr., C. T. Identifying algebraic properties to support optimization of unary similarity queries. In: 3rd Alberto Mendelzon International Workshop on Foundations of Data Management (AMW), Arequipa, Peru: CEUR-WS.org, 2009 (CEUR Workshop Proceedings, v.450).

Flickner, M.; Sawhney, H. S.; Ashley, J.; Huang, Q.; Dom, B.; Gorkani, M.; Hafner, J.; Lee, D.; Petkovic, D.; Steele, D.; Yanker, P. Query by image and video content: The QBIC system. IEEE Computer, v. 28, n. 9, p. 23-32, september 1995, 1995.

Furuie, S. S.; Rebelo, M. S.; Moreno, R. A.; Santos, M.; Bertozzo, N.; Motta, G. H. M. B.; Pires, F. A.; Gutierrez, M. A. Managing medical images and clinical information: InCor's experience. Information Technology in Biomedicine, IEEE Transactions on, v. 11, n. 1, p. 17-24, 2007.

Garcia-Molina, H.; Ullman, J. D.; Widom, J. Database systems - the complete book (2. ed.). Pearson Education, I-XXVI, 1-1203 p., 2009.

Gauker, C. A critique of the similarity space theory of concepts. Mind $\&$ Language, v. 22, n. 4, p. 317-345, 2007. 
Geusebroek, J.-M.; Burghouts, G. J.; Smeulders, A. W. M. The Amsterdam library of object images. International Journal of Computer Vision, v. 61, n. 1, p. 103$112,2005$.

Gonzalez, R. C.; Woods, R. E. Digital image processing. 3 ed. Addison-Wesley, 2007.

Groff, J.; Weinberg, P.; Oppel, A. J. SQL the complete reference. 3 ed. McGraw-Hill Osborne Media, 2009.

Guliato, D.; Melo, E. V.; Rangayyan, R. M.; Soares, R. C. PostgreSQl-IE: An image-handling extension for PostgreSQL. Journal of Digital Imaging, 2008.

Guttman, A. R-tree : A dynamic index structure for spatial searching. In: $A C M$ SIGMOD International Conference on Management of Data, Boston, MA: ACM PRess, 1984, p. $47-57$.

Guyon, I.; Elisseeff, A. An introduction to variable and feature selection. Journal of Machine Learning Research, v. 3, p. 1157-1182, 2003.

Haralick, R. M. Statistical and structural approaches to texture. In: IEEE, 1979, p. $786-804$.

He, X.; Ma, W.-Y.; King, O.; Li, M.; Zhang, H. Learning and inferring a semantic space from user's relevance feedback for image retrieval. In: 10th ACM International Conference on Multimedia, New York, NY, USA: ACM, 2002, p. 343-346.

Hualtason, G. R.; SAmet, H. Incremental distance join algorithms for spatial databases. In: ACM SIGMOD International Conference on Management of Data, ACM Press, 1998, p. 237-248.

Hualtason, G. R.; Samet, H. Distance browsing in spatial databases. ACM Transactions on Database Systems (TODS), v. 24, n. 2, p. 265 - 318, 1999.

Hualtason, G. R.; Samet, H. Index-driven similarity search in metric spaces. $A C M$ Transactions on Database Systems (TODS), v. 21, n. 4, p. 517 - 580, 2003.

Hsu, W.; Antani, S.; Long, L. R.; Neve, L.; Thoma, G. R. SPIRS: A webbased image retrieval system for large biomedical databases. International Journal of Medical Informatics, v. 78, n. 1, p. 13-24, 2009.

Hu, W.; Xie, N.; Li, L.; Zeng, X.; Maybank, S. J. A survey on visual content-based video indexing and retrieval. IEEE Transactions on Systems, Man, and Cybernetics, Part C, v. 41, n. 6, p. 797-819, 2011. 
HuANG, H. K. PACS and imaging informatics: Basic principles and applications. 2 ed. John Wiley and Sons, 2010.

Huang, J.; Kumar, S. R.; Mitra, M.; Zhu, W.-J.; Zabih, R. Image indexing using color correlograms. In: Conference on Computer Vision and Pattern Recognition (CVPR), Washington, DC, USA: IEEE Computer Society, 1997, p. 762-768.

Huang, P.-W.; Hsu, L.; Su, Y.-W.; Lin, P.-L. Spatial inference and similarity retrieval of an intelligent image database system based on object's spanning representation. Journal of Visual Languages and Computing, v. 19, n. 6, p. 637-651, 2008.

IBM CORPORATION Image, audio, and video extenders administration and programming guide. 550 p., DB2 Universal Database Version 8, 2003.

ISO/IEC SQL - part 2: Foundation. Working Draft, 2003.

Jacox, E. H.; SAmet, H. Metric space similarity joins. ACM Transactions on Database Systems, v. 33, n. 2, 2008.

Jing, F.; Li, M.; Zhang, L.; Zhang, H.; e Zhang, B. Learning in region-based image retrieval. In: International Conference on Image and Video Retrieval (CIVR), Springer, 2003, p. 198-207 (Lecture Notes in Computer Science, v.2728).

KAlpathy-Cramer, J.; Hersh, W. Multimodal medical image retrieval: image categorization to improve search precision. In: International Conference on Multimedia Information Retrieval (MIR), New York, NY, USA: ACM, 2010, p. 165-174.

Kaster, D. S.; Bugatti, P. H.; Ponciano-Silva, M.; Traina, A. J. M.; MarQues, P. M. A.; Santos, A. C.; Traina JR, C. MedFMI-SiR: A powerful DBMS solution for large-scale medical image retrieval. In: International Conference on Information Technology in Bio- and Medical Informatics, Berlin/Heidelberg: Springer, 2011a, p. 16-30 (Lecture Notes in Computer Science, v.6865).

Kaster, D. S.; Bugatti, P. H.; Traina, A. J. M.; Traina JR., C. Incorporating metric access methods for similarity searching on Oracle database. In: XXIV Simpósio Brasileiro de Banco de Dados (SBBD), Fortaleza, CE, Brasil: Sociedade Brasileira de Computação (SBC), 2009, p. 1-15.

Kaster, D. S.; Bugatti, P. H.; Traina, A. J. M.; Traina JR, C. FMi-SiR: A flexible and efficient module for similarity searching on Oracle database. Journal of Information and Data Management, v. 1, n. 2, p. 229-244, 2010.

Kaster, D. S.; Oliveira, W. D.; Bueno, R.; Traina, A. J. M.; Traina Jr, C. Nearest neighbor queries with counting aggregate-based conditions. Journal of Information and Data Management, v. 2, n. 3, p. 401-416, 2011 b. 
Katayama, N.; Satoh, S. Distinctiveness-sensitive nearest-neighbor search for efficient similarity retrieval of multimedia information. In: IEEE International Conference on Data Engineering (ICDE), Heidelberg, Germany: IEEE Computer Society, 2001, p. 493-502.

Khotanzad, A.; Hong, Y. H. Invariant image recognition by Zernike moments. IEEE Transactions on Pattern Analysis and Machine Intelligence (PAMI), v. 12, n. 5, p. 489-497, 1990.

Kokare, M.; Chatterji, B.; Biswas, P. Comparison of similarity metrics for texture image retrieval. In: Conference on Convergent Technologies for Asia-Pacific Region, 2003, p. 571-575.

Lee, K.-M.; Street, W. N. Incremental feature weight learning and its application to a shape-based query system. Pattern Recognition Letters, v. 23, n. 7, p. 865-874, 2002 .

Lehmann, T. M.; Güld, M.; Thies, C.; Fischer, B.; Spitzer, K.; Keysers, D.; Ney, H.; Kohnen, M.; Schubert, H.; Wein, B. B. Content-based image retrieval in medical applications. Methods of Informatics in Medicine, v. 43, p. 354-361, 2004.

LeVenshtein, V. Binary codes capable of correcting deletions, insertions, and reversals. Cybernetics and Control Theory, v. 10, n. 8, p. 707-710, 1966.

LEVY, S. Considerações sobre a ética e o prontuário eletrônico do paciente. In: MARIN, H. D. F.; Massad, E.; Azevedo Neto, R. S. D., eds. O Prontuário Eletrônico do Paciente Na Assitência, Informação e Conhecimento Médico, Faculdade de Medicina da Universidade de São Paulo, p. 183-201, 2003.

Li, C.; Chang, K. C.-C.; Ilyas, I. F.; Song, S. RankSQL: Query algebra and optimization for relational top-k queries. In: Proceedings of the ACM SIGMOD International Conference on Management of Data, Baltimore, Maryland, USA: ACM, 2005, p. 131-142.

LiU, Y.; ZhanG, D.; Lu, G.; MA, W.-Y. A survey of content-based image retrieval with high-level semantics. Pattern Recognition Letters, v. 40, p. 262 - 282, elsevier Ltd., 2007.

Long, L. R.; Antani, S.; Deserno, T. M.; Thoma, G. R. Content-based image retrieval in medicine: Retrospective assessment, state of the art, and future directions. International Journal of Healthcare Information Systems and Informatics, v. 4, n. 1, p. 1-16, 2009. 
Mahalanobis, P. C. On the generalised distance in statistics. Proceedings of the National Institute of Sciences of India, v. 2, n. 1, p. 49-55, 1936.

Disponível em http://www.insa.ac.in/insa_pdf/20005b8c_49.pdf

Marin, H. D. F.; Massad, E.; Azevedo Neto, R. S. D. Prontuário eletrônico do paciente: Definições e conceitos. In: Marin, H. D. F.; Massad, E.; Azevedo Neto, R. S. D., eds. O Prontuário Eletrônico do Paciente Na Assitência, Informação e Conhecimento Médico, Faculdade de Medicina da Universidade de São Paulo, p. 1-20, 2003.

Marques, P. M. D. A.; Santos, A. C. D.; Júnior, J. E.; Goes, W. M.; CasTRO, C. R. Implantação de um sistema de informação em radiologia em hospital univeristário. Radiologia Brasileira, v. 33, p. 155-160, 2000.

Melton, J.; EIsenberg, A. SQL multimedia and application packages (SQL/MM). ACM SIGMOD Records, v. 30, n. 4, p. 97-102, 2001.

Mokhtarian, F.; Mackworth, A. Scale-based description and recognition of planar curves and two-dimensional objects. IEEE Pattern Analysis and Machine Intelligence, v. 8, n. 1, p. 34-43, 1986.

Montesi, D.; Trombetta, A.; Dearnley, P. A. A similarity based relational algebra for web and multimedia data. Information Processing and Management, v. 39, n. 2, p. 307-322, 2003.

Müller, H.; Michoux, N.; Bandon, D.; Geissbuhler, A. A review of contentbased image retrieval systems in medical applications-clinical benefits and future directions. International Journal of Medical Informatics, v. 73, n. 1, p. 1-23, 2004.

National Electrical Manufacturers Association Digital Imaging and Communications in Medicine (DICOM). Publication Standard 3.x, 2008.

Disponível em ftp://medical.nema.org/medical/dicom/2008/

Névéol, A.; Deserno, T. M.; Darmoni, S. J.; Güld, M. O.; Aronson, A. R. Natural language processing versus content-based image analysis for medical document retrieval. Journal of the American Society for Information Science and Technolog, v. 60 , p. 123-134, 2009.

Oracle Corporation Oracle Multimedia DICOM developer's guide, $11 \mathrm{~g}$ release 1 (11.1). Oracle, 312 p., 2007a.

Oracle Corporation Oracle Multimedia user's guide, $11 \mathrm{~g}$ release 1 (11.1). Oracle, 234 p., $2007 \mathrm{~b}$. 
Pan, J.; MAnocha, D. Fast GPU-based locality sensitive hashing for k-nearest neighbor computation. In: 19th ACM SIGSPATIAL International Symposium on Advances in Geographic Information Systems (ACM-GIS), ACM, 2011, p. 211-220.

Papadias, D.; TaO, Y.; Mouratidis, K.; Hui, C. K. Aggregate nearest neighbor queries in spatial databases. ACM Transactions on Database Systems (TODS), v. 30, n. 1 , p. $529-576,2005$.

PARK, D.-J.; KIM, H.-J. An enhanced technique for k-nearest neighbor queries with non-spatial selection predicates. Multimedia Tools and Applications, v. 19, n. 1, p. 79103, 2003.

PARK, D.-J.; LEE, D.-H. SPY-TEC+ : an integrated index structure for k-nearest neighbor queries with semantic predicates in multimedia database. International Journal of Software Engineering and Knowledge Engineering, v. 21, n. 7, p. 989-1011, 2011.

Pass, G.; Zabih, R.; Miller, J. Comparing images using color coherence vector. In: ACM Multimedia, Boston, MA: ACM Press, 1996, p. 65-73.

Penzo, W. Rewriting rules to permeate complex similarity and fuzzy queries within a relational database system. IEEE Transactions on Knowledge and Data Engineering (TKDE), v. 17, n. 2, p. 255-270, 2005.

Rahman, M. M.; Antani, S. K.; Thoma, G. R. A classification-driven similarity matching framework for retrieval of biomedical images. In: International Conference on Multimedia Information Retrieval (MIR), New York, NY, USA: ACM, 2010, p. $147-154$.

Razente, H. L.; Barioni, M. C. N.; Traina, A. J. M.; Traina Jr., C. Aggregate similarity queries in relevance feedback methods for content-based image retrieval. In: 15th ACM symposium on Applied computing (SAC), Fortaleza, Ceara, Brazil: ACM, 2008, p. 869-874.

Ren, W.; Singh, S.; Singh, M.; Zhu, Y. S. State-of-the-art on spatio-temporal information-based video retrieval. Pattern Recogn., v. 42, p. 267-282, 2009.

Robinson, J. T. The k-d-b-tree: A search structure for large multidimensional dynamic indexes. In: ACM SIGMOD International Conference on Management of Data, ACM Press, 1981, p. 10-18.

Rocha-Junior, J. B.; Gkorgkas, O.; Jonassen, S.; Nørvåg, K. Efficient processing of top-k spatial keyword queries. In: 12th International Symposium on Advances in Spatial and Temporal Databases (SSTD), Springer, 2011, p. 205-222 (Lecture Notes in Computer Science, v.6849). 
Roussopoulos, N.; Kelley, S.; Vincent, F. Nearest neighbor queries. In: CAREY, M. J.; SchneIder, D. A., eds. ACM SIGMOD International Conference on Management of Data, San Jose, CA: ACM Press, 1995, p. 80-91.

Rubin, R.; Gonzaga, A.; Alves, J.; Barbieri, C.; Barbieri, G. Avaliação de fraturas ósseas através da análise de texturas em imagens radiográficas. In: II Workshop Regional em Engenharia Biomédica e I Simpósio Regional de Instrumentação e Imagens Médicas, São Pedro, SP, 2003, p. 46.

Santini, S.; Gupta, A. A wavelet data model for image databases. In: IEEE Intl. Conf. on Multimedia and Expo, Tokyo, Japan: IEEE Computer Society, 2001.

SANTINI, S.; JAIn, R. Gabor space and the development of preattentive similarity. In: 13th International Conference on Pattern Recognition (ICPR), Los Alamitos, CA, USA: IEEE Computer Society, 1996, p. 40-44.

Silva, Y. N.; Aly, A. M.; Aref, W. G.; Larson, P.-A. SimDB: a similarity-aware database system. In: ACM SIGMOD International Conference on Management of Data, Indianapolis, Indiana, USA: ACM, 2010a, p. 1243-1246.

Silva, Y. N.; Aref, W. G.; Ali, M. H. Similarity group-by. In: 25th International Conference on Data Engineering (ICDE), Shanghai, China: IEEE, 2009, p. 904-915.

Silva, Y. N.; Aref, W. G.; Ali, M. H. The similarity join database operator. In: 26th International Conference on Data Engineering (ICDE), Long Beach, California, USA: IEEE, 2010b, p. 892-903.

Smeaton, A. F.; Over, P.; Doherty, A. R. Video shot boundary detection: Seven years of TRECVid activity. Computer Vision and Image Understanding, v. 114, n. 4, p. $411-418,2010$.

Smeulders, A. W. M.; Worring, M.; Santini, S.; Gupta, A.; Jain, R. Contentbased image retrieval at the end of the early years. IEEE Transactions on Pattern Analysis and Machine Intelligence (PAMI), v. 22, n. 12, p. 1349-1380, 2000.

Szańto, B.; Pozsegovics, P.; Vaḿossy, Z.; Sergyań, S. Sketch4match - contentbased image retrieval system using sketches. In: 9th International Symposium on Applied Machine Intelligence and Informatics (SAMI), 2011, p. 183-188.

Tachinardi, U.; Furuie, S. S. Arquivamento e transmissão de imagens médicas. In: Marin, H. D. F.; Massad, E.; Azevedo Neto, R. S. D., eds. O Prontuário Eletrônico do Paciente Na Assitência, Informação e Conhecimento Médico, Faculdade de Medicina da Universidade de São Paulo, p. 97-108, 2003. 
Tan, Y.; Zhang, J.; Hua, Y.; Zhang, G.; Huang, H. Content-based image retrieval in picture archiving and communication systems. In: Medical Imaging 2006: PACS and Imaging Informatics, San Diego, CA, USA: SPIE, 2006, p. 282-289.

TaO, Y.; YI, K.; Sheng, C.; Kalnis, P. Efficient and accurate nearest neighbor and closest pair search in high-dimensional space. ACM Transactions on Database Systems, v. 35, n. 3, p. 20:1-20:46, 2010.

Torres, R. S.; Falcão, A. X.; Gonçalves, M. A.; Papa, J. P.; Zhang, B.; Fan, W.; Fox, E. A. A genetic programming framework for content-based image retrieval. Pattern Recognition, v. 42, n. 2, p. 283-292, 2009.

Traina, A. J. M.; Traina Jr., C.; De Aguiar Ciferri, C. D.; Ribeiro, M. X.; de Azevedo Marques, P. M. How to cope with the performance gap in contentbased image retrieval systems. International Journal of Healthcare Information Systems and Informatics, v. 4, n. 1, p. 47-67, 2009.

Traina, A. J. M.; Traina Jr., C.; Bueno, J. M.; Chino, F. J. T.; Marques, P. M. D. A. Efficient content-based image retrieval through metric histograms. World Wide Web Journal, v. 6, n. 2, p. 157-185, 2003.

Traina Jr., C.; Filho, R. F. S.; Traina, A. J. M.; Vieira, M. R.; Faloutsos, C. The omni-family of all-purpose access methods: a simple and effective way to make similarity search more efficient. The International Journal on Very Large Databases, v. 16, n. 4, p. 483-505, 2007.

Traina Jr., C.; Traina, A. J. M.; Faloutsos, C.; Seeger, B. Fast indexing and visualization of metric datasets using slim-trees. IEEE Transactions on Knowledge and Data Engineering (TKDE), v. 14, n. 2, p. 244-260, 2002.

Traina Jr., C.; Traina, A. J. M.; Vieira, M. R.; Arantes, A. S.; Faloutsos, C. Efficient processing of complex similarity queries in RDBMS through query rewriting. In: 15th International Conference on Information and Knowledge Management (CIKM), Arlington, VA, USA, 2006, p. 4-13.

Tzanetakis, G.; Cook, P. R. Musical genre classification of audio signals. IEEE Transactions on Speech and Audio Processing, v. 10, n. 5, p. 293-302, 2002.

Vasconcelos, N.; Lippman, A. A unifying view of image similarity. In: 15th International Conference on Pattern Recognition (ICPR), 2000, p. 38-41.

Vieira, M. R.; Traina, Caetano, J.; Traina, A. J. M.; Arantes, A. S.; FaLOUTSOS, C. Estimating suitable query radii to boost k-nearest neighbor queries. 
In: 19th International Conference on Scientific and Statistical Database Management (SSDBM), Banff, Canada: ACM Press, 2007.

Vieira, M. R.; Traina, Caetano, J.; Traina, A. J. M.; Chino, F. J. T. DBMtree: A dynamic metric access method sensitive to local density data. In: Brazilian Symposium on Databases (SBBD), Brasília, DF: SBC, 2004, p. 33-47.

Wan, C.; LiU, M. Content-based audio retrieval with relevance feedback. Pattern Recognition Letters, v. 27, n. 2, p. 85-92, 2006.

WeI, C.-H.; Li, Y.; HuAng, P. J. Mammogram retrieval through machine learning within BI-RADS standards. Journal of Biomedical Informatics, v. 44, n. 4, p. 607-614, 2011.

Welter, P.; Riesmeier, J.; Fischer, B.; Grouls, C.; Kuhl, C.; Deserno, T. M. Bridging the integration gap between imaging and information systems: a uniform data concept for content-based image retrieval in computer-aided diagnosis. Journal of the American Medical Informatics Association, v. 18, n. 4, p. 506-510, 2011.

Wilson, D. R.; Martinez, T. R. Improved heterogeneous distance functions. Journal of Artificial Intelligence Research, v. 6, p. 1-34, morgan Kaufmann Publishers, 1997.

YeH, W.-H.; Chang, Y.-I. An efficient iconic indexing strategy for image rotation and reflection in image databases. Journal of Systems and Software, v. 81, n. 7, p. 1184 1195, 2008.

Yeung, A. K. W.; Hall, G. B. Spatial database systems: Design, implementation and project management, v. 87 de The GeoJournal Library. 1 ed. Springer, 2007.

Yianilos, P. N. Data structures and algorithms for nearest neighbor search in general metric spaces. In: Fourth Annual ACM/SIGACT-SIAM Symposium on Discrete Algorithms (SODA), Austin, TX, 1993, p. 311-321.

YuAn, Y.-H.; Sun, Q.-S.; Zhou, Q.; XIA, D.-S. A novel multiset integrated canonical correlation analysis framework and its application in feature fusion. Pattern Recognition, v. 44, p. 1031-1040, 2011.

Zahn, C. T.; Roskies, R. Z. Fourier descriptors for plane closed curves. IEEE Transactions on Computers, v. c-21, n. 3, p. 269-281, 1972. 